\title{
Navajo Generating Station and Air Visibility Regulations: Alternatives and Impacts
}

David J. Hurlbut, Scott Haase, Gregory Brinkman, Kip Funk, Rachel Gelman, Eric Lantz, Christina Larney, David Peterson, Christopher Worley National Renewable Energy Laboratory

Ed Liebsch HDR Engineering, Inc.

Prepared under Task No. WFJ5.1000

Technical Report

NREL/TP-6A20-53024 • Revised March 2012

Contract No. DE-AC36-08G028308

Produced under direction of the U.S. Department of the Interior by the National Renewable Energy Laboratory (NREL) under Interagency Agreement R11PG30024 and Task No. WFJ5.1000. 


\section{ERRATA SHEET}

NREL REPORT/PROJECT NUMBER: NREL/TP-6A20-53024

DOE NUMBER: N/A

TITLE: Navajo Generating Station and Air Visibility Regulations: Alternatives and Impacts, Energy Analysis, NREL (National Renewable Energy Laboratory)

AUTHOR(S): David J. Hurlbut, Scott Haase, Gregory Brinkman, Kip Funk, Rachel Gelman, Eric Lantz, Christina Larney, David Peterson, Christopher Worley

National Renewable Energy Laboratory

Ed Liebsch

HDR Engineering, Inc.

ORIGINAL PUBLICATION DATE: 1/18/2012

DATE OF CORRECTIONS (MM/DD/YYYY): 3/15/2012

Revised March 2012:

- Page 75: Replaced incorrect data in Table 5-1.

- Page 84: Replaced incorrect data in Table 5-6.

- Page 106: Replaced incorrect data in Table 7-1.

This report, as originally published, also contained editorial errors that have been corrected in this revision. No changes, except those noted here, affect the substance of the report or the authors' intent.

Instructions for Hard Copies:

- This publication was released as an electronic only document. If copies were made, please use previous printed copies (with Errata Sheet) before distributing. 



\section{NOTICE}

This report was prepared as an account of work sponsored by an agency of the United States government. Neither the United States government nor any agency thereof, nor any of their employees, makes any warranty, express or implied, or assumes any legal liability or responsibility for the accuracy, completeness, or usefulness of any information, apparatus, product, or process disclosed, or represents that its use would not infringe privately owned rights. Reference herein to any specific commercial product, process, or service by trade name, trademark, manufacturer, or otherwise does not necessarily constitute or imply its endorsement, recommendation, or favoring by the United States government or any agency thereof. The views and opinions of authors expressed herein do not necessarily state or reflect those of the United States government or any agency thereof.

Available electronically at http://www.osti.gov/bridge

Available for a processing fee to U.S. Department of Energy

and its contractors, in paper, from:

U.S. Department of Energy

Office of Scientific and Technical Information

P.O. Box 62

Oak Ridge, TN 37831-0062

phone: 865.576 .8401

fax: 865.576 .5728

email: mailto:reports@adonis.osti.gov

Available for sale to the public, in paper, from:

U.S. Department of Commerce

National Technical Information Service

5285 Port Royal Road

Springfield, VA 22161

phone: 800.553 .6847

fax: 703.605 .6900

email: orders@ntis.fedworld.gov

online ordering: http://www.ntis.gov/help/ordermethods.aspx 


\section{Executive Summary}

The U.S. Environmental Protection Agency (EPA) intends to issue rules for controlling emissions from the Navajo Generating Station (Navajo GS) that contribute to haze at the Grand Canyon and at several other national parks and wilderness areas. The final rule will be based on what EPA determines is the best available retrofit technology (BART) for the control of haze-causing air pollutants, especially nitrogen oxides $\left(\mathrm{NO}_{\mathrm{x}}\right)$.

Several factors make this case unusually complex. Unlike other coal plants in the West, Navajo GS came into being at the initiative of the federal government. Low-cost power from Navajo GS runs the massive pumps of the Central Arizona Project (CAP) - a major water delivery project built to fulfill terms of the Colorado River Compact, a multistate water agreement that many consider to be one of the most contentious in U.S. history. In addition, the plant and the coal mine that supplies it are located on tribal lands. The U.S. Bureau of Reclamation (Reclamation) owns the largest share of the plant on behalf of the federal government. Some of Reclamation's sister agencies within the U.S. Department of the Interior, however, have missions relating to tribal affairs, national parks management, and habitat protection that in this case are not easily reconciled with Reclamation's job of supporting the CAP with low-cost power.

Many of the analyses conducted by and for parties in this case have contemplated three possible BART outcomes:

- accepting existing plant improvements as the standard with no additional retrofit;

- adopting a new control technology such as selective catalytic reduction (SCR) as the standard; or

- shutting down Navajo GS because of the cost of SCRs and other upgrades that may be required under future emission rules.

The two SCR scenarios include SCR only, and SCR plus additional controls (baghouses and sorbent injection) in anticipation of future emission regulations. Navajo GS owners are also considering selective noncatalytic reduction, which would cost less than SCR but would remove less $\mathrm{NO}_{x}$.
Under any outcome, the burden of compliance will probably fall most heavily on those who rely on the federal government's $24.3 \%$ share of the power plant. Furthermore, the web of needs laying claim to the government's share is uniquely complex. Therefore, a BART outcome that met Interior's interests - secure sources of power for CAP, no additional disruption of tribal economic development, and good stewardship of national parks and other public lands - would in all likelihood be adaptable to the needs of the utilities that rely on Navajo GS for part of their conventional supply needs. This would especially be true if the outcome allowed time for Interior to prepare for a smooth transition to cleaner energy sources for CAP, and allowed the utilities time to fully depreciate their current investments in Navajo GS.

EPA's statutory authority in this particular proceeding focuses on visibility at national parks and other priority areas. The analysis and findings of this report (conducted by NREL for the Department of the Interior) focus on these statutory issues and therefore address only a small subset of the issues facing coal-fired power plants throughout the country. This report does not address the larger question of whether Navajo GS should continue operating or should retire. Rather, the questions have to do with how proposed changes to the plant are likely to affect visibility. (A supplemental volume examines the feasibility of using clean generating technologies to achieve comparable outcomes.)

With respect to BART determinations, the Clean Air Act requires EPA to

...take into consideration the costs of compliance, the energy and nonair quality environmental impacts of compliance, any existing pollution control technology in use at the source, the remaining useful life of the source, and the degree of improvement in visibility which may reasonably be anticipated to result from the use of such technology.'

1 CAA Sec. 169A, Sec. 42 USC 7491 (g)(2). 
This report's main conclusions

address these statutory factors.

\section{Cost of compliance}

Economic analysis suggests that, holding all other factors the same, installing SCRs at Navajo GS would likely cost less than shutting it down and replacing it with power from unused capacity elsewhere in the West. Key uncertainties that could affect the basic economics include (among other factors) investment recovery timelines, changes in future plant ownership, changes in transmission path ratings, renegotiating the site lease with Navajo Nation, and delivery commitments under long-term power contracts. ${ }^{2}$ Figure ES-1 shows likely ranges of additional annual costs associated with two SCR scenarios, and with shutting down the plant and replacing it with the West's least expensive unused capacity.

The cost burden of either SCR option or shutdown would probably fall more heavily on the Bureau of Reclamation than it would on any of the five utilities that also own shares of Navajo GS. This is due to the fact that Reclamation and the Central Arizona Water Conservation District rely on Navajo GS for $92 \%$ of the total electricity needed for the CAP, while the utility partners rely on the plant for only $9 \%$ to $26 \%$ of their total electricity supply.

SCR capital costs would result in a likely retail rate increase of between 0.02 cents to 0.06 cents per kilowatt-hour for Navajo GS' utility partners. This would translate into a rate impact of $0.2 \%$ to $0.6 \%$. Other uncertainties could result in increased business costs besides capital costs that would also be recovered in retail rates. Separately, The operation and maintenance (O\&M) costs associated with SCRs would increase Navajo GS variable production costs by $3 \%$ to $4 \%$, which would leave the plant still as one of the lowest-cost generators in the Desert Southwest.

2 Chapters 1 and 2 contain additional explanation of these uncertainties.
Unlike its utility partners, Reclamation lacks an established rate mechanism for recovering its share of future capital costs for Navajo GS. Assuming no federal appropriations, the additional capital costs and production costs associated with SCRs would probably increase power costs for the CAP by 0.39 cents to 0.48 cents per kilowatt-hour. For agricultural users and Indian tribes, water rates from CAP would likely increase between $13 \%$ and $16 \%$. For municipal and industrial users, the increase would likely be between $5 \%$ and $7 \%$. Baghouses and sorbent injection would roughly double the impact on water rates.

\section{Energy impacts of compliance}

Installing SCRs would not significantly change the amount of energy provided by Navajo GS. On-site employment at the power plant and the mine would be unchanged, except for the possible addition of a small number of jobs at the power plant to operate and maintain the SCR equipment.

Shutting down Navajo GS would change the regional flow of power. Least-cost redispatch would tend toward replacement power from combined cycle natural gas plants in Nevada, Arizona and Southern California that already exist and have spare capacity. Southern California currently obtains a large portion of its electricity supply from Arizona and Nevada. Shutting down Navajo GS would tend to reduce these flows, 
with more of the power that is generated in Arizona remaining in state.

\section{Nonair quality environmental impacts of compliance}

Environmental impacts aside from air quality primarily affect the Navajo and Hopi populations living near the power plant and the mine that supplies its coal. Non-governmental organizations express concerns about harm to health and groundwater in particular. No epidemiological studies have specifically examined health impacts resulting from either Navajo GS emissions or coal mining operations. Conflicting studies offer different conclusions about the effect of mining operations on local ground water. Nevertheless, these impacts - regardless of their true extent - are largely a function of whether the plant operates at all. Visibility-related retrofits that would result in continued operations at the plant and the mine would likely cause no discernible change in these environmental impacts.

\section{Existing pollution control technology}

Scrubbers installed at the three Navajo GS units in 2000 have reduced $\mathrm{SO}_{2}$ emissions by more than $95 \%$. Low- $\mathrm{NO}_{\mathrm{x}}$ burners and separated overfire air systems have reduced $\mathrm{NO}_{\mathrm{x}}$ emissions by $40 \%$, relative to what the plant's air permit allowed before these controls were added. This compares to the $78 \%$ reduction that could be achieved with the addition of SCRs, and the $50 \%$ to $60 \%$ reduction estimated for SNCR controls.

\section{Remaining useful life}

Navajo GS will have been in service 45 years when its site lease with Navajo Nation expires in 2019. While 45 years was a typical useful lifespan for smaller coal plants in the U.S. built prior to Navajo GS, larger coal plants built around the time of Navajo GS appear to be lasting longer, in that relatively fewer of their group are retiring early and the ones that remain continue to sustain high capacity factors. The utility partners' capital investments in Navajo GS (including retrofits to date) are on track to be fully depreciated no later than 2026, when the plant will have had more than 50 years in service.

\section{Degree of improvement in visibility}

While conclusions in this report regarding the electricity sector are clear, those regarding visibility must be more circumspect. The question fundamental to this proceeding - how reducing $\mathrm{NO}_{\mathrm{x}}$ from Navajo GS would contribute to improving visibility at the Grand Canyon and other areas of concern - requires a deeper inquiry and more time than was allowed for this project, and it requires expertise in atmospheric chemistry and air transport modeling, not power sector expertise. Evidence suggests that $\mathrm{NO}_{\mathrm{x}}$ emissions from Navajo GS are a likely incremental contributor to haze at the Grand Canyon. Whether the incremental contribution is significant or even perceptible is a matter of debate among experts in the field of visibility science.

Monitoring and other evidence suggests $\mathrm{NO}_{\mathrm{x}}$ is a weaker contributor than $\mathrm{SO}_{2}$, which has already declined $95 \%$ at Navajo GS since the installation of scrubbers in 2000. The body of research to date (summarized in this report) is inconclusive as to whether removing approximately two-thirds of the current $\mathrm{NO}_{\mathrm{x}}$ emissions from Navajo GS would lead to any perceptible improvement in visibility at the Grand Canyon and other areas of concern.

\section{Summary of Tribal Benefits and Impacts}

The EPA's BART determination will have diverse impacts on Arizona's tribes. There are two primary categories of effects: those related to power generation and mining, and those affecting the cost of CAP water delivered to tribes who have signed water settlement agreements, including potential funding that could be made available through the Lower Colorado River Basin Development Fund (Development Fund).

Tribal economic benefits associated with the direct operations of both the Navajo GS and Kayenta minemore than $\$ 150$ million per year-would continue to accrue under all future scenarios with the exception of complete plant shut down, or the shutdown of one or more individual units. Approximately 450 Native Americans are employed at the Navajo GS, and 400 are employed at the mine. The total wages and benefits 
paid to Native employees of the plant and mine are approximately $\$ 100$ million per year. In addition, the Kayenta mine also makes annual payments of just over \$50 million per year to the Navajo Nation and Hopi Tribe (\$13 million to Hopi, \$37 million to Navajo) for coal royalties and bonuses, groundwater usage, and purchase of electricity from the Navajo Tribal Utility Authority. Additional benefits for the tribes include several hundred thousand dollars per year in scholarship funds, and local property taxes which primarily go to schools in the region. SRP also pays the Navajo Nation about \$1 million/year in lease and air permit fees for the Navajo GS itself.

A significant increase in the cost of power from Navajo GS could affect settlements with some Indian tribes who surrendered future water right claims in exchange for low-cost access to CAP water and other benefits. Installation of SCR controls at Navajo GS would likely increase tribes' water delivery rates by $13 \%$ to $16 \%$ ( $\$ 7$ to $\$ 9$ per acre-foot); SCR controls with baghouses would double that impact. A more detailed examination of the implications for tribal water settlements (for example, determining the threshold at which the rate increase would be materially significant) would require a legal analysis that was beyond the scope of this study. If Navajo GS were to shut down, the Indian and Agricultural users of CAP water would see per acre-foot increases of as much as $66 \%$, while municipal and industrial users would see increases up to $52 \%$.

A significant area of concern for CAP water-using tribes relates to the potential for sales of surplus Navajo GS power to exceed the $\$ 55$ million annual CAP repayment obligation. In cases where annual revenue into the fund exceed $\$ 55$ million, the "second cascade" of funding disbursements would kick-in, with initial funds in the second cascade going to reduce the fixed operations, maintenance and replacement charges associated with the delivery of CAP water to Indian tribes. Under a new agreement related to the sales of surplus Navajo generation, approximately 1 TWh of primarily off-peak power would be up for sale on the general wholesale power market, making this portion of excess power revenue more directly subject to market prices. Current power prices are not high enough to support flows into second-cascade disbursements, nor have they been since 2008. Two factors could mitigate against higher power prices in the future: success of energy efficiency programs in Arizona and other Southwest states, and additional natural gas supplies resulting from the development of shale gas. 


\section{Table of Contents}

Executive Summary ii

Introduction 1

$1 \quad$ Navajo GS Origin and Operations $\quad 7$

1.1 Regulatory Background and Ownership Interests 9

1.2 Navajo GS in the Utility Partners' Generating Fleets 15

$\begin{array}{lll}1.3 & \text { Power Plant Operations } & 22\end{array}$

2 Regional System Impacts of Retiring Navajo GS 27

2.1 Selection of modeling approach 28

2.2 Redispatch: What the system would use to replace Navajo GS 32

2.3 Production costs: How expensive to do without Navajo GS? 35

2.4 Impact on Bureau of Reclamation and CAP 40

3 Control Technologies-Cost of Retrofits 43

3.1 Technologies Implemented for Emission Controls 44

3.2 Particulate Matter Reduction and Sorbent Injection 49

$\begin{array}{ll}3.3 & \text { Conclusion }\end{array}$

4 Central Arizona Project and Navajo Generating Station 53

$\begin{array}{lll}4.1 & \text { Background to CAP } & 53\end{array}$

4.2 CAP Repayment Obligations and the Development Fund 54

4.3 Navajo GS and CAP Water Rates 58

$\begin{array}{lll}4.5 & \text { Summary } & 69\end{array}$ 
5 Assessment of Visibility Science $\quad 71$

$\begin{array}{lll}5.1 & \text { Regulatory Framework } & 71\end{array}$

5.2 Emissions and Visibility Trends for Southwestern States 74

5.3 Modeling Studies of Navajo GS Visibility Impacts 76

5.4 Monitoring and Related Studies at Regional Class I Areas $\quad 80$

5.5 Visibility Monitoring Metrics and Regional Trends 83

5.6 Control Technology Options and Cost/Benefit Analysis 85

$\begin{array}{ll}5.7 & \text { Summary of Key Points }\end{array}$

6 Impacts on American Indian Tribes in Arizona 93

$\begin{array}{lll}\text { 6.1 Tribes and Power Generation } & 93\end{array}$

$\begin{array}{lll}\text { 6.2 } & \text { Tribes with CAP water allocations } & 101\end{array}$

$7 \quad$ Economic and Employment Impacts 105

7.1 Estimation of primary and secondary effects related to Navajo GS 105

7.2 Economic and employment profile of the three-county region 106

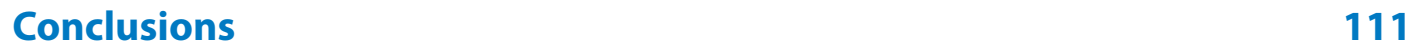




\section{Figures}

Figure ES-1. Likely ranges of additional annual costs for retrofits, shutdown iii

Figure 1-1. Navajo Generating Station and Central Arizona Project $\quad$ N

Figure 1-2. Age, capacity factor and size of coal units in WECC 16

Figure 1-3. Estimated Share of SCR Retrofits Based on Current Ownership

(\$ millions) 20

Figure 2-1. Balancing authority areas modeled by NREL 30

$\begin{array}{lll}\text { Figure 2-2. Bus points included in the model } & 30\end{array}$

Figure 2-3. Navajo GS in the power supply curve for the Desert Southwest 31

Figure 2-4. Spot price of natural gas at the Permian Basin Hub, 2008 to date 31

Figure 2-5. Annual net generation by BA, base case 34

Figure 2-6. Change in net generation without Navajo GS $\quad 34$

Figure 2-7. LMP distribution with and without Navajo GS (Natural Gas: $\$ 6.90$ per mmBtu) 38

Figure 2-8. $\quad$ Change in average annual LMPs when retiring Navajo GS 39

Figure 3-1: $\quad$ Estimates of SCR capital costs in the Western Interconnection 48

Figure 4-1. Revenue flows into the development fund 54

Figure 4-2. Distribution of CAP water deliveries in 2010 (acre-feet) 58

$\begin{array}{lll}\text { Appendix A: } & \text { First Cascade of the Settlements Act Payment Priorities } & 70\end{array}$

Figure 5-1. Navajo GS location relative to PSD Class I areas within 300 km

Figure 5-2. Relationship between atmospheric light extinction, deciviews, and visual range $\quad 73$

Figure 5-3. $\quad \mathrm{SO}_{2}$ emission trends for large power plants in the vicinity of the GCNP 76

Figure 5-4. $\quad \mathrm{NO}_{x}$ emission trends for large power plants in the vicinity of the GCNP 76

Figure 5-5. Annual and seasonal wind roses for Flagstaff, Arizona 82

Figure 5-6. Annual profile of sulfate, nitrate and sulfate:nitrate ratio for Indian Gardens 85

Figure 5-7. PM2.5, sulfate and nitrate annual average trends for Bryce Canyon 85

Figure 5-8. PM2.5, sulfate and nitrate annual average trends for Canyonlands 86

Figure 5-9. PM2.5, sulfate and nitrate annual averagetrends for GCNP/Hance Camp 86

Figure 5-10. PM2.5, sulfate and nitrate annual average trends for GCNP/Indian Gardens 87 
Figure 5-11. PM2.5, sulfate and nitrateannual average trends for Mesa Verde

Figure 5-12. PM2.5, sulfate and nitrate annual average trends for Petrified Forest

Figure 6-1. $\quad$ Navajo generating station tribe map

Figure 6-2. N N Navajo Nation, Kayenta Mine revenues and general fund budget 2002-2005 (\$ millions)

99

Figure 7-2. Total wages, by Sector, Apache, Coconino, and Navajo Counties, AZ, 2001-2010.

\section{Tables}

Table 1-2. $\quad$ EPA Regulatory Actions Affecting Navajo Generating Station

Table 1-3. National Environmental Policy Act (NEPA) Actions Affecting Navajo Generating Station

Table 1-4. Other Regulatory Actions Affecting Navajo Generating Station

Table 1-5. Contribution of Navajo Generating Station to Utility Partners' Generating Fleets (Owned, Operating Capacity Only)

Table 1-6. $\quad$ Utility Partners' Interests in Navajo Generating Station \$ in thousands

Table 1-7. Major Differences Between Capital Costs and Production Costs

Table 1-8. $\quad$ SCR Capital Cost Relative to Net Utility Plant

Table 1-9. SCR, Baghouse, Sorbent Injection Capital Costs Relative to Net Utility Plant

Table 1-10. Retail Rate Impact of SCR Capital Cost

Table 1-11. Retail Rate Impact of SCR, Baghouse, Sorbent Injection (Cents per kWh)

Table 1-12. Retail Rate Impact of SCR, SNCR, SCR with Additional Controls (\% of Retail Rates)

Table 1-13: $\quad$ Impact of SCR, Baghouse, Sorbent Injection Capital Costs on CAP Pumping Power Cost

Table 1-14: $\quad$ Impact of SCR, Baghouse, Sorbent Injection Costs on CAP Water Rates SNL Energy; wwW.snl.com

Figure 1-4. Navajo GS monthly capacity factor

Table 1-15. N N Navajo GS Operation Summary (2010)

Table 1-16. Maximum Adjusted Nitrogen Oxide Emission Rates, 2009 - 2011 (lb/mmBtu)

Table 1-17. Average Adjusted Nitrogen Oxide Emission Rates, 2009 - 2011 (lb/mmBtu)

Table 2-1. Distribution of Navajo GS Production as Modeled in Base Case

Table 2-2. BA Replacement Needs Resulting from Retiring Navajo GS

Table 2-3. $\quad$ Types of Generators Used to Replace Navajo GS

Table 2-4. Interconnection-wide Production Costs (\$ millions)

Table 2-5. Interconnection-wide LMP Averages, Minima and Maxima (\$/MWh) 
Table 2-6. $\quad$ Changes in BAs' Average LMP Assuming Navajo GS Retirement

Table 2-7. $\quad$ LMP Sensitivities for Natural Gas Price, Navajo GS Retirement

Table 2-8. Regression Analysis of Mohave Retirement and Wholesale Power Prices in California

Table 3-1: $\quad$ Nitrogen Oxide Emission Reduction Technologies

Table 3-2: $\quad \quad \quad \quad \quad \quad \quad$ O Permit Limits and Technology Performance

Table 3-4: $\quad$ Plants With Installed SCR Technology (Texas and Western interconnections)

Table 3-3: $\quad$ Selective catalytic reduction in U.S. power plants

Table 3-5: $\quad$ Power Plants With Installed SCR Technology (Eastern Interconnection)

Table 3-6: $\quad$ Two estimates for SCR installation at Navajo GS

Table 3-7: $\quad$ Capital Costs of SCR Installations Proposed in the Western Interconnection

Table 3-8: $\quad$ Selective non-catalytic reduction in

U.S. power plants

Table 3-9: $\quad$ US Installations of SNCR's By State

Table 3-10: $\quad$ SNCR Capital, Operation and Maintenance Estimated Costs

Table 3-11: $\quad$ Cost for SCR and Polishing Baghouse

Table 4-4. $\quad$ Scenario in which $\$ 10$ million is Available for Second Cascade of Payment Priorities (\$ M) 58

Table 4-1. Actual Revenues into the Development Fund, 2009 and 2010

Table 4-2. $\quad$ Net Values of Navajo GS Surplus Power Sales Revenues into the Development Fund, Backcast Based on the Post Four-Party Agreement Revenue Arrangement (in \$ million)

Table 4-3. Revenues into the Development Fund in 2009 and 2010, Backcast Analysis Based on the Post Four-Party Agreement arrangement (\$ M)

Table 4-5. $\quad$ Projected Costs of CAP Water by Component (\$/AF)

Table 4-6. $\quad$ CAP Water Delivery Rates (\$/AF)

Table 4-7. $\quad$ Net Value of Navajo GS Surplus Power Under a 2011 Base Case Scenario (\$ M)

Table 4-8. Revenues into the Development Fund Under

Table 4-9. Impact of SCR Installation on CAWCD's Navajo GS Power Costs

Table 4-10. Increase in the CAP Pumping Energy Charge under the SCR Installation Scenario

Table 4-11. C Changes in CAP Water Rate Components Under Low and High Cost SCR Installation Scenarios

Table 4-12. Increase in CAP Water Rates Under the Low Cost SCR Installation Scenario

Table 4-13. Increases in the Pumping Energy Charge Under the High Cost SCR Installation Scenario 
Table 4-14. Impact of SCR plus Baghouse \& Sorbent Injection Installation on CAWCD's

Navajo GS Power Costs

Table 4-15. Increases in the CAP Pumping Energy Charge under the SCR plus Baghouse \& Sorbent Injection Installation Scenario

Table 4-16. $\quad$ Increase in CAP Water Rate Components Under the SCR plus Baghouse \& Sorbent Injection Scenario (\$/AF)

Table 4-17. Increase in CAP Water Rates under the Low Cost SCR plus Baghouse \& Sorbent Injection Installation Scenario

Table 4-18. Increase in CAP Water Rates Under the High Cost SCR plus Baghouse \&

Sorbent Injection Installation Scenario

Table 4-19. Impact of a Navajo GS Shutdown Scenario on CAP Pumping Power Costs

Table 4-20. Increases in the CAP Pumping Energy Charge and CAP Repayment Recovery Charge Under the Navajo GS Shutdown Scenario

Table 4-21. Increase in CAP Water Rate Components Under the Navajo GS Shutdown Scenario $(\$ / A F)$

Table 4-22. $\quad$ Increase in CAP Water Rates Under the Navajo GS Shutdown Scenario (Low Power Price) 68

Table 4-23. Increase in CAP Water Rates Under the Navajo GS Shutdown Scenario (High Power Price) 68

Table 4-24. Increase in CAP Water Rates Under Various Navajo GS Scenarios (\$/AF) 69

Table 4-25. $\quad$ Percentage Increase in CAP Water Rates Under Various Navajo GS Scenarios (\$/AF) 70

Table 5-1. $\quad \mathrm{SO}_{2}$ and $\mathrm{NO}_{\mathrm{x}}$ Emissions Trends from 2002-2008 in Southwestern United States 75

Table 5-2. $\quad$ Comparison of Modeling Procedures for SRP and EPA Visibility Studies on Navajo GS 77

Table 5-3. $\quad$ CALPUFF Results for Original Navajo GS Baseline and for LNB/SOFA Operation 78

Table 5-4. CALPUFF Results for Navajo GS with SCR Operation 79

Table 5-5. CALPUFF Results for Navajo GS, SCR Improvement over LNB/SOFA

Table 5-6. Ammonium Nitrate Concentration Trends $\quad$ Am

Table 5-7. Navajo GS Cost/Benefit Analysis Ranges for SCR Based on SRP and EPA/NPS Analyses 90

Table 5-8. Visibility Cost/Benefit Comparisons $\quad$ V

Table 6-1. $\quad$ Poverty Rates on Navajo and Hopi Reservations, 2005-2009 95

Table 6-2. Tribal Benefits Paid by PWCC (\$ Millions) $\quad$ Th

Table 6-3. $\quad$ Hopi Tribal Revenue from Kayenta Mine Operations (\$ Millions) 96

Table 6-4. $\quad$ Navajo Nation Revenue from Kayenta Mine Operations (\$ Millions) 96

Table 7-1. $\quad$ Estimated On-site and Regional Employment Effect of Navajo GS 106

Table 7-2. Population and Ethnicity by County and Tribe $\quad$ Po7

Table 7-3. Apache, Coconino, and Navajo County Employment and Wages by Industry 109 



\section{Introduction}

The Navajo Generating Station has a distinctive role in the West's story of electric generation and water development. It is the western grid's largest coal-fired power plant. Its stacks are 15 miles from where the Colorado River enters Grand Canyon National Park. It anchors the local economies of the Navajo and Hopi Indian tribes in northeastern Arizona. It powers the massive pumps for the Central Arizona Project (CAP) — a major water delivery project built to fulfill terms of the Colorado River Compact, a multistate water agreement that many consider to be one of the most contentious in U.S. history. Its largest owner is not a traditional utility, but the federal government itself.

Pursuant to the Clean Air Act (CAA), the U.S. Environmental Protection Agency (EPA) announced in 2009 its intent to issue rules for controlling emissions from Navajo GS that could affect visibility at the Grand Canyon and at several other national parks and wilderness areas. The final rule will conform to what EPA determines is Navajo GS' best available retrofit technology (BART) for the control of haze-causing air pollutants, especially nitrogen oxides $\left(\mathrm{NO}_{\mathrm{x}}\right)$.

The CAA's statutory requirement for a BART determination will likely have collateral effects on other statutory mandates for several federal agencies, many of which are under the U.S. Department of the Interior. Also at play are policies regarding the long-term strategic transformation of electric generation in the United States, and Interior's role in that transformation as the manager of federal lands and trusts. As a result, Interior has to reconcile diverse and sometimes divergent policy missions with respect to Navajo GS. A full and accurate understanding of the power sector is crucial to a wellconsidered response, and for that reason Interior requested assistance from the U.S. Department of Energy and its National Renewable Energy Laboratory (NREL) in developing an objective base of technical knowledge. This study is NREL's response to Interior's request.

While EPA is ultimately responsible for setting Navajo GS' BART standards in its final rule, it will be Interior's responsibility to manage compliance and the related impacts insofar as the BART determination affects the missions of its agencies. The likely range of options for what Interior and its agencies can do, however, is one set of questions EPA must consider in making its BART determination. This study by NREL aims to assist both Interior and EPA by providing an objective assessment of issues relating to the power sector that may be outside the primary expertise of either, yet nevertheless will be crucial to a BART determination for Navajo GS.

NREL has taken an interdisciplinary approach to this study, drawing on its experience in systems analysis, economics, finance, policy development, and research into advanced clean energy technologies. The objective is to provide base information and insights into:

- the role Navajo GS plays in the overall power supply picture;

- how BART-related changes to the cost and operation of Navajo GS are likely to impact electricity customers, CAP water customers, and Tribes; and

- how issues present in the Navajo GS case relate to the increasing use of cleaner energy sources, a transition that is happening throughout the electricity sector.

This report draws on work NREL has done and is currently doing with the Western Governors' Association, the Western Electricity Coordinating Council (WECC), regional organizations, and several western states. Insights from these efforts inform how NREL models bellwether changes in policy, technology or fuel supply that might affect electric generation in the Western Interconnection. All of these activities have involved close collaboration with state policy makers, regulators, industry and other stakeholders to ensure the assumptions and inputs are consistent with real-world experience. The detailed inputs that NREL uses in this analysis with respect to plant operating costs, flow limits on each transmission element, local electricity demand, and many other system characteristics are identical to those used by WECC (the Western Interconnection's regional reliability organization) in its own studies of regional system reliability. 


\section{Aims of this study}

Two closely woven imperatives shape the scope of this analysis. First are the statutory factors that the CAA requires EPA to consider in determining which technologies constitute BART for Navajo GS. The law requires EPA to

...take into consideration the costs of compliance, the energy and nonair quality environmental impacts of compliance, any existing pollution control technology in use at the source, the remaining useful life of the source, and the degree of improvement in visibility which may reasonably be anticipated to result from the use of such technology.

Navajo GS' role as the primary source of power for the water pumps of the Central Arizona Project (CAP) adds a formidable layer of complexity to some aspects of this statutory requirement, particularly with respect to the cost of compliance, the energy impacts of compliance, and the remaining useful life of the source. Environmental impacts other than air quality occur primarily on the lands of Navajo Nation and the Hopi Tribe, which brings into play the federal government's trust responsibilities to Native American peoples. The tribal impacts involve economic development benefits as well as potential health concerns.

The second imperative affecting the scope of this study is the long-term transformation of how the United States generates its electricity. Numerous legislative and executive measures have aimed to increase the utilization of clean energy sources, and major initiatives by the Department of the Interior are consistent with those goals. Transformation is more than a goal, however, as the change is already occurring. Coal's share of U.S. electric generation has decreased over the past two decades, while at the same time generation from cleaner sources such as natural gas and renewable energy has increased. Sectoral transformation — as policy and as a fact — shapes the options Interior will have in responding to whatever EPA determines to be BART for Navajo GS. Taking the next step forward to a clean energy future, and doing so without unnecessary economic disruption, requires understanding the sector as it is today.
Looking solely at retrofit technologies discounts broader energy policy goals that Interior is attempting to promote in various venues. For this reason, the study will include a supplemental volume examining alternative generating options. While we recognize that this may be outside a strict reading and short-term interpretation of the statutory factors cited previously, sectoral transformation towards clean energy technologies is a factor in evaluating the long-term cost of compliance and the long-term energy impacts of compliance with respect to extending the useful life of a 35-year-old supercritical coal plant. ${ }^{2}$

\section{Alternatives from cleaner energy sources}

The analysis of the alternatives themselves will follow this report as a companion volume, due to the time constraints of this project. Much of the analysis presented in this volume is normally part of an in-depth NREL study, as it establishes the real-world context affecting how clean energy options would work. In this case, the contextual analysis is also relevant to many issues before Interior and its various agencies, apart from being background necessary to assessing the feasibility of clean energy alternatives. Timely publication of this background analysis will enable its consideration by EPA in developing its proposed BART rule for Navajo GS. We anticipate that EPA and commenters will have sufficient time to consider alternative technologies later in the rulemaking.

In examining clean energy alternatives, NREL's analytical objective is to identify which ones are the most applicable to Navajo GS, and how they may be integrated in the least disruptive manner. Analysis begins with examining the systems and the environment into which those technologies would connect.

\footnotetext{
2 In its final BART rule for the San Juan Generating Station in northwest New Mexico, EPA declined to consider coal-to-liquids technology as a possible BART. Although EPA encouraged the owners and Navajo Nation to examine the technology in detail, it concluded "we cannot consider it as a potential $\mathrm{NO}_{x}$ BART technology as it would involve a complete redesign of the plant. We note the BART guidelines state that ' $[\mathrm{w}] \mathrm{e}$ do not consider BART as a requirement to redesign the source when considering available control alternatives.' " EPA, Final Rule, EPA-R06-OAR-2010-0846; FRL9451-1, Aug. 22, 2011, 76 Fed. Reg. 52388 ("San Juan Final Rule").
} 
The question of alternative generation involves more than a simple megawatt-for-megawatt replacement of Navajo GS' capacity. This is especially true for renewable resources such as wind, solar and geothermal. The replacement might be nowhere near the current plant site, if the nearby natural resources are not of sufficient quality to be commercially viable. Or, the replacement might not have the technical characteristics of a base load plant, which would require changes in how other units on the grid are dispatched. Many such factors apart from the technology itself determine whether a given alternative is practically and economically feasible.

The analysis in chapters 1, 2 and 3 indicate that the basic costs of early retirement of Navajo GS would likely be more than the capital and production costs of retrofitting the plant, regardless of what EPA's BART determination turns out to be (subject to the caveats detailed in those chapters). A consequence of this finding is that the remaining useful life of Navajo GS constitutes a window of time for the Bureau of Reclamation, its utility partners, CAWCD, and the affected Tribes to prepare for a smooth transition from coal to clean energy. The transition need not be 2,250 MW of generation capacity located at one site, because as Chapter 1 will show, Navajo GS' owners have various needs and different levels of dependency on the plant.

Examples of the alternatives to be covered in the supplement are:

- Solar augmentation at one of the existing Navajo GS units. This technology uses both coal combustion and concentrating solar thermal power to create steam, reducing the amount of coal needed to generate the same amount of electricity. It also preserves the ability of the solar-augmented unit to continue providing base load capacity.

- Geothermal as a potential base load replacement. NV Energy's ownership position in Navajo GS is equivalent to $250 \mathrm{MW}$ of base load capacity, which historically has served Las Vegas and the rest of southern Nevada. A major transmission line currently under construction would, for the first time, provide southern Nevada access to northern Nevada's rich geothermal resources. With the new line, NV Energy could replace all of the base load capacity it currently has at Navajo
GS by expanding further into one of the most active geothermal plays in the country.

- On-site solar at CAP pumping stations. The federal government's purpose in developing Navajo GS was to provide power for CAP pumps. CAP's path through central Arizona has some of the country's best areas for solar power. One option that NREL is already evaluating for Interior is solar distributed generation (DG) at the site of CAP pumps. Every megawatt-hour produced on site is one megawatt-hour that does not have to come from Navajo GS, does not cause additional $\mathrm{NO}_{\mathrm{x}}$ emissions, and does not require long-distance transmission.

The supplemental report will include a preliminary analysis of these and other technologies for the purpose of identifying those that warrant further site-specific analysis. The report will not recommend any alternative, as doing so would require site-specific analysis. Interior and NREL anticipate a follow-on phase of this study that would provide a more detailed assessment of the most feasible alternative generating technologies.

\section{Assumptions and key concepts}

Many aspects of this report required making assumptions to address uncertainties that cannot be modeled. Some of these assumptions are based on historical data where such information is available. In other cases, the assumptions are based on reason and knowledge of how the power sector operates. We list here some of the key assumptions used throughout the analysis.

- This study takes state and federal policies on an "as is" basis. We do not examine scenarios with a carbon tax or a cap-and-trade program. While such analyses may be valuable, they are beyond this study's time, resources and scope.

- We assume no additional federal appropriations to offset BART-related costs. We assume that the federal government's share of BART-related costs will be $24.3 \%$ of the total cost, and that this share will be recovered entirely through water rates charged by CAWCD for the use of CAP water. Appropriations and federally backed financing have historically covered Reclamation's share of 
the capital costs, and a future appropriation of any size would mitigate some of the impact on CAP water users and tribes. As of this writing, however, there is no clear indication that future appropriation or federal financing is forthcoming.

- The cost scenarios examined here focus on visibility-related technologies such as selective catalytic reduction (SCR). Some other analyses count the cost of technologies such as baghouses that do not address visibility, significantly increasing those estimates of BART costs. Here, we treat the cost of baghouses as elective and supplemental costs, not as costs that would be inherent to a BART decision. This is consistent with EPA findings in similar BART proceedings. We nevertheless provide separate estimates of baghouse costs for additional reference.

- We distinguish between a plant's capital costs and its operating costs. An important implication of this assumption is that if installing BART upgrades increases Navajo GS' capital cost but does not change its operating costs, the plant will run just as much with the new control technology as it does now.

- We assume that utilities will add their share of any capital improvements to their rate base just as they would any other capital investment. We further assume that the utility's weighted cost of capital is the appropriate discount rate to use when annualizing capital cost, as it represents the utility's true long-term time value of money.

- We assume that impacts relating to capital costs and production costs are the base of an economic comparison of outcomes, but we do not assume they represent the extent of the business costs associated with a given BART outcome. Present uncertainties such as renegotiating the Navajo GS site lease may impose additional costs of doing business and may have their own incremental impact on retail rates. Quantifying these uncertainties in a non-arbitrary manner is problematic, however. We therefore use capital costs and production costs as the basis for comparison, recognizing that additional costs may exist.
- We assume that the Bureau of Reclamation and CAWCD will not routinely sell surplus electricity on the wholesale power market at a loss. In other words, we assume they would act in an economically rational manner just as the utility partners would.

- We assume that Navajo GS' replacement cost is represented by the cost of obtaining the same amount of power per year from spare capacity on existing generators. We use production cost modeling to estimate near-term power replacement costs. Over time, however, system load will increase and additional generating capacity will be required. This would be the case with or without Navajo GS, although the additional capacity would be needed sooner if Navajo GS were retired early.

- The results of production cost modeling represent an economically optimum outcome that accounts for known, quantifiable constraints. Transaction costs such as existing power delivery obligations are not modeled, nor are other potential sources of inefficiency. Because they represent economic inefficiencies, these factors would likely increase the actual cost of replacement. Therefore, the replacement costs discussed in Chapter 2 represent best-case, least-cost scenarios.

- We assume that any estimate of future costs or prices is best represented as a plausible range rather than as a single estimated number. Such future values are bounded by a band of uncertainty, and representing them as a single number imputes more certainty than they warrant.

- The analysis is largely based on the current cost of operating Navajo GS because these costs are known. Future production costs may be higher depending on renegotiation of coal and the plant site leases, but these uncertainties cannot be quantified at this time.

- Continued participation of Los Angeles Department of Water and Power (LADWP) is uncertain for the reasons discussed in Chapter 1. For this analysis, we assume that the economic attributes of LADWP's $21.2 \%$ share would transfer to a new owner if LADWP were to divest its 
position in Navajo GS. In other words, we assume that the consequences discussed in Chapters 1, 2, and 3 that are specific to LADWP would largely hold true for a successor interest, although details such as cost of capital may be different. Assuming otherwise would require knowing who the successor interest would be. Generally, if LADWP or any of the other current owners decides not to continue to participate, continued operation would depend on another buyer being found, or the remaining participants absorbing the remainder of the costs.

\section{Organization of this report}

Chapter 1 provides baseline information about the plant's history and its operational characteristics. This background is essential to understanding the remaining useful life of Navajo GS, and how the costs of compliance would be distributed. Key to this analysis will be depreciated capital, net plant in service, cost of capital, and other financial metrics. The chapter begins with an overview of the federal actions relating to water development that led to the creation of Navajo GS and the participation of the Department of the Interior. The regulatory discussion examines the plant's role in each partner's generation portfolio, and describes the current status of capital financing and net plant in service. It also contrasts the various types of owners (investor-owned utilities, a municipally owned utility, a public power utility, and the Bureau of Reclamation) and how each owner makes decisions with respect to operations and capital investment.

Chapter 2 establishes analytical benchmarks for evaluating the energy impacts of compliancespecifically, how the local and regional power systems would respond in the event that retiring Navajo GS were more economical than BART retrofits. Retirement approximates a worst-case scenario, on the assumption that the owners of the Navajo GS plant would invest in additional emission controls if the resulting net cost were less than the cost of replacing the plant. The chapter uses production cost modeling to forecast where the replacement power would come from, and how much more it would cost utilities and their customers. The methodology used is similar to how utilities and regional reliability organizations would approach the question themselves. However, this chapter also pays close attention to Navajo GS' largest owner, which is not a utility. The federal government's position in Navajo GS lacks the flexibility enjoyed by the plant's utility partners, with the result that the effects of retirement would be greater.

With the shutdown scenario fully examined, the report turns to retrofit options in Chapter 3. This chapter focuses on SCR retrofits as the most aggressive with respect to $\mathrm{NO}_{\mathrm{x}}$ reduction. Other less-costly alternatives are addressed, including those recently installed at the plant. The chapter also describes supplemental retrofits such as baghouses.

The heavier financial impact on the federal share of Navajo GS would particularly affect CAP water users. These impacts are the subject of Chapter 4 . The federal government authorized Navajo GS (and its unusual ownership arrangement) for the purpose of enabling Arizona to take possession of water that the Colorado River Compact entitled the state. Consequently, the Compact and all related laws and legal settlements define the federal government's role in Navajo GS, which in turn constitutes a crucial element in assessing the cost of compliance. Chapter 4 examines the two major types of issues: impact on CAP water rates, and how additional power costs could affect the revenue streams used to retire CAP debt obligations.

Chapter 5 provides an overview of the science relating to atmospheric visibility. It summarizes information to date dealing with visibility issues at the Grand Canyon and other nearby Class I areas.

Chapter 6 examines the impacts on the tribes and on local economies. It separately examines two groups of affected tribes: those that are close to the Navajo plant and the nearby coal mine that provides fuel; and those that rely on CAP water. The Navajo and Hopi tribes constitute a significant portion of the on-site labor force at the plant and at the mine. In addition, leases and other agreements between the tribes and the plant owners, and between the tribes and the mine's owner Peabody Coal, provide a stream of revenue to each tribal government. For the water-using tribes, the arrangements described in Chapter 4 affect the water rates paid by the tribes, and they affect the availability of money to improve water delivery infrastructure. 
Finally, Chapter 7 provides a baseline overview of Navajo GS' role in the economy of northeastern Arizona.

\section{Caveats}

NREL makes no recommendation about what the final BART determination for Navajo GS should be. We offer conclusions about what outcomes are probable based on our empirical analysis of key scenarios, and we have a high degree of confidence in those conclusions. How those conclusions should be weighed against other factors outside our analysis requires value comparisons that would be inappropriate for NREL to make. These determinations are part of EPA's charge under the CAA, and are subject to judicial review and legislative oversight. NREL is not an interested party to the Navajo GS BART proceedings, but is rather a resource to Interior and to EPA.

The work contained in this report represents the research and analysis that could be conducted and written within a three-month period. This short timeline necessarily limited the analysis for this report. The three-month window was set by EPA's own timeline for issuing a proposed BART rule for Navajo GS, and by the timing of the interagency agreement between Interior and DOE that authorized NREL to begin work. NREL's own procedures also require time for independent peer review of major reports, which reduced research time even more. Consequently, some aspects of Navajo GS and its upcoming haze rule may not be addressed in as much detail as would have been possible with additional time.

\section{Acknowledgments}

Others have contributed to this study, but only the principal contributors were listed as co-authors. This study has benefitted from the knowledge and advice of other NREL experts in many areas relating to the topics addressed here. We are also very grateful for comments and suggestions provided by our panel of outside experts, who gave of their time to serve as independent peer reviewers. 


\section{Navajo GS Origin and Operations}

The Navajo Generating Station (Navajo GS), outside of Page, Arizona, has been producing energy since 1974. Congress authorized creation of the 2,250 MW coal-fired power plant in conjunction with its creation of the Central Arizona Project (CAP), a 336-mile water distribution system built to deliver more than 1.5 million acre-feet of Colorado River water annually from Lake Havasu in western Arizona to agricultural users, Indian tribes, and millions of municipal water users in Maricopa, Pinal, and Pima counties.

Congressional authorization is an unusual genesis for a coal-fired power plant. The special relationship between the plant and the CAP is an important factor in evaluating the consequences of a best available retrofit technology (BART) determination for Navajo GS. The haze provisions of the Clean Air Act Amendments of 1990 require EPA to set BART standards for Navajo GS, but they also require EPA to take into consideration (among other factors) the costs of compliance, the remaining useful life of the source, and existing pollution control technology in use at the source. This chapter provides background on these statutory factors in particular. Subsequent chapters address other statutory factors, such as the energy impacts of compliance, environmental impacts other than air quality, and the degree of improvement in visibility that may reasonably be anticipated to result from the technologies under discussion.

As Figure 1-1 shows, the plant's geographic area of influence is wide, ranging from Peabody Western Kayenta Coal Mine (the source of the coal used to run the power plant) on the Navajo and Hopi reservations, to the Los Angeles Department of Water and Power, one of the five utilities with an interest in the plant.

The first section of this chapter details the history of the federal government's stake in Navajo GS, its current ownership structure, and how the corporate and oversight structure of different owners affects their method of paying for capital investments. It introduces many of the key players shown in the relational flowchart depicted in
Figure 1-1. The section also discusses uncertainties arising from other ongoing regulatory efforts beyond EPA's current proceedings to establish a BART rule for the plant.

The discussion then turns to the position of Navajo GS in each partner's generation portfolio. This is a crucial element in understanding the cost of BART compliance, as the true impact is not solely a function of the technology's capital cost. Equally important is the way the partner recovers its capital costs, and its options for getting power from other sources. The section describes the degree to which each owner depends upon the plant, and the financial mechanisms it uses to recover costs. The last section discusses the operations of the plant, its coal use, and its emissions as reported to EPA. It also describes major emission controls installed at the plant. 




Figure 1-1. Navajo Generating Station and Central Arizona Project 


\subsection{Regulatory Background and Ownership Interests}

The legislation establishing the CAP included authority for the Secretary of the Interior to participate in a power generation facility for the purpose of powering CAP's pumping stations. ${ }^{1}$ Originally, CAP supporters envisioned building hydroelectric dams in the Grand Canyon for this purpose. Strong public opposition to the proposed dams made it unlikely that Congress would pass the legislation authorizing the CAP without an alternative way to power it. A thermal power plant was determined to be more acceptable to the public and "[i]n place of the hydroelectric dams, the Secretary of the Interior was allowed to enter into an agreement with non-Federal power interests for entitlement to $24.3 \%$ of the power produced at the non-Federal Navajo Generating Plant."2

Negotiations to plan and build a coal-fired power plant began in June 1968, and utilities in the Southwest were invited to participate. In a letter to President Nixon in 1969, Assistant Secretary of Interior James R. Smith outlined the negotiations in which parties concluded:

"[t]he most feasible plan to supply the power requirements of the Central Arizona Project and to augment the Lower Colorado River Basin Development Fund is to acquire generation and transmission capacity by participation with nonFederal entities in the construction and operation of generation and transmission facilities." ${ }^{3}$

The steering committee included the Bureau of Reclamation and a representative from each interested utility. The utilities included the current five utility owners - Salt River Project, Los Angeles Department of Water and Power (LADWP), Arizona Public Service Company (APS), Nevada Power Company, and Tucson Electric Power (TEP) - as well as representatives from San Diego Gas and Electric Company, Southern California Edison
Company, El Paso Electric Company, and Public Service Company of New Mexico. El Paso Electric Company and Public Service Company of New Mexico withdrew in February 1969, while San Diego Gas and Electric Company and Southern California Edison Company withdrew in May $1969 .^{4}$

Plant construction began in 1970 with the SRP leading the effort. Bechtel was the lead contractor for construction, and by 1976 all three of the plant's 750 MW units were on line.

\subsubsection{Ownership Interests}

Other major coal plants in the West have multiple owners, but federal ownership makes Navajo GS unique. Of the six entities that have an ownership interest in the plant, the U.S. Bureau of Reclamation holds the largest $-24.3 \%$. The purpose of the federal government's participation in Navajo GS is to ensure that CAP receives the necessary energy to power the pumps that move up to 1.5 million acre-feet or more of Colorado River water across Arizona, pursuant to federal law. ${ }^{5}$ Figure 1-1 illustrates the intricate link between Navajo GS and CAP, which Chapter 4 discusses in greater detail. The U.S. Department of the Interior, Reclamation's parent agency, has another level of interests arising from the connections between the plant, CAP and the federal government's trust responsibility to the Indian Tribes. Another Interior agency, the Office of Surface Mining, regulates the coal mine-also on tribal land - that supplies the plant on an exclusive basis.

The Department of the Interior and the five utility partners executed the Navajo Project Co-Tenancy Agreement on March 23, 1976. Table 1-1 details the ownership shares. SRP, the largest utility owner, operates the plant and has responsibility for scheduling, operating, and maintaining the three units. The remaining owners receive their allotments of the power generated pro rata, and contribute to the cost of running the plant according to their initial investment. SRP and LADWP are the only owners other than Reclamation that have an interest greater than $20 \%$.

\footnotetext{
4 Smith, p. 3.

5 Colorado River Basin Project Act, U.S. Code 43 (2010), §1523(b).
} 
Table 1-1. Navajo Generating Station Ownership

\begin{tabular}{|l|l|l|l|}
\hline \multicolumn{1}{|c|}{ Owner } & Share & \multicolumn{1}{c|}{ Type of entity } & Oversight authority \\
\hline $\begin{array}{l}\text { U.S. Bureau of } \\
\text { Reclamation }\end{array}$ & $24.3 \%$ & $\begin{array}{l}\text { Federal agency within the } \\
\text { Department of Interior }\end{array}$ & Federal legislation \\
\hline $\begin{array}{l}\text { Salt River Project } \\
\text { Political Subdivision of State of } \\
\text { Arizona; Governed by the board } \\
\text { of directors }\end{array}$ & Board of Directors (elected) \\
\hline $\begin{array}{l}\text { Los Angeles } \\
\text { Department of Water } \\
\text { and Power }\end{array}$ & $21.7 \%$ & Municipal Utility & Board of Commissioners \\
\hline $\begin{array}{l}\text { Arizona Public } \\
\text { Service Co. }\end{array}$ & $21.2 \%$ & $\begin{array}{l}\text { Investor-owned utility (parent: } \\
\text { Pinnacle West Capital Corp, LLC) }\end{array}$ & $\begin{array}{l}\text { Regulated by Arizona } \\
\text { Corporation Commission }\end{array}$ \\
\hline $\begin{array}{l}\text { Nevada Power Co. } \\
\text { mayor) }\end{array}$ & $\begin{array}{l}\text { Investor-owned utility } \\
\text { (parent: NV Energy) }\end{array}$ & $\begin{array}{l}\text { Regulated Nevada Public } \\
\text { Utility Commission }\end{array}$ \\
\hline $\begin{array}{l}\text { Tucson Electric } \\
\text { Power Co. }\end{array}$ & $11.3 \%$ & $\begin{array}{l}\text { Investor-owned utility } \\
\text { (parent: UniSource Energy) }\end{array}$ & $\begin{array}{l}\text { Regulated by Arizona } \\
\text { Corporation Commission }\end{array}$ \\
\hline
\end{tabular}

\subsubsection{Regulatory Framework}

Three of the owners fall under the jurisdiction of state utility regulators with authority to approve capital expansion, resource procurement plans, and customer rates. The Arizona Corporation Commission (ACC) regulates APS and TEP. The ability of these two utilities to recover through customer rates any costs associated with their ownership positions in Navajo GS is largely subject to ACC approval.

Nevada Power Company merged with Sierra Pacific Power Company in 1999. The merger resulted in one combined utility - NV Energy — serving most of Nevada. Although operating financially as one utility, NV Energy's two transmission networks still operate separately: Nevada Power Company in the south, and Sierra Pacific in the north. NV Energy is regulated by the Nevada Public Utilities Commission (NPUC).

SRP and LADWP are both public power utilities responsible to a board (elected directors in the case of SRP, commissioners appointed by the Mayor of Los Angeles in the case of LADWP). Both SRP and LADWP have greater flexibility with regard to planning and cost recovery sincethey are not regulated by a state PUC. ${ }^{6}$ This

\footnotetext{
6 Even though SRP is not under the jurisdiction of the ACC, it is statutorily required to receive approval from the Commission for siting power lines and thermal power plants greater than $100 \mathrm{MW}$ (ARS 40-360). Also, SRP is statutorily required to go before the ACC for approval of its financings.
}

difference in governance structure marks a key distinction between investor-owned utilities (IOUs) and those owned by a public entity. In essence, publicly owned utilities are governed and regulated by the political entities that created them, while IOUs are regulated by the state's PUC.

While ownership positions in Navajo GS have not changed during the entire time the plant has been operating, LADWP's ownership interest will likely be affected soon by legislative action in the State of California. Senate Bill 1368 (2006 legislative session) precludes a utility from making investments to extend the life of a plant that exceeds the rate of emissions of greenhouse gases for combined-cycle natural gas power plant. ${ }^{7}$ Navajo GS does not currently meet this emissions standard, and would not likely meet the standard if it were to install emissions control measures the EPA is currently considering through its BART rulemaking process.

For this analysis, we assume that the attributes of LADWP's $21.2 \%$ share would transfer to a new owner if LADWP were to divest its position in Navajo GS. In other words, we assume that the consequences discussed in this chapter that are specific to LADWP's share of the plant would largely hold true for a successor interest, acknowledging that details may differ in ways that

\footnotetext{
7 California Public Utility Code $\S 8340-8341$. SB 1368 requires that the greenhouse gases emission performance not exceed the rate of emissions of greenhouse gases for combined-cycle natural gas base load generation.
} 
cannot be predicted or modeled without knowing who the successor interest would be. Generally, if LADWP or any of the other current owners decides not to continue to participate, continued operation would depend on another buyer being found, or the remaining participants absorbing the remainder of the costs.

\subsubsection{Environmental regulations}

The proximity of the Navajo GS plant to eleven Class 1 visibility areas is the focus of EPA's current rulemaking, but various environmental regulations have affected the plant throughout its history. The most significant has been the Clean Air Act, including its amendments in 1977 and 1990. ${ }^{8}$ The 1977 amendments resulted in the need to install $\mathrm{SO}_{2}$ scrubbers on all three units, which cost the partners $\$ 420$ million in all. ${ }^{9}$ Navajo GS' $\mathrm{SO}_{2}$ emissions have declined considerably since the installation of scrubbers.

Several other ongoing or upcoming regulatory measures could affect Navajo GS beyond EPA's BART determination. Tables 1-2, 1-3 and 1-4 provide a compilation of regulatory activities cited by Navajo GS' utility owners as having the potential to affect the plant's operation and its future. Together, these other pending actions create an additional layer of uncertainty that affects the present calculus of whether visibility-related BART upgrades would be economically viable.

Navajo GS has been operating for nearly thirty-five years. The plant site lease is up for renewal in 2019 approximately forty-five years from the start of operation for its first unit. Other supporting agreements needed to continue operating Navajo GS expire within the next ten years. The renegotiation of these instruments - mainly the rights-of-way for transmission lines, plant site, railroad, and water intake and water line - is an added uncertainty and will trigger a National Environmental Policy Act (NEPA) review.

The next few years will be crucial in determining how long the plant will continue operating. In 2011 alone, the plant faced new regulation under the GHG Tailoring

\footnotetext{
8 The Clean Air Act, U.S. Code $43 \S 7401$ et seq. (1970); amended by Clean Air Act Amendments of 1977 (91 Stat. 685, P.L. 95-95); Clean Air Act Amendments of 1990 (104 Stat. 2468, P.L. 101-549).

9 Does not include capitalized interest, taxes and other administrative and general costs. Salt River Project, Navajo Generating Station, http://www. srpnet.com/about/stations/Navajo.aspx.
}

Rule, the Utility Boiler MACT, and the updated ESA work plan that listed species and critical habitats. In addition, Navajo GS will be facing new $\mathrm{SO}_{2}$ NAAQS attainment designations, ozone attainment designations, coal combustion residual regulation, and cooling water intake structure mitigation measures by the end of 2012. Further uncertainties lie in actions that do not have final schedules at present. These actions include: Transport Rule II ( $\left.\mathrm{NO}_{\mathrm{x}}\right)$; Particulate Matter NAAQS; Utility Boiler GHG NSPS; Final NEPA Guidance from the Council on Environment Quality on the effects of Climate Change and GHGs; and the BART petition pertaining to Reasonably Attributable Visibility Impairment (RAVI).

Regulatory uncertainties are common for coal plants. Complicating these uncertainties in the case of Navajo GS is the plant's link to the CAP and to the local economies - especially tribal economies - that CAP water sustains. A reasonable first step in sorting through the complexity to make the necessary decisions is to understand the plant's business fundamentals using traditional utility measurements. The next section looks at Navajo GS from the perspective of its owners, focusing on the way each one finances its share, and on the plant's position in the utility's resource portfolio. 
Table 1-2. EPA Regulatory Actions Affecting Navajo Generating Station

\begin{tabular}{|c|c|c|}
\hline Agency Actions & Schedule & Summary of Action \\
\hline $\begin{array}{l}\text { Utility Mercury and } \\
\text { Air Toxics Standard } \\
\text { (MATS) }\end{array}$ & $\begin{array}{l}\text { Proposed } \\
\text { March 2011/ } \\
\text { Final announced } \\
\text { December } 2011\end{array}$ & $\begin{array}{l}\text { Limit hazardous air pollutant emissions (i.e. mercury, } \\
\text { arsenic, chromium, nickel, lead, and hydrochloric acid). } \\
\text { Regulations will require existing and new coal-fired } \\
\text { utility units to meet new emissions limits for mercury, } \\
\text { non-mercury metals, acid gases. New emission controls, } \\
\text { such as baghouses, could be required at Navajo GS to } \\
\text { meet the emissions limits in the final rule. }\end{array}$ \\
\hline $\begin{array}{l}\text { Greenhouse Gas } \\
\text { (GHG) Tailoring } \\
\text { Rule }\end{array}$ & $\begin{array}{l}\text { Effective January } \\
2011\end{array}$ & $\begin{array}{l}\text { Sets thresholds for GHG emissions that define when } \\
\text { permits under the New Source Review PSD and Title V } \\
\text { Operating Permit programs are required for new and } \\
\text { existing industrial sources. Sources that trigger PSD for } \\
\text { GHG emissions are required to conduct a BACT analysis. } \\
\text { EPA released technical guidance in March } 2011 \text { to assist } \\
\text { States in determining BACT for new and modified } \\
\text { sources subject to PSD for GHGs. }\end{array}$ \\
\hline
\end{tabular}

$\begin{array}{ll}\text { SO }_{2} \text { National } & \text { Final June 2010; } \\ \text { Ambient Air } & \text { Initial Attainment } \\ \text { Quality Standards } & \text { Designations } \\ \text { (NAAQS) } & \text { Summer } 2012\end{array}$

\begin{tabular}{|l|l|}
\hline $\begin{array}{l}\text { Cooling water } \\
\text { intake structures }\end{array}$ & $\begin{array}{l}\text { Proposed April } \\
\text { 2011/Final } 2012\end{array}$ \\
\hline $\begin{array}{l}\text { Coal Combustion } \\
\text { Residuals }\end{array}$ & $\begin{array}{l}\text { Proposed June } \\
\text { 2010/Final Pending }\end{array}$ \\
\hline
\end{tabular}

\begin{tabular}{|l|l|}
\hline $\begin{array}{l}\text { Ozone NAAQS } \\
\text { Review }\end{array}$ & Proposed \\
2013/Final pending
\end{tabular}

\section{Particulate Matter (PM) NAAQS Pending}

\begin{tabular}{|l|l|}
\hline Transport Rule II & $\begin{array}{l}\text { Pending (schedule } \\
\text { delayed due to } \\
\text { late promulgation } \\
\left(\mathbf{N O}_{\mathbf{x}}\right)\end{array}$ \\
& $\begin{array}{l}\text { of revised ozone } \\
\text { NAAQS) }\end{array}$ \\
\hline
\end{tabular}

\section{Utility Boiler \\ GHG New Source \\ Performance \\ Standards (NSPS)}

Revised by EPA on June 2, 2010, creating a new 1-hour standard. Modeling of individual stationary sources, including Navajo GS, may be required to determine whether any emission reductions are needed to meet the new 1-hour NAAQS.

EPA to require all steam electric generating stations that have cooling water intake structures with design intake flows > 2MGD to implement technologies to prevent impingement/entrainment of aquatic life.

EPA to issue federal regulations for the disposal and long-term management of coal combustion residuals.

EPA is reviewing to determine whether a lower standard is required. A lower standard could create additional ozone nonattainment areas in AZ and the Western US. If EPA lowers the standard, additional NOx controls may be required on stationary sources as Navajo GS.

EPA to affirm or revise current PM NAAQS - if lowered, further emissions reductions for the power sector may be required.

When new NAAQS for ozone is issued, EPA plans to propose an updated interstate pollution transport rule for the revised NAAQS. A final rule is expected approximately one year after the proposed rule and could include the Western U.S.

EPA is under a court settlement to set NSPS standards for this source category for GHG emissions. When EPA

New Schedule pending establishes standards for new sources, the agency will also produces "guidelines" for regulating existing sources such as Navajo GS. This action could result in a GHG emission standard for Navajo GS. 
Table 1-3. National Environmental Policy Act (NEPA) Actions Affecting Navajo Generating Station

\begin{tabular}{|c|c|}
\hline Agency Actions & Schedule \\
\hline
\end{tabular}

Draft NEPA

Guidance on Effects

of Climate Change

and GHGs

(Council on

Environmental

Quality, CEQ)
Draft February 2010/

final pending

The draft guidance explains how

Federal agencies should analyze the environmental impacts of GHG emissions and climate change when they describe the environmental impacts of a proposed action under NEPA. It provides tools for agency reporting, including a presumptive threshold of 25,000 metric tons of carbon dioxide equivalent emissions from the proposed action to trigger a quantitative analysis, and instructs agencies how to assess the effects of climate change on the proposed action and their design.

2019 - plant site and water intake/water line renewals due;

Renegotiation will require NEPA review \& approval.

Federal Land
Rights-of-Way
(Bureau of Indian
Affairs, Bureau of
Land Management,
National Park
Service)

2021 - railroad and transmission line renewals due;

2022 - southern transmission line easement (Bureau of Land

Management);

2032 - permit covering small parcel for water intake from Lake Powell (National Park Service)

\section{Water Service}

Contract

(Bureau of

Extension process has been initiated.

\section{Reclamation)}

Mining Permits

(Office of Surface

$2024 / 25$

Mining, OSM)

Mining Plan

Approval (Bureau of 2024/25

Land Management)

Renegotiation will require NEPA review \& approval.

Plan approval needed for future mining areas within Indian mining leases. 


\begin{tabular}{|c|c|c|}
\hline Agency Actions & Schedule & Summary of Action \\
\hline $\begin{array}{l}\text { Endangered Species } \\
\text { Act (ESA) listing } \\
\text { work plan (U.S. Fish } \\
\text { \& Wildlife Service) }\end{array}$ & $\begin{array}{l}\text { Listings and critical } \\
\text { habitats published } 2011 \\
\text { - } 2016 \text { per settlement } \\
\text { schedule }\end{array}$ & $\begin{array}{l}\text { In response to litigation, USFWS agreed to a } \\
\text { multi-year work plan to evaluate } 250 \text { species for } \\
\text { listing and/or designation of critical habitat under } \\
\text { the ESA. Of those } 250 \text { species, } 29 \text { occur in Arizona } \\
\text { and } 11 \text { may impact current or future power } \\
\text { generation. }\end{array}$ \\
\hline $\begin{array}{l}\text { BART Petition } \\
\text { - Reasonably } \\
\text { Attributable } \\
\text { Visibility } \\
\text { Impairment (RAVI) }\end{array}$ & $\begin{array}{l}\text { Submitted to DOI May } \\
\text { 5, 2009; DOI responded } \\
\text { March 8, } 2011\end{array}$ & $\begin{array}{l}\text { On May 5, } 2009 \text { several environmental groups } \\
\text { submitted a petition to DOI requesting that } \\
\text { the agency certify that visibility impairment in } \\
\text { the Grand Canyon is reasonably attributable to } \\
\text { emissions from Navajo. DOI responded to the } \\
\text { petition by letter on March } 8,2011 \text {, indicating } \\
\text { that the EPA is in the process of establishing BART } \\
\text { under the Regional Haze Rule. DOI explained } \\
\text { that it reserves the right to certify RAVI if finds } \\
\text { that the proposed BART determination does not } \\
\text { adequately mitigate Navajo- purported visibility } \\
\text { impact. }\end{array}$ \\
\hline $\begin{array}{l}\text { California } \\
\text { Senate Bill } 1368\end{array}$ & Passed in 2006 & $\begin{array}{l}\text { GHG Emission Performance Standard to go into } \\
\text { effect no later than } 2019 \text { (applies to baseload for } \\
\text { publicly owned electric utilities). }\end{array}$ \\
\hline
\end{tabular}

Table 1-5. Contribution of Navajo Generating Station to Utility Partners' Generating Fleets (Owned, Operating Capacity Only)

\begin{tabular}{|c|c|c|c|c|c|}
\hline & SRP & LADWP & APS & $\begin{array}{c}\text { NV } \\
\text { Energy }\end{array}$ & TEP \\
\hline$\%$ ownership of Navajo ${ }^{a}$ & $21.7 \%$ & $21.2 \%$ & $14.0 \%$ & $11.3 \%$ & $7.5 \%$ \\
\hline MW ownership of Navajo GS & 488.3 & 477 & 315 & 254.3 & 168.8 \\
\hline Share of GWh generated, 2010 & $3,565.2$ & $3,483.1$ & $2,300.1$ & $1,856.5$ & $1,232.2$ \\
\hline Coal fleet MW & $2,209.5$ & 477 & $1,747.1$ & 928.1 & 753.2 \\
\hline Navajo share as \% of coal fleet & $22.10 \%$ & $100.00 \%$ & $18.00 \%$ & $27.40 \%$ & $22.40 \%$ \\
\hline Total fleet MW & $6,527.0$ & $6,300.2$ & $7,019.0$ & $7,369.1$ & $2,495.3^{(c)}$ \\
\hline Navajo share as $\%$ of total fleet & $7.50 \%$ & $7.60 \%$ & $4.50 \%$ & $3.50 \%$ & $6.80 \%$ \\
\hline Total fleet 2010 GWh & $26,113.5$ & $13,337.3$ & $21,208.1$ & $20,570.9$ & $5,427.4$ \\
\hline Navajo share as \% of total GWh & $13.7 \%$ & $26.1 \%$ & $10.8 \%$ & $9.0 \%$ & $22.7 \%$ \\
\hline
\end{tabular}

Note: does not include contract power purchases or planned plants. Owned, operating plants only.

(a) The U.S. Bureau of Reclamation owns the remaining 24.3\% of Navajo GS (546.8 MW; 3,992.4 GWh generated in 2010).

(b) Includes assets of Nevada Power Company and Sierra Pacific Power Company.

(c) Coal/gas fuel switching unit (Sundt Unit 4, $156 \mathrm{MW}$ ) included in both total fleet MW and in coal fleet MW count. 


\subsection{Navajo GS in the Utility Partners' Generating Fleets}

Navajo GS constitutes a varying portion of each utility partner's owned generating asset portfolio, ranging from $3.5 \%$ (NV Energy) to 7.6\% (LADWP) of each utilities' overall owned generation portfolio. ${ }^{10}$ More significant, however, is the role of Navajo GS in each utility's base load fleet. A utility's base load is its lowest level of hourly demand over the course of the year. The daily and hourly fluctuations that are a natural part of electricity demand will always occur at levels that are more than the system's base load. Demand above base load, therefore, is typically served by generators that cycle on and off (or that ramp up and down) on a daily basis. Generators serving base load, on the other hand, can theoretically run at the same constant level and are normally dispatched first in order to satisfy demand.

Coal and nuclear units typically operate as base load capacity. Their share of energy tends to be proportionally larger than the capacity they represent, due to the fact that they run more constantly throughout the year. This is the case for Navajo GS, as shown in Table 1-5.

\section{Salt River Project (SRP)}

SRP owns the largest share of the plant of any of the utility partners. SRP's coal portfolio also includes a power purchase agreement (PPA) for the output from $100 \mathrm{MW}$ of Unit 3 of the Springerville, Arizona coal-fired facility, which is owned by Tri-State Generation. ${ }^{11}$ In addition to its share of Navajo GS and the Springerville PPA, SRP owns the 423 MW Unit 4 of the Springerville plant plus an additional 1,298 MWs of coal-fired assets in Colorado, New Mexico and Arizona. ${ }^{12}$ SRP does not appear to have plans to retire any of its coal units in the near future.

\section{Los Angeles Department of Water and Power (LADWP)}

Although Navajo GS constitutes the entirety of LADWP's owned coal assets, LADWP has a PPA with Utah Power and Light for up to 1,202 MW of the coal-fired

\footnotetext{
10 SNL Energy, SNL Web Platform Tool, http://www.snl.com/ SNLWebPlatform.aspx (web-based portal of news, data and research on the electric power sector); Salt River Project, Navajo Generating Station, http:// www.srpnet.com/about/stations/Navajo.aspx.

11 Salt River Project, SRP Contract Power Purchases http://www.srpnet.com/ about/stations/contractpower.aspx.

12 Salt River Project, Springerville Generating Station, http://www.srpnet. com/about/stations/springerville.aspx; SNL Energy 2011.
}

Intermountain Power Project (IPP). Together, Navajo GS and IPP currently account for $39 \%$ of the energy delivered to LADWP customers. ${ }^{13}$ To comply with the mandates established by SB 1368 as early as possible, LADWP plans to eliminate coal assets from its portfolio. ${ }^{14}$ LADWP's IRP recommends adding a 500-MW combined cycle natural gas plant with a $52 \%$ capacity factor. LADWP estimates that divestment of Navajo GS in 2014 would reduce their GHG emissions by 10.5 million metric tons and bring in about $\$ 360$ million in capital investment from the asset sale. LADWP anticipates the capital cost of the new natural gas plant to be $\$ 637$ million. $^{15}$

\section{Arizona Public Service (APS)}

In addition to Navajo GS, APS has partial ownership in the Cholla coal-fired power plant near Joseph City, Arizona, and the Four Corners plant near Farmington, New Mexico, adding approximately 1,432 MW of coalfired assets to its portfolio. Neither of these plants is slated for retirement in the near future.

\section{NV Energy}

Through its subsidiaries, Nevada Power Company and Sierra Pacific Power Company, NV Energy owns 674 MW of coal-fired assets in Nevada in addition to its share of Navajo GS. The North Valmy Generating Station, near Valmy, Nevada, which operates at approximately a $63 \%$ capacity factor, is scheduled to retire Unit 1 (261 MW) in 2022. Sierra Pacific Power Company does not need to add a significant amount of generation to its portfolio to continue to meet projected load requirements until the Valmy Unit 1 retirement. ${ }^{16}$

\footnotetext{
13 City of Los Angeles Department of Water and Power (LADWP), 2010 Power Integrated Resource Plan, http://www.ladwp.com/ladwp/cms/ ladwp014239.pdf.

14 LADWP, p. ES-4.

15 LADWP, p. M-19.

16 Sierra Pacific Power Company, Sierra Pacific Power Company Integrated Resource Plan, Docket No. 10-07003, Volume 3 of 22. 2010.
} 
Of the utility partners, TEP has the smallest ownership, both in terms of total fleet capacity installed and total GWh generated. TEP owns $584 \mathrm{MW}$ of coal-fired assets in New Mexico and Arizona in addition to its share of Navajo GS. ${ }^{17}$ This includes partial ownership of the Four Corners and San Juan plants in New Mexico, in addition to the Sundt Unit $4 \mathrm{coal} / \mathrm{gas}$ fuel switching facility in Arizona. None of these plants appear to be scheduled for retirement in the near future.

\subsubsection{Age and remaining useful life of the plant}

Navajo GS' three units were



Note: Navajo GS units in red. Unit 2 had a one-time outage in 2010 for LNB/SOFA installation; its 2009 capacity factor was $89 \%$. Source: SNL Financial 2011

Figure 1-2. Age, capacity factor and size of coal units in WECC constructed between 1974 and 1976, and in 2011 the units were 34, 35 and 36 years old. A scatter plot of operating coal units in WECC (Figure 1-2) shows that the three Navajo GS units are old relative to coal units of comparable size (the size of the bubble is determined by the unit's capacity). Generally, units with lower costs of production run more often and therefore have higher capacity factors.

The Navajo GS plant site lease is up for renewal in December 2019. According to the EIA-860 database, the average capacity-weighted age of a coal plant that had been retired by 2009 was approximately 48 years oldpractically the same as the service life of Navajo GS that the partners originally anticipated when they signed the initial agreement. ${ }^{18}$ This historical number might not be indicative of plants comparable to Navajo GS, however. Survival analysis conducted by NREL for other system modeling efforts suggests that among the cohort of coal plants comparable to Navajo GS, fewer are shutting down early when compared to the survival of earlier-generation plants over the same amount of time. ${ }^{19}$

17 SNL Energy 2011.

18 EIA-860 Database (2009), http://38.96.246.204/pub/electricity/f860y09.zip. Accessed November 28, 2011.

19 For more on the methodology NREL used to examine survival rates for coal plants, see Kaplan, E. L.; Meier, P.: Nonparametric estimation from incomplete observations. J. Amer. Statist. Assn. 53:457-481, 1958.

Table 1-6 shows the utility partners' current remaining capital interests in Navajo GS, based on net plant in service (the utility's value of plant assets that has not yet been depreciated). The owners anticipate that the depreciation of their capital positions in the plant - their initial investments as well as all improvements and additions to date-will continue to as long as 2026. A significant amount of the undepreciated capital is in recent environmental retrofits to the plant. Additional capital costs associated with SCR retrofits could extend the depreciation period out to 2044 .

\subsubsection{Advanced Planning}

Each partner utility currently has assets in advanced planning or under construction. SRP is planning to construct a 1,150 MW gas-fired combined-cycle gas turbine (CCGT) plant at Pinal Central in Arizona. LADWP is planning two gas-fired CCGT plants in California - a $500 \mathrm{MW}$ addition to Haynes Repowering and the 900 MW Scattergood Repowering. The Solana plant, currently under construction by APS, will be the largest concentrating solar plant in Arizona with a capacity of $280 \mathrm{MW}$. Among the other partner utilities, several photovoltaic and solar thermal plants, two wind farms and two geothermal plants are also in advanced planning or are under construction in California, Arizona, Idaho and Nevada. ${ }^{20}$

20 SNL Financial 2011 
Table 1-6. Utility Partners' Interests in Navajo Generating Station

\begin{tabular}{|c|c|c|c|c|c|}
\hline Utility & $\begin{array}{l}\text { Plant in } \\
\text { Service }\end{array}$ & $\begin{array}{l}\text { Accumulated } \\
\text { Depreciation }\end{array}$ & $\begin{array}{l}\text { Net Plant } \\
\text { in Service }\end{array}$ & $\begin{array}{c}\text { Construction } \\
\text { Work in } \\
\text { Progress }\end{array}$ & Source \\
\hline SRPa & $\$ 384,749$ & $(\$ 333,344)$ & $\$ 51,405$ & $\$ 21,395$ & SRP 2011 \\
\hline LADWP & 329,000 & $(298,000)$ & 31,000 & $\mathrm{n} / \mathrm{a}$ & Nguyen 2011 \\
\hline APS ${ }^{b}$ & 260,590 & $(163,281)$ & 97,309 & 11,041 & PNW 2011 \\
\hline NV Energy ${ }^{b}$ & 249,646 & $(141,326)$ & 108,320 & 1 & NV Energy 2011 \\
\hline TEP $^{b}$ & 121,000 & $(84,000)$ & 37,000 & 6,000 & Unisource 2011 \\
\hline $\begin{array}{l}\text { in thousands } \\
\text { (a) As of April 30th, } \\
\text { (b) As of December }\end{array}$ & 2010 & & & & \\
\hline
\end{tabular}

NV Energy has two activities of particular relevance to its position in Navajo GS. First is the development of geothermal power in its Sierra Pacific balancing authority (BA) area. Projects totaling more than 800 MW in maximum summer capacity are in NV Energy's interconnection queue. ${ }^{21}$ Second is the construction of a new $500 \mathrm{kV}$ transmission line that will be the first bulk power link between NV Energy's northern and southern BAs. Lines of this size typically provide as much as 1,500 MW of transfer capability. Consequently, NV Energy will soon have the capability of bringing to the Las Vegas area an amount of renewable base load power equal to what it is currently receiving from its share of Navajo GS (254 MW).

\subsubsection{Navajo Generating Station Financing}

A generator's capital costs and its cost of production are apples and oranges in the world of utility finance. Improperly combining them analytically can, depending on the context, lead to spurious conclusions about the cost of retrofitting an existing generator. This analysis examines and presents capital costs and production costs separately.

Table 1-7 highlights some of the crucial differences between capital costs and production costs. Production costs include O\&M expenses as well as expenses for fuel. Nearly four-fifths of Navajo GS' O\&M expenses are variable, meaning that they increase or decrease along with

21 NV Energy, IPP OATT Applications for Interconnection (posted on Open Access Same-time Information System), November 3, 2011. changes in the amount of electricity generated at the plant. Only production costs make a plant more expensive to run. If an upgrade to the plant were to increase capital cost but not production cost, then as a general rule the plant would run just as much as it did before the addition (assuming no other operational changes). The capital costs are recovered elsewhere in the utility's rates, and that revenue is not affected by how much the plant runs.

All five utility partners use similar rate mechanisms to recover capital costs. Each regulated IOU has an approved rate base that pools its depreciated capital investments (primarily power plants, transmission lines, substations, and distribution lines) and other eligible assets. The utility's regulatory body (in the case of APS, TEP or NV Energy, either the ACC or NPUC) decides which assets are included in the rate base and which are not. In addition, the regulators determine the rate of return that the utility is allowed to earn on its rate base. These two elementsrate base and the rate of return - determine the utility's revenue requirement, which is then allocated to all of the utility's customers through base rates.

$$
\begin{aligned}
& \text { rate base } \times \text { rate of return } \\
& =\text { revenue requirement }
\end{aligned}
$$

Public utilities such as SRP and LADWP have similar recovery mechanisms, except that the rate base and rate of return are determined by the utility's governing entity, not by state regulators. 


\section{Production costs}

Include operation and maintenance expenses (in addition to fuel expenses)

Treated as an asset; costs are financed with a combination of equity and long-term debt, depreciated over time

Treated as an expense; costs are paid as incurred, in cash or with short-term debt

Obligation to pay does not stop if plant shuts down prematurely; it becomes a stranded cost

Most expense occurs when plant operates ${ }^{a}$

Adding capital cost does not increase the unit's production cost, does not affect economic dispatch ${ }^{b}$

Recovered as a fixed component of the base rates charged to all of the utility's customers

$\$ / M W h$ for capital costs measures dollars per megawatt of power sold to all customers

Adding O\&M cost increases the unit's production cost, tends to reduce economic dispatch ${ }^{\mathrm{b}}$

Recovered as a pass-through charge allocated to all customers as needed

\$/MWh for production costs measures dollars per megawatt of power generated by the unit

(a) Some O\&M costs are fixed and occur independent of how much the plant operates. Fixed O\&M costs accounted for $22 \%$ of Navajo GS production costs in 2010.

(b) "Economic dispatch" refers to operating the least-cost plants most often, and running the highest-cost plants only when needed due to peak demand or system emergencies.

Table 1-8. SCR Capital Cost Relative to Net Utility Plant

\begin{tabular}{|c|c|c|c|}
\hline & $\begin{array}{l}\text { Net utility } \\
\text { plant }^{\mathrm{a}} \\
\text { (\$ millions) }\end{array}$ & $\begin{array}{c}\text { Share of capital } \\
\text { cost } \\
\text { (\$ millions) }\end{array}$ & $\begin{array}{l}\text { Share of capital cost as } \% \\
\text { of current net utility plant }\end{array}$ \\
\hline SRP & $\$ 6,959$ & $\$ 100.9$ to $\$ 118.1$ & $1.4 \%$ to $1.7 \%$ \\
\hline LADWP & 6,703 & 98.6 to 115.4 & $1.4 \%$ to $1.7 \%$ \\
\hline APS & 9,146 & 65.1 to 76.2 & $0.9 \%$ to $1.1 \%$ \\
\hline NV Energy & 8,930 & 52.5 to 61.5 & $0.8 \%$ to $0.9 \%$ \\
\hline TEP & 2,410 & 34.9 to 40.8 & $0.5 \%$ to $0.6 \%$ \\
\hline
\end{tabular}

(a) Total plant in service less accumulated depreciation. Does not include non-utility property. Inclusive of plant held for future use. Sources: SRP 2011d, LADWP 2010b, PNW 2011, NV Energy 2011, Unisource 2011, Sargent \& Lundy 2010

Table 1-9. SCR, Baghouse, Sorbent Injection Capital Costs Relative to Net Utility Plant

\begin{tabular}{|l|c|c|c|}
\hline & $\begin{array}{c}\text { Net utility } \\
\text { plant }^{\text {a }} \\
\text { (\$ millions) }\end{array}$ & $\begin{array}{c}\text { Share of capital cost } \\
\text { (\$ millions) }\end{array}$ & $\begin{array}{c}\text { Share of capital cost as \% of } \\
\text { current net utility plant }\end{array}$ \\
\hline SRP & $\$ 6,959$ & $\$ 230.4$ to $\$ 247.9$ & $3.3 \%$ to $3.6 \%$ \\
\hline LADWP & 6,703 & 225.1 to 242.2 & $3.2 \%$ to $3.5 \%$ \\
\hline APS & 9,146 & 148.6 to 160.0 & $2.1 \%$ to $2.3 \%$ \\
\hline NV Energy & 8,930 & 120.0 to 129.1 & $1.7 \%$ to $1.9 \%$ \\
\hline TEP & 2,410 & 79.6 to 85.7 & $1.1 \%$ to $1.2 \%$ \\
\hline
\end{tabular}

(a) Total plant in service less accumulated depreciation. Does not include non-utility property. Inclusive of plant held for future use. Sources: SRP 2011d, LADWP 2010b, PNW 2011, NV Energy 2011, Unisource 2011, Sargent \& Lundy 2010 
Table 1-10. Retail Rate Impact of SCR Capital Cost

\begin{tabular}{|l|c|c|c|c|}
\hline & $\begin{array}{c}\text { Applied } \\
\text { discount } \\
\text { rate }^{\text {a }}\end{array}$ & $\begin{array}{c}\text { Annual revenue } \\
\text { requirement } \\
\text { over } \mathbf{2 0} \text { years for } \\
\text { capital cost of } \\
\mathbf{S C R}\end{array}$ & $\begin{array}{c}\text { Annual utility } \\
\text { retail sales } \\
\text { (million } \mathbf{k W h} \text { ) }\end{array}$ & $\begin{array}{c}\text { Rate impact of } \\
\text { annual capital cost } \\
\text { (cents per } \mathbf{k W h})\end{array}$ \\
\hline SRP & $9.8 \%$ & \$11.7 to $\$ 13.7$ & 32,538 & 0.036 to 0.042 \\
\hline LADWP & $6.0 \%$ & 8.6 to 10.1 & 26,205 & 0.033 to 0.039 \\
\hline APS & $8.3 \%$ & 6.8 to 7.9 & 28,225 & 0.024 to 0.028 \\
\hline NV Energy & $8.3 \%$ & 5.5 to 6.4 & 29,261 & 0.019 to 0.022 \\
\hline TEP & $8.0 \%$ & 3.6 to 4.2 & 9,388 & 0.038 to 0.044 \\
\hline
\end{tabular}

(a) Based on utility's cost of capital; rate provided by SRP includes a risk premium.

Table 1-11. Retail Rate Impact of SCR, Baghouse, Sorbent Injection (Cents per kWh)

\begin{tabular}{|c|c|c|c|c|c|}
\hline & \multicolumn{3}{|c|}{$\begin{array}{l}\text { Additional annualized } \\
\text { capital costs }\end{array}$} & \multicolumn{2}{|c|}{$\begin{array}{l}\text { Additional production } \\
\text { costs }\end{array}$} \\
\hline & $\begin{array}{c}\text { SCR } \\
\text { (20 years) }\end{array}$ & $\begin{array}{c}\text { SCR, } \\
\text { baghouses, } \\
\text { sorbent } \\
\text { injection }^{\mathrm{a}} \\
\text { (20 years) }\end{array}$ & $\begin{array}{c}\text { SCR, } \\
\text { baghouses, } \\
\text { sorbent } \\
\text { injection }^{\mathrm{a}} \\
\text { (10 years) }\end{array}$ & SCR & $\begin{array}{c}\text { SCR, } \\
\text { baghouses, } \\
\text { sorbent } \\
\text { injection }{ }^{\mathrm{a}}\end{array}$ \\
\hline SRP & 0.036 to 0.042 & 0.087 & 0.122 & 0.008 to 0.011 & 0.014 \\
\hline LADWP & 0.033 to 0.038 & 0.080 & 0.124 & 0.010 to 0.014 & 0.017 \\
\hline APS & 0.024 tyo 0.028 & 0.058 & 0.085 & 0.006 to 0.008 & 0.010 \\
\hline NV Energy & 0.019 to 0.022 & 0.045 & 0.066 & 0.005 to 0.006 & 0.008 \\
\hline TEP & 0.038 to 0.044 & 0.092 & 0.135 & 0.010 to 0.013 & 0.016 \\
\hline
\end{tabular}

(a) Only Sargent \& Lundy estimated the combined costs of SCR, baghouses and sorbent injection. National Park Service did not provide comparable estimates.

Table 1-12. Retail Rate Impact of SCR, SNCR, SCR with Additional Controls (\% of Retail Rates)

\begin{tabular}{|l|c|c|c|c|c|}
\hline & $\begin{array}{c}\mathbf{2 0 1 0} \text { average } \\
\text { retail rate } \\
\text { (cents per } \\
\mathbf{k W h}\end{array}$ & $\begin{array}{c}\mathbf{S C R} \\
\text { (20 years) }\end{array}$ & $\begin{array}{c}\text { SNCR } \\
\mathbf{2 0} \\
\text { years) }\end{array}$ & $\begin{array}{c}\text { SCR, baghouses, } \\
\text { sorbent injection } \\
\text { (20 years) }\end{array}$ & $\begin{array}{c}\text { SCR, baghouses, } \\
\text { sorbent injection } \\
\text { (10 years) }\end{array}$ \\
\hline SRP & 9.26 & $0.5 \%$ to $0.6 \%$ & $0.05 \%$ & about $1.1 \%$ & about $1.5 \%$ \\
\hline LADWP & 12.38 & $0.3 \%$ to $0.4 \%$ & $0.04 \%$ & about $0.8 \%$ & about $1.1 \%$ \\
\hline APS & 10.63 & about $0.3 \%$ & $0.03 \%$ & about $0.6 \%$ & about $0.9 \%$ \\
\hline NV Energy & 10.58 & $0.2 \%$ to $0.3 \%$ & $0.02 \%$ & about $0.5 \%$ & about $0.7 \%$ \\
\hline TEP & 8.94 & $0.5 \%$ to $0.6 \%$ & $0.06 \%$ & about $1.2 \%$ & about $1.7 \%$ \\
\hline
\end{tabular}


Retail base rates recover capital costs. Another billing component typically recovers costs that vary based on how much energy the utility's generating fleet produces; these costs generally include coal and other fuels used to generate power, and operation and maintenance (O\&M) costs. Adding SCRs to a coal plant would increase the rate base, but once the equipment was in place the production costs would be little different from what they had been before. Consequently, the cost of running the upgraded plant would be largely unchanged. The cost of the upgrade would be recovered through the utility's rate base, spreading the cost across all customer rates and making cost recovery independent of the electricity generated at the upgraded plant.

The cost of the SCR upgrade ranges from $0.5 \%$ to $1.7 \%$ of the utility partners' net utility plant, a measure of the total plant in service less accumulated depreciation. This figure is also inclusive of construction work in progress and any plant held for future use.

Table 1-6 shows the utility partners' financial position in Navajo GS at the end of their last fiscal years. Net plant in service indicates the capital investment in the plant minus depreciation. In the event of a shut down, once the plant is no longer generating revenue, any remaining net plant in service would be reflected as a loss on the income statement, and therefore, as a one-time earnings impact. The capital investment in Navajo GS would also be removed from the regulated utilities' rate base, resulting in a loss on the return on assets and ultimately impacting rates. The utilities would also realize a reduction in Operations \& Maintenance (O\&M) costs, which would decrease the cost of service that feeds into the variable portion of the rates charged to the customer.

Table 1-10 shows the impact of SCR capital costs on the rates ultimately paid by each utility's retail customers. The increases in net utility plant shown in Table 1-8 are treated in Table 1-10 as capital items with a 20-year economic life, and annualized according to each utility's weighted average cost of capital. The annualized capital cost is spread across retail rates paid by all the utility's customers, approximated here by applying the annualized cost to total retail electricity sales. The estimated increase ranges from 0.019 cents per kilowatt-hour for NV Energy (assuming SCR costs at the low end of the plausible cost

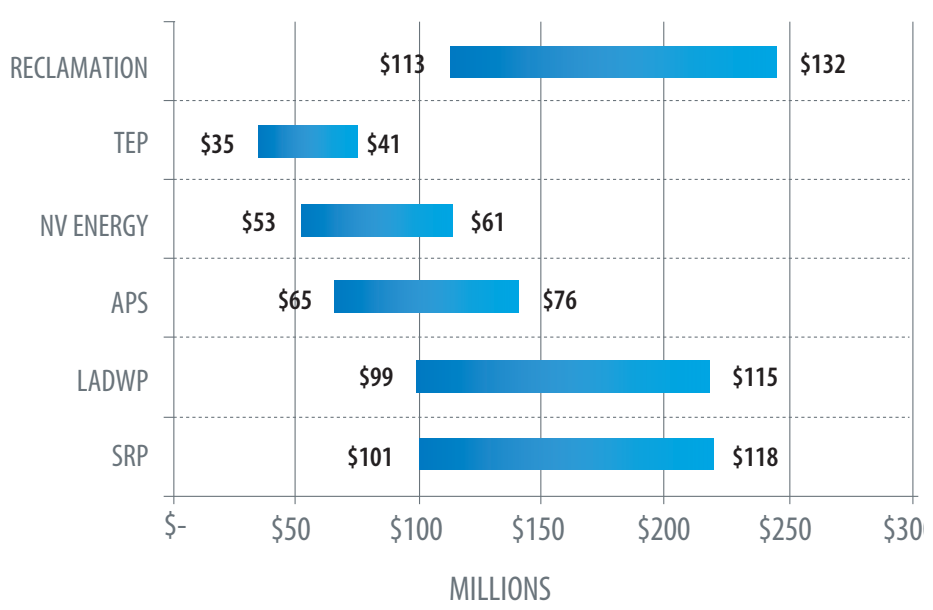

See Chapter 3 for derivation of SCR cost ranges.

Figure 1-3. Estimated Share of SCR Retrofits Based on Current Ownership (\$ millions)

range) to 0.044 cents per kilowatt hour for TEP (assuming SCR costs at the high end of the plausible cost range).

Tables 1-11 and 1-12 show the ultimate retail rate impacts of three scenarios, applying thesame approach broken down in Table 1-10. Table 1-11 includes each utility's share of the additional production costs (as operation and maintenance costs based on current production levels), applied to total retail sales. The scenarios include the capital costs of SCR controls only, the capital cost of SCR controls combined with baghouses and sorbent injection, and the SCR/baghouse/sorbent injection scenario annualized across 10 years rather than 20 years. Estimated rate increases under the SCR-only scenario range from $0.2 \%$ to $0.6 \%$. Under the accelerated SCR/baghouse/ sorbent injection scenario, rates would increase by an estimated $0.7 \%$ to $1.7 \%$.

\section{Salt River Project}

SRP's estimated original cost of Navajo GS, including the cost of the ESPs, was in the range of \$220 to \$240 million, which was financed through a combination of revenue bonds and corporate funds. These costs were added into SRP's base rates as the Navajo GS units became operational in the mid-1970s.

The emission controls are similarly financed through revenue bonds and corporate funds set aside for capital improvements, derived from rate income from previous years. The costs are recovered through a rate increase, 
which already occurred for the $\mathrm{SO}_{2}$ scrubber addition. The cost of the low- $\mathrm{NO}_{\mathrm{x}}$ burners will be added to SRP retail rates at the time of the next price process. ${ }^{22}$ Adding the SCR retrofits, estimated to cost between $\$ 100.9$ and $\$ 118.5$ million, would likely be financed through revenue bonds and corporate funds, and SRP would recover the costs through a subsequent rate increase.

SRP is currently depreciating Navajo GS and the environmental control additions through 2019, based off of when the rights-of-way and land lease contracts expire. Any extension to the depreciation timeline, in addition to changes in rates and the recovery of costs, would have to be approved by SRP's Board of Directors.

\section{Los Angeles Department of Water and Power}

LADWP's share of the construction cost of Navajo GS was $\$ 148.4$ million, which was financed by the issuance of power project bonds. These bonds were not specific to the Navajo GS plant, and included several power generation projects and transmission and distribution systems. The service on these bonds was immediately added to LADWP's electric rate base. LADWP's share of the ESPs was $\$ 42.4$ million, its share of the $\mathrm{SO}_{2}$ scrubbers was approximately $\$ 89$ million and its share of the low $\mathrm{NO}_{x}$ burners was approximately $\$ 9.5$ million. These additions were funded through power project bonds and cash reserves obtained from sales revenues. ${ }^{23}$

LADWP's financial position in Navajo GS is relatively lighter than that of the other utility partners, based on net plant in service and on the utility's plans for the early divestiture of its share of Navajo GS in 2014. LADWP is currently depreciating Navajo GS through 2019. LADWP's share of the SCR cost would be between $\$ 98.6$ and $\$ 115.7$ million and would likely be financed through the issuance of power project bonds, cash reserves and a rate increase. However, investing in a major BART upgrade is economically rational only if LADWP does not divest and retains its ownership stake in Navajo GS beyond 2019. If this were to occur, the depreciation schedule would expand to Navajo GS' full service life, which is currently pegged at $2044 .^{24}$

\footnotetext{
22 Cooper, Thomas. Salt River Project, email correspondence, September 28, 2011. www.nrel.gov/navajo.

23 Nguyen, Luan. LADWP, email correspondence, September 19, 2011. www.nrel.gov/navajo.

24 Nguyen 2011.
}

\section{Arizona Public Service Co.}

APS' share of the original construction cost of Navajo GS is estimated to be approximately $\$ 105$ million, based on its ownership share and was added to APS' rate base between 1974 and 1976. The $\mathrm{SO}_{2}$ scrubbers cost $\$ 58.8$ million, while the low- $\mathrm{NO}_{\mathrm{x}}$ burners cost an additional $\$ 6.6$ million. While the total cost of the $\mathrm{SO}_{2}$ scrubbers was directly added to APS' rates, the low- $\mathrm{NO}_{\mathrm{x}}$ system was eligible for Environmental Improvement Charge credits, as part of the Arizona Corporation Commission Decision Number 69663 . The cost of the low- $\mathrm{NO}_{\mathrm{x}}$ system, less the aforementioned credits, has been added to the rate base in the current rate case, filed earlier in 2011. ${ }^{25}$

The SCR addition is estimated to cost APS between $\$ 65.1$ and $\$ 76.4$ million. ${ }^{26}$ If APS follows the traditional utility financing model, the capital costs of the SCR addition would be included in its rate base and would be financed with a combination of $40 \%$ debt and $60 \%$ equity.

\section{Tucson Electric Power Co.}

TEP's share of the original construction cost of Navajo GS was approximately \$56 million. TEP's share of Navajo GS units 1 and 2 was factored into rates in 1978, and unit 3 was included in rates in $1982 .{ }^{27}$ The $\mathrm{SO}_{2}$ scrubbers cost TEP approximately $\$ 31.5$ million and were financed through tax-exempt pollution control bonds, the service on which was included in TEP's 2008 retail rate order. TEP's share of the low- $\mathrm{NO}_{x}$ burners was about $\$ 3.4$ million and was paid with available cash.

TEP has depreciated Navajo GS over its full expected service life, which the ACC has approved to reflect the current terminal date of 2026. If the SCRs were installed, this would only alter TEP's depreciation timeline if the addition impacted the terminal date. Due to TEP's small ownership stake in Navajo GS, the SCR addition will likely cost TEP between $\$ 34.9$ and $\$ 40.9$ million. TEP expects to finance the SCRs with a combination of $40 \%$ debt and $60 \%$ equity, though that combination may shift towards $45 \%$ debt and $55 \%$ equity in the future. ${ }^{28}$

\footnotetext{
25 Samuel Jr., Gordon. Arizona Public Service (APS), email correspondence, November 10, 2011.

26 Sargent \& Lundy 2010.

27 Gin, Don, Tucson Electric Power. email correspondence, October 4, 2011. www.nrel.gov/navajo.

28 Grant, Kent, Tucson Electric Power, telephonic conversation, October 20, 2011.
} 


\section{NV Energy}

NV Energy's share of the cost to build the Navajo GS plant was approximately $\$ 84$ million. This was financed through a traditional utility mix of close to $40 \%$ debt and $60 \%$ equity, and the cost was added to NV Energy's rate base shortly after the construction was completed. The cost of the $\mathrm{SO}_{2}$ scrubbers was $\$ 14.3$ million and $\$ 12.4$ million for units 1 and 2, respectively. Unit 3's cost was unavailable in the time allowed for this study, but is currently included in NV Energy's latest rate case. The cost of the low- $\mathrm{NO}_{x}$ burners was \$1.6 million and \$1.8 million for units 1 and 2 , respectively. Similarly, unit 3's cost was unavailable but is included in the current rate case. These environmental control additions were financed with a traditional utility mix of debt and equity. NV Energy expects to finance the proposed SCR additions in the same way. ${ }^{29}$ It is estimated that the SCRs would cost NV Energy in the range of $\$ 52.5$ to $\$ 61.7$ million. ${ }^{30}$

With the current environmental controls installed, NV Energy anticipates the Navajo GS plant to be fully depreciated in 2024, 2025 and 2026 (for units 1, 2 and 3, respectively), though its net plant in service is currently the highest of any of the utilities. If the SCRs were added to the plant, NV Energy could potentially request the Public Utilities Commission of Nevada that the depreciation timeline be altered through a LSAP, or life span analysis process. $^{31}$

\section{U.S. Bureau of Reclamation}

The Bureau of Reclamation has used several approaches to fund its share of Navajo GS plant capital expenditures over the history of the plant. The original cost of the plant to the Bureau of Reclamation, including the ESPs, was $\$ 200$ million. The Southern Transmission and Western Transmission Systems cost another \$25 and \$12 million, respectively. The $\mathrm{SO}_{2}$ scrubbers cost an additional $\$ 102$ million. All of this was funded through CAP construction appropriations and the cost of the construction, the transmission systems, and the $\mathrm{SO}_{2}$ scrubbers were ultimately allocated to project purposes. These costs were deemed as reimbursable and the CAWCD is repaying the

\footnotetext{
29 Geraghty, Kevin. NV Energy, telephonic conversation, October 28, 2011.

30 Sargent \& Lundy 2010.

31 Geraghty 2011.
}

federal government for these costs through payments into the Lower Colorado Basin Development Fund over a 50year period.

Lower Colorado Basin Development Fund revenues funded the Bureau's $\$ 11$ million share $\$$ \$3.7 million per year over a three-year construction period) of the cost of the low-NO $\mathrm{N}_{\mathrm{x}}$ burners. These costs were then reimbursed by SRP on an amortized basis and the remaining balance was reimbursed by CAWCD. ${ }^{32}$

The Bureau of Reclamation's share of the cost of the SCRs is estimated to be between $\$ 113.0$ and $\$ 132.6$ million. This analysis assumes CAWCD would be responsible for the entirety of this cost, and that the probability of securing appropriations to fund all or part of the SCR cost is low. In the absence of guidance otherwise, this analysis assumes that all of the federal share would be passed on to CAWCD for recovery from CAP rates, financed through revenue bonds. CAWCD's Replacement Fund could assist with the funding of the SCR; however, the fund will not cover the full cost of the SCR installation.

Table 1-13 shows the estimate impact of various BART outcomes, based on the capital cost of retrofits, and the cost they would add to CAP pumping power. O\&M costs for SCRs, baghouses and sorbent injection would add another 0.11 cents to 0.14 cents per kilowatt hour. Chapter 4 follows these likely costs through CAWCD rates in detail. Table 1-14 summarizes the ultimate impact on water rates as explained in that chapter.

\subsection{Power Plant Operations}

Navajo GS is configured with three $750 \mathrm{MW}$ supercritical tangentially fired boilers, supplied by Combustion Engineers, Co. (now Alstom Power, Co.). The first unit of the power plant was commissioned and began commercial operation in 1974, with the other two units following in 1975 and 1976. The plant original construction costs were $\$ 650$ million. $^{33}$

\footnotetext{
32 Stemmer, Matthew, U.S. Bureau of Reclamation, email correspondence, September 27, 2011. www.nrel.gov/navajo.

33 SRP Website: www.srpnet.com/about/stations/Navajo.aspx
} 
Table 1-13: Impact of SCR, Baghouse, Sorbent Injection Capital Costs on CAP Pumping Power Cost

\begin{tabular}{|c|c|c|c|c|}
\hline & \multirow{2}{*}{$\begin{array}{c}2010 \text { pumping } \\
\text { power cost (cents } \\
\text { per } k W h \text { ) }\end{array}$} & \multirow{2}{*}{$\begin{array}{l}\text { Annual } \\
\text { capital cost (\$ } \\
\text { millions) }\end{array}$} & \multicolumn{2}{|c|}{ Impact of annual capital cost } \\
\hline & & & (cents per kWh) & $\%$ \\
\hline SCR only & 3.09 & $\$ 9.1$ to $\$ 10.6$ & 0.324 to 0.380 & $\begin{array}{c}10.5 \% \text { to } \\
12.3 \%\end{array}$ \\
\hline $\begin{array}{l}\text { SCR/baghouse/ } \\
\text { sorbent } \\
\text { injection }\end{array}$ & 3.09 & $\$ 20.7$ to $\$ 22.3$ & 0.739 to 0.796 & $\begin{array}{c}23.9 \% \text { to } \\
25.8 \%\end{array}$ \\
\hline
\end{tabular}

Note: Calculations assume CAWCD uses municipal revenue bonds at 5\%, and annual CAP pumping power requirements are 2,800 million $\mathrm{kWh}$. Total pumping power costs for 2010 are calculated at 3.09 cents per kwh, based on CAWCD reported data for total energy purchased for pumping $(2,940 \mathrm{GWh})$ and total power expenses $\left(\$ 90.8\right.$ million) for that year. ${ }^{\mathrm{a}}$

(a) CAWCD, 2012/2013 Biennial Budget, November 2011.

Table 1-14: Impact of SCR, Baghouse, Sorbent Injection Costs on CAP Water Rates

\begin{tabular}{|c|c|c|}
\hline Water customer class & $\begin{array}{l}\text { Increase from } \\
\text { SCR only }\end{array}$ & $\begin{array}{l}\text { SCR/baghouses/sorbent } \\
\text { injection }\end{array}$ \\
\hline \multicolumn{3}{|l|}{ Municipal and Industrial } \\
\hline Long-term Subcontract & $6 \%-7 \%$ & $13 \%-14 \%$ \\
\hline Non-Subcontract & $5 \%-6 \%$ & $11 \%-12 \%$ \\
\hline Recharge & $5 \%-6 \%$ & $11 \%-12 \%$ \\
\hline AWBA Interstate Recharge & $4 \%-5 \%$ & $9 \%-10 \%$ \\
\hline Federal (Tribes) & $13 \%-16 \%$ & $29 \%-32 \%$ \\
\hline Agricultural & $13 \%-16 \%$ & $29 \%-32 \%$ \\
\hline
\end{tabular}

Navajo GS converts coal, mined at the Kayenta Mine, into electricity through combustion. The power plant utilizes approximately 8 million tons of low-sulfur bituminous coal per year. ${ }^{34}$ The Kayenta Mine is located on Hopi and Navajo lands on a highland plateau called Black Mesa, approximately 78 miles from the Navajo Generating Station. Kayenta Mine processes the coal through crushers, then transports the product 17 miles to storage silos. The coal is transported to the storage silos using a conveyor system, and then to the power plant using an electric closed loop rail line. The Kayenta Mine employs approximately 422 tribal members, and the mine is owned by Peabody Western Coal Company. The Kayenta Mine began operation in 1973.

Navajo Generating station was originally configured as three units, each unit with the capability of generating 750

\footnotetext{
34 Part 71 Federal Operating Permit Draft Statement of Basis, Peabody Western Coal Company - Black Mesa Complex Permit No. NN-OP 09-010: Peabody Energy Website: http://www.peabodyenergy.com/content/276/ Publications/Fact-Sheets/Kayenta-Mine.
}

MW power. The facility operates under a Title V, Major Source Operating Permit, with SRP as the managing participant. The plant also operates with an Acid Rain permit and Part 71 Permit. The current Title V was issued July 3, 2008 by the Navajo Nation Environmental Protection Agency, and expires July 3, 2013. ${ }^{35}$

All three units are configured with a pulverized coalfired supercritical tangentially fired boilers using No. 2 fuel oil for ignition/start-up fuel. The stacks are equipped with $\mathrm{SO}_{2}$ and $\mathrm{NO}_{\mathrm{x}}$ monitoring through a Continuous Emissions Monitoring System (CEMS). The material handling equipment was originally integrated with dust collection systems to control particulate at each transfer point, and water suppression has been utilized to control dust at storage locations and from unpaved roads. ${ }^{36}$ The plant generates electricity using a three-pressure steam cycle, including a re-heat section for improved system

\footnotetext{
35 Permit Number NN-ROP-05-06. Navajo Nation EPA Website: www. navajonationepa.org

36 Title V Permit to Operate, Permit \# NN-ROP-05-06, 07/03/2008.
} 
efficiencies. The plant is cooled using mechanical draft cooling towers. The plant uses about 28,000 acre-feet of water per year from Lake Powell for the cooling, acid gas scrubbing, boiler water make-up, and other auxiliary water uses. A zero liquid discharge system uses a brine concentrator and crystallizer to help disposal of highly concentrated brine. Each unit is configured with four feed-water heaters, one direct contact deaerator, and three indirect feed water heaters.

Originally the facility was configured with hot side electrostatic precipitators (ESP). In 1997-1999, NGS underwent modifications that included spray-type flue gas desulfurization (FGD) systems and efficiency improvements of the steam turbines to increase gross power generation. The steam turbine efficiency increases were implemented to compensate for the loss of net power generation, due to the additional air quality control equipment auxiliary power usage. These modifications maintained the $7,725 \mathrm{MBtu} / \mathrm{hr}$ boiler input and $750 \mathrm{MW}$ net generation.

Currently, Navajo GS operates with low-NO burners (LNB) and separated overfire air (SOFA) to reduce $\mathrm{NO}_{x}$ formation during combustion and control the excess air required for complete combustion, while maintaining furnace temperatures. Reducing the amount of excess air and maintaining combustion temperatures minimizes the quantity of $\mathrm{NO}_{\mathrm{x}}$ formed.

\subsubsection{Operational Data}

The Navajo Generating Station operates as a base load plant, but its capacity factor fluctuates as shown in Figure 1-4. Table 1-15 summarizes the facility's 2010 operations. Navajo GS' capacity factor for this year was somewhat below normal, due to additional planned outages for the installation of low $\mathrm{NO}_{\mathrm{x}}$ burners and SOFA.

Throughout recent years, the plant's capacity factor has been fairly stable (taking into account the time needed to install the low- $\mathrm{NO}_{\mathrm{x}}$ burners), indicating the equipment and systems have been maintained. Seasonal drops in monthly generation coincide with planned maintenance outages. Each units is maintained on a six-year cycle, alternating between 4-week minor outages and 8-week major outages every three years. Somewhat longer seasonal outages from 2009 to 2011 correspond to the installation of low- $\mathrm{NO}_{\mathrm{x}}$ burners.

\subsection{2 $\mathrm{SO}_{2}$ controls}

As Chapter 5 discusses in greater detail, $\mathrm{SO}_{2}$ is another emission that contributes to the formation of regional haze. Amendments to the Clean Air Act in 1990 led to more stringent emission requirements for coal plants across the country. Plant owners installed scrubbers at Navajo GS, after which $\mathrm{SO}_{2}$ emissions from the plant declined by more than $95 \%$.

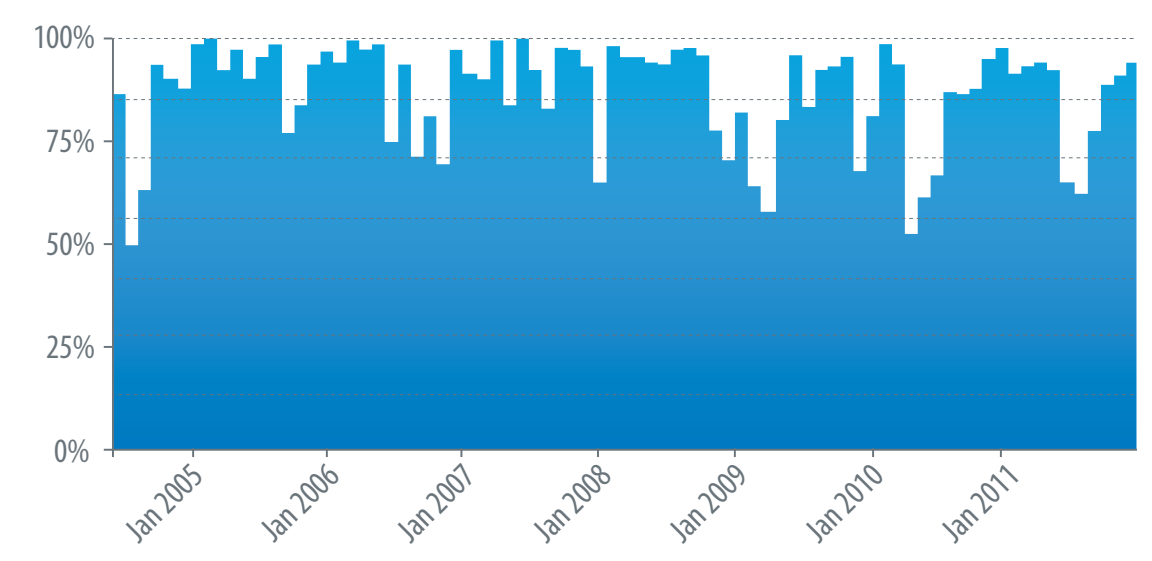

SNL Energy; www.snl.com

Figure 1-4. Navajo GS monthly capacity factor 
Table 1-15. Navajo GS Operation Summary (2010)

\begin{tabular}{|l|c|}
\hline Capacity & $2,250 \mathrm{MW}$ \\
\hline Capacity factor & $83 \%$ \\
\hline Heat rate & $10,085 \mathrm{Btu}$ per kWh \\
\hline $\begin{array}{l}\text { Production cost, } \\
\text { which includes }\end{array}$ & $\$ 24.45$ per MWh \\
\hline $\begin{array}{l}\text { Fuel expenses } \\
\text { Non-fuel O\&M expenses }\end{array}$ & 17.80 per MWh \\
\hline
\end{tabular}

Table 1-16. Maximum Adjusted Nitrogen Oxide Emission Rates, 2009 - 2011 (lb/mmBtu)

\begin{tabular}{|c|c|c|c|c|c|c|}
\hline \multirow{2}{*}{ Report } & \multicolumn{2}{|c|}{ Unit 1 } & \multicolumn{2}{c|}{ Unit 2 } & \multicolumn{2}{c|}{ Unit 3 } \\
\cline { 2 - 7 } & Reported & Calculated & Reported & Calculated & Reported & Calculated \\
\hline Maximum & 0.572 & 0.572 & 0.774 & 0.774 & 0.578 & 0.498 \\
\hline Max 2009 & 0.572 & 0.572 & 0.511 & 0.511 & 0.578 & 0.498 \\
\hline Max 2010 & 0.569 & 0.569 & 0.774 & 0.774 & 0.465 & 0.465 \\
\hline Max 2011 & 0.552 & 0.552 & 0.481 & 0.481 & 0.478 & 0.478 \\
\hline
\end{tabular}

Navajo GS has wet scrubbers, two for each operating unit. Engineering and construction began 1994. Around the same time as the scrubber installation, efficiency upgrades were conducted on the steam turbines to overcome the additional operating electrical loads due to the scrubber system and the additional pressure loss through flue gas ductwork. The efficiency upgrades maintained the plants original net output at 2,250 MW. The wet scrubbers and efficiency upgrades cost the owners $\$ 420$ million. The facility currently is operating with a removal efficiency greater than $95 \%$.

\subsubsection{Emission Limits for $\mathrm{NO}_{\mathrm{x}}$}

Table 1-16 shows the peak $\mathrm{NO}_{\mathrm{x}}$ emissions for each of the three units from 2009 through 2011 to date, based on data from the plant's Continuous Emissions Monitoring System. The highest emissions happened during 2009, and were from Unit 2.

Table 1-17 summarizes average $\mathrm{NO}_{\mathrm{x}}$ emissions for the same years. Unit 1 (the last of the three units to receive low- $\mathrm{NO}_{\mathrm{x}}$ burners and SOFA) recorded the highest average emission, while Unit 2 and Unit 3 both showed a substantial reduction in $\mathrm{NO}_{x}$ since 2009. By the second quarter of 2011, all three reported an average emission rate of $0.217 \mathrm{lb} / \mathrm{mmBtu}$ or better. 
Table 1-17. Average Adjusted Nitrogen 0xide Emission Rates, 2009 - 2011 (lb/mmBtu)

\begin{tabular}{|c|c|c|c|c|c|c|}
\hline \multirow{2}{*}{ Report } & \multicolumn{2}{|c|}{ Unit 1} & \multicolumn{2}{|c|}{ Unit 2} & \multicolumn{2}{|c|}{ Unit 3} \\
\hline & Reported & Calculated & Reported & Calculated & Reported & Calculated \\
\hline Q1-09 & 0.386 & 0.386 & 0.349 & 0.349 & 0.365 & - \\
\hline Q2-09 & 0.377 & 0.377 & 0.364 & 0.364 & 0.200 & 0.200 \\
\hline Q3-09 & 0.397 & 0.397 & 0.352 & 0.352 & 0.200 & 0.200 \\
\hline Q4-09 & 0.358 & 0.358 & 0.308 & 0.308 & 0.202 & 0.202 \\
\hline Q1-10 & 0.348 & 0.348 & 0.269 & 0.269 & 0.199 & 0.199 \\
\hline Q2-10 & 0.389 & 0.389 & 0.217 & 0.217 & 0.207 & 0.207 \\
\hline Q3-10 & 0.406 & 0.406 & 0.219 & 0.219 & 0.219 & 0.219 \\
\hline Q4-10 & 0.400 & 0.400 & 0.213 & 0.213 & 0.201 & 0.201 \\
\hline Q1-11 & 0.396 & 0.396 & 0.212 & 0.212 & 0.209 & 0.209 \\
\hline Q2-11 & 0.201 & 0.201 & 0.217 & 0.217 & 0.217 & 0.217 \\
\hline Maximum & 0.406 & 0.406 & 0.364 & 0.364 & 0.365 & 0.219 \\
\hline Max 2009 & 0.397 & 0.397 & 0.364 & 0.364 & 0.365 & 0.202 \\
\hline Max 2010 & 0.406 & 0.406 & 0.269 & 0.269 & 0.219 & 0.219 \\
\hline Max 2011 & 0.396 & 0.396 & 0.217 & 0.217 & 0.217 & 0.217 \\
\hline
\end{tabular}

Source: SRP, Emission Reporting Data from Historian, VS_1b\&1c_NGS Unit 1 Emission Data, VS_1b\&1c_NGS Unit 2 Emission Data, VS_1b\&1c_NGS Unit 3 Emission Data. 


\section{Regional System Impacts of Retiring Navajo GS}

This chapter examines how the rest of the Western Interconnection would respond if Navajo GS were to close. Meeting the same overall level of demand with a slightly different mix of resources would entail measurable costs, and these costs provide a robust and meaningful comparison with the cost of BART compliance alternatives.

What follows is an economic analysis of the implications of retirement; it is not a full reliability analysis. To understand the full implications, a reliability study would need to analyze the effects of Navajo GS retirement on the ability of utilities in the Western Electric Coordinating Council (WECC, the Western Interconnection's regional reliability organization) to meet planning reserve and serve load reliably. The economic analysis performed for this study assumes that any reliability problems introduced by retirement would not add significant costs to the system, and that the need to conduct a reliability analysis would be driven by the basic economics of shutdown. In this respect, this analysis is a "best case" scenario regarding retirement.

The rest of the power system would tend to correct itself in the event of a Navajo GS retirement. Even though Navajo GS is its largest operating coal plant, the Western Interconnection theoretically has enough unused capacity throughout the year to make up the loss if the plant were to close. Contractual limitations or other business considerations may prevent some power trading that otherwise would be economically efficient; changes in transmission path ratings not captured in this economic analysis could also hamper some exchanges. Nevertheless, it is unlikely that the full capacity of Navajo GS would need to be replaced. Capacity expansion is typically driven by changes in system-wide factors such as reserve margins - the percentage of total available capacity in excess of the year's total demand. The reserve margin for the Desert Southwest is currently in excess of 30\% (and nearly $35 \%$ when taking into account anticipated new plants), well in excess of the area's reference reserve margin of $13.5 \%$. Without Navajo GS, the area's reserve margin would fall to $22 \%$ (27\% with anticipated new plants). ${ }^{1}$

1 The Desert Southwest includes Arizona, New Mexico (excluding a small part linked to the Eastern Interconnection), and southern Nevada. North American Electric Reliability Corporation (NERC), "2011 Summer Reliability Assessment," March 2011.
Eventually, load growth would offset the excess capacity, and this would happen sooner if Navajo GS were retired.

Because investment in one new unit involves hundreds of megawatts, millions of dollars, and significant risk all rolled up into a single capital expense, an individual utility will plan new capacity based on its own reserve margin, its own load growth, and the amount of capacity it is already holding in reserve for future electricity demand. Many factors affecting a specific expansion decision are beyond what this analysis captures. To simplify the task and provide an economic reference point, this analysis assumes that no additional capacity is necessary after Navajo GS retirement, and the costs of retirement are incurred exclusively due to the higher cost of the replacement energy from existing unused capacity. As with other chapters in this study, the analysis contained in this chapter is a close-up look at one piece of the Navajo GS complex case study. The factors accounted for in this chapter are limited to the economic operation of the regional electric grid. A utility typically would conduct a similar analysis for any plant closure, plant retrofit, or construction of a new plant.

This chapter's analysis does not account for the complicating factors that make Navajo GS unique. It does not provide a measure of the tribal impacts and local economic development effects of retiring the plant, neither does it address how possible increases in power costs might affect CAP water users. Both of these effects require their own analytical approaches, and no attempt is made to artificially account for them here. Instead, this chapter aims to develop a comprehensive understanding about traditional utility economic metrics, so that they can be accurately considered alongside issues addressed more thoroughly in other chapters of this report.

Navajo GS' utility partners are substantially different from the Bureau of Reclamation in ways that affect what the findings of this chapter mean. Most utilities serve a diverse customer base with a diverse portfolio of generating resources. Capital costs and production costs alike are spread among all customers and not assigned to a single user. By contrast, Reclamation's share of Navajo GS is virtually the sole source of power for one single user, the Central Arizona Project. This sole-source 
relationship greatly magnifies the impacts on CAP of the outcomes modeled in this chapter. For this reason, the following sections frequently address the consequences for Reclamation and CAP differently from outcomes for the utility partners.

\subsection{Selection of modeling approach}

To frame the statutory BART criterion of energy-related impacts, NREL posed this question:

\section{How would grid operators change what they do in the event of a Navajo GS retirement?}

NREL has used production cost modeling to answer this question analytically. Production cost modeling is a mainstay of planning in the electric sector, used frequently by large utilities, regional reliability organizations, and regional transmission organizations. It addresses with specificity many questions that are central to the energy impacts of compliance, which the Clean Air Act specifically requires states and the EPA to consider in making a BART determination.

A production cost model picks the combination of units out of the existing generating fleet that would minimize the cost of serving load. The model simulates real-time network conditions, including planned operational limits on each transmission line, the cost of cold-starting a generating unit, limits on how quickly a unit can increase or decrease its output, reserve requirements, line losses, and other factors that may affect a specific unit's ability to respond to an economic-based instruction for dispatching power onto the system. Within these operational constraints, the model then dispatches enough power from the generation fleet to match demand at each moment over the course of a typical year. The least-cost dispatch portfolio accounts for each generating unit's production cost (or more precisely, the cost at the plant of producing one additional MW of power), and transmission constraints that may limit the deliverability of power from units with the lowest production cost. For this study, it is assumed that the transmission path ratings do not change due to the retirement of Navajo GS.

A production cost model does not take into account the capital cost of adding new capacity. It takes the configuration of the power system as it is, neither adding new capacity nor retiring old plants even if they are unused. Capital costs are assumed to be fixed and independent of how much or how little the plant actually runs throughout the year. The costs coming out of a production cost model, therefore, reflect only a portion of what customers ultimately pay through their electric rates. Nevertheless, they reflect the costs that utility operators try to minimize when deciding how to run their systems day-to-day and hour-to-hour.

While other types of power system modeling exist, NREL determined that they are less applicable to the questions at hand. For example, capacity expansion models are designed to forecast how much new capacity is likely to be added and how much is likely to retire under certain long-term assumptions. These models are appropriate for forecasting long-term changes across the entire power system, and for modeling system-wide responses to system-wide changes in policy, resource availability, climate change, or fuel prices. Capacity expansion models are less useful in examining a specific plant with peculiar or even unique circumstances, because the input assumptions need to be generally (and plausibly) applicable to entire categories of generators modeled over a long period of time. Consequently, capacity expansion models do not have sufficient temporal or geographic resolution to capture how power system operations would respond to a discreet change at a single location, such as the retirement of a coal plant as large as Navajo GS.

For example, a capacity expansion model may predict the future addition of a certain amount of wind power or natural gas capacity, but will usually distribute the additional capacity generally without predicting exactly where it might be sited. The complex and often litigious matters of siting and permitting are simplified or even ignored, because whether the predicted plant actually ends up in the next county or the next state has little impact on the long-term macro-level phenomena that capacity expansion models are designed to examine.

Plant retirements are similarly heuristic, as a decision to permanently close a plant often relies on case-specific factors that cannot be captured by a capacity expansion model. Local economic impacts, limits to state regulatory jurisdiction, management, and other plant-specific factors that are not modeled can keep some units on line regardless of what a capacity expansion model might predict, and vice versa. As long as these unmodeled plant-specific factors do not bias the results in only 
one direction, however, they generally do not detract from system-wide conclusions, such as the total amount of capacity likely to become less viable under certain assumptions about emission regulation.

EPA has used capacity expansion modeling to examine the long-term national effects of its regional haze regulations, as well as the cross-state air pollution rule, the proposed toxics rule, various proposals for addressing climate change, and other proposed national policies. ${ }^{2}$ In some runs, the EPA model predicts Navajo GS would be one of many coal plants likely to be retired early. Based NREL's own extensive experience with capacity expansion modeling, however, less weight is placed on outcomes for individual plants when using this type of modeling. In any case, NREL's task in this study is different from EPA's task of modeling nationwide policy effects. Instead of predicting whether and how many generators will retire, this task is to measure the potential consequences to the rest of the system in the event Navajo GS does retire.

A reliability analysis would use more detailed AC powerflow models and dynamic models to test reliability metrics in the power system. This type of analysis was beyond the scope of this economic analysis. AC powerflow analysis would help determine whether the retirement would lead to voltage problems, while dynamic analysis would help assess the impacts of the retirement on serving load during generator and transmission outages.

Production cost modeling relies on a number of specialized terms and concepts. These terms make up the vocabulary of understanding the results, so an understanding of what they mean is an essential starting point for this chapter's discussion.

Balancing authority (BA) areas. A BA is essentially the grid's unit of central control. The North American Electric Reliability Corporation (NERC) defines a BA area as the specific collection of generators and load whose total metered output and consumption must balance moment by moment. ${ }^{3}$ If demand increases by $20 \mathrm{MW}$, the BA must issue instructions to one or more units in its portfolio to ramp up by $20 \mathrm{MW}$, or import it from a neighboring BA with unused reserve.

\footnotetext{
2 Link to http://www.epa.gov/visibility/actions.html and http://www.epa.gov/ airmarkt/progsregs/epa-ipm/index.html.

3 The balance is also net of any power transfers into or out of the BA across ties with neighboring BAs.
}

A large utility is often its own BA, although two or more utilities can participate in a single BA. Figure 2-1 shows the approximate areas of the BAs used in this analysis; several small BAs are analytically combined with their surrounding BAs for the sake of clarity. The BAs that constitute NERC's Desert Southwest subregion include SRP, APS, TEP, Nevada Power (on the map, NEVP), the Imperial Irrigation District (IID), the Western Area Power Administration's Lower Colorado service area (WALC), Public Service Company of New Mexico (PNM), and El Paso Electric (EPE).

Nodes. Nodes are geographic points on the system where changes can occur that would affect real-time costs elsewhere on the system. They are points where either a generator connects to the grid, power leaves the transmission network to serve load, or multiple transmission paths connect or diverge. Figure 2-2 shows the bus points in the Western Interconnection that constitute the nodes used in NREL's analysis.

Locational marginal prices (LMPs). LMPs reflect the immediate cost of producing power at a given node. The value of an LMP - expressed in dollars per MWh-indicates the cost to the entire system of changing generation or demand at that node by one megawatt. Generally, two factors can drive an LMP higher: the production cost of a particular generator, and transmission constraints that limit the ability to move low-cost power to a demand point.

For clarity, NREL has aggregated nodal outcomes by BA in many instances. Except for the Bureau of Reclamation, each Navajo GS partner also operates as a BA, making this a convenient and relevant tool for combining information. Not only does it comport with how the system operates, it also provides a meaningful approach to estimating the impact on the areas most likely to be affected by a Navajo GS retirement.

An important factor affecting the outcome of a production cost analysis is where a plant's production costs fall relative to other generators in the region. All else being equal, a plant with a lower cost will be dispatched before a plant with a higher cost. A production cost model will meet the demand for energy at any given point beginning with the units with the lowest cost, and will proceed through the stack of available generators, ranked in order from lowest to highest cost, until demand is met. 


A region's power supply curve depicts the generators available within a particular region, in the general order that the units would be selected by a production cost model.

Figure 2-3 shows the power supply curve for NERC's Desert Southwest subregion. Each point on the curve represents a specific power plant; a point's color indicates the plant's energy source. The distance between a given plant and the one immediately to its left captures the plant's available capacity (in megawatts); its value on the vertical axis shows the production cost of that amount of capacity, in dollars per MWh dispatched. The value of the plant's location on the horizontal axis represents the total amount of system capacity that would be economic if the market price were set at that plant's cost of production.

The production cost of Navajo GS is slightly above \$20 per MWh. Future costs could increase depending on the outcome of negotiation over a new coal supply contract. The Desert Southwest's summer peak hourly demand is around 29,000 MW; its base load (the lowest demand during the year) is between 9,000 and 10,000 $\mathrm{MW}^{4}$ Taking these data points into account, a cursory examination of the area's power supply curve suggests that

- Among other coal plants in the region, Navajo GS has a comparatively low cost of production;

- Navajo GS would be economical most of the time and would be used as often as possible, based on the plant's current operational characteristics, and

- losing Navajo GS would change the dispatch of the remaining generators with production costs higher than $\$ 20$.

4 The non-coincident minimum load was 9,211 MW for all BAs in the Desert Southwest sub-region.



Figure 2-3. Navajo GS in the power supply curve for the Desert Southwest

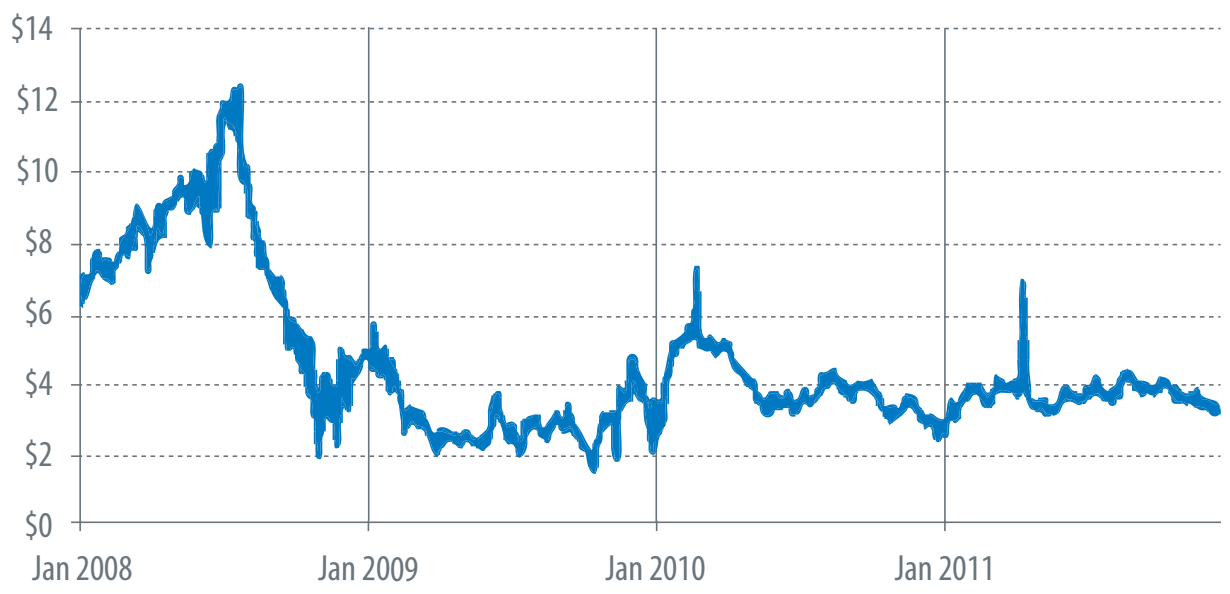

Data from SNL Financial LC

Figure 2-4. Spot price of natural gas at the Permian Basin Hub, 2008 to date

Fuel prices are the most important determinant of a generator's production cost. This is especially true of natural gas generators in areas where natural gas constitutes a large share of the generator fleet. NREL's base scenario assumes an average natural gas price of approximately $\$ 6.90$ per mmBtu. Because of the historical volatility of natural gas prices, however, NREL has incorporated into its analysis two sensitivity runs: one scenario assuming natural gas prices averaging $\$ 13$ per mmBtu, and one assuming prices averaging $\$ 4$ per $\mathrm{mmBtu}$. This range captures most of the pricing points for natural gas from the Permian Basin hub since January 
2008, as shown in Figure 2-4. Current prices are near the low end of the sensitivity range NREL has modeled. However, additional demand would tend to push natural gas prices slightly higher if a Navajo GS retirement were to result in greater utilization of combined cycle gas units (as was the case after the retirement of the Mohave coal plant in southern Nevada).

Production cost modeling provides a rigorous and methodical way of examining in detail what those changes might look like. The remaining sections of this chapter examine three critical areas. First is where redispatch is likely to occur if the electricity currently provided by Navajo GS has to come from elsewhere. Second is the additional cost associated with the likely redispatch. The third examines how the outcomes might affect the Bureau of Reclamation differently than the other Navajo GS partners who are all BAs.

\subsection{Redispatch: What the system would use to replace Navajo GS}

Annual net generation from Navajo GS has averaged 17.2 TWh since 2001, and has been as high as 17.7 TWh. ${ }^{5}$ Results from NREL's modeling predict 17.5 TWh from the plant under normal system conditions. This is the amount of power that other units on the system would have to make up if Navajo GS were to retire.

Figure 2-5 maps the distribution of annual net generation throughout the Western Interconnection as modeled under normal system conditions. The BAs with the largest amounts of net generation generally coincide with the areas of largest demand. Production in the Pacific Northwest also reflects bulk transfer of hydropower to California, which is by far the largest demand center in the West. Although Navajo GS is physically situated in northern Arizona, its net generation is allocated among its owners that operate as BAs: SRP, LADWP, APS, Nevada Power, and TEP.

Figure 2-6 shows where the increase in generation would likely occur in the event of a Navajo GS retirement. The 17.5 TWh that would no longer come from Navajo GS is excluded from the data shown in the map. Consequently,

\footnotetext{
5 Average excludes 2009 and 2010, when two units shut down temporarily in
} order to install low-NOx burners. the increase in net generation shown for Nevada Power, SRP, and APS indicates additional power from other plants in these systems.

Table 2-1 shows the extent to which the Navajo GS partners rely on the plant to serve demand. As mentioned earlier in this chapter, the utility partners also operate as BAs, which distinguishes them from the Bureau of Reclamation. Each utility's share of Navajo GS is one of several generation resources that the utility manages as a portfolio to meet demand across its entire BA. By contrast, the Bureau of Reclamation's share is earmarked for the direct use of one major power user - the Central Arizona Project - and therefore was considered in the NREL analysis as unavailable to serve other demand.

Table 2-2 shows how much Navajo GS contributes to each BA supply portfolio. This table also shows the extent to which other plants within the BA would make up the loss, based on the NREL modeling results. What is not made up internally would need to come from other BAs, either as imported power or (what is more likely for the Desert Southwest) by reducing flows to California and retaining more power within the local BAs. ${ }^{6}$ Together, the utility partners would have to obtain a net $7.7 \mathrm{TWh}$ of power from elsewhere in the Western Interconnection, in addition to $4.3 \mathrm{TWh}$ to replace the Bureau of Reclamation share. This includes power for the CAP system (approximately $2.8 \mathrm{TWh}$ ) as well as excess power that could be sold (as described in Chapter 4). In other words, the NREL model suggests that the utility partners themselves would economically replace less than one-third of what Navajo GS currently provides. Figure 2-6 shows that most of the balance would come from resources in (or committed to) southern California.

Salt River Project would face particular challenges in replacing the energy it currently receives from Navajo GS. Of all the plant's utility partners, SRP relies on Navajo GS the most. Results from NREL's modeling suggest that other units within the SRP balancing area would be able to economically cover only $17 \%$ (about $700 \mathrm{GWh}$ ) of the loss to SRP if Navajo GS were to retire. SRP would need other resources to replace $3.1 \mathrm{TWh}$ of what it currently receives from Navajo GS.

\footnotetext{
6 Aside from Navajo GS, three other major base load plants in the Desert Southwest—Palo Verde, Four Corners, and San Juan—had about 15 TWh of their 2010 output committed to utilities in California.
} 
Table 2-1. Distribution of Navajo GS Production as Modeled in Base Case

\begin{tabular}{|l|c|c|c|}
\hline \multicolumn{1}{|c|}{ Owner } & Balancing & \multicolumn{2}{|c|}{ Navajo share } \\
\cline { 3 - 4 } & authority & (\%) & 4.3 \\
\hline U.S. Bureau of Reclamation & No & $24.3 \%$ & 3.8 \\
\hline Salt River Project & Yes & $21.7 \%$ & 3.7 \\
\hline $\begin{array}{l}\text { Los Angeles Department of } \\
\text { Water and Power }\end{array}$ & Yes & $21.2 \%$ & 2.5 \\
\hline Arizona Public Service Co. & Yes & $14.0 \%$ & 2.0 \\
\hline Nevada Power Co. & Yes & $11.3 \%$ & 1.3 \\
\hline Tucson Electric Power Co. & Yes & $7.5 \%$ & 17.5 \\
\hline
\end{tabular}

Table 2-2. BA Replacement Needs Resulting from Retiring Navajo GS

\begin{tabular}{|c|c|c|c|c|c|}
\hline \multirow{3}{*}{$\begin{array}{c}\text { BA receiving Navajo } \\
\text { GS power }\end{array}$} & \multirow{3}{*}{$\begin{array}{c}\text { Total net } \\
\text { generation } \\
T W h\end{array}$} & \multirow{2}{*}{\multicolumn{2}{|c|}{$\begin{array}{c}\text { Navajo as } \\
\text { share of BA } \\
\text { total }\end{array}$}} & \multicolumn{2}{|c|}{ Without Navajo } \\
\hline & & & & $\begin{array}{l}\text { Change in BA } \\
\text { generation }^{\mathrm{a}}\end{array}$ & $\begin{array}{l}\text { Additional } \\
\text { replacement } \\
\text { needed }\end{array}$ \\
\hline & & $T W h$ & $\%$ & $T W h$ & $T W h$ \\
\hline Salt River Project & 26.5 & 3.8 & $14 \%$ & 0.7 & 3.1 \\
\hline LADWP & 31.7 & 3.7 & $12 \%$ & 0.6 & 3.1 \\
\hline $\begin{array}{l}\text { Arizona Public Service } \\
\text { Co. }\end{array}$ & 30.2 & 2.5 & $8 \%$ & 0.9 & 1.5 \\
\hline Nevada Power Co. & 21.2 & 2.0 & $9 \%$ & 2.9 & -0.9 \\
\hline $\begin{array}{l}\text { Tucson Electric Power } \\
\text { Co. }\end{array}$ & 15.2 & 1.3 & $9 \%$ & 0.5 & 0.8 \\
\hline Total for BAs & 124.9 & 13.2 & $11 \%$ & 5.5 & 7.7 \\
\hline $\begin{array}{l}\text { U.S. Bureau of } \\
\text { Reclamation }\end{array}$ & & & & & 4.3 \\
\hline
\end{tabular}

(a) Net of the 17.5 TWh that would no longer come from Navajo GS 

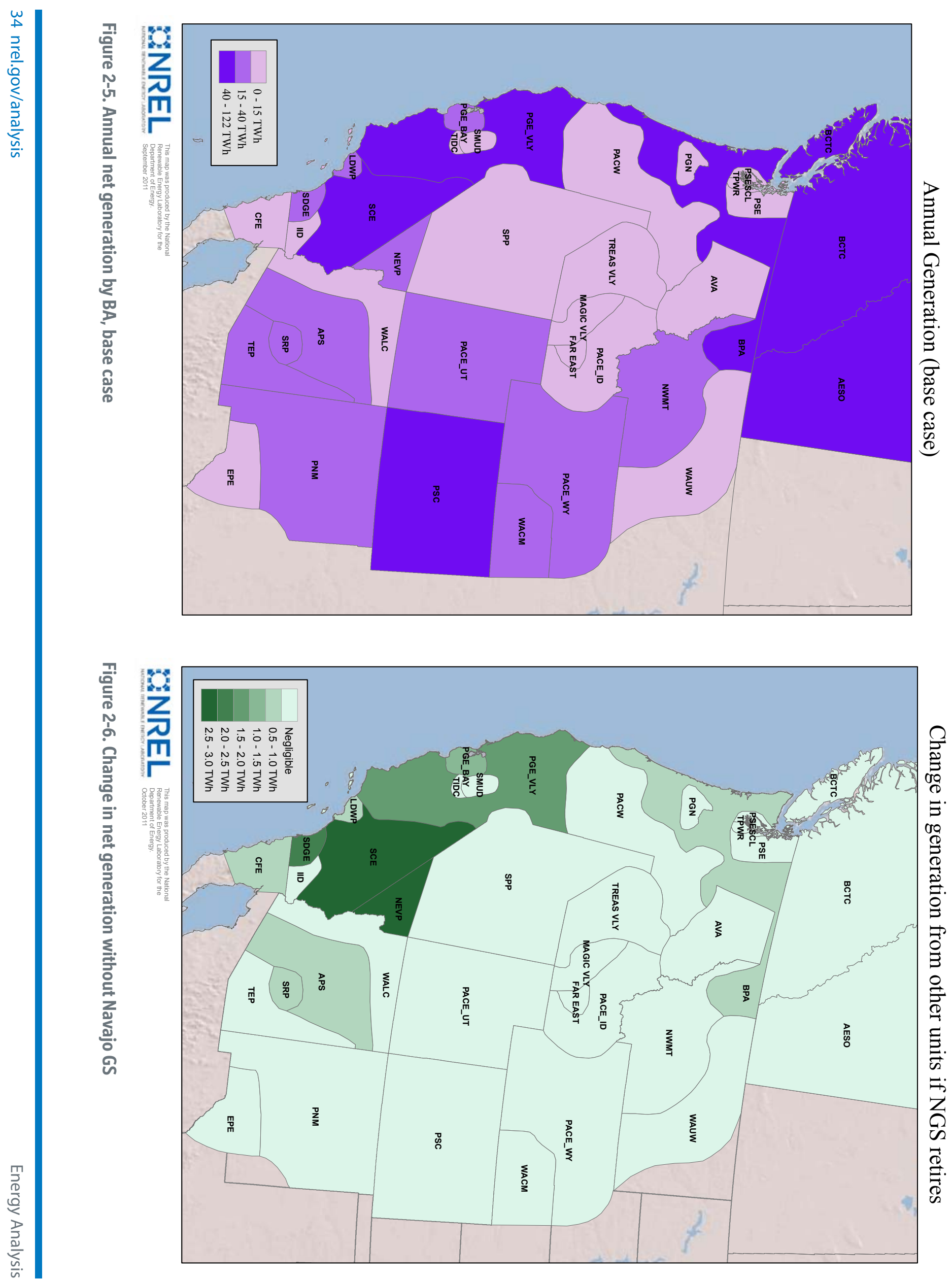
Table 2-3. Types of Generators Used to Replace Navajo GS

\begin{tabular}{|l|c|c|c|c|}
\hline \multicolumn{1}{|c|}{ BA } & $\begin{array}{c}\text { Rank, by total } \\
\text { additional } \\
\text { TWh }\end{array}$ & $\begin{array}{c}\text { Additional TWh } \\
\text { on combined } \\
\text { cycle gas units }\end{array}$ & $\begin{array}{c}\text { Additional } \\
\text { TWh on } \\
\text { other unit } \\
\text { types }\end{array}$ & $\begin{array}{c}\text { Total } \\
\text { additional } \\
\text { TWh }\end{array}$ \\
\hline Nevada Power & 1 & 2.88 & 0.02 & 2.90 \\
\hline Cal. ISO (SCE) & 2 & 2.37 & 0.18 & 2.55 \\
\hline Cal. ISO (SDG\&E) & 3 & 2.06 & 0.03 & 2.09 \\
\hline Cal. ISO (PG\&E & 4 & 1.49 & 0.03 & 1.52 \\
\hline APS & 5 & 0.64 & 0.28 & 0.92 \\
\hline SRP & & 0.60 & 0.05 & 0.65 \\
\hline LADWP & & 0.67 & -0.10 & 0.57 \\
\hline TEP & & 0.00 & 0.48 & 0.48 \\
\hline All others & & 3.77 & 2.06 & 5.83 \\
\hline Total & & 14.5 & 3.0 & 17.5 \\
\hline
\end{tabular}

(Navajo BAs in bold italic)

LADWP has already announced its intention to divest its position in Navajo GS, even though its position would be almost as difficult as that of SRP. It would also need to import about 3.1 TWh of replacement power, which the NREL model suggests would most likely come from generators within the California ISO.

By contrast, Nevada Power appears to have sufficient flexibility on generators within its BA area to adjust to a Navajo GS retirement by relying entirely on internal resources. NREL's modeling results suggest that units in the Nevada Power BA area could economically generate 900 GWh more than what Nevada Power would lose from a Navajo GS retirement. This excess is equivalent to almost one-third of what SRP would need to obtain, and is more than what TEP would need to obtain.

NREL's modeling results suggest that more than fourfifths of the replacement power for Navajo GS would come from combined cycle natural gas generators. Table 2-3 shows the breakdown of replacement generation between combined cycle plants and other types of plants. The greatest increase is in the Nevada Power BA, and nearly all of that increase is on combined cycle units. Combined cycle plants in the Nevada Power BA are generally more efficient than elsewhere in the Interconnection, which is why the greatest change in utilization would occur there. The Western Interconnection's fleet of combined cycle units currently has a capacity factor of $44 \%{ }^{7}$ Within the Desert Southwest, combined cycle plants have a capacity factor of $35 \%$, reflecting lower utilization and proportionally more spare capacity. These figures, combined with the results from NREL's modeling, clearly indicate the ability to use existing natural gas units to replace power that may be lost due to retiring Navajo GS.

\subsection{Production costs: How expensive to do without Navajo GS?}

Changing dispatch to compensate for the loss of Navajo GS would increase total production costs across the Western Interconnection by between $1.6 \%$ and $3.1 \%$. This represents the additional cost of generating the same amount of power, but doing so without Navajo GS. Table 2-4 shows the range of modeled changes in total production costs, according to the prevailing price of natural gas. The table also shows what production costs would be with natural gas prices near their historic high of $\$ 13$ per mmBtu. (Recall the discussion earlier in this chapter that these results assume no obstacles to economically efficient transactions between sellers and buyers of power, and no changes in transmission path ratings.)

\footnotetext{
7 A plant's capacity factor indicates actual use relative to its theoretical potential over a given time period. A plant running at full capacity all the time would have a capacity factor of $100 \%$. The capacity factor would be $85 \%$ if the plant ran at $85 \%$ all the time, or if it were shut down for maintenance $15 \%$ of the time but ran at full capacity the rest of the time.
} 
Table 2-4. Interconnection-wide Production Costs (\$ millions)

\begin{tabular}{|l|c|c|c|c|c|c|}
\hline & \multicolumn{3}{|c|}{ Total cost, \$ million per year } & \multicolumn{3}{|c|}{ Total cost per MWh } \\
\hline \multicolumn{1}{|c|}{ Natural gas: } & $\$ 4$ & $\mathbf{\$ 6 . 9 0}$ & $\mathbf{\$ 1 3}$ & $\mathbf{\$ 4}$ & $\mathbf{\$ 6 . 9 0}$ & $\mathbf{\$ 1 3}$ \\
\hline Base Case & $\$ 12,660$ & $\mathbf{\$ 1 6 , 2 5 1}$ & $\mathbf{\$ 2 3 , 8 2 9}$ & $\mathbf{\$ 1 3 . 0 4}$ & $\mathbf{\$ 1 6 . 7 4}$ & $\mathbf{\$ 2 4 . 5 4}$ \\
\hline Without Navajo GS & $\$ 12,857$ & $\mathbf{\$ 1 6 , 7 5 3}$ & $\mathbf{\$ 2 4 , 9 8 6}$ & $\mathbf{\$ 1 3 . 2 4}$ & $\mathbf{\$ 1 7 . 2 5}$ & $\mathbf{\$ 2 5 . 7 3}$ \\
\hline Difference & $\$ 197$ & $\$ 502$ & $\$ 1,157$ & $\mathbf{\$ 0 . 2 0}$ & $\mathbf{\$ 0 . 5 2}$ & $\mathbf{\$ 1 . 1 9}$ \\
\hline Difference (\%) & $1.6 \%$ & $3.1 \%$ & $4.9 \%$ & $1.6 \%$ & $3.1 \%$ & $4.9 \%$ \\
\hline
\end{tabular}

LMPs would change especially in the vicinity of the plant that was removed, and near the plants that run more to make up the loss. Recall that the three most important factors affecting LMP values are generators' production costs, the level of demand at the system's load nodes, and flow limits on lines in the transmission network. An LMP increases under a certain scenario because less expensive power either does not exist or cannot reach that node due to line congestion.

LMPs indicate marginal costs (i.e., the value of providing one additional megawatt of power or the value of reducing load by one megawatt) at specific locations. LMPs and total annual production costs may both be expressed as dollars per megawatt-hour, but they differ in that the latter captures the average cost of all power used, while the former reflects the incremental cost of only the most expensive megawatt-hour used and is therefore higher than average production costs. LMPs are the basis of power prices in organized wholesale markets such as the ones in California and Alberta. Elsewhere in WECC outside the organized wholesale markets, LMPs are useful indicators of the cost of acquiring an additional increment of power. The Arizona utilities begin from a favorable position with respect to marginal costs relative to the rest of the Western Interconnection, as illustrated in Figure 2-7. LMPs in Arizona are typically from 3\% to 4\% below the Interconnection average, and are even further below the rest of the Interconnection when natural gas prices are high. In comparison, California's LMPs are generally 10\% to $13 \%$ above the Interconnection average due to the fact that it has virtually no internal coal capacity and therefore relies on natural gas to a greater extent. California's relatively high LMPs push the Interconnection average higher due to the relatively large amount of load affected.
The LMP differences between Arizona and California provide an economic explanation of why power transfers from the Desert Southwest to California are so large. High LMPs signal a local demand for lower-cost power, either because none is nearby or because transmission congestion limits its deliverability. Enabling the power to move from low-LMP nodes to the high-LMP nodes would result in exchanges that will leave both areas better off: for the importing area, lower-cost power; for the exporting area, more economic output. The flow of power across the Colorado River into California from Arizona, Nevada and New Mexico is around 50 TWh during a typical year. ${ }^{8}$ NREL's modeling indicates that retiring Navajo GS would raise total production costs by $2 \%$ to $3 \%$ for the Western Interconnection as a whole (see Table 2-5). In the scenario assuming extremely high natural gas prices, the total production cost impact is approximately 5\%. As shown in Figure 2-8, the Desert Southwest would see most of the increase in marginal costs, with LMPs remaining stable throughout most of the remainder of the West. LMPs at some nodes along the California-Nevada border would also increase, but these LMPs are naturally high due to local transmission constraints. The amount of load at these nodes is small.

The economic fundamentals driving power transactions from the Desert Southwest to California would be substantially the same in the absence of Navajo GS. LMPs in California will still be higher than those in the Desert Southwest even without Navajo GS, although the difference would be somewhat smaller. This is consistent with the redispatch outcomes discussed previously in this chapter. While California BAs would make up as much

\footnotetext{
8 Western Electricity Coordinating Council (WECC), "2009 Western Interconnection Transmission Path Utilization Study,” June 24, 2010.
} 
Table 2-5. Interconnection-wide LMP Averages, Minima and Maxima (\$/MWh)

\begin{tabular}{|l|c|c|c|c|c|c|}
\hline & \multicolumn{3}{|c|}{ Base case } & \multicolumn{3}{c|}{ Without Navajo } \\
\hline \multicolumn{1}{|c|}{ Natural gas: } & $\$ 4$ & $\$ 6.90$ & $\$ 13$ & $\$ 4$ & $\$ 6.90$ & $\$ 13$ \\
\hline Minimum & $\$ 6.11$ & $\$ 12.36$ & $\$ 29.56$ & $\$ 6.03$ & $\$ 13.22$ & $\$ 33.23$ \\
\hline Average (load-weighted) & $\$ 31.77$ & $\$ 48.84$ & $\$ 84.77$ & $\$ 32.43$ & $\$ 50.13$ & $\$ 88.23$ \\
\hline Maximum & $\$ 64.72$ & $\$ 85.94$ & $\$ 146.35$ & $\$ 74.29$ & $\$ 94.28$ & $\$ 143.67$
\end{tabular}

as two-thirds of what would be lost from Navajo GS, significant power flows westward across the Colorado River would continue because the economics would still make sense.

Table 2-6 aggregates the nodal results for the five BAs that rely on Navajo GS. These LMP averages represent the average costs of all nodes in a BA (weighted by load). The LMPs shown for the base case do not reflect the cost of Navajo GS alone, but rather the cost of Navajo GS blended with the cost of all other power currently used by the utility to serve load. LMPs for the retirement scenario indicate what the blended cost of incremental generation within the BA would be without Navajo GS.

SRP would experience the largest price impact. With Navajo GS, SRP has marginal production costs that are lower than those of any other utility partner, including its Arizona peers. Retiring Navajo GS would increase SRP's marginal production costs by $\$ 2.48$ per $\mathrm{MWh}$ - the largest absolute increase as well as the largest percentage increase among all Navajo GS utility partners. Even with that increase, however, SRP's marginal production costs would still be lower than those of any other, although by a much smaller margin.

The other two Arizona utility partners, APS and TEP, would see their marginal production costs increase by as much as $5 \%$ if they were to lose their share of Navajo GS. As described earlier in this chapter, both rely on Navajo GS to a lesser extent than SRP does, and both have a greater ability to draw on resources elsewhere in their BAs to replace what would be lost if Navajo GS were no longer available. This additional measure of internal resource flexibility would partially mitigate the price impact on APS and TEP of retiring Navajo GS.
Production costs for LADWP and Nevada Power are already higher than the Western Interconnection average, and retiring Navajo GS would have a proportionately smaller impact on them than on their Arizona utility partners. This is largely due to the amount of unused internal capacity in California and southern Nevada that the utilities would use to replace Navajo GS. The smallest relative price impact would be on LADWP, which is already divesting its position in Navajo GS. LADWP currently has the highest internal production cost of any Navajo GS partner.

As discussed earlier in this chapter, the NREL model indicates that two-thirds of the power needed to replace Navajo GS would come from other BAs, with most of that amount coming from California. Figure 2-7 shows that LMPs in California tend to be relatively high even under normal operating conditions. Replacing Navajo GS would increase LMPs in Northern California by around $2 \%$, and in most of Southern California by around 3\% (except for Imperial Irrigation district and SDGE, where the increase would be around $6 \%$ ).

The NREL modeling highlights the following conclusions with respect to changes in production costs.

- The Arizona utilities currently have internal power production costs that are less expensive than average WECC costs;

- Retiring Navajo GS would increase production costs proportionally more for the Arizona utilities than for the rest of the West; but

- After retiring Navajo GS, production costs for the Arizona utilities would still be lower than for the rest of the West, although by a smaller margin. 

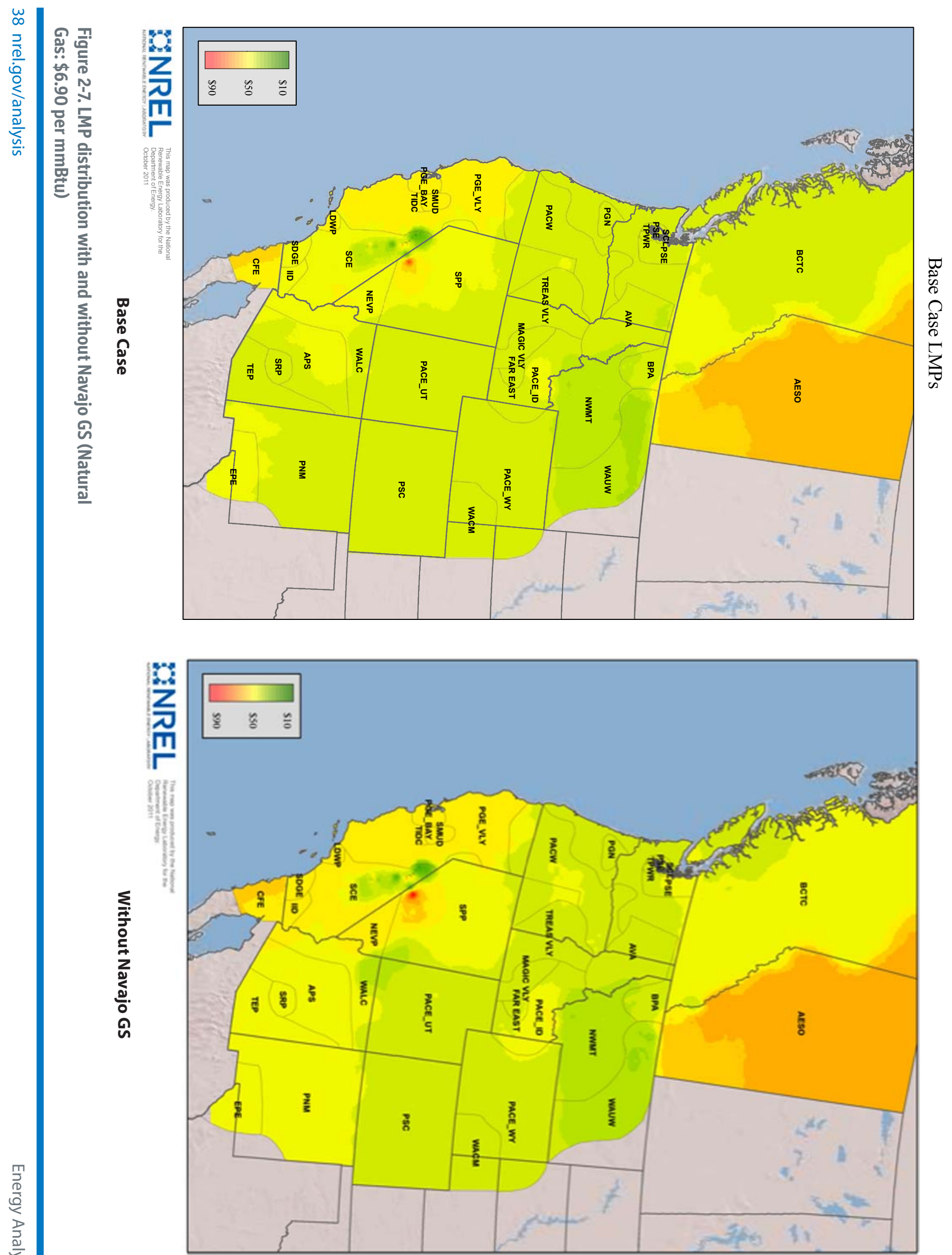


\section{LMP Deltas as \% of Base Case LMP}

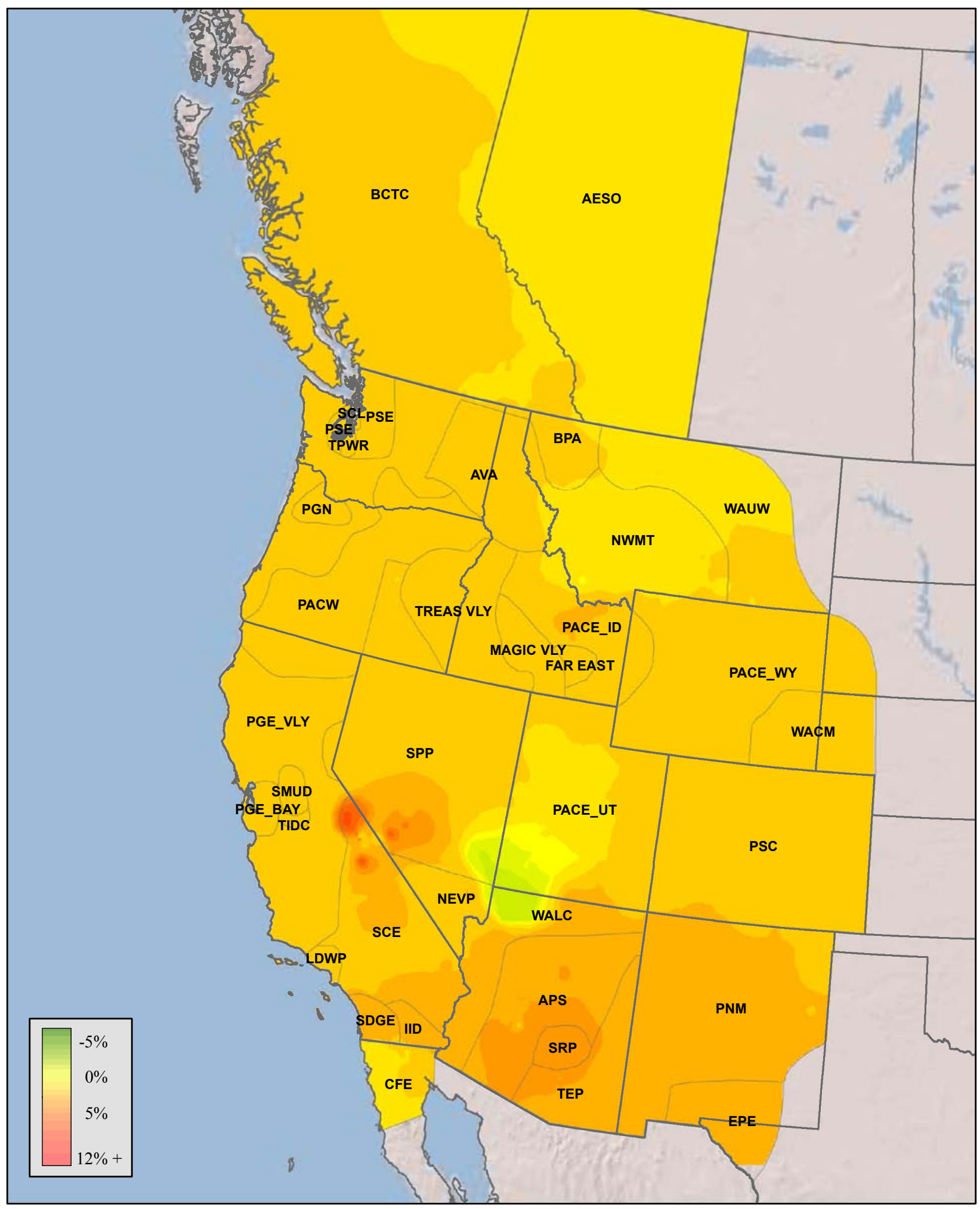

\section{ONREL

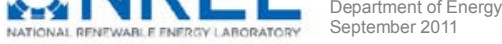

Figure 2-8. Change in average annual LMPs when retiring Navajo GS 
Table 2-6. Changes in BAs' Average LMP Assuming Navajo GS Retirement

\begin{tabular}{|c|c|c|c|c|}
\hline \multirow{3}{*}{$\begin{array}{c}\text { BA receiving Navajo } \\
\text { power } \\
\text { Salt River Project }\end{array}$} & \multicolumn{4}{|c|}{ BA average LMP (\$/MWh) } \\
\hline & $\begin{array}{c}\text { With } \\
\text { Navajo GS }\end{array}$ & $\begin{array}{l}\text { Without } \\
\text { Navajo GS }\end{array}$ & \multicolumn{2}{|c|}{ Change } \\
\hline & $\$ 47.00$ & $\$ 49.48$ & $\$ 2.48$ & $5.3 \%$ \\
\hline LADWP & $\$ 51.92$ & $\$ 53.57$ & $\$ 1.65$ & $3.2 \%$ \\
\hline Arizona Public Service Co. & $\$ 47.50$ & $\$ 49.88$ & $\$ 2.37$ & $5.0 \%$ \\
\hline Nevada Power Co. & $\$ 50.71$ & $\$ 52.49$ & \$1.77 & $3.5 \%$ \\
\hline Tucson Electric Power Co. & $\$ 47.51$ & $\$ 49.82$ & $\$ 2.30$ & $4.8 \%$ \\
\hline WECC average & $\$ 48.84$ & $\$ 50.13$ & $\$ 1.29$ & $2.6 \%$ \\
\hline
\end{tabular}

\subsubsection{Navajo GS retirement relative to changes in natural gas prices}

To provide a context for the impact of retiring Navajo GS, NREL compared LMP changes due to retiring the plant with LMP changes due to normal fluctuations in natural gas prices. Figure 2-4 at the beginning of this chapter tracks the daily price of natural gas at the Permian Basin hub since 2008. Figure 2-9 charts the distribution of daily prices over a more recent time horizon. Nearly $95 \%$ of the time, the price of natural gas was between $\$ 3.40$ and $\$ 5.40$ per mmBtu. A change from $\$ 4$ to $\$ 5$ is therefore representative of normal fluctuations in the price of natural gas, at least for the present time.

As shown in Table 2-6, retiring Navajo GS would increase LMPs in the owners' BAs from $3 \%$ to $5 \%$, and by $2 \%$ to $3 \%$ for the Interconnection as a whole. Increasing the price of natural gas from $\$ 4$ to $\$ 5$ per $\mathrm{mmBtu}$, on the other hand, increases LMPs by $18-19 \%$ across the board. Table 2-7 shows the detailed impacts by BA, both with and without Navajo GS.

The price outcomes NREL modeled for a theoretical Navajo GS retirement mirror how the California wholesale market responded to the retirement of the Mohave coal plant in 2006. At 1.6 GW, Mohave was smaller than Navajo GS, but it dispatched nearly two-thirds of its output to California. NREL conducted a statistical analysis of daily wholesale prices in Southern California from the beginning 2005 to the end of 2007. The results showed that while the price of natural gas had a statistically significant effect on wholesale prices, the retirement of Mohave did not (see Table 2-8).

Overall, changes in production costs and marginal prices that would be caused by retiring Navajo GS would be less than the changes caused by day-to-day and monthto-month movements in the price of natural gas. The wholesale impact may be evident by tracking LMPs over an extended period of time, but would be difficult to discern within a short time horizon.

\subsection{Impact on Bureau of Reclamation and CAP}

Up to this point, much of the discussion in this chapter has focused on Navajo GS' utility partners. The effect on the Bureau of Reclamation, CAWCD, and entities that rely on CAP water, however, would be different due to the fact that Reclamation is the only Navajo GS partner that is neither a utility nor a BA. Chapter 3 examines in more detail consequences of retirement versus other options with respect to the impact on CAP. Here, the discussion is limited to Reclamation's cost of replacing power from Navajo GS.

The key differences between Reclamation and its utility partners are these.

- A utility draws on many resources to balance load from many points on its system. Reclamation relies primarily on one resource (Navajo GS) to meet one source of demand (CAP). 


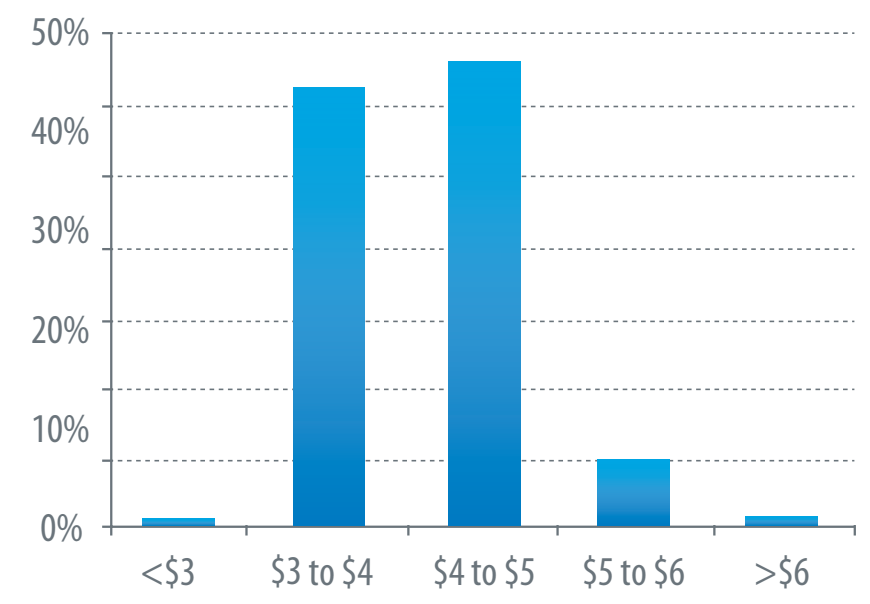

Figure 2-9. Distribution of daily natural gas prices, January 2010 - September 2011

- LMPs reflect a utility's marginal cost of producing power. How the utility schedules and dispatches various generators in its portfolio will change daily and hourly based on total demand and on which units are selected, and this in turn changes LMPs and production costs for any given hour. LMPs have little bearing on Reclamation's cost of power, however. What matters is Navajo GS' operating cost, which changes little regardless of when CAP needs the power.

- Any change in the cost or availability of one generator is dampened by its relative size in the utility's portfolio of generators; the larger the portfolio, the smaller the impact of one single generator on aggregated production costs. For Reclamation, any change in the cost or availability of Navajo GS transfers entirely to CAP water users.

If Reclamation no longer had Navajo GS as a resource, it would need to turn to the wholesale market for some or all of the replacement power. While Reclamation could conceivably reallocate some of the power generated from the Glen Canyon and Hoover hydroelectric plants, this analysis proceeds from the more conservative assumption that no such reallocation would occur. Even if Reclamation were to draw on its hydroelectric capacity, the reallocation in turn would likely require some replacement from the wholesale market to ensure Reclamation's obligations to all of its public power customers could be met.

Recall from Table 2-3 that most of the new power generated to replace Navajo GS' 15 TWh would likely come from
Nevada Power and from generators in Southern California. More precisely, less of the $50 \mathrm{TWh}$ of power generated in the Desert Southwest would flow westward to California and more would stay in Arizona. This would require more generation from California's own plants.

The wholesale costs Reclamation would face in replacing Navajo GS power would be close to the LMPs in the areas where the CAP pumps are located. For load nodes (i.e., points of demand where power leaves the network and is used) LMPs reflect the economic value of additional power, taking into account all the factors affecting how the additional power would be produced and delivered. LMPs in the areas where the largest CAP pumps are located would range between $\$ 33$ and $\$ 50$ per MWh based on the price of natural gas. Table 2-7 shows that this price range would be rather consistent among APS, SRP and TEP.

Reclamation would end up in roughly the same economic place as the Arizona utilities with respect to the cost of replacement power, but it would be coming from a different and lower-cost starting point. While its utility partners face current costs consistent with the base case LMPs shown in Table 2-7, Reclamation's current power costs are tied to the production cost of Navajo GS alone. This means that Reclamation's initial position would be $33 \%$ to $44 \%$ below the base case LMPs (again, with LMPs varying based on the price of natural gas).

The bottom line for Reclamation, therefore, is that the effective cost of replacement supply could be as much as double its current cost. This conclusion is based on comparing Navajo GS' current production cost (around \$20 per MWh) with what LMPs near the CAP pumps would be in the event of a Navajo GS retirement, as shown in Table 2-7 for APS, SRP and TEP. This contrasts with the much smaller increase in LMPs-between $4 \%$ and 5\% — for the Arizona utilities.

The federal government authorized the creation of Navajo GS to ensure a low-cost supply of power to pump water out of the Colorado River for the Central Arizona Project. Retiring Navajo GS would eliminate not only the plant, but would also eliminate the operational arrangements that made such low-cost power possible. With respect to the Bureau of Reclamation and CAP, therefore, replacing Navajo GS would involve much more than the ordinary changes in production cost that the utility partners would experience. 
Table 2-7. LMP Sensitivities for Natural Gas Price, Navajo GS Retirement

\begin{tabular}{|c|c|c|c|c|}
\hline $\mathbf{B A}$ & $\begin{array}{l}\text { Navajo GS } \\
\text { scenario }\end{array}$ & $\begin{array}{c}\text { Gas at \$4/ } \\
\text { mmBtu }\end{array}$ & $\begin{array}{c}\text { Gas at \$5/ } \\
\text { mmBtu }\end{array}$ & $\begin{array}{c}\% \text { change due to } \\
\text { natural gas }\end{array}$ \\
\hline \multirow{3}{*}{ Salt River Project } & Base case & $\$ 31.08$ & $\$ 36.66$ & $18 \%$ \\
\hline & Retire & $\$ 32.44$ & $\$ 38.46$ & $19 \%$ \\
\hline & $\begin{array}{l}\% \text { change due to } \\
\text { retirement }\end{array}$ & $4 \%$ & $5 \%$ & \\
\hline \multirow{3}{*}{ LADWP } & Base case & $\$ 34.26$ & $\$ 40.53$ & $18 \%$ \\
\hline & Retire & $\$ 35.28$ & $\$ 41.71$ & $18 \%$ \\
\hline & $\begin{array}{l}\% \text { change due to } \\
\text { retirement }\end{array}$ & $3 \%$ & $3 \%$ & \\
\hline \multirow{3}{*}{$\begin{array}{l}\text { Arizona Public } \\
\text { Service Co. }\end{array}$} & Base case & $\$ 31.39$ & $\$ 37.05$ & $18 \%$ \\
\hline & Retire & $\$ 32.72$ & $\$ 38.77$ & $18 \%$ \\
\hline & $\begin{array}{l}\% \text { change due to } \\
\text { retirement }\end{array}$ & $4 \%$ & $5 \%$ & \\
\hline \multirow{3}{*}{ Nevada Power Co. } & Base case & $\$ 32.73$ & $\$ 39.08$ & $19 \%$ \\
\hline & Retire & $\$ 33.75$ & $\$ 40.26$ & $19 \%$ \\
\hline & $\begin{array}{l}\% \text { change due to } \\
\text { retirement }\end{array}$ & $3 \%$ & $3 \%$ & \\
\hline \multirow{3}{*}{$\begin{array}{l}\text { Tucson Electric } \\
\text { Power Co. }\end{array}$} & Base case & $\$ 31.34$ & $\$ 37.02$ & $18 \%$ \\
\hline & Retire & $\$ 32.64$ & $\$ 38.71$ & $19 \%$ \\
\hline & $\begin{array}{l}\% \text { change due to } \\
\text { retirement }\end{array}$ & $4 \%$ & $5 \%$ & \\
\hline \multirow{3}{*}{ WECC average } & Base case & $\$ 31.77$ & $\$ 37.74$ & $19 \%$ \\
\hline & Retire & $\$ 32.43$ & $\$ 38.58$ & $19 \%$ \\
\hline & $\begin{array}{l}\% \text { change due to } \\
\text { retirement }\end{array}$ & $2 \%$ & $2 \%$ & \\
\hline
\end{tabular}

Table 2-8. Regression Analysis of Mohave Retirement and Wholesale Power Prices in California SP15 price = natural gas price + Mohave + previous day's SP15 price + intercept

Number of observations: 727 (valid daily values, January 3, 2005 through December 28, 2007) Goodness of fit (adjusted $\left.\mathbf{r}^{2}\right): 0.53$

$$
\text { Explanatory variable Coefficient Tstatistic }
$$

Natural gas price

(spot price at El Paso Permian Basin hub)

\begin{tabular}{l|l}
3.6 & $7.14^{\mathrm{a}}$
\end{tabular}

Mohave plant

(binary variable: 1 for operating period, 0 for retirement)

$-1.6-1.23$

Previous day's SP15 price

(control for time series effects)

0.56

$17.45^{a}$

Intercept

$6.5 \quad 2.53^{a}$

(a) Significant at $95 \%$ confidence level

Sources of data: Energy Information Administration (wholesale market data for California SP15); SNL Information (natural gas prices, Mohave net generation and shutdown) 


\section{Control Technologies-Cost of Retrofits}

This chapter summarizes the emission control technologies currently installed at Navajo GS, as well as other leading technologies for controlling nitrogen oxide $\left(\mathrm{NO}_{\mathrm{x}}\right)$ emissions. The chapter also discusses complementary technologies that can work in conjunction with those designed primarily to control $\mathrm{NO}_{x}$.

The Clean Air Act (CAA) has mandated several emission control programs at EPA, many benchmarked to requirements for 2064. Some of the CAA programs affecting power generation address acid rain, climate change, reduction of air pollutants, and protection of health and ecosystems. The regulations are intended to address sulfur oxides $\left(\mathrm{SO}_{\mathrm{x}}\right), \mathrm{NO}_{\mathrm{x}}$, ammonia, particulate matter, and regional haze. Future regulations are likely to address mercury and air toxics (MATS).

This section discusses how each of the above items has been addressed at Navajo GS, or if not, what the major options are for doing so. Navajo GS has already made several significant modifications to integrate emission control technologies, among them flue gas desulfurization (FGD), low $\mathrm{NO}_{\mathrm{x}}$ burners (LNB), separated over fire air (SOFA), and electrostatic precipitators (ESP). Each technology has reduced one or more of the pollutants EPA is targeting under the authority of the CAA. This section discusses technologies being considered by Navajo GS' stakeholders and the EPA to address regional haze visibility issues within Class I areas, including the Grand Canyon. The discussion includes technology capabilities, as well as cost and impact to Navajo GS and its stakeholders.

EPA proposed the MATS in May 2011 to establish utility boiler maximum achievable control technology emissions standards for hazardous air pollutants (HAPs). ${ }^{1}$ MATS will establish emission limits for hydrogen chloride $(\mathrm{HCl})$, mercury $(\mathrm{Hg})$, and other (non-Hg) HAP metals via standards for total particulate matter (PM). The proposed MATS rule contains separate limits for new or reconstructed units and for existing units. It also has separate limits for boilers designed to burn coal at low heat values, the threshold being 8,300 Btu per pound. The emissions standards for units with higher heat rates (above 8,300 Btu per pound) are the ones expected to apply to Navajo GS' units, if the rule is finalized as proposed. EPA released a final ruling in December 2011, but as of this writing it had not yet appeared in the Federal Register.

The Regional Haze Rule is part of the regional haze program, implemented under the CAA. As discussed elsewhere in this report, the rule was initiated to address and improve visibility in federally protected (Class 1) national park and wilderness areas. Each state is required to develop "goals for improving visibility" under the rule. ${ }^{2}$ The program provides states guidance on selecting days with the worst and best visibility during the year, on the effects of relative humidity on visibility, on procedures for calculating visibility impairments, and on other related issues. Reduction in power plant $\mathrm{NO}_{\mathrm{x}}$ and $\mathrm{SO}_{2}$ emissions are two of the strategic emission reductions intended to help achieve the CAA goals by 2064 .

The CAA requires EPA to develop rules to implement a program of visibility protection, which would require the application of best available retrofit technology (BART) to certain facilities. The primary focus of these rules was the prevention and remediation of regional haze impacts on Class I areas by large emissions sources.

1 EPA Website, www.epa.gov

2 EPA Fact Sheet, "The Environmental Protection Agency Releases Guidance on Implementing Its Regional Haze Program". http://www.epa. gov/ttn/caaa/t1/fact_sheets/rh_girhp_fs.pdf 
Table 3-1: Nitrogen Oxide Emission Reduction Technologies

\begin{tabular}{|c|c|c|c|}
\hline \multicolumn{2}{|c|}{ Modification technology } & \multicolumn{2}{|c|}{ Post-combustion technology } \\
\hline Low- $\mathrm{NO}_{x}$ Burners & LNB & Selective Non-Catalytic Reduction & SNCR \\
\hline Overfire Air & OFA & Selective Catalytic Reduction & SCR \\
\hline Sequentially Overfire Air & SOFA & & \\
\hline Flue Gas Recirculation & FGR & & \\
\hline
\end{tabular}

Table 3-2: NO Permit Limits and Technology Performance

\begin{tabular}{|l|c|c|c|c|}
\hline & Ib/MMBtu & $\begin{array}{c}\text { Change from permit } \\
\text { pre-LNB/SOFA }\end{array}$ & $\begin{array}{c}\text { Change from } \\
\text { LNB/SOFA }\end{array}$ \\
\hline Pre-LNB/SOFA & Permit & 0.36 & & \\
\hline LNB/SOFA & Permit & 0.24 & $33 \%$ & $25 \%-40 \%$ \\
\hline LNB/SOFA/SNCR ${ }^{a}$ & Assumed & $0.18-0.144$ & $50 \%-60 \%$ & $67 \%$ \\
\hline LNB/SOFA/SCR & Estimated & 0.08 & $78 \%$ & \\
\hline
\end{tabular}

(a) Assumed reduction of $25 \%$ to $40 \%$

Source: ENSR/AECOM, BART Analysis for the Navajo Generating Station Units 1-3, November 2007.

\subsection{Technologies Implemented for Emission Controls}

In the mid 1990s, Navajo's owners began the transition to clean up the plant's acid gas emissions by installing wet flue gas desulfurization (FGD) systems on all three units. The FGD systems were installed and operational in 1999. During the system retrofit, Navajo also underwent steam turbine efficiency upgrades to account for the additional auxiliary power required to operate the FGD System and maintain a net power generation capacity of 2,250 MW.

NGS underwent low $\mathrm{NO}_{x}$ burners and separated over fire air (LNB/SOFA) retrofits starting in 2009, and completing in 2011. During the retrofit the NGS also revised their Title V Operating Permit to reduce the maximum level of $\mathrm{NO}_{x}$ emissions from $0.36 \mathrm{lb} / \mathrm{MMBtu}$ to $0.24 \mathrm{lb} / \mathrm{MMBtu}$. The LNB/SOFA retrofits on Units 3 and 2 were completed in 2009 and 2010. The retrofit on Unit 1 was finished in 2011.

\subsubsection{NO Control Technologies}

Nitrogen oxide emissions, include $\mathrm{NO}$, and $\mathrm{NO} 2$ and is identified as $\mathrm{NO}_{x}$ emissions or simply $\mathrm{NO}_{x}$, which is being called from reduction at federal, state, and local levels. For fossil-fuel power plants, there is a variation of technologies available to minimize or reduce the $\mathrm{NO}_{\mathrm{x}}$ emissions. These can be categorized as modification techniques, and postcombustion technologies, as identified in Table 3-1.

Each technology has benefits and limitations for $\mathrm{NO}_{\mathrm{x}}$ controls and are limited to the ultimate reduction of levels of $\mathrm{NO}_{x}$ on coal-fired power plants. 


\subsubsection{Low NO Burners and Separated Over Fire Air}

Low- $\mathrm{NO}_{\mathrm{x}}$ Burners (LNB) are furnace modifications that control air-to-fuel ratios to reduce $\mathrm{NO}_{\mathrm{x}}$ formation during combustion. This type of control technology represents a cost-effective means to reduce $\mathrm{NO}_{\mathrm{x}}$ emissions by $40 \%$ without chemicals and their potentially negative environmental consequences. LNB installation was completed in April 2011 at a cost of approximately $\$ 45$ million.

Separated Over Fire Air (SOFA) is a method to control temperature within the furnace, and complete combustion of the fuels without introducing an over abundance of excess air. This combustion technique introduces oxygen into the system at different elevations or zones of the furnace. By controlling the combustion in zones, the temperature and quantity of excess air can be controlled. This reduces the nitrogen introduced into the system, ultimately reducing the quantity of $\mathrm{NO}_{\mathrm{x}}$ produced.

The Title $\mathrm{V}$ air permit reduced Navajo GS's $\mathrm{NO}_{\mathrm{x}}$ limits to $0.24 \mathrm{lb} / \mathrm{MMBtu}$ from $0.36 \mathrm{lb} / \mathrm{MMBtu}$. This is a reduction of 33\%, due to the installation of LNB and SOFA. Table 3-2 summarizes the permitted limits and anticipated $\mathrm{NO}_{\mathrm{x}}$ limits based on different control technologies.

\subsubsection{Selective Catalytic Reduction}

Selective Catalytic Reduction (SCR) is a method for converting $\mathrm{NO}_{\mathrm{x}}$ into a diatomic nitrogen $\left(\mathrm{N}_{2}\right)$ and water. The process uses a catalyst, and reagent in a specific temperature window to nitrogen oxides. Reagents most commonly used include ammonia (anhydrous or aqueous), or urea. The catalysts are often manufactured from ceramic materials which are embedded with various materials, which can include titanium oxide, and oxides of base metals (vanadium, tungsten, zeolites, or various precious metals). Additionally,
Table 3-3: Selective catalytic reduction in U.S. power plants

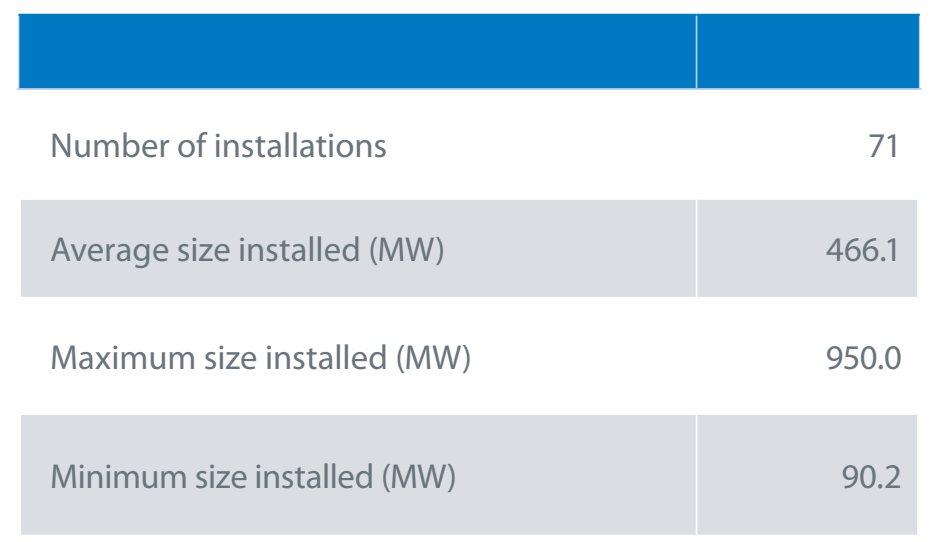

Source: SNL Utility Database, www.snl.com

porosity or geometry of the catalyst is a factor. Flue gas with higher dust loading requires a larger pore to prevent premature plugging; however there is a trade-off between plugging prevention, total reaction, and operational life of equipment. SCR systems in commercial use typically reduce $\mathrm{NO}_{\mathrm{x}}$ emissions by 90 percent or more, and thermodynamic calculations indicate that reductions in excess of 99 percent are possible at $650^{\circ} \mathrm{F}^{3}$

Table 3-3 summarizes the number of SCR installations in the United States. As Table 3-4 and Table 3-5 show, 90\% of them are in the Eastern Interconnection. This is nearly the same proportion as the distribution of all U.S. coal units that are between 90.2 MW and $950 \mathrm{MW}$ in capacity. Two sets of SCR cost estimates are in the record with respect to Navajo GS: one by the U.S. National Park Service (NPS), and the other by the engineering consulting firm

\footnotetext{
3 Institute of Clean Air Companies, selective Catalytic Reduction (SCR) Control of $\mathrm{NO}_{\mathrm{x}}$ Emissions from Fossil Fuel-Fired Electric Power Plants, May, 2009.
}

Table 3-4: Plants With Installed SCR Technology (Texas and Western interconnections)

\begin{tabular}{|c|c|c|c|c|c|}
\hline State & Plant & Net MW & State & Plant & Net MW \\
\hline TX & W A Parish ST 5 & 734.1 & CO & Comanche ST 3 & 820.0 \\
\hline TX & W A Parish ST 6 & 734.1 & WY & Wygen 3 ST 5 & 110.0 \\
\hline TX & W A Parish ST 7 & 614.6 & & & \\
\hline TX & W A Parish ST 8 & 654.0 & & & \\
\hline TX & J K Spruce ST 2 & 820.0 & & & \\
\hline
\end{tabular}


Table 3-5: Power Plants With Installed SCR Technology (Eastern Interconnection)

\begin{tabular}{|c|c|c|c|c|c|}
\hline State & Plant & $\begin{array}{l}\text { Net } \\
\text { MW }\end{array}$ & State & Plant & Net MW \\
\hline $\mathrm{AL}$ & Charles R Lowman ST 2 & 236.0 & $\mathrm{NH}$ & Merrimack ST 1 & 113.6 \\
\hline$A L$ & Charles R Lowman ST 3 & 236.0 & $\mathrm{NH}$ & Merrimack ST 2 & 345.6 \\
\hline$A L$ & James H. Miller Jr. ST 1 & 705.5 & NY & Kintigh ST 1 & 655.1 \\
\hline$A L$ & James H. Miller Jr. ST 2 & 705.5 & $\mathrm{OH}$ & J M Stuart ST 1 & 610.2 \\
\hline $\mathrm{AL}$ & James H. Miller Jr. ST 3 & 705.5 & $\mathrm{OH}$ & J M Stuart ST 4 & 610.2 \\
\hline $\mathrm{AL}$ & James H. Miller Jr. ST 4 & 705.5 & $\mathrm{OH}$ & Killen Station ST 2 & 660.6 \\
\hline$A L$ & Colbert ST 5 & 550.0 & $\mathrm{OH}$ & Conesville ST 4 & 841.5 \\
\hline $\mathrm{FL}$ & St Johns River Power ST 1 & 679.0 & $\mathrm{OH}$ & Miami Fort ST 8 & 557.7 \\
\hline $\mathrm{FL}$ & St Johns River Power ST 2 & 679.0 & $\mathrm{OH}$ & J M Stuart ST 2 & 610.2 \\
\hline $\mathrm{FL}$ & Deerhaven ST 2 & 250.7 & $\mathrm{OH}$ & J M Stuart ST 3 & 610.2 \\
\hline GA & Hammond ST 4 & 578.0 & SC & Cope ST1 & 417.3 \\
\hline IL & Marion ST 4 & 173.0 & SC & Cross ST 1 & 590.9 \\
\hline IL & Dallman ST 1 & 90.2 & SC & Cross ST 2 & 556.2 \\
\hline IL & Dallman ST 2 & 90.2 & SC & Winyah ST 3 & 315.0 \\
\hline IL & Dallman ST 3 & 207.3 & SC & Winyah ST 4 & 315.0 \\
\hline IL & Dallman ST 4 & 280.0 & TN & Bull Run (TN) ST 1 & 950.0 \\
\hline IN & A B Brown ST 1 & 265.2 & $\mathrm{TN}$ & Kingston ST 1 & 175.0 \\
\hline IN & A B Brown ST 2 & 265.2 & TN & Kingston ST 2 & 175.0 \\
\hline IN & Merom ST 1 & 540.0 & TN & Kingston ST 3 & 175.0 \\
\hline IN & Merom ST 2 & 540.0 & TN & Kingston ST 4 & 175.0 \\
\hline IN & Petersburg ST3 & 574.3 & $\mathrm{TN}$ & Kingston ST 9 & 200.0 \\
\hline KY & East Bend ST 2 & 669.3 & VA & Birchwood Power Fac. ST 1 & 258.3 \\
\hline KY & H L Spurlock ST 1 & 357.6 & VA & Chesterfield ST 4 & 187.5 \\
\hline KY & H L Spurlock ST 2 & 592.1 & VA & Chesapeake ST4 & 239.3 \\
\hline KY & Elmer Smith ST 1 & 163.2 & WI & Weston ST 4 & 595.0 \\
\hline KY & Trimble County ST 2 & 760.0 & WI & Elm Rd. Stn. (Oak Cr.) ST 1 & 615.0 \\
\hline KY & D B Wilson ST 1 & 566.1 & WI & Elm Rd. Stn. (Oak Cr.) ST 2 & 615.0 \\
\hline MI & Dan E Karn ST 1A & 136.0 & WI & South Oak Creek ST 5 & 275.0 \\
\hline MO & $\begin{array}{c}\text { Southwest Power Station } \\
\text { ST1 }\end{array}$ & 194.0 & WI & South Oak Creek ST 6 & 275.0 \\
\hline MO & New Madrid ST 1 & 600.0 & WI & Pleasant Prairie ST 1 & 616.5 \\
\hline MO & New Madrid ST 2 & 600.0 & \multirow[t]{3}{*}{ WI } & \multirow[t]{3}{*}{ Pleasant Prairie ST 2} & \multirow[t]{3}{*}{616.5} \\
\hline NE & $\begin{array}{l}\text { Whelan Energy Center } \\
\text { ST } 2\end{array}$ & 220.0 & & & \\
\hline NE & Nebraska City ST 2 & 738.0 & & & \\
\hline
\end{tabular}

Source: SNL Utility Database, www.snl.com 
Table 3-6: Two estimates for SCR installation at Navajo GS

\begin{tabular}{|c|c|c|c|c|}
\hline \multirow{2}{*}{ NGS Unit } & \multicolumn{2}{|c|}{ Capital Costs } & \multicolumn{2}{c|}{ Annual O\&M Costs } \\
\cline { 2 - 5 } & $\begin{array}{c}\text { National Park } \\
\text { Service }\end{array}$ & Sargent \& Lundy & $\begin{array}{c}\text { National Park } \\
\text { Service }\end{array}$ & Sargent \& Lundy \\
\hline Unit 1 & $\$ 134,400,638$ & $\$ 151,825,000$ & $\$ 5,071,061$ & $\$ 3,982,000$ \\
\hline Unit 2 & $\$ 177,394,173$ & $\$ 205,808,000$ & $\$ 6,030,304$ & $\$ 3,982,000$ \\
\hline Unit 3 & $\$ 153,185,596$ & $\$ 188,250,000$ & $\$ 5,608,740$ & $\$ 3,982,000$ \\
\hline Total & $\mathbf{\$ 4 6 4 , 9 8 0 , 4 0 7}$ & $\mathbf{\$ 5 4 5 , 8 8 3 , 0 0 0}$ & $\mathbf{\$ 1 6 , 7 1 0 , 1 0 5}$ & $\mathbf{\$ 1 1 , 9 4 6 , 0 0 0}$ \\
\hline
\end{tabular}

Table 3-7: Capital Costs of SCR Installations Proposed in the Western Interconnection

\begin{tabular}{|c|c|c|c|c|}
\hline Plant & Costs & $\begin{array}{c}\text { Net } \\
\text { MW }\end{array}$ & $\begin{array}{c}\text { Capital } \\
\text { cost per } \\
\text { kW }\end{array}$ & Reference \\
\hline Four Corners 4/5 & $\$ 242,250,000$ & 750 & $\$ 323$ & Four Corners 4/5 (BART Analysis) \\
\hline Boardman (PGE BART) & $\$ 190,850,000$ & 550 & $\$ 347$ & Boardman (PGE BART) \\
\hline Boardman (ERG) & $\$ 137,500,000$ & 550 & $\$ 250$ & Boardman (ERG BART) \\
\hline Bridger 1/2/3/4 & $\$ 166,950,000$ & 530 & $\$ 315$ & Bridger 1/2/3/4 (BART Analysis) \\
\hline Naughton 3 & $\$ 136,950,000$ & 330 & $\$ 415$ & Naughton 3 (BART Analysis) \\
\hline San Juan GS- Unit 1 & $\$ 71,740,000$ & 340 & $\$ 211$ & EPA [FR Doc. 2011-20682 Filed \\
\hline San Juan GS - Unit 2 & $\$ 79,560,000$ & 340 & $\$ 234$ & 8-19-11; 8:45 am] \\
\hline San Juan GS - Unit 3 & $\$ 88,963,000$ & 497 & $\$ 179$ & \\
\hline San Juan GS - Unit 4 & $\$ 83,655,000$ & 507 & $\$ 165$ & \\
\hline
\end{tabular}

Sargent \& Lundy (S\&L). Both were reviewed for this study. NPS' cost estimate uses the Modified Cost Manual Approach developed by EPA, and incorporates several inputs provided by Navajo GS operating partner SRP. ${ }^{4}$ S\&L developed a construction estimate based on their experience, specific site details provided by SRP, and equipment costs provided by suppliers and manufacturers. Construction would require a planned outage, assumed to last eight weeks for each unit. The NPS calculations of lost revenues are smaller than those of S\&L, which may be attributable to basing the calculations on a unit capacity of $750 \mathrm{MW}$ as compared with its gross capacity of $812 \mathrm{MW}$.

Table 3-6 compares the overall estimates of capital costs and O\&M costs. The two estimates employ different assumptions, but both follow comparable methodologies. Because the assumptions differ within reason, this study uses both in tandem to establish the high and low bounds of a plausible range of future SCR costs specific to Navajo GS. Using a plausible range to model future cost recognizes

4 Worksheets provided by D. Shepherd, National Park Service; available at www.nrel.gov/navajo. that actual costs will be affected by conditions that cannot be anticipated. For this reason, SCR costs throughout this report are modeled as a plausible range.

To empirically test whether the range bounded by the two estimates was indeed plausible, this study compared them against cost estimates for SCR retrofits proposed elsewhere in the Western Interconnection. Recall from Table 3-5 and Table 3-4 that the use of SCR controls is less widespread in the Western Interconnection than in the Eastern Interconnection. The smaller number can magnify the effect of site-specific differences on an overall comparison. Capital and operating costs can vary widely depending on the type of combustion (wall fired, tangentially fired, etc.), the source of coal being used by the facility, and greenfield installations versus retrofit installations.

Table 3-7 compares cost estimates for SCR installations planned at a number of facilities in the Western Interconnection: the San Juan Generating Station in New Mexico, the Boardman Power Plant in Oregon, Naughton Unit 3 
in Wyoming, and the Four Corners Power Plant in New Mexico. Estimated costs (in dollars per kilowatt of net generating capacity) range from $\$ 165$ to $\$ 415$, with an average of $\$ 252$. The variation in costs can be attributed to economies of scale, as well as complexities included in the design and construction of each individual retrofit.

SCR installations at Comanche \#3 in Colorado and Wygen \#3 in Wyoming are not include in Table 3-7. Both incorporated SCR controls into the initial design and construction of the new units, significantly reducing cost per kilowatt as compared to retrofitting SCRs to an already existing unit.

Different boiler/furnace designs have limitations to $\mathrm{NO}_{\mathrm{x}}$ control technologies. Circulating fluidized bed boilers have high ash loading in the flue gas and tend to not work well with SCR technologies, where other pulverized coalfired boiler designs are amenable to SCR retrofits. Navajo GS has three units, which are pulverized, tangentially fire boilers, with very low ash loading in the flue gas - generally, a well-fitted candidate for SCR technologies.

Figure 3-1 illustrates how the cost range bounded by the S\&L and NPS estimates compares with the range of cost estimates across the Western Interconnection. The range of these two estimates - specific to Navajo GS - is entirely within the range for the entire interconnection, and is markedly narrower. In addition, both are near the same quartile of the interconnection range, which would be the case if both were reasonable analyses of the same conditions. The comparison, therefore, supports using the $\mathrm{S} \& \mathrm{~L}$ and NPS estimates as the bounds of a plausible range of SCR costs for Navajo GS.

This study, however, does not take either set of estimates further than total cost. Both were deficient in their respective methodologies for annualizing the total capital costs they estimated. Chapter 1 describes in detail the approach used in this study to annualize capital costs for each of the six Navajo GS owners, and to incorporate the O\&M costs into the plant's overall production cost.

\subsubsection{Selective Non-Catalytic Reduction}

Selective non-catalytic reduction (SNCR) is a post-combustion technology that injects a reagent into the flue gas, where the flue gas temperature is within a range of 1,700

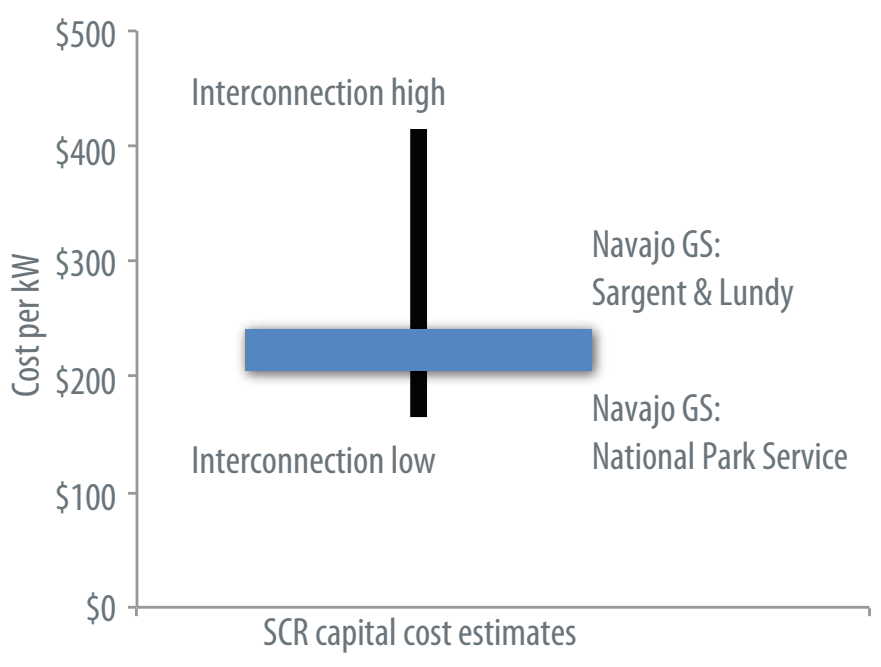

Figure 3-1: Estimates of SCR capital costs in the Western Interconnection

${ }^{\circ} \mathrm{F}$ and $2400{ }^{\circ} \mathrm{F} .{ }^{5}$ The reagent typically is an urea or ammonia. The temperature range is dependent upon the reagent utilized. The SNCR technology depends upon the selective $\mathrm{NO}_{\mathrm{x}}$ reduction through the direct contact of ammonia or urea droplets, eliminating the need for catalyst. Without the need for a catalyst, the capital costs are low in comparison to other post-combustion technologies. The reagent injected into the system selectively reacts with $\mathrm{NO}_{\mathrm{x}}$ in the presence of oxygen, forming primarily nitrogen and water.

Several reagents have been utilized and tested, however ammonia and urea are most widely used for utility scale applications.

The reaction occurs in a large temperature window, but as the temperature approaches the lower limits, less reaction occurs. Ammonia slip begins to promulgate and becomes its own source of emission. At higher temperatures, the reaction is no longer selective, and the nitrogen intermediates $(\mathrm{NH} 2, \mathrm{HCO}$, etc.) begin reacting with oxygen to form $\mathrm{NO}_{\mathrm{x}}$.The furnace design is also a parameter to recognize when incorporating SNCR as a control technology. The furnace chamber, as well as the ductwork and heat recover sections, all are part of the reaction chamber where $\mathrm{NO}_{\mathrm{x}}$ reduction takes place.

SNCR typically have the capability of reducing $\mathrm{NO}_{\mathrm{x}}$ by 25 percent to 40 percent, depending on the applications. Longterm studies performed by EPRI for a 720 MW tangentially fired boiler (which is similar to Navajo GS) verified that

5 Evaluation of An SNCR Trim System on A 720 MW Tangential Design Coal-Fired Utility Boiler, EPRI, Palo Alto, CA: 2003. 1008029. 
SNCR could remove on average between 17.8 percent and 20.6 percent of $\mathrm{NO}_{\mathrm{x}}$ emissions depending upon load. Ammonia slip for this test varied from 4 to $18 \mathrm{ppm}$.

As Table 3-8 shows, SNCR controls have been installed at 34 units that, as a group, are smaller than the group on which SCR controls exist. Table 3-9 shows that most of these installations have been on the East Coast; none is in the Western Interconnection.

Table 3-10 breaks down EPRI's estimate of capital and O\&M costs by owner. Total capital cost for all three units would be close to $\$ 16.5$ million. Estimates of operation and maintenance costs are based on EPRI's study performed on installing SNCR technologies on a $720 \mathrm{MW}$ tangentially fired power plant. ${ }^{6}$

\subsection{Particulate Matter Reduction and Sorbent Injection}

Particulates, $\mathrm{SO}_{3}$, mercury, and other toxic emissions can be controlled through sorbent injection and filter techniques. Filter techniques include electrostatic precipitators, and fabric filter bag houses. Sorbent injection can include injecting trona, the raw material for soda ash, limestone, or similar material to react with $\mathrm{SO}_{2}$ and $\mathrm{SO}_{3}$ to produce calcium sulfite and carbon dioxide. Activated carbon in some process is injected into the fluegas to attach to heavy metals, including mercury to reduce emission.

\subsubsection{Electrostatic Precipitators}

Electrostatic precipitators (ESP) are particulate control units for removing dust from the flue gas of large solid fuel fired boilers. The principle operation of an ESP comprises six processes: ionization, migration, collection, charge dissipation, particle dislodging, and particle removal. ${ }^{7}$

The system uses an electrostatic charging system to electrically charge the particles. The charged particles are then attracted to a plate, which is oppositely charged much like a magnet. The particles are then shaken from the plates using vibrations generated by the rapping system, and the dust is collected in hoppers at the bottom of the ESP. ESP technology can generally collect between $60 \%$ and $80 \%$ of the inlet dust load.

\footnotetext{
6 EPRI, Evaluation of an SNCR Trim System on a 720 MW Tangential Design Coal-Fired Utility Boiler.

7 Electrostatic Precipitator Knowledge Base, http://www.neundorfer.com/ knowledge_base/electrostatic_precipitators.aspx\#itp
}

Navajo GS currently is operating with a hot side ESP. Hot side ESPs operate upstream of the air heater and FGD. Currently they are obtaining a removal of $90 \%$ of PM10 particulate with the existing ESPs.

\subsubsection{Fabric Filter Baghouse and Sorbent Injection}

Additions of scrubbers and SCR systems at coal-fired power plants have significantly reduced concentrations of the pollutants $\mathrm{SO}_{2}$ and $\mathrm{NO}_{\mathrm{x}}$. Unexpected side effects caused by the chemical processes in the downstream equipment can be the result of additional control equipment. One side effect is increased emissions of $\mathrm{SO}_{3}$ and a resulting increase in the opacity of stack emissions - a phenomenon sometimes called the "blue plume." "Blue plume" is visible from the stack of a power plant when $\mathrm{SO}_{3}$ is converted into vapor-phase sulfuric acid $\left(\mathrm{H}_{2} \mathrm{SO}_{4}\right)$. The "blue plume" color and opacity is dependent on the concentration of aerosol, size of aerosols, gas temperature, and atmospheric conditions. In most cases, the plume becomes visible whe $\mathrm{H}_{2} \mathrm{SO}_{4}$ concentrations exceed 10 to $20 \mathrm{ppm}$.

Components within the fluegas path of a power plant have creates a complex chemical plant, which both increases and reduces the potential $\mathrm{SO}_{3}$ levels being generated and made available to convert into $\mathrm{H}_{2} \mathrm{SO}_{4} . \mathrm{SO}_{3}$ formation is effected by the furnace, $\mathrm{SCR}$, air preheaters, electrostatic precipitators, and wet scrubbers. $\mathrm{SO}_{3}$ formation begins in the furnace and is a by-product of combustion of sulfur containing fuels. The extent of the reaction depends on the quantity of sulfur in the fuel. Coal from the Kayenta mine is a bituminous coal with a sulfur content between 0.3 and $0.5 \%{ }^{8}$ Approximately $1 \%$ of $\mathrm{SO}_{2}$ contained in the fluegas would be converted to $\mathrm{SO}_{3}$. As the sulfur containing fluegas passes the SCR catalyst, the $\mathrm{SO}_{2}$ is again oxidized, and form between $0.5 \%$ and $1.5 \%$ additional $\mathrm{SO}_{3}$, doubling the quantity of $\mathrm{SO}_{3}$ in the fluegas. The air preheater reduces the fluegas temperature, inturn reducing the $\mathrm{SO}_{3}$ between $10 \%$ and $50 \%$. However, the reduction in temperature also increases the risk of $\mathrm{H}_{2} \mathrm{SO}_{4}$ formation at the lower temperatures $\left(<500^{\circ} \mathrm{F}\right)$. The ESPs can also reduce the quantity of $\mathrm{SO}_{3}$ levels. This reduction is dependent on the quantity and quality of flyash is the fluegas, as well as the temperature. Reductions can fall in the range of $10 \%$ to $50 \%$. Finally, the wet scrubber reduces $\mathrm{SO}_{3}$ levels, typically forming

\footnotetext{
8 A Summary of Coal Deposits in the Colorado Plateau: Arizona, Colorado, New Mexico, and Utah, Mark A. Kirschbaum and Laura R.H. Biewick, Page B3.
} 
Table 3-8: Selective non-catalytic reduction in

U.S. power plants

\begin{tabular}{|l|c|}
\hline & \\
\hline Number of installations & 34 \\
\hline Average size installed (MW) & 184.4 \\
\hline Maximum size installed (MW) & 661.5 \\
\hline Minimum size installed (MW) & 19.0 \\
\hline
\end{tabular}

Source: SNL Utility Database, www.snl.com

Table 3-9: US Installations of SNCR's By State

\begin{tabular}{|c|c|c|c|c|c|}
\hline State & Plant & Net MW & State & Plant & Net MW \\
\hline $\mathrm{FL}$ & Crist ST 4 & 93.7 & MS & Victor J. Daniel Jr. ST 1 & 548.3 \\
\hline $\mathrm{FL}$ & Crist ST 5 & 93.7 & $\mathrm{NH}$ & Schiller ST 6 & 50.0 \\
\hline IA & Sutherland (IA) ST 3 & 81.6 & $\mathrm{NH}$ & Schiller ST 4 & 50.0 \\
\hline IL & Marion CFB 1 & 33.0 & $\mathrm{NH}$ & Schiller ST 7 & 50.0 \\
\hline IL & $\begin{array}{c}\text { Corn Products - Illinois ST } \\
\text { TGO1 }\end{array}$ & 22.5 & NJ & Mercer ST 1 & 326.4 \\
\hline $\mathrm{FL}$ & Crist ST 4 & 93.7 & NJ & Mercer ST 2 & 326.4 \\
\hline $\mathrm{FL}$ & Crist ST 5 & 93.7 & NJ & B. L. England ST 1 & 136.0 \\
\hline IA & Sutherland (IA) ST 3 & 81.6 & NJ & B. L. England ST 2 & 163.2 \\
\hline IL & Marion CFB 1 & 33.0 & PA & Scrubgrass ST GEN1 & 94.7 \\
\hline IL & $\begin{array}{l}\text { Corn Products - Illinois ST } \\
\text { TGO1 }\end{array}$ & 22.5 & PA & $\begin{array}{l}\text { P H Glatfelter Co. - Penns ST } \\
\text { GEN6 }\end{array}$ & 39.1 \\
\hline KY & H L Spurlock ST 3 & 329.4 & TN & $\begin{array}{c}\text { Bowater Newsprint Calhoun } \\
\text { Oper ST GEN1 }\end{array}$ & 19.0 \\
\hline KY & H L Spurlock ST 4 & 329.4 & TN & Johnsonville (TN) ST 1 & 125.0 \\
\hline MA & Salem Harbor ST 1 & 81.9 & TN & Johnsonville (TN) ST 4 & 125.0 \\
\hline MA & Salem Harbor ST 2 & 82.0 & TX & Sandow (Alcoa) ST 5 & 661.5 \\
\hline MA & Salem Harbor ST 3 & 165.7 & VA & Chesapeake ST1 & 112.5 \\
\hline MD & Warrior Run Cogen ST GEN1 & 229.0 & VA & Chesapeake ST2 & 112.5 \\
\hline$M D$ & Luke Mill ST GEN1 & 35.0 & VA & Clover ST 1 & 424.0 \\
\hline MI & $\begin{array}{l}\text { T B Simon Power Plant ST } \\
\text { GEN4 }\end{array}$ & 21.0 & VA & Clover ST 2 & 424.0 \\
\hline MN & Clay Boswell ST 4 & 558.0 & WI & Manitowoc ST 9 & 63.4 \\
\hline MO & Sikeston ST 1 & 261.0 & & & \\
\hline
\end{tabular}

Source: SNL Utility Database, www.snl.com

Table 3-10: SNCR Capital, Operation and Maintenance Estimated Costs

\begin{tabular}{|c|c|c|c|}
\hline Owner & Share (\%) & Share of capital costs & Share of operating costs \\
\hline SRP & $21.7 \%$ & $\$ 3,544,153$ & $\$ 1,276,904$ \\
\hline LADWP & $21.2 \%$ & $\$ 3,462,491$ & $\$ 1,247,482$ \\
\hline APS & $14.0 \%$ & $\$ 2,286,550$ & $\$ 823,809$ \\
\hline NV Energy & $11.3 \%$ & $\$ 1,845,573$ & $\$ 664,932$ \\
\hline TEP & $7.5 \%$ & $\$ 1,224,938$ & $\$ 441,326$ \\
\hline BOR & $24.3 \%$ & $\$ 3,968,798$ & $\$ 1,429,897$ \\
\hline Total & $\mathbf{1 0 0 . 0 \%}$ & $\mathbf{\$ 1 6 , 3 3 2 , 5 0 3}$ & $\mathbf{\$ 4 , 8 8 4 , 3 5 1}$ \\
\hline
\end{tabular}


Table 3-11: Cost for SCR and Polishing Baghouse

\begin{tabular}{|c|c|c|c|c|}
\hline \multirow{2}{*}{} & \multicolumn{2}{|c|}{$\begin{array}{c}\text { SCR with sorbent injection, } \\
\text { polishing baghouse }\end{array}$} & \multicolumn{2}{|c|}{$\begin{array}{r}\text { SCR with sorbent injection, } \\
\text { full baghouse }\end{array}$} \\
\cline { 2 - 5 } & Capital Costs & O\&M Costs & Capital Costs & O\&M Costs \\
\hline Unit 1 & $\$ 154,946,000$ & $\$ 4,257,000$ & $\$ 372,184,000$ & $\$ 4,257,000$ \\
\hline Unit 2 & $\$ 209,324,000$ & $\$ 4,257,000$ & $\$ 410,919,000$ & $\$ 4,257,000$ \\
\hline Unit 3 & $\$ 189,772,000$ & $\$ 4,257,000$ & $\$ 347,869,000$ & $\$ 4,257,000$ \\
\hline Total & $\$ 554,042,000$ & $\$ 12,771,000$ & $\$ 1,130,972,000$ & $\$ 12,771,000$ \\
\hline
\end{tabular}

$\mathrm{H}_{2} \mathrm{SO}_{4}$ mist, or vapor-phase sulfuric acid. The conversion is dependent upon the scrubber design and temperature profiles through the system. Reduction generally is in the range of $30 \%$ to $40 \%$. Wet scrubbers are not efficient systems for removing $\mathrm{H}_{2} \mathrm{SO}_{4}$ aerosols, of which most will exit the stack. The end result is difficult to predict, as the configuration of every power plant is different.

MATS in the near future will require higher filtration and removal of particulate matter. ESPs currently do not have the capability of meeting this more stringent particulate removal capability. $\mathrm{SO}_{3}$ formation can be a result of adding SCR systems into larger coal fired power plants, and sorbent injection of limestone similar materials can be used to reduce the $\mathrm{SO}_{3}$ to current permitted maximum levels.

Sorbent injection is utilized as a medium to tie-up the $\mathrm{SO}_{3}$ molecules so they can be captured by a fabric filter baghouse. The sorbent is a calcium or salt based substance, often limestone or trona. The sorbent is injected into the flue gas stream, and then collected by the baghouse. Sargent \& Lundy has developed sorbent injection capital costs estimates for Navajo GS. Table 3-11 shows the annualized costs for each of Navajo's three units for a polishing type baghouse and sorbent injection installed with the SCR, and the baghouse placed between the SCR and wet scrubber.
In the event a polishing baghouse and sorbent injection system is not effective in minimizeing the $\mathrm{SO}_{3}$ and $\mathrm{H}_{2} \mathrm{SO}_{4}$ formation by the SCR and downstream equipment, a full baghouse would be required to be installed. Table 11 provides the costs for SCR, sorbent injection and both types of baghouse intallation at Navajo GS. 


\subsection{Conclusion}

Several technologies are available to help address $\mathrm{NO}_{\mathrm{x}}$, particulate, acid gases, ammonia and other emissions that impair visibility. Navajo GS has had spray type FGD systems on each unit since the mid 1990s. Additionally, each unit has LNBs and SOFA integrated into its system for nitrogen oxide control and reduction.

All units currently are operating under a Title $\mathrm{V}$ air permit that limits $\mathrm{NO}_{\mathrm{x}}$ emissions to less than $0.24 \mathrm{lb} / \mathrm{MMBtu}$, more stringent than the $0.36 \mathrm{lb} / \mathrm{MMBtu}$ standard the facility had to meet prior to 2009. As of 2011, all three units are operating under these new limits. The first two units that had LNBs and SOFA installed currently have maximum $\mathrm{NO}_{\mathrm{x}}$ emissions of $0.217 \mathrm{lb} / \mathrm{MMBtu}$.

SCR technologies can potentially reduce NGS emissions to between 0.07 and $0.09 \mathrm{lb} / \mathrm{MMBtu}$. Cost estimates developed by S\&L and NPS appear reasonable, both in terms of their methodologies and assumptions, and in comparison with estimates for other proposed SCR installations in the Western Interconnection. Estimated capital cost for SCRs on all three units ranges from $\$ 465$ million to $\$ 546$ million; annual O\&M costs estimates range from $\$ 11.9$ million to $\$ 16.7$ million.
SNCR would cost less, but would remove less $\mathrm{NO}_{\mathrm{x}}$. SNCR technologies have proven to remove between $20 \%$ and $40 \%$ of total $\mathrm{NO}_{\mathrm{x}}$, with a higher ammonia slip potential for the facility. This study evaluated the potential $\mathrm{NO}_{x}$ removal at 25\% reduction, utilizing EPRI's findings for installing SNCR on a $720 \mathrm{MW}$ tangentially coal-fired power plant. The capital investment was considerably less, as was the operation and maintenance costs. Only ammonia or urea is used to control $\mathrm{NO}_{x}$, and no catalyst would be required to be replace annually. Capital costs for SNCR would likely total near \$16.5 million, with annual O\&M around \$6 million. $\mathrm{NO}_{\mathrm{x}}$ emissions would be anticipated to be between 0.18 and $0.14 \mathrm{lb} / \mathrm{MMBtu}$.

Sorbent inject and baghouse technologies also are potential modifications that could supplement SCR. Further analysis of the system needs to be completed prior to understanding the need, and often the impacts to sulfuric acid generation and emissions are not fully evaluated until after the SCR is installed and the facility is operating. The impact to the facility could potentially add $\$ 587$ million to capital costs and $\$ 9$ million to annual O\&M costs. 


\section{Central Arizona Project and Navajo Generating Station}

This chapter of the report focuses on how increased costs associated with the installation of BART emissions controls at Navajo GS (or alternatively, a Navajo GS shutdown) would impact the Central Arizona Project (CAP). Two areas are key: how the costs would affect CAP water rates charged by CAWCD and how higher power costs would affect CAP repayment obligations of the Central Arizona Water Conservation District (CAWCD).

An increase in the amount CAWCD has to pay for Navajo GS power will lead to an increase in the pumping energy charge billed to all CAP water users, as Navajo GS provides the bulk of the electricity that powers the CAP pumping system used to deliver water from the Colorado River to Maricopa, Pima, and Pinal counties. In addition, an increase in CAWCD's annual payment toward its CAP repayment obligation due to the installation of BART emissions controls will require CAWCD to increase CAP water rates of some customers in order to recover the additional expense.

Several agreements anticipate sale of Navajo GS surplus power to be a major source of revenue for the Lower Colorado River Basin Development Fund (Development Fund). If the allocation of costs for emission controls increases the production costs of Navajo GS power, the net revenues from surplus power sales will be reduced, resulting in less money flowing into the Development Fund from the sale of Navajo GS surplus power. This reduction in revenues may increase the amount of money that the CAWCD must contribute toward its annual repayment obligation to the federal government for the reimbursement of CAP construction costs, and it may reduce the financial capability of the Development Fund to meet some commitments to Indian tribes negotiated and established through the Arizona Water Settlements Act of 2004 (Settlements Act).

\subsection{Background to CAP}

In 1968, Congress passed the Colorado River Basin Project Act (Basin Project Act), which authorized the U.S. Bureau of Reclamation (Reclamation) to construct the CAP. The purpose of the project was to provide Arizona with access to the State's annual 2.8 million acre-feet (AF) entitlement of Colorado River water. Completed in 1993, the CAP annually delivers 1.5 million AF of Arizona's allocation of Colorado River water to Maricopa, Pima and Pinal counties through a series of canals and pumping stations. The 336-mile CAP delivery system lifts Colorado River water up an elevation of 3,000 feet from Lake Havasu to the system's end near the City of Tucson.

The CAWCD was created in 1971 to assume the responsibility for repayment to the federal government of the reimbursable costs of CAP construction. It is a multicounty water conservation district that includes Maricopa, Pima, and Pinal counties. CAWCD operates and maintains the CAP and is responsible for the delivery of CAP water to customers. CAWCD has authority to levy an ad valorem tax of up to 10 cents per $\$ 100$ assessed valuation of property within the District's service area to fund administrative costs and repayment of CAP construction costs. The current ad valorem tax rate is set at 6 cents per $\$ 100$ of assessed valuation.

\subsubsection{Relationship between CAP and Navajo GS}

The 1968 Basin Project Act also authorized the Secretary of the Interior to enter into agreements with non-federal entities for the construction of power plants required to operate CAP. ${ }^{1}$ The U.S. federal government secured a $24.3 \%$ interest in Navajo GS, which equates to approximately $4.3 \mathrm{TWh}$ of power annually to power the CAP operations. The CAP uses about 2.8 TWh of Navajo GS power annually, which accounts for approximately $92 \%$ of all power used by CAP. The remaining portion of the federal share of Navajo GS generation unused by CAP pumping operations, called Navajo GS surplus power, totals approximately $1.5 \mathrm{TWh}$ annually.

Salt River Project (SRP) is the plant's managing partner, responsible for operations, maintenance, and replacement (OM\&R). SRP bills the other plant owners for OM\&R according to each one's ownership share in Navajo GS. Under long-term contracts that expired on September 30, 2011, SRP billed Reclamation for the annual OM\&R costs and capital expenditures related to federal government's ownership share of Navajo GS. Reclamation in turn billed

143 U.S.C. 1523 Section 303 


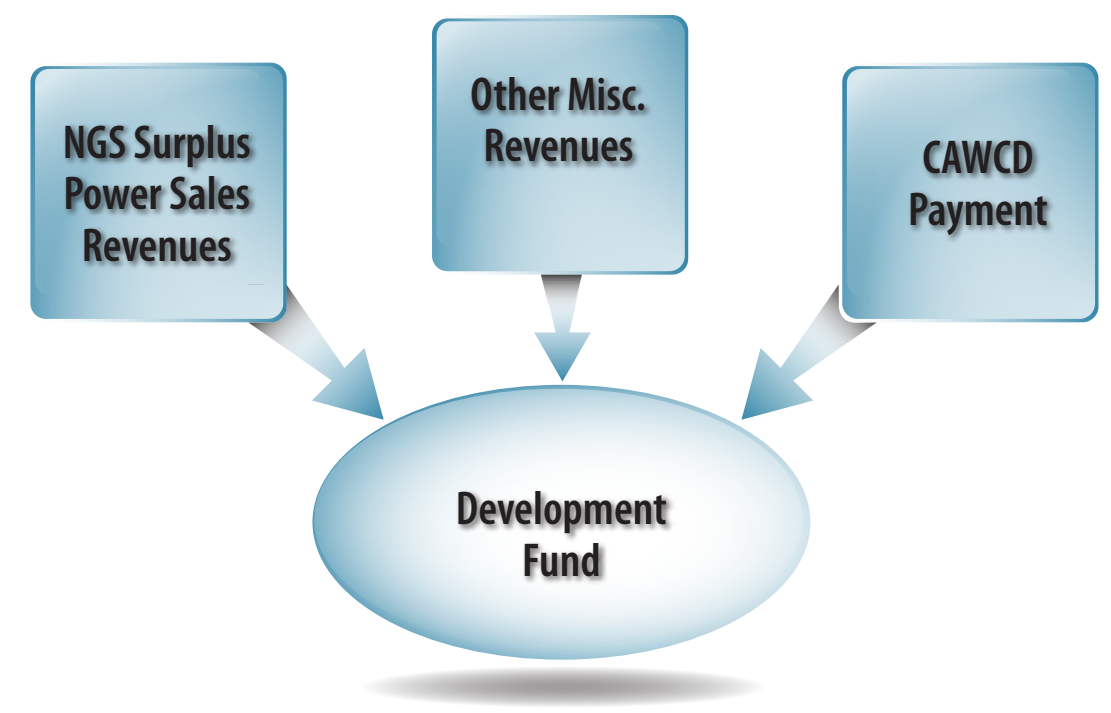

Figure 4-1. Revenue flows into the development fund

CAWCD for power used for CAP pumping and SRP for the share of the costs associated with the use of the federal government's share of Navajo GS power not used for CAP pumping. $^{2}$ As of October 1, 2011, SRP bills Reclamation for the government's full share of Navajo GS generation. Reclamation then bills CAWCD for the OM\&R cost associated with the power used for CAP pumping. The surplus portion of the federal share unused by CAWCD is sold through a long-term contract with SRP and on the open power market.

\subsection{CAP Repayment Obligations and the Development Fund}

CAWCD is responsible for meeting an annual repayment obligation to the federal government for the reimbursement of the CAP construction costs, which amounts to approximately $\$ 55$ million a year. CAWCD's annual payment flows into the Development Fund, which is managed by Reclamation.

In meeting its annual $\$ 55$ million CAP repayment obligation, CAWCD relies on revenues from other sources to lower its annual payment into the Development Fund. These other sources of revenues, primarily the sale of Navajo GS surplus power and other miscellaneous sources, are deposited into the Development Fund each year and

2 These contracts, known as the Four-Party Agreements, will be discussed in more detail in a following section. credited against CAWCD's annual payment. ${ }^{3}$ CAWCD's annual payment into the Development Fund is the difference between the total $\$ 55$ million annual repayment obligation and the total revenues from Navajo GS surplus power sales and net other miscellaneous sources (shown in Figure 4-1).

The funds used by CAWCD to make its annual payment into the Development Fund are generated from two sources. CAWCD levies ad valorem taxes on real property owners within the three-county CAP service area. In addition, CAWCD assesses capital charges on municipal \& industrial subcontractors.

\subsubsection{Navajo surplus power sales revenues}

As indicated above, the revenues generated from sale of Navajo GS surplus power are deposited into the Development Fund and credited toward the repayment obligation of CAP construction costs owed by CAWCD. ${ }^{4}$ The following section describes how the amount of revenue from the sale of Navajo GS surplus power has been generated in the past, and the future Navajo GS surplus power sales arrangement.

3 Other miscellaneous revenues deposited into the Development Fund come from Hoover and Parker-Davis dam surcharges, $\mathrm{SO}_{2}$ credit sales, and other miscellaneous sources. Other miscellaneous revenues typically total $\$ 6-10$ million annually.

4 Section 303 of the Basin Project Act authorized the U.S. Department of the Interior to sell the remaining Navajo GS power that was unused by CAP (projected to be about 1.5 TWh annually) on open power markets and deposit revenues received into the Development Fund. Section 107 of the Hoover Power Plant Act of 1984 (Hoover Power Act) authorized the use of revenues from Navajo GS surplus power sales to aid in the repayment of CAP construction costs owed by CAWCD 
Table 4-1. Actual Revenues into the Development Fund, 2009 and 2010

\begin{tabular}{|l|c|c|}
\hline \multicolumn{1}{|c|}{ Source of Revenue } & $\mathbf{2 0 0 9}$ & $\mathbf{2 0 1 0}$ \\
\hline SRP consideration fee for Navajo GS power (\$ M) & $\$ 21.8$ & $\$ 21.8$ \\
\hline Net other miscellaneous revenues $(\mathbf{\$} \mathbf{M})$ & $\$ 1.2$ & $\$ 11.9$ \\
\hline CAWCD payment to meet $\mathbf{\$} 55 \mathrm{M}$ repayment obligation $(\mathbf{\$} \mathbf{M})$ & $\$ 32.0$ & $\$ 21.3$ \\
\hline
\end{tabular}

\section{Arrangement prior to September 30, 2011}

Following the adoption of the Navajo Power Marketing Plan in 1987, SRP agreed to a series of long-term contracts for the use of Navajo GS power, including Navajo GS surplus power. These contracts, known collectively as the Four-Party Agreements, provided a consistent amount of Navajo GS surplus power sales revenue flowing into the Development Fund, as SRP agreed to deposit \$21.75 million annually into the Development Fund as a consideration fee for the use of Navajo GS surplus power. This $\$ 21.75$ million payment was deposited into the Development Fund and credited towards CAWCD's $\$ 55$ million annual CAP repayment obligation. Each year, other miscellaneous revenues deposited into the Development Fund further reduced CAWCD's annual payment. At year's end, CAWCD was required to make a payment into the Development Fund that equaled the difference between the other revenue amounts deposited in the Development Fund and CAWCD's $\$ 55$ million CAP repayment obligation. Table 4-1 shows the revenues and CAWCD's payment into the Development Fund for 2009 and 2010.

Table 4-1 shows that CAWCD's payment towards its annual \$55 million CAP repayment obligation was $\$ 32$ million in 2009 and \$21.3 million in 2010. The yearto-year variation in CAWCD's payment was largely dependent on amount of other miscellaneous revenues flowing into the Development Fund.

\section{Arrangement after September 30, 2011}

All Four-Party Agreements expired on September 30, 2011. After October 1, 2011, the value of the Navajo GS surplus sales revenues will be determined by two sources of revenue. SRP has signed an agreement to receive 220,000 MWh of Navajo GS surplus power for an annual payment of $\$ 25$ million. ${ }^{5}$

5 SRP is responsible for paying the production costs associated with their $220,000 \mathrm{MWh}$ of NGS surplus power in addition to the value of the SRP
The remaining Navajo GS surplus power (estimated to be 1.28 TWh annually) will be sold in accordance with the 2007 plan adopted by Reclamation. The Western Area Power Administration (on behalf of Reclamation) will market the remainder of Navajo GS surplus power and deposit revenues from the sales into the Development Fund. These revenues will also be credited against CAWCD's annual CAP repayment obligation. However, the amount of revenues generated from the sales of the remainder of Navajo GS surplus power will be highly variable and largely dependent on the market price for power at the time of the sale and Navajo GS power production costs.

NREL used a "backcasting" analysis to test how the post Four-Party Agreement revenue arrangement may impact the Development Fund. For the purposes of the backcasting analysis and deriving estimates throughout this chapter, NREL conservatively selected a Navajo GS power production cost of $\$ 30$ per MWh. ${ }^{6}$

Table 4-2 shows what the net values of Navajo GS surplus power would have been if the post Four-Party Agreement

contract ( $\$ 25$ million).

6 The applicable production cost of Navajo GS power was not supplied to NREL by the parties. Two sources of information exist, but they yield different answers. Annual data provided in various federal filings for Navajo indicated total production costs (coal costs and O\&M costs) of $\$ 23.90$ per MWh and $\$ 24.45$ per MWh for 2009 and 2010, respectively. Data from CAWCD's annual financial statement reflecting what the district paid for power give a somewhat higher estimate: $\$ 32.14$ per MWh and $\$ 32.27$ per MWh for 2009 and 2010, respectively. NREL was not able to determine, within the timeframe of this study, whether the amount charged to CAWCD included costs other than fuel and O\&M, and if so, what those costs were. For the purposes of the backcasting exercise and deriving estimates throughout this chapter, NREL conservatively selected a proxy value toward the higher end of this range to represent Navajo's production costs: $\$ 30$ per MWh.

These results are sensitive to the actual production cost of Navajo power. Costs close to those reflected in federal filings would have resulted in net gains for both years. 
Table 4-2. Net Values of Navajo GS Surplus Power Sales Revenues into the Development Fund, Backcast Based on the Post Four-Party Agreement Revenue Arrangement (in \$ million)

\begin{tabular}{|c|c|c|}
\hline & 2009 & 2010 \\
\hline \multicolumn{3}{|l|}{ SRP contract (220,000 MWh of Navajo GS surplus power) } \\
\hline \multicolumn{3}{|l|}{ Net value of remaining Navajo GS surplus power in power markets } \\
\hline A. Total federal share of Navajo GS power generation & 3.9 TWh & 4.0 TWh \\
\hline B. "Hoover B" power used for CAP pumping & $0.2 \mathrm{TWh}$ & $0.2 \mathrm{TWh}$ \\
\hline C. CAP pumping power requirements & 3.0 TWh & 3.0 TWh \\
\hline D. SRP contract for Navajo GS power & $0.2 \mathrm{TWh}$ & $0.2 \mathrm{TWh}$ \\
\hline $\begin{array}{l}\text { E. Remainder of Navajo GS surplus power } \\
(\mathrm{A}+\mathrm{B}-\mathrm{C}-\mathrm{D})\end{array}$ & $0.9 \mathrm{TWh}$ & 1.0 TWh \\
\hline 1. Value of remaining Navajo GS surplus at market prices & $\$ 24.3$ & $\$ 29.8$ \\
\hline 2. Production cost of remaining Navajo surplus at $\$ 30 / \mathrm{MWh}$ & $\$ 27.0$ & $\$ 29.8$ \\
\hline
\end{tabular}

Net value of remaining Navajo GS surplus power

$(\$ 2.7)$

0

Sources: U.S. Energy Information Administration, Forms 923 and 906 (for net generation); Central Arizona Project Annual Report, 2010 (for pumping energy); CAWCD, Financial statements and Other Financial Information, 2010, p. 35 (for Hoover B power purchases); SNL Information (for wholesale power prices at CAISO SP-15 hub)

revenue structure had been in place in 2009 and 2010, assuming Navajo GS power production costs were $\$ 30$ per MWh. The analysis also uses wholesale power market prices, which averaged $\$ 27$ per MWh in 2009 and $\$ 30$ per MWh in 2010. ${ }^{7}$

Table 4-2 shows that under the post Four-Party Agreement revenue arrangement that the value of the SRP contract would have been $\$ 25$ million in 2009 and 2010. If wholesale power market prices averaged $\$ 27$ per MWh in 2009 and $\$ 30$ per MWh in 2010, the net value of the remaining Navajo GS surplus power would be a net loss of \$2.7 million in 2009 and \$0 million in 2010 .

Under the post Four-Party Agreement arrangement, these revenues from Navajo GS surplus power sales would flow

\footnotetext{
7 These results are sensitive to the actual production cost of Navajo power. Costs close to those reflected in federal filings would have resulted in net gains for both years.
}

into the Development Fund and would be credited toward CAWCD's $\$ 55$ million annual CAP repayment obligation. Table 4-3 shows the revenue flows into the Development Fund under a backcast scenario for 2009 and 2010 based on the post Four-Party Agreement arrangement.

Table 4-3 shows that the post Four-Party Agreements revenue arrangement would have decreased CAWCD's payment, from $\$ 32$ million to $\$ 31.5$ million in 2009 , and from $\$ 21.3$ million to $\$ 18.1$ million in 2010. The Navajo GS surplus power sales revenue in 2009 would have likely have been a net loss if CAWCD had to pay the cost of that power at the rates indicated in its 2010 financial statements. However, if the market prices for power had been higher, CAWCD's payment into the Development Fund could have been smaller than what it actually was in 2009 and 2010.

Note that the amount of remaining Navajo GS surplus power available for sale on power markets in 2009 (0.9 
Table 4-3. Revenues into the Development Fund in 2009 and 2010, Backcast Analysis Based on the Post Four-Party Agreement arrangement (\$ M)

\begin{tabular}{|l|c|c|}
\hline \multicolumn{1}{|c|}{ Source of Revenue } & $\mathbf{2 0 0 9}$ & $\mathbf{2 0 1 0}$ \\
\hline Net value of SRP contract & $\$ 25$ & $\$ 25.0$ \\
\hline Net value of remaining Navajo GS surplus power in power markets & $\$ 2.7)$ & $\$ 0$ \\
\hline Net other miscellaneous revenues & & \\
\hline CAWCD payment to meet $\$ \mathbf{5 5 M}$ repayment obligation & $\$ 1.2$ & $\$ 11.9$ \\
\hline
\end{tabular}

TWh) and 2010 (1 TWh) was less than the $1.28 \mathrm{TWh}$ anticipated by CAWCD going forward. This is attributable to planned outages during 2009 and 2010 for the installation of low- $\mathrm{NO}_{\mathrm{x}}$ burners. The following analysis in this report assumes that remaining Navajo GS surplus power available for sale on the power markets will be 1.28 TWh per year.

\subsubsection{Use of Development Fund revenues}

In 2004, the Settlements Act altered how the Development Fund was structured and how the Fund revenues were to be used. The flows of revenue into the Fund did not change; revenues deposited into the fund still were credited against CAWCD's annual payment toward meeting its $\$ 55$ million repayment obligation. However, the Settlements Act authorized the revenues to be made available to fund the delivery of CAP water to Indian tribes and to fund Arizona Indian water settlements. Reclamation was tasked to manage the Development Fund and disperse the revenues to meet Settlements Act obligations to the tribes. Reclamation did not disperse Development Fund revenues to meet Settlements Act obligations until after January 1, 2010. ${ }^{8}$

The Settlements Act set the priorities for how the Development Funds revenues are to be directed in meeting federal obligations under Indian water settlements. The Settlements Act established two groups of Development Fund payments, each arranged as cascading priorities. The first cascade of payment priorities for Indian water settlements under the Settlements Act is funded by CAWCD's annual \$55 million CAP repayment obligation. As long as CAWCD continues to meet its $\$ 55$ million annual CAP repayment obligation, additional costs associated with the installation of Navajo GS BART emissions controls or a Navajo GS shutdown should not impact the Development Fund's ability to meet this first cascade of payment priorities. The list and order of the first cascade of payment priorities is shown in Appendix A.

The Settlements Act established a second cascade of Development Fund payment priorities (shown in Appendix B). This second cascade will only receive Development Fund revenues if the annual Navajo GS surplus power sales revenues and other miscellaneous revenues exceed CAWCD's annual CAP repayment obligation of $\$ 55 \mathrm{M}$.

Table 4-4 shows a hypothetical scenario where the second cascade of priority payments would receive Development Fund revenue.

Table 4-4. Scenario in which $\$ 10$ million is Available for Second Cascade of Payment Priorities (\$ M)

\section{Source of Revenue}

Net value of SRP contract for 220, 000 MWh of Navajo GS surplus power

Net value of remaining Navajo GS surplus power

$\$ 30.0$

Net other miscellaneous revenues

$\$ 10.0$

CAWCD payment to meet $\$ 55 \mathrm{M}$ repayment 0.0

Excess revenue for second cascade of priority payments

$\$ 10.0$

Table 4-4 illustrates that if, hypothetically, the net value from the market sale of the remaining Navajo GS surplus power sales were $\$ 30$ million annually, the total amount

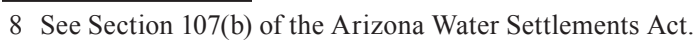


of revenues flowing into the Development Fund for that year would be $\$ 65$ million, which would exceed CAWCD's $\$ 55$ million CAP repayment obligation by $\$ 10$ million. Such a scenario would mean that CAWCD would not be required to make a payment into the Development Fund in that year, as the $\$ 55$ million annual repayment obligation would be completely met by revenues from the Navajo GS surplus power sales, SRP contract, and other miscellaneous revenues. It would also mean $\$ 10$ million excess revenue would flow into the second cascade of payment priorities.

Even in the absence of the installation of BART emissions controls at Navajo GS, the second cascade of priorities under the Settlements Act will only receive Development Fund revenues when market power prices are high. For the net value of the remaining Navajo GS surplus power sales to be $\$ 30$ million (as shown in Table 4-4), Navajo GS surplus power would have to be sold at an average market price of $\$ 53$ per MWh, assuming $\$ 30$ per MWh production costs for Navajo GS. ${ }^{9}$ Since 2008 when wholesale power prices were unusually high due to high natural gas prices, the only time the Southern California market has sustained prices above $\$ 53$ was during the first quarter of 2010 (based on a 30-day moving average of dayahead on-peak prices at the CAISO SP-15 hub).

\subsection{Navajo GS and CAP Water Rates}

Navajo GS supplies the bulk of the power required for the CAP system, which moves water from the Colorado River to Maricopa, Pima, and Pinal counties. The CAP system delivers water to a range of municipal and industrial (M\&I), tribal (federal), and agricultural customers. Figure 4-2 shows the amount that each sector received of the total 1.5 million AF of CAP water delivered in 2010.

\subsubsection{Water Rates}

Several cost components drive the CAP water rates charged to customers. Table 4-5 shows the current and projected costs associated with these component costs. ${ }^{10}$ The cost of Navajo GS power directly impacts the CAP pumping energy charge rate component.

The rate components apply to different sectors and uses, resulting in different CAP water rates structures charged

\footnotetext{
9 If actual production costs were closer to $\$ 24$, wholesale prices would need to be $\$ 47$.

10 Central Arizona Project, Final 2011/2012 Rate Schedule Update, June 2, 2011.
}



Figure 4-2. Distribution of CAP water deliveries in 2010 (acre-feet)

Table 4-5. Projected Costs of CAP Water by Component (\$/AF)

\begin{tabular}{l|c|c|c|c|c|c|}
\hline & $\mathbf{2 0 1 1}$ & $\mathbf{2 0 1 2}$ & $\mathbf{2 0 1 3}$ & $\mathbf{2 0 1 4}$ & $\mathbf{2 0 1 5}$ & $\mathbf{2 0 1 6}$ \\
\hline $\begin{array}{l}\text { Capital } \\
\text { Charges }\end{array}$ & 15 & 15 & 15 & 10 & 5 & \\
\hline $\begin{array}{l}\text { Fixed } \\
\text { OM\&R }\end{array}$ & 69 & 73 & 76 & 78 & 81 & 83 \\
$\begin{array}{l}\text { Pumping } \\
\text { Energy }\end{array}$ & 53 & 49 & 50 & 51 & 56 & 58 \\
\hline
\end{tabular}

to each sector. Table 4-6 shows the CAP water delivery rates for the different categories of users and uses, projected to 2016.

\section{M\&l water rates}

CAP water rates for M\&I users vary (shown in Table 4-6). Users of subcontract water pay both the fixed OM\&R and pumping energy charges, which is $\$ 122$ per AF in 2011. Non-subcontract and recharge CAP water costs include an additional capital charge per $\mathrm{AF}$, resulting in a water rate of $\$ 137$ in 2011. ${ }^{11}$

\footnotetext{
11 Non-subcontract M\&I users do not have long-term subcontracts in place for CAP water.
} 
Table 4-6. CAP Water Delivery Rates (\$/AF)

\begin{tabular}{|l|c|c|c|c|c|c|}
\hline & $\mathbf{2 0 1 1}$ & $\mathbf{2 0 1 2}$ & $\mathbf{2 0 1 3}$ & $\mathbf{2 0 1 4}$ & $\mathbf{2 0 1 5}$ & $\mathbf{2 0 1 6}$ \\
\hline $\begin{array}{l}\text { M\& I } \\
\text { Long-term Subcontract }\end{array}$ & 122 & 122 & 126 & 129 & 137 & 141 \\
$\begin{array}{l}\text { Non-Subcontract } \\
\text { Recharge }\end{array}$ & 137 & 137 & 141 & 139 & 142 & 141 \\
Interstate Recharge & 137 & 137 & 141 & 139 & 142 & 141 \\
\hline $\begin{array}{l}\text { Federal (Tribes) } \\
\text { Agricultural }\end{array}$ & 167 & 163 & 164 & 162 & 166 & 167 \\
\hline A & 122 & 122 & 126 & 129 & 137 & 141 \\
\hline
\end{tabular}

\section{Federal water rates}

CAP water rates for federal deliveries (primarily Indian water allocations) of CAP water include both delivery charge rate components - fixed OM\&R and pumping energy charges. However, the Settlements Act authorized the use of Development Fund revenues to pay for the fixed OM\&R cost for most Indian tribes receiving CAP water deliveries. Therefore, as long as Development Fund revenues are available, the tribes will pay only the energy pumping charge for CAP water (\$53 in 2011) rather than both the energy pumping charge and fixed OM\&R costs shown in Table 4-6.

\section{Agriculture water rates}

As shown in Table 4-6, agricultural users pay a reduced rate for delivery of CAP water. Under the Settlements Act, non-Indian agricultural users of CAP water gave up their rights to priority CAP water in order to be relieved of debt incurred during the construction of CAP distribution systems in irrigation districts. The Settlements Act granted irrigation districts access to CAP water for a water service charge equal to the energy pumping charge until the end of $2030 .^{12}$

\subsection{Rate Impact Scenarios: Base case, SCR Installation, SCR plus Baghouse plus Sor- bent Injection Installation, Shutdown}

This section examines the impact that SCR installation, SCR plus baghouse plus sorbent injection installation or Navajo GS shutdown would have on CAWCD's repayment obligation into the Development Fund and on water rates paid by CAP customers. First, the section establishes a business as usual scenario to establish a base case that

12 The Colorado River Documents 2008, Chapter 5, p 5-15.

can be compared with the SCR installation, SCR plus baghouse installation, and Navajo GS shutdown scenarios.

These assumptions are made with respect to how the cost of any BART upgrade would be calculated and passed on to CAP water users.

- Reclamation - and ultimately CAWCD and CAP water users - would only be responsible for $24.3 \%$ of the total upgrade costs, consistent with Reclamation's share of Navajo GS. They would not be responsible for the other $75.7 \%$, which the other utility partners would pay for using their normal rate base financing mechanisms.

- The capital costs associated with Reclamation's share of the BART upgrades would be amortized over 20 years, at a rate of $5 \%$ using the bonding authority of CAWCD. This is a default assumption, made necessary by the uncertainty over how Reclamation would pay for its share of the upgrade cost. Reclamation currently has no cost recovery mechanism comparable to the rate base approach that its utility partners would use. The further assumption is that Congressional action would be required to add the federal government's share of BART upgrades to the mechanisms currently used to recover other capital costs relating to Navajo GS, and that such action should not be the basis of analysis unless and until passed by Congress.

- CAWCD's demand for pumping power is inelastic; that is, the cost of power does not affect the amount of power the district takes from Navajo GS to operate the CAP pumps. 
- We also assume that demand for CAP water by M\&I, agricultural, and tribal users will be inelastic. Although high prices for CAP water may prompt some water users to seek other available water sources, there is no easy way to quantify such a curtailment in CAP water demand.

Therefore, the analysis in this section assumes that CAP water demand will remain fixed, regardless of price.

- Changes in the cost of Navajo GS power due to BART or other emission control retrofits would be added to the pumping power charges from Reclamation to CAWCD, resulting in an increase in the pumping energy charge assessed to CAP water users by CAWCD.

- Annualized capital costs of BART controls would be applied to CAP pumping power only. Variable production costs would be applied to pumping power and excess power.

- Any increase in the production cost of Navajo GS power would decrease the net value of the Navajo GS surplus power and result in an increase in CAWCD's annual payment towards its annual CAP repayment obligation. The analysis assumes that CAWCD would have to recover this increase in its annual payment by assessing a "CAP repayment recovery charge" on all M\&I CAP water deliveries, rather than through an increase in the ad valorem tax. ${ }^{13}$

- For each scenario, current power market conditions are used in calculating the net value of the Navajo GS surplus power, using the average power market price between 2009 and 2011 $\$ 27.25$ per MWh. ${ }^{14}$ Under this power market scenario, the production costs of Navajo GS power (\$30 per MWh) would actually be higher than the market price for the remaining Navajo GS surplus power, resulting in a negative net value. Rather than generate surplus power that would be sold at a loss, the assumption is that plant operators would ramp Navajo GS down and only generate the power required for CAP annual pumping needs

13 The CAP repayment recovery charge would not be assessed on agricultural or Federal CAP water deliveries.

14 Average market price for day ahead power sold in the California ISO at the SP15 hub from April 2009 through October 2011. Average takes into account on-peak and off-peak prices, assuming $11 \%$ of excess is sold as peak power and $89 \%$ as off-peak. This on-peak/off-peak ratio reflects the makeup of the remaining NGS surplus power. Prices sourced through SNL power markets data. Assumes 1,280,000 MWh surplus available for the market.
(2.8 TWh) and enough surplus power to meet the annual obligations of the SRP contract $(220,000$ MWh). The net value of the Navajo GS surplus power would be equal only to the net value of the SRP contract for surplus power.

\subsubsection{Base Case Scenario}

The base case scenario assumes that Navajo GS continues to operate without being required to install additional BART emissions controls. The pumping energy charge to CAP water users would remain the same as 2011 rates (shown in Table 4-5). The base case scenario establishes the baseline annual payment made by CAWCD toward its CAP repayment obligation.

To project the amount of CAWCD's annual payment into the Development Fund, the net value of the Navajo GS surplus power sales under a 2011 base case scenario was calculated. Table 4-7 shows what the net value of Navajo GS surplus power sales would be in 2011 using the average power market price for power between 2009 and 2011, along with Navajo GS power production costs of $\$ 30$ per MWh.

Table 4-7 shows that the net value of the Navajo GS surplus power under SRP contract would be \$18.4 million in 2011, while the net value of the remaining Navajo GS surplus power would be a loss of \$3.5 million in 2011 using a market price of $\$ 27.25$ per MWh. The negative net value of the remaining Navajo GS surplus power underscores how sensitive these revenues will be to market conditions. Again, the assumption is that Reclamation would avoid selling power at a loss (i.e., below its cost of production) and would instead curtail generation. CAWCD would receive no credit toward its annual CAP repayment obligation from the sale of the remaining Navajo GS surplus power.

Table 4-8 shows the revenue flows into the Development Fund under the 2011 base case scenario, where the net value of the remaining Navajo GS surplus power sales would be zero.

Table 4-8 shows that under the 2011 base case scenario, CAWCD's annual payment toward its $\$ 55$ million CAP repayment obligation would be $\$ 20$ million. Under this base case scenario, other miscellaneous revenues are set at $\$ 10$ million, which is consistent with CAWCD's financial projections. 
Table 4-7. Net Value of Navajo GS Surplus Power Under a 2011 Base Case Scenario (\$ M)

Net value of SRP contract $(220,000$ MWh of Navajo GS surplus power)

Value of SRP contract

$\$ 25.0$

Net value of remaining 1.28 TWh Navajo GS surplus power in power markets

Value of remaining surplus power at a market price of $\$ 27.25 / \mathrm{MWh}$

Total production cost of Navajo NS power at $\$ 30 / \mathrm{MWh}$

$\$ 38.4$

Net value of remaining Navajo GS surplus power

Table 4-8. Revenues into the Development Fund Under the 2011 Base Case Scenario

\section{Source of Revenue}

(millions)

Net value of SRP contract for 220,000 MWh of Navajo GS surplus power

$\$ 25.0$

Net value of remaining Navajo GS surplus power

Other miscellaneous revenues

$\$ 10.0$

CAWCD payment to meet $\$ 55 \mathrm{M}$ CAP repayment obligation

$\$ 20.0$

Table 4-9. Impact of SCR Installation on CAWCD's Navajo GS Power Costs

\begin{tabular}{|c|c|c|}
\hline & low & high \\
\hline Federal share of total SCR capital cost & $\$ 113.0 \mathrm{M}$ & $\$ 132.6 \mathrm{M}$ \\
\hline Annual 20 year capitalized costs at $5 \%$ interest & $\$ 9.1 \mathrm{M}$ & $\$ 10.6 \mathrm{M}$ \\
\hline Capital cost added to CAWCD's Navajo GS power costs (per MWh) & $\$ 3.25 /$ & $\$ 3.79 /$ \\
\hline (based on 2.8 TWh of annual CAP pumping energy use) ${ }^{a}$ & $M W h$ & $M W h$ \\
\hline Federal share of annual SCR O\&M costs & $\$ 2.9 \mathrm{M}$ & $\$ 4.1 \mathrm{M}$ \\
\hline $\begin{array}{l}\text { O\&M cost added to cost of federal share of Navajo GS power (per MWh) } \\
\text { (based on } 4.25 \text { TWh annual federal share of Navajo GS power) }^{b}\end{array}$ & $\begin{array}{l}\$ 0.68 / \\
M W h\end{array}$ & $\begin{array}{l}\$ 0.96 / \\
M W h\end{array}$ \\
\hline Capital and O\&M cost added to CAWCD's power costs (per MWh) & $\begin{array}{l}\$ 3.93 / \\
M W h\end{array}$ & $\begin{array}{l}\$ 4.75 / \\
M W h\end{array}$ \\
\hline $\begin{array}{l}\text { Total increase in CAWCD's annual power costs } \\
\text { (based on 2.8 TWh annual CAP pumping power use) }\end{array}$ & $\$ 11.0 \mathrm{M}$ & $\$ 13.3 \mathrm{M}$ \\
\hline $\begin{array}{l}\text { (a) SCR capital costs are assigned only to the annual power use of CAWCD, not to the entire } \mathrm{f} \\
\text { All of the capital costs would be paid annually through a fixed amount of Navajo GS power us }\end{array}$ & $\begin{array}{l}\text { l share of } 1 \\
\text { CAWCD. }\end{array}$ & jo GS po \\
\hline
\end{tabular}




\subsubsection{SCR Installation Scenario}

The costs associated with capital and annual O\&M of SCR emission controls at the Navajo GS would increase the cost of Navajo GS power. The cost estimates of installing SCR technology at Navajo GS vary. As Chapter 5 explains in further detail, this report uses two cost estimates to establish a plausible cost range of installing SCR technology at Navajo GS. Table 4-9 shows the impact of SCR capital and O\&M costs on CAWCD's Navajo GS power costs.

Table 4-9 indicates that SCR capital and O\&M costs will result in an increase in CAWCD's Navajo GS power costs by between $\$ 3.93$ per MWh and $\$ 4.75$ per MWh. If base case Navajo GS power costs are $\$ 30$ per MWh, these results suggest that adding SCRs will affect the cost of Navajo GS pumping power by up to $16 \%$. Such an increase would add as much as \$13.1 million to CAWCD's annual power costs each year.

\section{Impact of SCR installation on CAP water rates}

An increase in CAWCD's Navajo GS power costs due to SCR installation would impact CAP water rates by increasing the pumping energy charge for CAP water users. Table 4-10 shows how the SCR installation would impact CAP pumping energy charge.

Table 4-10 shows that under a low cost SCR scenario the total increase in CAWCD's annual power costs $(\$ 11.0$ million) would result in approximately a $\$ 7$ per AF in the pumping energy charge for CAP water customers. Under a high cost SCR scenario, the total increase in CAWCD's annual power costs ( $\$ 13.3$ million) would result in approximately a $\$ 9$ per AF increase in the pumping energy charge for CAP water customers.
Table 4-11 shows the impact of CAP pumping energy charges on 2011 base case CAP water rate components.

The increase in pumping energy charge would apply to all sectors and uses of CAP water. Table 4-12 shows how increases in the pumping energy charge would impact each sector of users under the low cost SCR installation scenario.

As shown in Table 4-12, a $\$ 7$ per AF increase in the pumping energy charge will result in Indian tribes and agricultural CAP water customers experiencing the largest proportional increase in CAP water rates (a 13\% increase over base water rates). The M\&I CAP water users will also see substantial increases in CAP water rates (a 4 to $6 \%$ increase over base water rates).

As shown in Table 4-13, an $\$ 8$ per AF increase in the pumping energy charge will result in Indian tribes and agricultural CAP water customers experiencing the largest proportional increase in CAP water rates (a 16\% increase over base water rates), while M\&I CAP water users will also see substantial increases in CAP water rates (a 5\% to $7 \%$ increase over base water rates).

\section{Impact of SCR installation on Development Fund revenues}

Table 4-8 shows that under the 2011 base case scenario, CAWCD's annual payment toward its $\$ 55$ million CAP repayment obligation would be $\$ 20$ million. Neither the low nor high cost SCR installation scenario would alter the value of the Navajo GS surplus power, resulting in no change in CAWCD's annual payment from the 2011 base case under the SCR installation scenarios.

Table 4-10. Increase in the CAP Pumping Energy Charge under the SCR Installation Scenario

\begin{tabular}{l|r|r|}
\hline & low & high \\
\hline Increase in CAP pumping energy charge & & \\
\hline Total increase in CAWCD's annual power costs & $\$ 11.0 \mathrm{M}$ & $\$ 13.3 \mathrm{M}$ \\
\hline Total water deliveries in 2011 (in AF) & $\$ 1.55 \mathrm{M}$ & $\$ 1.55 \mathrm{M}$ \\
\hline Increase in CAP pumping energy charge per AF & $\$ 7.10 / \mathrm{AF}$ & $\$ 8.58 / \mathrm{AF}$ \\
\hline
\end{tabular}


Table 4-11. Changes in CAP Water Rate Components Under Low and High Cost SCR Installation Scenarios

\begin{tabular}{|l|c|c|c|}
\hline Water rate components (\$ per AF) & Base Rate & Low & High \\
\hline CAP system capital charge & 15 & 15 & 15 \\
\hline Fixed OM\&R for CAP system charge & 69 & 69 & 69 \\
\hline Pumping energy charge & 53 & 60 & 62 \\
\hline
\end{tabular}

Table 4-12. Increase in CAP Water Rates Under the Low Cost SCR Installation Scenario

\begin{tabular}{|l|c|c|c|}
\hline Sectors & Base Rate & $\begin{array}{c}\text { Low SCR } \\
\text { Rate }\end{array}$ & \% Increase \\
\hline M \& I users (\$ per AF) & & & \\
Long-term Subcontract & 122 & 122 & $6 \%$ \\
Non-Subcontract & 137 & 144 & $5 \%$ \\
Recharge & 137 & 144 & $5 \%$ \\
AWBA Interstate Recharge & 167 & 174 & $4 \%$ \\
\hline Federal/Indian users (\$ per AF) & 53 & 60 & $13 \%$ \\
\hline Agricultural users (\$ per AF) & 53 & 60 & $13 \%$ \\
\hline
\end{tabular}

Table 4-13. Increases in the Pumping Energy Charge Under the High Cost SCR Installation Scenario

\begin{tabular}{|c|c|c|c|}
\hline Sectors & Base Rate & $\begin{array}{c}\text { Low SCR } \\
\text { Rate }\end{array}$ & $\%$ Increase \\
\hline
\end{tabular}

M \& I users (\$ per AF)

Long-term Subcontract

Non-Subcontract

$\begin{array}{lll}122 & 131 & 7 \% \\ 137 & 146 & 6 \% \\ 137 & 146 & 6 \% \\ 167 & 176 & 5 \%\end{array}$

AWBA Interstate Recharge

53

Federal/Indian users (\$ per AF)

Agricultural users (\$ per AF)

53

62

$16 \%$

62

$16 \%$ 


\subsubsection{SCR plus Baghouse \& Sorbent Injection Installation Scenario}

The installation of SCR plus baghouse \& sorbent injection (BH\&SI) emissions controls at the Navajo GS would result in an increase in the cost of Navajo GS power. The cost estimates of installing SCR plus BH\&SI at Navajo GS used in this report uses are described in Chapter 3. Table 4-14 shows the impact of SCR plus BH\&SI installation and O\&M cost on Navajo GS power costs.

Table 4-14 indicates that SCR plus BH\&SI capital and annual O\&M costs would add between $\$ 8.61$ per MWh and $\$ 9.43$ per MWh to CAWCD's power costs. This would increase CAWCD's annual power costs by as much as \$26.4 million.

\section{Impact of SCR plus baghouse \& sorbent injection in- stallation on CAP water rates}

An increase in Navajo GS power costs due to SCR plus BH\&SI installation will impact CAP water rates by increasing the pumping energy charge for CAP water users. Table 4-15 shows the impact of SCR plus BH\&SI installation on the CAP pumping energy charge.
Table 4-15 shows that under a low cost SCR plus BH\&SI scenario the total increase in CAWCD's annual power costs ( $\$ 24.1$ million) would result in a $\$ 16$ per AF increase in the pumping energy charge for CAP water customers. Under a high cost SCR plus BH\&SI scenario, the total increase in CAWCD's annual power costs ( $\$ 26.4$ million) would result in a $\$ 17$ per AF increase in the pumping energy charge for CAP water customers.

Table 4-16 shows the impact of the increased Navajo GS power costs from SCR plus BH\&SI installation on 2011 CAP water rate components.

An increase in the pumping energy charge would apply to all sectors and uses. Table 4-17 shows how an increase in the pumping energy and charges under the low cost SCR plus BH\&SI installation scenario would impact CAP water rates.

As shown in Table 4-17, a $\$ 16$ per AF increase in the pumping energy charge will result in Indian tribes and agricultural CAP water customers experiencing the largest proportional increase in CAP water rates (a 29\% increase

Table 4-14. Impact of SCR plus Baghouse \& Sorbent Injection Installation on CAWCD's Navajo GS Power Costs

Impact of SCR Plus Baghouse \& Sorbent Injection Installation

\begin{tabular}{lc} 
Federal share of BH\&SI capital cost & \$145.0 M \\
Annual 20 year capitalized costs at 5\% interest & $\$ 11.6 \mathrm{M}$ \\
$\begin{array}{l}\text { Capital cost added to CAWCD's Navajo GS power costs (per MWh) } \\
\text { (based on 2.8 TWh of annual CAP pumping energy use) }\end{array}$ & $\$ 4.14 / \mathrm{MWh}$ \\
\hline Federal share of annual BH\&SI O\&M costs & $\$ 2.3 \mathrm{M}$ \\
O\&M cost added to the cost of the federal share of Navajo GS power (per MWh) & $\$ 0.54 / \mathrm{MWh}$ \\
$\begin{array}{l}\text { (based on 4.25 TWh annual federal share of Navajo GS power) } \\
\text { Additional capital and O\&M cost of CAWCD's power costs for BH\&SI installation (per MWh) }\end{array}$ & $\$ 4.68 / \mathrm{MWh}$ \\
\hline $\begin{array}{l}\text { Additional capital and O\&M cost of CAWCD's power costs for SCR plus BH\&SI installation (per } \\
\text { MWh) }\end{array}$ & $\$ 8.61 / \mathrm{MWh}$ \\
& to \\
\hline Total increase in CAWCD's annual CAP pumping energy costs & $\$ 9.43 / \mathrm{MWh}$ \\
(based on 2.8 TWh annual CAP Navajo NG power use) & $\$ 24.1 \mathrm{M}$
\end{tabular}


Table 4-15. Increases in the CAP Pumping Energy Charge under the SCR plus Baghouse \& Sorbent Injection Installation Scenario

\begin{tabular}{|l|c|c|}
\hline & Low & High \\
\hline Increase in CAP pumping energy charge & & \\
\hline Total increase in CAWCD's annual power costs & $\$ 24.1 \mathrm{M}$ & $\$ 26.4 \mathrm{M}$ \\
\hline Total water deliveries in 2011 (in AF) & $1.55 \mathrm{M}$ & $1.55 \mathrm{M}$ \\
\hline Increase in CAP pumping energy charge per AF & $\$ 15.55 / \mathrm{AF}$ & \$17.03/AF \\
\hline
\end{tabular}

Table 4-16. Increase in CAP Water Rate Components Under the SCR plus Baghouse \& Sorbent Injection Scenario (\$/AF)

\begin{tabular}{|l|c|c|c|}
\hline Water rate components (\$ per AF) & Base Rate & Low & High \\
\hline CAP system capital charge & 15 & 15 & 15 \\
\hline Fixed OM\&R for CAP system charge & 69 & 69 & 69 \\
\hline Pumping energy charge & 53 & 69 & 70 \\
\hline
\end{tabular}

Table 4-17. Increase in CAP Water Rates under the Low Cost SCR plus Baghouse \& Sorbent Injection Installation Scenario

\begin{tabular}{|c|c|c|c|}
\hline Sectors & Base Rate & $\begin{array}{c}\text { Low SCR } \\
\text { Rate }\end{array}$ & $\%$ Increase \\
\hline \multicolumn{4}{|l|}{ M \& I users (\$ per AF) } \\
\hline Long-term Subcontract & 122 & 138 & $13 \%$ \\
\hline Non-Subcontract & 137 & 153 & $11 \%$ \\
\hline Recharge & 137 & 153 & $11 \%$ \\
\hline AWBA Interstate Recharge & 167 & 183 & $9 \%$ \\
\hline Federal/Indian users (\$ per AF) & 53 & 69 & $29 \%$ \\
\hline Agricultural users (\$ per AF) & 53 & 69 & $29 \%$ \\
\hline
\end{tabular}

over base water rates), while M\&I CAP water users will also see substantial increases in CAP water rates (a 11 to $14 \%$ increase over base water rates).

Table 4-18 shows how increases in the pumping energy charge would impact CAP water rates under the high cost SCR plus BH\&SI installation scenario.

As shown in Table 4-18, a $\$ 17$ per AF increase in the pumping energy charge will result in Indian tribes and agricultural CAP water customers experiencing the largest proportional increase in CAP water rates (a 32\% increase over base water rates), M\&I CAP water users will also see substantial increases in CAP water rates (a 10 to $14 \%$ increase over base water rates).

\section{Impact of SCR plus baghouse \& sorbent injection installation on Development Fund revenues}

Table 4- 8 shows that under the 2011 base case scenario, CAWCD's annual payment toward its $\$ 55$ million CAP repayment obligation would be $\$ 20$ million. Neither the low nor high cost SCR plus BH\&SI installation scenario would alter the value of the Navajo GS surplus power, resulting in no change in CAWCD's annual payment from the 2011 base case under the SCR installation scenarios. 
Table 4-18. Increase in CAP Water Rates Under the High Cost SCR plus Baghouse \& Sorbent Injection Installation Scenario

\begin{tabular}{|l|c|c|c|}
\hline Sectors & Base Rate & $\begin{array}{c}\text { Low SCR } \\
\text { Rate }\end{array}$ & \% Increase \\
\hline M \& I users (\$ per AF) & & & \\
Long-term Subcontract & 122 & 139 & $14 \%$ \\
Non-Subcontract & 137 & 154 & $12 \%$ \\
Recharge & 137 & 154 & $12 \%$ \\
AWBA Interstate Recharge & 167 & 184 & $10 \%$ \\
\hline Federal/Indian users (\$ per AF) & 53 & 70 & $32 \%$ \\
\hline Agricultural users (\$ per AF) & 53 & 70 & $32 \%$ \\
\hline
\end{tabular}

\subsubsection{Navajo GS Shutdown Scenario}

In the event of a Navajo GS shutdown, CAWCD will have to purchase replacement power to operate the CAP system pumps. NREL modeled the cost of purchasing power on the open power markets in the event of a Navajo GS shutdown, developing a low price and high price for power. Chapter 2 explains the methodology behind these estimates. Under the low price scenario, the market price for power would be $\$ 32.44$ per MWh. ${ }^{15}$ Under a high price scenario, the market price for power would be $\$ 49.48$ per MWh. Table 4-19 shows how a Navajo GS shutdown would impact CAP pumping power costs under low and high power price scenarios.

Under a low market price scenario, Table 4-19 shows that CAWCD would see its CAP pumping power costs increase by $\$ 6.8$ million, an $8 \%$ increase over the cost of using Navajo GS power (at $\$ 30$ per MWh). If CAWCD purchased replacement power under a high market power price scenario, the increase in CAP pumping power costs would be $\$ 54.5$ million, a $64 \%$ increase over the cost of using Navajo GS power. ${ }^{16}$

15 The low power market price $(\$ 32.44)$ used in the shutdown scenario is higher than market power price used to determine the net value of Navajo GS surplus revenue in the base case, SCR, and SCR plus BH\&SI scenarios (\$27.25) because the Navajo GS shutdown scenario involves the purchase of replacement power for CAP pumping, which would include the purchase of off-peak and on-peak power. The Navajo GS surplus power sold under the other scenarios would be primarily off-peak power, which has a lower market price than on-peak power.

16 The $\$ 6.8$ million increase in CAWCD pumping energy cost is derived by multiplying the $\$ 2.43$ per MWh by the $2,800,000 \mathrm{MWh}$ of Navajo GS power used by CAP each year. The $\$ 54.5$ million increase in CAWCD pumping energy cost is derived by multiplying the $\$ 19.46$ per MWh by the $2,800,000$ MWh of Navajo GS power used by CAP each year.

\section{Impact of Navajo GS shutdown on CAP water rates}

An increase in CAWCD power costs due to the purchase of replacement market power would impact CAP water rates by increasing the pumping energy charge for CAP water users. In addition, CAWCD will likely have to recover a significant increase in the annual payment toward its CAP repayment obligation, as there would no longer be any revenue flowing into the Development Fund from the sale of Navajo GS surplus power. Table 4-20 shows the impact of a Navajo GS shutdown scenario on the CAP pumping energy charge and CAP repayment recovery charge.

Table 4-20 shows that under a low power market price Navajo GS shutdown scenario the total increase in CAWCD's CAP pumping energy costs (\$6.8 million) would result in a $\$ 4$ per AF in the pumping energy charge for CAP water customers. Under a high power market price scenario, the total increase in CAWCD's CAP pumping energy costs ( $\$ 54.5$ million) would result in a $\$ 35$ per AF increase in the pumping energy charge for CAP water customers.

Table 4-20 also shows that the CAP repayment recovery charge associated with Navajo GS shutdown would be $\$ 29$ per AF assessed to M\&I CAP water customers. This significant charge reflects the loss of all revenues flowing into the Development Fund from the sale of Navajo GS surplus power through the SRP contract.

Table 4-21 shows the impact of the increased Navajo GS power costs on 2011 CAP water rate components. As indicated previously, CAP water rate components apply to different sectors and uses, resulting in differing 
Table 4-19. Impact of a Navajo GS Shutdown Scenario on CAP Pumping Power Costs

\begin{tabular}{|l|c|c|}
\hline Cost of Navajo GS power & $\begin{array}{c}\text { Low power } \\
\text { price }\end{array}$ & $\begin{array}{c}\text { High power } \\
\text { price }\end{array}$ \\
\hline Market price for power & $\$ 30.00 / \mathrm{MWh}$ & $\$ 30.00 / \mathrm{MWh}$ \\
\hline Increase in costs over Navajo GS power costs & $\$ 32.44 / \mathrm{MWh}$ & $\$ 49.48 / \mathrm{MWh}$ \\
\hline Total increase in CAP power costs over Navajo GS & $\$ 2.43 / \mathrm{MWh}$ & $\$ 19.46 / \mathrm{MWh}$ \\
\hline \% increase in CAP power costs over Navajo GS & $\$ 6.8 \mathrm{M}$ & $\$ 54.5 \mathrm{M}$ \\
\hline
\end{tabular}

Table 4-20. Increases in the CAP Pumping Energy Charge and CAP Repayment Recovery Charge Under the Navajo GS Shutdown Scenario

\section{Low Power High Power Price Price}

Increase in CAP pumping energy charge

\begin{tabular}{|l|c|c|}
\hline Total increase in annual CAP pumping energy costs & $\$ 6.8 \mathrm{M}$ & $\$ 54.5 \mathrm{M}$ \\
\hline Total water deliveries in 2011 (in AF) & $1.55 \mathrm{M}$ & $1.55 \mathrm{M}$ \\
\hline Increase in CAP pumping energy charge per AF & $\$ 4.39 \mathrm{AF}$ & $\$ 35.16 / \mathrm{AF}$ \\
\hline
\end{tabular}

CAP repayment recovery charge

\begin{tabular}{|l|c|c|}
\hline Base case CAWCD payment to meet \$55M CAP repayment obligation & $\$ 20.0 \mathrm{M}$ & $\$ 20.0 \mathrm{M}$ \\
\hline Shutdown CAWCD payment to meet \$55M CAP repayment obligation & $\$ 45.0 \mathrm{M}$ & $\$ 45.0 \mathrm{M}$ \\
\hline Increase in CAWCD payment to meet \$55M CAP repayment obligation & $\$ 25.0 \mathrm{M}$ & $\$ 25.0 \mathrm{M}$ \\
\hline Total 2011 M\&I CAP water deliveries (in AF) & $0.86 \mathrm{M}$ & $0.86 \mathrm{M}$ \\
\hline CAP repayment recovery charge to recover increase in payment per AF & $\$ 28.94 / \mathrm{AF}$ & $\$ 28.94 / \mathrm{AF}$
\end{tabular}

CAP water rates for each sector. Table 4-22 shows how an increase in the pumping energy charge and CAP repayment recovery charge due to a Navajo GS shutdown would impact each sector of users under low power market price conditions.

As shown in Table 4-22, M\&I CAP water customer would experience a greater proportional increase in CAP water rates than would Indian tribes and agricultural under low power market price conditions. The large increase in M\&I CAP water rates is due to the CAP repayment recovery charge, which would likely be required to recover CAWCD's increased payment into Development Fund due to the loss of Navajo GS surplus power sales revenues.

Table 4-23 shows CAP water rate impacts from a Navajo GS shutdown scenario under high power market conditions. As shown in Table 4-23 Indian and Agricultural CAP water users would experience the greatest proportional increase (66\%) in water rates due to a Navajo GS shutdown under high power market price conditions. M\&I CAP water users would also experience a substantial increase (38 to $52 \%$ ) in CAP water rates. Replacing Navajo GS power required for CAP pumps with market power under high price conditions would dramatically increase water rates.

\section{Impact of SCR installation on Development Fund revenues}

Under the Navajo GS shutdown scenario shown in Table 4-20, CAWCD's annual payment into the Development Fund would be $\$ 45$ million to compensate for the loss of revenues from the sale of Navajo GS surplus power. This $\$ 45$ million annual payment would be $\$ 25$ million greater than the $\$ 20$ million annual payment made under the base case scenario. 
Table 4-21. Increase in CAP Water Rate Components Under the Navajo GS Shutdown Scenario (\$/AF)

\begin{tabular}{|l|c|c|c|}
\hline Water rate components & Base Rate & $\begin{array}{c}\text { Low power } \\
\text { price rate }\end{array}$ & $\begin{array}{c}\text { High power } \\
\text { price rate }\end{array}$ \\
\hline Capital charge & 15 & 15 & 15 \\
\hline Fixed OM\&R & 69 & 69 & 69 \\
\hline Pumping energy charge & 53 & 57 & 88 \\
\hline CAP repayment recovery charge & - & 29 & 29 \\
\hline
\end{tabular}

Table 4-22. Increase in CAP Water Rates Under the Navajo GS Shutdown Scenario (Low Power Price)

\begin{tabular}{|c|c|c|c|}
\hline Sectors & Base Rate & $\begin{array}{c}\text { Low power } \\
\text { price rate }\end{array}$ & $\%$ Increase \\
\hline \multicolumn{4}{|l|}{ M \& I users (\$ per AF) } \\
\hline Long-term Subcontract & 122 & 155 & $27 \%$ \\
\hline Non-Subcontract & 137 & 170 & $24 \%$ \\
\hline Recharge & 137 & 170 & $24 \%$ \\
\hline AWBA Interstate Recharge & 167 & 200 & $20 \%$ \\
\hline Federal/Indian users (\$ per AF) & 53 & 57 & $8 \%$ \\
\hline Agricultural users (\$ per AF) & 53 & 57 & $8 \%$ \\
\hline
\end{tabular}

Table 4-23. Increase in CAP Water Rates Under the Navajo GS Shutdown Scenario (High Power Price)

\begin{tabular}{|c|c|c|c|}
\hline Sectors & Base Rate & $\begin{array}{c}\text { Low power } \\
\text { price rate }\end{array}$ & $\%$ Increase \\
\hline \multicolumn{4}{|l|}{ M \& I users (\$ per AF) } \\
\hline Long-term Subcontract & 122 & 186 & $52 \%$ \\
\hline Non-Subcontract & 137 & 201 & $47 \%$ \\
\hline Recharge & 137 & 201 & $47 \%$ \\
\hline AWBA Interstate Recharge & 167 & 231 & $38 \%$ \\
\hline Federal/Indian users (\$ per AF) & 53 & 88 & $66 \%$ \\
\hline Agricultural users (\$ per AF) & 53 & 88 & $66 \%$ \\
\hline
\end{tabular}

\subsection{Summary}

This chapter of the report examined the potential impacts of the installation of BART emissions controls at Navajo GS or a Navajo GS shutdown on Development Fund revenues and CAP water rates. The analysis looked at four separate Navajo GS scenarios - base case, SCR installation, SCR plus BH\&SI installation, and Navajo GS shutdown.

\subsubsection{Impacts on CAP water rates}

An increase in Navajo GS power costs will affect the water rates that CAWCD charges CAP water users. The installation of Navajo GS BART emission controls or a Navajo GS shutdown would lead to an increase in the pumping energy charges billed to all CAP water users. It could also require CAWCD to establish a mechanism to recover additional payments made toward its CAP 
repayment obligation due to lost Navajo GS surplus power sales revenues.

Under the scenario analysis, M\&I users will bear the cost of the increase in the CAP pumping energy charge, as well as the payment of the CAP repayment recovery charge. Indian and agricultural users will only pay the increase in the CAP pumping energy charge. Table 4-24 summarizes the impacts of SCR installation, SCR plus baghouse installation, and Navajo GS shutdown on CAP water rates, showing both projected CAP water rates under each scenario. Table 4-25 shows the percentage increase in water rates over 2011 base rates.

Table 4-24 shows that under a SCR installation scenario all CAP water customers will see rates increase by $\$ 7$ to 9 per AF. Under a SCR plus BH\&SI installation scenario, all CAP water customers will pay an additional $\$ 16$ to 17 per AF. In the event of a Navajo GS shutdown scenario, the price of replacement power will dictate CAP water rate increase. Under a low market power price scenario, M\&I users would see CAP water rates increase by $\$ 33$ per AF, while Indian and agricultural users will see rate increases of $\$ 4$ per AF. A high market power price scenario would result in M\&I water rate increases of $\$ 64$ per AF, while Indian and agricultural CAP customers would see water rates increase by $\$ 35$ per AF.

As shown in Table 4-25, Indian and agricultural CAP water users would generally experience a greater proportional increases in CAP water rates than M\&I customers, except under a Navajo GS shutdown scenario where low cost replacement power is available on the open power markets.

\subsubsection{Development Fund impacts}

As illustrated in previous sections of this chapter, SCR installations or a Navajo GS shutdown would impact Development Fund revenues credited toward CAWCD's annual \$55 million CAP repayment obligation. Any increase Navajo GS power costs would result in less revenue generated through the sale of Navajo GS surplus power on the open market, reducing the amount credited against CAWCD's annual payment into the Development Fund.

The chapter examined the impact of three scenarios on CAWCD's annual payment. Under the SCR and SCR plus BH\&SI installation scenarios, CAWCD's annual payment would remain \$20 million. A Navajo GS shutdown would result in a situation where the Development Fund would no longer receive revenues from the SRP contract, leaving CAWCD with an annual payment of $\$ 45$ million, which is substantially higher than CAWCD's 2009 payment and base case annual payment.

Development Fund disbursement obligations to Arizona Indian tribes established under Settlements Act should remain largely unaffected by SCR and SCR plus BH\&SI installation at Navajo GS or a Navajo GS shutdown. As long as CAWCD continues to meet its $\$ 55$ million annual CAP repayment obligation, additional costs associated with the installation of Navajo GS BART emissions

Table 4-24. Increase in CAP Water Rates Under Various Navajo GS Scenarios (\$/AF)

\begin{tabular}{|l|c|c|c|c|c|}
\hline \multicolumn{1}{|l|}{} & \multicolumn{2}{c|}{ Navajo GS shutdown } \\
\hline & $\begin{array}{c}\text { Base } \\
\text { Rate }\end{array}$ & $\begin{array}{c}\text { SCR } \\
\text { rate }\end{array}$ & $\begin{array}{c}\text { SCR plus } \\
\text { BH\&SI } \\
\text { rate }\end{array}$ & $\begin{array}{c}\text { Low } \\
\text { power } \\
\text { price rate }\end{array}$ & $\begin{array}{c}\text { High } \\
\text { power } \\
\text { price rate }\end{array}$ \\
\hline $\begin{array}{l}\text { M \& I users (\$ per AF) } \\
\text { Long-term Subcontract }\end{array}$ & 122 & $129-131$ & $138-139$ & 155 & 186 \\
$\begin{array}{l}\text { Non-Subcontract } \\
\text { Recharge }\end{array}$ & 137 & $144-146$ & $153-154$ & 170 & 201 \\
AWBA Interstate Recharge & 137 & $144-146$ & $153-154$ & 170 & 201 \\
\hline Federal/Indian users (\$ per AF) & 167 & $174-1476$ & $183-184$ & 200 & 231 \\
\hline \begin{tabular}{l} 
Agricultural users (\$ per AF) \\
\hline
\end{tabular} & 53 & $60-62$ & $69-70$ & 57 & 88 \\
\hline
\end{tabular}


Table 4-25. Percentage Increase in CAP Water Rates Under Various Navajo GS Scenarios (\$/AF)

\begin{tabular}{|l|l|l|c|c|c|}
\hline \multicolumn{2}{|c|}{} & \multicolumn{3}{|c|}{ Navajo GS shutdown } \\
\hline & $\begin{array}{c}\text { Base } \\
\text { Rate }\end{array}$ & SCR rate & $\begin{array}{c}\text { SCR plus } \\
\text { BH\&SI } \\
\text { rate }\end{array}$ & $\begin{array}{c}\text { Low } \\
\text { power } \\
\text { price rate }\end{array}$ & $\begin{array}{c}\text { High } \\
\text { power } \\
\text { price rate }\end{array}$ \\
\hline
\end{tabular}

M \& I users (\$ per AF)

Long-term Subcontract

Non-Subcontract

Recharge

AWBA Interstate Recharge

Federal/Indian users (\$ per AF)

Agricultural users (\$ per AF)

\begin{tabular}{|l|l|l|l|}
\hline $6 \%-7 \%$ & $13 \%-14 \%$ & $27 \%$ & $52 \%$ \\
\hline $5 \%-6 \%$ & $11 \%-12 \%$ & $24 \%$ & $47 \%$ \\
\hline $5 \%-6 \%$ & $11 \%-12 \%$ & $24 \%$ & $47 \%$ \\
\hline $4 \%-5 \%$ & $9 \%-10 \%$ & $20 \%$ & $38 \%$ \\
\hline $13 \%-16 \%$ & $29 \%-32 \%$ & $8 \%$ & $66 \%$ \\
\hline $13 \%-16 \%$ & $29 \%-32 \%$ & $8 \%$ & $66 \%$ \\
\hline
\end{tabular}

controls or a Navajo GS shutdown should not impact the Development Fund's ability to meet the first cascade of payment priorities. The increase cost of Navajo GS power would decrease the likelihood that Navajo GS surplus power sales would contribute enough revenue to completely offset and exceed CAWCD's $\$ 55$ million annual CAP repayment obligation and provide funds for

Appendix A: First Cascade of the Settlements Act Payment Priorities



Appendix B: Second Cascade of the Settlements Act Payment Priorities

the second cascade of payment priorities. However, even in the absence of the installation of BART emissions controls at Navajo GS, the second cascade of priorities under the Settlements Act will only receive Development Fund revenues when market power prices are substantially higher than current power market prices.

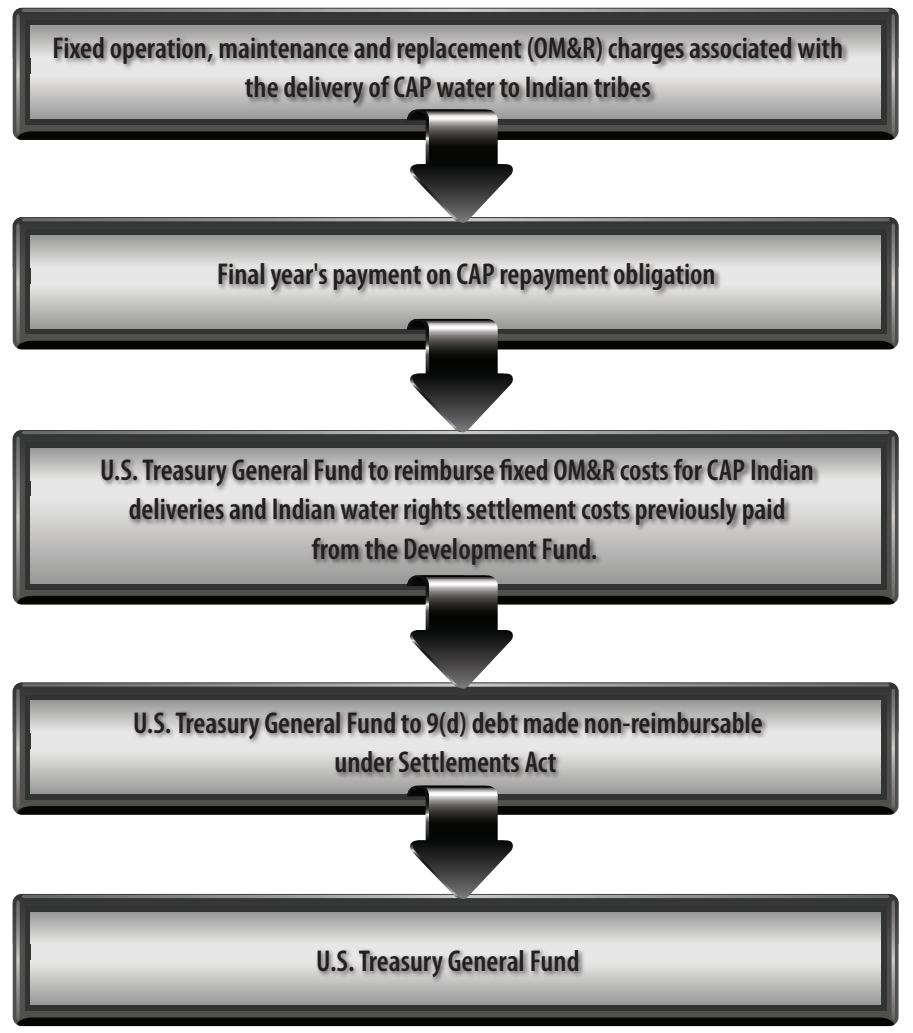




\section{Assessment of Visibility Science}

This chapter summarizes the state of the science with respect to the impacts of the Navajo Generating Station (Navajo GS) on visibility in several national parks and wilderness areas designated for visibility protection. It begins with a brief discussion of the statutory and regulatory basis for visibility protection of these lands under the Clean Air Act (CAA), and the regulatory basis for applicability of the regional haze BART requirements to Navajo GS, then examines the modeling and monitoring used by parties to the proceeding.

\subsection{Regulatory Framework}

Under the 1977 CAA amendments, Congress mandated the Prevention of Significant Deterioration of Air Quality (PSD) construction permitting program for stationary emissions sources. The purpose was to prevent degradation of air quality in Class I, Class II, and Class III areas. These area designations apply only where the air quality is better than the pollutant concentration limits established under the National Ambient Air Quality Standards (NAAQS).

There have been no Class III areas designated to date, and therefore, except for NAAQS nonattainment areas (established on a pollutant-by-pollutant basis), the nation is divided into only Class II and Class I areas. The Class I areas are certain national parks and wilderness areas of a certain size as defined within the CAA ("mandatory" Class I areas), plus any areas specially redesignated as Class I after the 1977 CAA amendments.

In addition to other types of protections required under the CAA, mandatory Class I areas nationwide generally have been designated for special visibility protection. The only exceptions are the Rainbow Lake Wilderness Area in Wisconsin and the Bradwell Bay Wilderness Area in Florida (Code of Federal Regulations, 40 CFR 81, Subpart D).

Navajo GS is located approximately 5 miles southeast of the Glen Canyon Dam, which created Lake Powell, as shown in Figure 5-1. Navajo GS is located within 300 kilometers $(\mathrm{km})$ of eleven (11) Class I national parks and wilderness areas. As Figure 5-1 shows, Class I areas surround the power plant in all four quadrants of the compass. Thus, it is important to consider the Navajo GS's potential visibility impacts on not only the Grand Canyon National Park, which is the nearest and most prominent Class I area, but on all these Class I areas. The CAA requires EPA to develop rules to implement a program of visibility protection, which would require the application of Best Available Retrofit Technology (BART) to certain facilities. The primary focus of these rules was the prevention and remediation of regional haze impacts on Class I areas by large emissions sources.

On July 6, 2005, the EPA published final amendments to its 1999 regional haze rules in the Federal Register, including 40 CFR 51, Appendix Y, thus finalizing guidance for BART determinations (70 FR 39104-39172). The regional haze rules establish guidelines that States may follow in setting BART emissions limits on emission sources that are:

1. BART-eligible, based on their having begun operation after August 8, 1962, and being "in existence" before August 8, 1977, which includes sources that had received a construction permit by the latter date

2. Sources that "may reasonably be anticipated to cause or contribute" to visibility impairment in any Class I area.

Under the EPA's BART guidelines, air quality modeling is used to determine whether a given source is potentially causing or contributing to visibility impairment in any Class I area. The CALMET/CALPUFF modeling system is air quality modeling software, recommended by EPA ${ }^{1}$, which is often used to make the assessments of visibility impacts for BART-subject facilities. Generally, EPA's BART rules state that any BART-eligible source, as defined above, should be subjected to a full BART control technology analysis to determine appropriate emissions controls, if the modeled visibility impact at any Class I area exceeds a threshold of 0.5 deciviews (dv).

A deciview is a unit or metric for haziness that was developed to provide a measure of visibility, such that a given change in deciviews would have an approximately

\footnotetext{
1 The final BART Guidelines expressly identify and endorse CALPUFF as an appropriate (but not necessarily exclusive) modeling tool for assessing source impacts on visibility. See 70 Fed. Reg. at 39,122.
} 


\section{PSD Class I Areas within $300 \mathrm{~km}$ of the Navajo Generating Station}

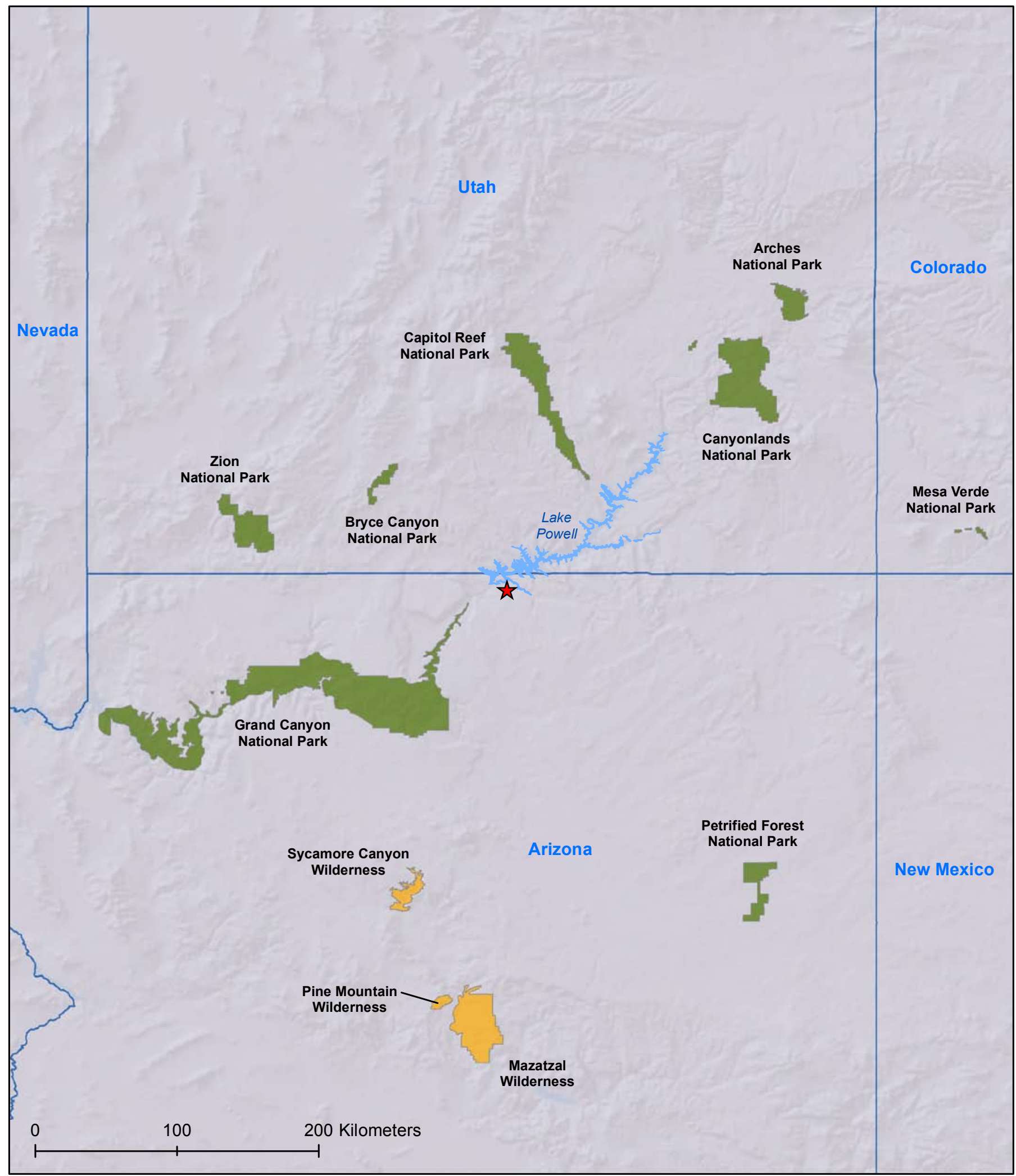

\section{This map was produced by the National

NPS Class I Areas USFS Class I Areas

Figure 5-1. Navajo GS location relative to PSD Class I areas within $300 \mathrm{~km}$ 
equivalent human perceptibility, whether one was observing a vista on a hazy day or a clear day. The deciview value is proportional to the natural logarithm of atmospheric light extinction (bext), where the light extinction is expressed as the inverse of a million meters $\left(\mathrm{Mm}^{-1}\right)$. The deciview value is calculated as follows:

$$
\mathrm{dv}=10 * \ln \left(\mathrm{b}_{\mathrm{ext}} / 10\right)
$$

Because metrics like deciviews and atmospheric light extinction are difficult to conceptualize, Figure 5-2 shows the relationship between light extinction, deciviews, and visual range. ${ }^{2}$ Visual range is a more familiar metric to the general public, as it is commonly used to describe weather conditions involving reduced visibility during precipitation events, dust storms, or fog. Also, it is worth noting that theoretically, in an unpolluted atmosphere at high elevation, light extinction can drop to less than $10 \mathrm{Mm}-1$, making the $\mathrm{dv}$ value drop below zero, as can be seen from Figure 5-2. At the elevation of the Colorado plateau, the best possible visual range (horizontally) is approximately $400 \mathrm{~km}$, corresponding to a value of zero dv or $10 \mathrm{Mm}$ 1. Such optimum visibility occurs when light is scattered only by air molecules, known as Raleigh scattering.

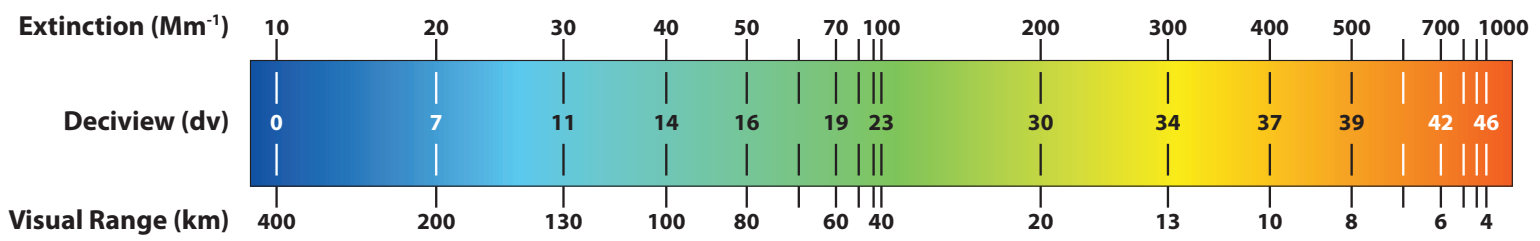

Figure 5-2. Relationship between atmospheric light extinction, deciviews, and visual range given day. control scenarios for the Navajo GS.

same discussion, EPA summarizes comments on the proposed Regional Haze rule, one of which cites a more recent study that found a much higher threshold for the difference in $\mathrm{dv}$ for human perceptibility, with a minimum value of between 1.5 and $2 \mathrm{dv}^{4}$ The latter study also found that a deciview was not a consistent measure of human perceptibility under a range of natural visibility conditions and observer-vista distances, but rather, gave consistent results only for observing objects with the same colorfulness and that were located at a distance of from one-quarter to one-half the observed visual range on a

Despite some possible shortcomings in the deciview metric, EPA and state agencies use it in applying regional haze regulations to emissions sources. This report uses deciviews as a relative (not absolute) modeled measure of the potential visibility impacts of various emissions

\subsubsection{Applicability of BART to the Navajo GS}

The regional haze BART regulations apply to Navajo GS because the facility meets the two qualifications listed in the rules. First, the facility is BART-eligible because it was in existence on August 7, 1977 and had not been in operation for more than

The human perceptibility of a given change in visibility measured in deciviews is a matter of some debate. The EPA, in its Regional Haze Regulations and Guidelines for BART, cites a 1991 report from the National Acid Deposition Assessment Program, which stated that a 5\% change in light extinction, corresponding to an approximate $0.5 \mathrm{dv}$ change in visibility, was approximately at the threshold of human perception. ${ }^{3}$ However, in the

\footnotetext{
2 Malm, William C., 1999. Introduction to Visibility, Air Resources Division, National Park Service, Cooperative Institute for Research in the Atmosphere (CIRA), NPS Visibility Program, Colorado State University, Fort Collins, CO 80523.

3 EPA 2005, Final Rule, Regional Haze Regulations and Guidelines for Best Available Retrofit Technology (BART) Determinations. See 70 Fed. Reg. at 39,119 .
}

15 years prior to that date. Second, dispersion modeling performed in 2007 predicted that the facility's emissions at the time would have a visibility impact of more than 0.5 deciviews at one or more Class I areas. ${ }^{5}$ Based on these two factors, the facility was required to perform a BART analysis and to thereby propose a BART emissions control strategy to EPA.

\footnotetext{
4 Henry, R.C., 2002. Just-Noticeable Differences in Atmospheric Haze, Journal of the Air \& Waste Management Association, 52:1238-1243, October.

5 ENSR/AECOM 2007. BART Analysis for the Navajo Generating Station Units $1-3$, November.
} 
For most power plants in the United States, the regulatory agency with direct oversight on BART matters is the state air quality regulatory agency. However, because Navajo GS is on Native American land (within the Navajo Nation), the jurisdiction for the BART determination rests with the EPA; in this case EPA Region 9 has jurisdiction.

\subsection{Emissions and Visibility Trends for Southwestern States}

This section summarizes sulfur dioxide $\left(\mathrm{SO}_{2}\right)$ and nitrogen oxides $\left(\mathrm{NO}_{\mathrm{x}}\right)$ emissions trends in the southwestern states of New Mexico, Colorado, Utah, Arizona, and Nevada, and the Pacific Coast state of California over the past decade. This section also provides emissions data for the past 15 years for Navajo GS and for the Mohave Generating Station (MGS), a coal-fired plant near the Arizona-Nevada border in Laughlin, Nevada, that ceased operation in 2005. MGS, which was about $70 \%$ of the size of Navajo GS in terms of operating capacity, was located approximately 50 miles southwest of the western end of the Grand Canyon.

This section also summarizes visibility trends based on data collected at various Class I areas in the region, as contained in the IMPROVE (Interagency Monitoring of Protected Visual Environments) database maintained at Colorado State University. ${ }^{6}$ The purpose of these data summaries is to help provide the reader an understanding of progress made to date in reducing emissions of visible pollutants in the region.

\subsubsection{Regional Emissions Trends}

New Mexico, Colorado, Utah, Arizona, Nevada, and California were selected for this summary because emissions from both industrial facilities and urban areas in this region are most likely to have an effect on visibility in the Class I areas that are within $300 \mathrm{~km}$ of Navajo GS, as depicted in Figure 5-1. Emissions sources in northern Mexico may also have effects on visibility in the region, but reliable emissions data from Mexico were unavailable for this study.

The National Emissions Inventory (NEI) is a comprehensive and detailed estimate of air emissions prepared every three years by the EPA. Table 5-1 is a summary of annual $\mathrm{SO}_{2}$ and $\mathrm{NO}_{\mathrm{x}}$ emissions from the NEI database $^{7}$ for 2002, 2005, and 2008, for each of the states listed above, plus added emissions from the two large coal-fired power plants within the Navajo Nation Navajo GS and the Four Corners Power Plant (FCPP). The Table 5-1 state-by-state totals do not include emissions from other tribal land sources. Therefore, the totals in Table 5-1 for Arizona include the NEI totals plus the added Navajo GS emissions from the EPA's Clean Air Markets Division (CAMD) database. ${ }^{8}$ The totals in Table 5-1 for New Mexico include the NEI totals plus the Four Corners Power Plant (located west of Farmington, New Mexico) emissions from the CAMD database.

While the data in Table 5-1 show only slight decreases in total $\mathrm{SO}_{2}$ and $\mathrm{NO}_{\mathrm{x}}$ emissions from the several states listed from 2002 to 2005 , there were much more significant decreases in total emissions between 2005 and 2008. The relatively large percentage drop in $\mathrm{SO}_{2}$ emissions was largely a function of much lower diesel fuel sulfur limits imposed by EPA for on-road and non-road engines in 2007. The significant decrease in $\mathrm{NO}_{\mathrm{x}}$ emissions from 2005 to 2008 was largely due to tighter tailpipe emissions standards for new on-road and non-road vehicle engines.

\subsubsection{Power Plant Emissions Trends}

Regionally, the emissions of $\mathrm{SO}_{2}$ and $\mathrm{NO}_{x}$ have been trending downward. There have also been significant reductions, however, in emissions from large power plants (MGS and Navajo GS) near Grand Canyon National Park (GCNP). These specific reductions have been studied for their visibility impacts on GCNP and other Class I areas in the region, and these studies are discussed in Section 5.4 .

Figures 5-3 and 5-4 show the trends in annual $\mathrm{SO}_{2}$ and $\mathrm{NO}_{\mathrm{x}}$ emissions from Navajo GS and MGS over the 14 years from 1997 through 2010. This period was selected because it stretches back to just before the first $\mathrm{SO}_{2}$ scrubber retrofits began on the three units at Navajo GS. As shown on these charts, there are no emissions from MGS after 2005 because that plant was shut down permanently late that year.

\footnotetext{
7 http://www.epa.gov/ttn/chief/eiinformation.html

8 http://camddataandmaps.epa.gov/gdm/index.cfm
} 
Table 5-1. $\mathrm{SO}_{2}$ and $\mathrm{NO}_{\mathrm{x}}$ Emissions Trends from 2002-2008 in Southwestern United States

\begin{tabular}{|c|c|c|c|}
\hline \multicolumn{4}{|c|}{$\mathrm{SO}_{2}$ Annual Emissions (tons per year) } \\
\hline State & 2002 & 2005 & 2008 \\
\hline California & 171,943 & 223,312 & 47,979 \\
\hline Nevada & 66,640 & 72,398 & 16,814 \\
\hline Arizona & 113,762 & 93,653 & 87,860 \\
\hline Utah & 51,970 & 52,496 & 30,437 \\
\hline New Mexico & 111,562 & 60,092 & 34,250 \\
\hline Colorado & 118,419 & 80,052 & 67,394 \\
\hline Totals & 634,296 & 582,003 & 284,734 \\
\hline \multicolumn{4}{|c|}{ NO $O_{x}$ Annual Emissions (tons per year) } \\
\hline State & 2002 & 2005 & 2008 \\
\hline California & $1,295,794$ & $1,419,014$ & $1,076,603$ \\
\hline Nevada & 121,713 & 132,998 & 83,930 \\
\hline Arizona & 377,460 & 334,958 & 273,777 \\
\hline Utah & 203,787 & 187,030 & 166,129 \\
\hline New Mexico & 312,488 & 279,142 & 183,473 \\
\hline Colorado & 319,555 & 257,536 & 248,144 \\
\hline Totals & $2,630,797$ & $2,610,678$ & $2,032,056$ \\
\hline
\end{tabular}

Source: National Emissions Inventory

As shown in Figure 5-3, Navajo GS and MGS together were emitting more than 100,000 tons/year of $\mathrm{SO}_{2}$ in 1997. The scrubber installations on the three Navajo GS units took place between 1997 and 2000, decreasing the plant's $\mathrm{SO}_{2}$ emissions by more than $90 \%$. The shutdown of MGS at the end of 2005 reduced the region's $\mathrm{SO}_{2}$ emissions by more than 40,000 tons/year, on average. Consequently, total $\mathrm{SO}_{2}$ emissions of the coal-fired power plants nearest GCNP are now less than 5\% of what they were in 1997, or roughly 5,000 tons per year from Navajo GS. This reduction was expected to yield significant improvement in visibility metrics at GCNP and other regional Class I areas because fine sulfate particles formed from $\mathrm{SO}_{2}$ were expected to be the primary contributor to regional haze in the area. ${ }^{9}$

As a result of the emissions decreases, $\mathrm{SO}_{2}$ emissions from Navajo GS are unlikely to be a focus for current BART

\footnotetext{
9 Grand Canyon Visibility Transport Commission, Recommendations for Improving Western Vistas, Jun10, 1996
}

proceeding. To date, the primary focus has been on $\mathrm{NO}_{x}$ emissions.

The $\mathrm{NO}_{\mathrm{x}}$ emissions trends from MGS and Navajo GS are shown in Figure 5-4. The Navajo GS NO emissions had been averaging approximately 35,000 tons/year through 2008, but then began dropping each subsequent year as low-NO burners (LNB) and separated overfire air (SOFA) technology was installed, one unit per year, in 2009, 2010, and 2011. The Unit $1 \mathrm{LNB} / \mathrm{SOFA}$ retrofit was the last to be completed, earlier in 2011. The emission rates achieved on Units 2 and 3 in the first half of 2011 suggest that the Navajo GS units with operating LNB/SOFA systems will emit slightly more than $0.21 \mathrm{lb} / \mathrm{MMBtu} .{ }^{10}$ This rate would result in annual plant-total $\mathrm{NO}_{\mathrm{x}}$ emissions, based on historical plant usage, in the neighborhood of 20,000 tons/year. This implementation of LNB/SOFA technology should yield approximately a $42 \%$ reduction (a decrease of

10 http:/camddataandmaps.epa.gov/gdm/index.cfm 


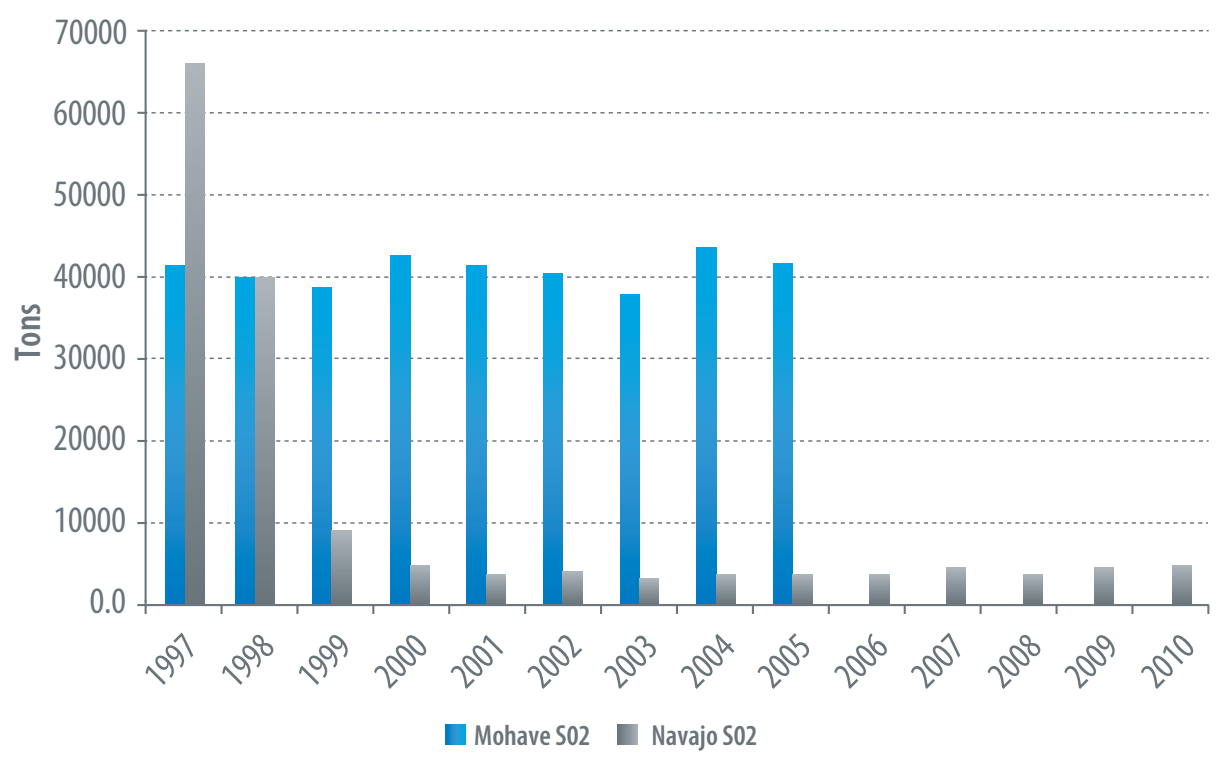

Figure 5-3. S02 emission trends for large power plants in the vicinity of the GCNP



Figure 5-4. NOx emission trends for large power plants in the vicinity of the GCNP
- How rapidly will nitrate particles form with increasing downwind distance?

- How much conversion to fine particulate nitrate will occur by the time emissions are transported over Class I areas in the Southwest?

The focus of power plant emissions controls already installed in the western United States has primarily been on $\mathrm{SO}_{2}$ emissions, which produce sulfate particles. $\mathrm{SO}_{2}$ has been the initial focus because sulfate has a larger impact on regional haze compared to nitrate. In the southwestern states in particular, sulfate is an even greater concern compared to nitrate, because $\mathrm{SO}_{2}$ tends to form sulfate more readily at higher temperatures. Sulfate formation appears to still be dominant over nitrate formation in winter months, but just not as dominant as during the summer (see discussion and chart in Section 5.4). Thus, for example, measured nitrate levels tend to be greater in the northern states, and greater in general in winter (or late fall through early spring) months as compared to summer months. In the southwestern region potentially affected by emissions from Navajo GS, the winter months are expected to be of greatest concern for nitrate formation. approximately 15,000 tons) in $\mathrm{NO}_{\mathrm{x}}$ emissions compared to historical Navajo GS emissions.

Some of the region-wide $\mathrm{NO}_{\mathrm{x}}$ emissions, whether from power plants, other industrial sources, or mobile sources, will eventually form nitrate particles as the emissions are transported downwind. These fine nitrate particles contribute to regional haze. Two of the most significant questions regarding Navajo GS $\mathrm{NO}_{\mathrm{x}}$ emissions are:

\subsection{Modeling Studies of Navajo GS Visibility Impacts}

\subsubsection{CALPUFF Model}

Multiple visibility modeling studies have been conducted for Navajo GS since 2007, in response to requirements of the Regional Haze rule. These multiple studies include 
two by consultants for the Salt River Project (SRP) that are summarized in this section ${ }^{11},{ }^{12}$, and a modeling study by the EPA referenced in its advance notice of proposed rulemaking (ANPR) regarding BART for both Navajo GS and the Four Corners Power Plant. ${ }^{13}$ All of the Navajo GS studies discussed here used the CALPUFF modeling system, although the CALPUFF model versions differ and the input data differ somewhat in each study.

The CALPUFF model is considered by EPA to be a screening tool for visibility assessment. The model is not designed to account for a myriad of possible atmospheric chemical and photochemical reactions of pollutants, natural atmospheric gases, and particles, but rather deals with relatively simple chemical reactions that transform $\mathrm{SO}_{2}$ and $\mathrm{NO}_{x}$ to fine sulfate and nitrate particles. How accurately CALPUFF handles the sulfate and nitrate transformations has been questioned, but as a recognized screening method, EPA considers CALPUFF to be an appropriate tool for comparing alternative control strategies on a single-source basis. ${ }^{14}$

11 ENSR/AECOM 2007. BART Analysis for the Navajo Generating Station Units $1-3$, November.

12 SRP 2011. Visibility Modeling Using Upgraded CALPUFF Model, Submitted for Consideration in Developing Best Available Retrofit Technology Proposal for Navajo Generating Station, February.

13 EPA 2009. Assessment of Anticipated Visibility Improvements at Surrounding Class I Areas and Cost Effectiveness of Best Available Retrofit Technology for Four Corners Power Plant and Navajo Generating Station: Advanced Notice of Proposed Rulemaking, 74 Fed. Reg. 44313

14 EPA 2005, Final Rule, Regional Haze Regulations and Guidelines for Best Available Retrofit Technology (BART) Determinations. See 70 Fed. Reg. at 39,123 .

\subsubsection{Navajo GS Modeling Studies}

The Navajo GS emission control technology scenarios modeled for visibility impacts included installation of LNB/SOFA technology and selective catalytic reduction (SCR) technology together with LNB/SOFA. Because the Navajo GS plant owners have recently voluntarily installed LNB/SOFA on all three Navajo GS units in 2009, 2010, and 2011, the focus of this assessment is on the potential improvement in visibility to be gained by installation of SCR vs. the current LNB/SOFA system. With respect to the existing $\mathrm{SO}_{2}$ control, the wet scrubbers on Navajo GS are essentially doing the best technologically feasible level of control at this time, removing up to $95 \%$ of $\mathrm{SO}_{2}$ and emitting less than $0.06 \mathrm{lb} / \mathrm{MMBtu}$ at the outlet. Direct particulate matter emissions are also effectively controlled with electrostatic precipitators and the wet scrubbers. Table 5-2 provides a summary of some of the key modeling differences between two SRP studies and EPA's study that formed the basis for its August 28, 2009 ANPR. Note that for the 2011 SRP study, CALPUFF Version 6.4 was used. However, EPA does not consider CALPUFF Version 6.4 to be an appropriate tool for BART determination at this time. Although SRP contends that the newer version performs better than CALPUFF Version 5.8, EPA said as recently as August 2011 that the newer CALPUFF version has not been adequately tested and subjected to public review and comment. ${ }^{15}$

\footnotetext{
15 EPA 2011. Approval and Promulgation of Implementation Plans; New Mexico; Federal Implementation Plan for Interstate Transport of Pollution Affecting Visibility and Best Available Retrofit Technology Determination, 76 FR 52388.
}

Table 5-2. Comparison of Modeling Procedures for SRP and EPA Visibility Studies on Navajo GS

\begin{tabular}{|c|c|c|c|}
\hline Modeling Procedure & SRP 2007 & EPA 2009 & SRP 2011 \\
\hline CALPUFF Version No. & & & \\
\hline Background Ammonia (NH3, ppb) & $0.2-1.0^{a}$ & $0.7-1.3(1.0-1.5)^{b}$ & CMAQ est. ${ }^{c}$ \\
\hline Direct SO4 Emissions (Ib/hr) & 13.02 & 11.25 & 13.02 \\
\hline \multicolumn{4}{|c|}{$\begin{array}{l}\text { (a) Varied monthly from } 0.2 \text { in winter to } 1.0 \text { summer. The SRP } 2007 \text { study added to these background NH3 values to account } \\
\text { for estimated NH3 slip associated with SCR option. } \\
\text { (b) Varied monthly from } 0.7 \text { in late winter to } 1.3 \text { in June, except that at Mesa Verde, higher values were used, ranging monthly } \\
\text { from } 1.0 \text { to } 1.5 \mathrm{ppm} \text {. } \\
\text { (c) The modeled NH3 concentrations predicted by the CMAQ model were used. The NPS has commented that the CMAQ } \\
\text { NH3 predictions are at the lower end of the range of limited measurements in western states, which could result in } \\
\text { underestimation of ammonium nitrate formation. }{ }^{16}\end{array}$} \\
\hline
\end{tabular}

16 Memorandum from Pat Brewer, NPS, to David Hurlbut, NREL, September 19, 2011. 
Table 5-3. CALPUFF Results for Original Navajo GS Baseline and for LNB/SOFA Operation

\begin{tabular}{|c|c|c|c|c|}
\hline \multirow[b]{2}{*}{ Class 1 Area } & \multicolumn{2}{|c|}{$\begin{array}{l}\text { Navajo GSP: Baseline Impact } \\
\text { (dv) }\end{array}$} & \multicolumn{2}{|c|}{$\begin{array}{c}\text { Navajo GS: LNB/SOFA Impact } \\
\text { (dv) }\end{array}$} \\
\hline & SRP 2007 & EPA 2009 & SRP 2007 & EPA 2009 \\
\hline Arches & 2.05 & 3.25 & 1.51 & 2.08 \\
\hline Bryce Canyon & 2.00 & 3.66 & 1.58 & 2.44 \\
\hline Canyonlands & 2.47 & 4.37 & 1.96 & 2.98 \\
\hline Capitol Reef & 2.68 & 5.48 & 2.31 & 4.08 \\
\hline Grand Canyon & 2.56 & 5.41 & 2.29 & 4.35 \\
\hline Mazatzal & 0.71 & 1.16 & 0.47 & 0.73 \\
\hline Mesa Verde & 1.42 & 2.24 & 1.04 & 1.33 \\
\hline Petrified Forest & 1.52 & 2.62 & 1.14 & 1.54 \\
\hline Pine Mountain & 0.66 & 1.08 & 0.46 & 0.64 \\
\hline Sycamore Canyon & 1.31 & 1.96 & 0.92 & 1.28 \\
\hline Zion & 1.83 & 3.73 & 1.47 & 2.65 \\
\hline
\end{tabular}

Tables 5-3, 5-4, and 5-5 present a summary of the CALPUFF modeling results for the three studies listed in Table 5-2 and discussed above. Table 5-3 provides the CALPUFF model results at the eleven Class I areas within $300 \mathrm{~km}$ of Navajo GS, calculated in deciviews, for the original baseline conditions (prior to LNB/SOFA installation) and for operation with LNB/SOFA in place with an emission rate for each unit equivalent to $0.24 \mathrm{lb} /$ MMBtu. As discussed previously, reported data for the first half of 2011 indicate that Units 2 and 3, which were retrofitted in 2009 and 2010, were actually emitting $\mathrm{NO}_{x}$ at approximately $10 \%$ below this modeled level, between 0.21 and $0.22 \mathrm{lb} /$ MMBtu. Note that Table 5-3 does not provide results for the SRP 2011 CALPUFF version 6.4 study, because that report did not provide baseline or LNB/SOFA results.

Table 5-4 shows the CALPUFF results for Navajo GS operating with SCR technology for $\mathrm{NO}_{\mathrm{x}}$ emissions control. Table 5-4 does not include results for the SRP 2011 CALPUFF Version 6.4 study, because that report did not provide SCR results, but rather, provided only the resulting differences between LNB/SOFA as shown in Table 5-5.

Table 5-5 shows the predicted incremental improvement in visibility between the LBN/SOFA operation at an assumed
$\mathrm{NO}_{\mathrm{x}}$ emission rate equivalent to $0.24 \mathrm{lb} / \mathrm{MMBtu}$, and the SCR-controlled emission rates assumed to be equal to 0.08 lb/MMBtu for each study.

While there were other differences between the studies, such as modeling grid spacing, the major differences in the results in Table 5-5 are likely due primarily to the different background ammonia concentrations, and in the case of the CALPUFF Version 6.4 results, a significant change in the way the model algorithms convert $\mathrm{NO}_{\mathrm{x}}$ to nitrate. In addition, SRP's analyses (both the 2007 and 2011 studies) attempt to account for ammonia slip from the SCR process, as well as additional sulfuric acid mist (H2SO4) produced by the SCR catalyst. SRP assumed a slightly larger amount of $\mathrm{H} 2 \mathrm{SO} 4$ emissions compared to EPA's study. Combined with the revised CALPUFF 6.4 treatment of nitrate, which significantly reduces its rate of production in the plumes, the adverse effects of the additional $\mathrm{H} 2 \mathrm{SO} 4$ results in the prediction of a slight degradation for visibility in some Class I areas listed. Between background ammonia and the handling of $\mathrm{H} 2 \mathrm{SO} 4$, the former appears to account for much of the difference between SRP and EPA in their model results.

To summarize, comparing LNB/SOFA vs. addition of SCR to all units at Navajo GS, the maximum improvement at any Class I area estimated by SRP in both its 2007 study 
Table 5-4. CALPUFF Results for Navajo GS with SCR Operation

\begin{tabular}{|l|c|c|}
\hline & \multicolumn{2}{|c|}{$\begin{array}{c}\text { Navajo GS Plant: SCR Impact } \\
\text { (dv) }\end{array}$} \\
\hline Class 1 Area & SRP 2007 & EPA 2009 \\
\hline Arches & 0.99 & 0.89 \\
\hline Bryce Canyon & 1.23 & 1.10 \\
\hline Canyonlands & 1.35 & 1.25 \\
\hline Capitol Reef & 1.89 & 2.04 \\
\hline Grand Canyon & 2.29 & 2.46 \\
\hline Mazatzal & 0.38 & 0.37 \\
\hline Mesa Verde & 0.58 & 0.52 \\
\hline Petrified Forest & 0.76 & 0.66 \\
\hline Pine Mountain & 0.34 & 0.32 \\
\hline Sycamore Canyon & 0.63 & 0.59 \\
\hline Zion & 1.10 & 1.05 \\
\hline
\end{tabular}

Table 5-5. CALPUFF Results for Navajo GS, SCR Improvement over LNB/SOFA

\begin{tabular}{|l|c|c|c|}
\hline & \multicolumn{3}{|c|}{ Navajo GS Plant: SCR Improvement over } \\
LNB/SOFA ( $\mathbf{\Delta d v})$
\end{tabular}


and its 2011 study are slightly more than a half deciview, with either zero improvement or a very slight degradation predicted at some Class I areas modeled. EPA's 2009 results, in contrast, show visibility improvement as high as approximately 2 deciviews for some Class I areas if SCR is installed on all units at Navajo GS. However, EPA recognizes that CALPUFF may overestimate nitrate formation. A study of the degree of possible overestimation indicated that using NH3 background concentrations even in the 0.5 to $1.0 \mathrm{ppb}$ range (EPA used an even higher range for its 2009 modeling) can result in overestimation of nitrate impacts by a factor of 2 to $4 .{ }^{17}$

Whether one accepts EPA's ANPR statement that a change of approximately one deciview is the threshold for a perceptible change, or the observational field study referenced in EPA's Regional Haze rule which found a threshold of just under two deciviews is the minimum perceptibility threshold, the results summarized here reflect contrasting findings. SRP's finding in each of its two studies is that the installation of SCR will not yield a perceptible improvement in visibility at the listed Class I areas. EPA's finding is that installation of SCR will result in a perceptible improvement in visibility at multiple Class I areas.

As mentioned above, background ammonia concentrations are a critical factor in predicting ammonia nitrate formation. The assumed ammonia concentrations input to SRP's and EPA's analyses differed significantly, as summarized in Table 5-2, and are likely responsible for the majority of the differences between the SRP and EPA model results. The high nitrate episodes measured at IMPROVE sites in the Colorado Plateau are cold season, rather than warm season events. Similarly, the high nitrate episodes modeled for the Class I areas in the region are cold season, rather than warm season events. Therefore, it is most crucial to get the ammonia concentrations correct in the cool months, as that is when both modeling and monitoring indicate that there can be relatively high nitrate days.

Limited studies have been done to date to measure

\footnotetext{
17 Scire et. al. 2003. Evaluation of the CALPUFF Model in Predicting Concentration, Visibility and Deposition at Class I Areas in Wyoming. Presented at the AWMA Specialty Conference: Guideline on Air Quality Models: The Path Forward. Mystic, Connecticut, Oct. 23-24, 2003.
}

ambient air ammonia concentrations in the Four Corners region. One of these studies was done by SRP in 2010 to help support CALPUFF modeling studies for Navajo GS. ${ }^{18}$ That study measured average wintertime ammonia concentrations ranging from 0.63 to to $0.22 \mathrm{ppb}$ at two sites approximately $100 \mathrm{~km}$ south and north Navajo GS, respectively. A prior study (Dec. 2006 - Dec. 2007) measured ammonia at several sites, including one in Oklahoma, two sites in southwest Colorado (one at Mesa Verde) and three sites in northwest New Mexico. ${ }^{19}$ The most rural and least agricultural of these sites was Mesa Verde, where ammonia averaged $0.2 \mathrm{ppb}$, with lower values in the winter and higher in the summer. Sites nearer urban areas such as Farmington, New Mexico and nearer sources of emissions averaged around $1 \mathrm{ppb}$, again with lower values on the colder months and higher values generally during the warm months of the year.

The studies summarized above indicate that in more remote areas of the southwest, especially during winter months, there is much less ammonia available in the atmosphere. The ammonia ranges used by EPA's modeling, ranging from $0.7 \mathrm{ppb}$ to $1 \mathrm{ppb}$ in the winter months, depending on modeled Class I area, are much higher than measured in the above studies. For example, winter month ammonia measured at Mesa Verde was in the 0.1 to $0.2 \mathrm{ppb}$ range. As pointed out in the referenced SRP ammonia study, use of EPA's higher ammonia values produces modeled ammonium nitrate concentrations an order of magnitude higher than measured values for many cases. On the other hand, use of the SRP ammonia background values in CALPUFF produces a much better comparison between modeled and measured values.

\subsection{Monitoring and Related Studies at Regional Class I Areas}

While the preceding summaries of modeling analyses disagree over whether further $\mathrm{NO}_{\mathrm{x}}$ emissions controls at Navajo GS would yield a perceptible improvement in visibility, there have also been some published

\footnotetext{
18 Salt River Project, September 2010. Measurements of Ambient Background Ammonia on the Colorado Plateau and Visibility Modeling Implications.

19 Sather, et. al., 2008. Baseline Ambient Gaseous Ammonia Concentrations in the Four Corners Area and Eastern Oklahoma, USA. Journal of Environmantal Monitorin, first published on the web 25th September 2008
} 
observational studies that have attempted to discern whether prior emission reductions from power plant retrofits in the area have resulted in perceptible changes in visibility or related metrics. In addition, visibility-related parameters have been monitored at several regional Class I areas as part of the IMPROVE program, for which a nationwide database is maintained by Colorado State University. ${ }^{20}$ The following sections present some of these data, with a focus on nitrate observations and trends, in relation to emissions changes that have been occurring at power plants in the area and region-wide.

\subsubsection{Papers Examining Visibility Improve- ments from Emission Reductions}

Two published studies have sought to determine whether emission reductions at power plants near the Grand Canyon have resulted in any perceptible or any measurable changes in visibility or in visibility-related parameters. These studies include those on the effects of shutting down MGS at the end of 2005, and the effects of installing scrubbers from 1997 through 1999 for acid gas/SO 2 control at Navajo GS.

To help in understanding these studies regarding the effects of MGS and Navajo GS emissions, it is helpful to understand general meteorological patterns in the region. Figure 5-5 provides an annual wind rose for Flagstaff based on data available online ${ }^{21}$ for the years 1982-1990 (nine years), as well as seasonal wind roses for the same period. Flagstaff is in north-central Arizona, approximately 100 miles south of Navajo GS and approximately 150 miles east of MGS. The ground elevation at Flagstaff is similar to that of Navajo GS. The near-surface winds represented here for Flagstaff are not necessarily representative of plume-level transport winds for Navajo GS (which will typically be well above ground level), especially given the channeling effects of interspersed mountain ranges, valleys and canyons. However, these wind data at least show that the wind patterns in the region can have strongly predominant directions, and that the predominant directions can vary significantly with season.

\footnotetext{
20 CSU 2011: http://vista.cira.colostate.edu/improve/

21 Data from http://www.webmet.com. The data were plotted with WRPLOT View software available at the same web site as provided by Lakes Environmental Software.
}

The bars on the wind rose charts in Figure 5-5 indicate the frequency as speed of winds from a particular direction. These wind data show that on an annual average basis, winds in the Flagstaff area are most often from the northeast or southwest. On a seasonal basis, winds from the southwest are more predominant in spring, summer, and fall, but in the winter months, winds from the northeast are somewhat more frequent than southwest winds.

With respect to the late 1990s scrubber retrofits at Navajo GS, a study by Green et. al. was performed in 2005 to evaluate particulate sulfur and visibility levels in the Grand Canyon, before and after the scrubber retrofits. ${ }^{22}$ The study found that installation of the scrubbers, which reduced Navajo GS $\mathrm{SO}_{2}$ emissions by more than $90 \%$, produced a measurable reduction in both particulate sulfate levels and in light extinction in GCNP, especially during the winter months when plume transport conditions favor movement of the Navajo GS plumes over and often through the canyon. The study also indicated that the more extreme, high sulfate events in GCNP decreased markedly from before the scrubber retrofits.

A second study more recently (2010) examined the effects of the shutdown of the MGS (located $\sim 50$ miles southwest of the west end of GCNP) at the end of 2005. ${ }^{23}$ This study found a slight reduction in sulfate concentrations, in the range of 0.1 to 0.32 micrograms per cubic meter $(\mu \mathrm{g} / \mathrm{m} 3)$ in the summer at monitoring sites in GCNP. The study authors stated this range was approximately $3 \%-10 \%$ of summer sulfate concentrations. For nitrates, the authors found that summer nitrate concentrations fell by $0.12 \mu \mathrm{g} /$ $\mathrm{m} 3$ at Indian Gardens (approximately halfway down the canyon) and at Hance Camp on the South Rim. However, the study also found no improvement in visibility measured in deciviews or light extinction. The authors speculated that this lack of improvement may have been caused by natural or other variations in other aerosols, which could have masked any improvement that might have been expected due to the slight sulfate reduction and nitrate reductions.

\footnotetext{
22 Green, et. al. 2005. The Effects of Scrubber Installation at the Navajo Generating Station on Particulate Sulfur and Visibility Levels in the Grand Canyon. Journal of the Air and Waste Management Association, Vol. 55, p. 1675 , November.

23 Terhorst and Berkman 2010. Effect of Coal-Fired Power Generation on Visibility in a Nearby National Park. Atmospheric Environment, Vol. 44 (p. 2524-2531).
} 


\section{Station \#03103 - Flagstaff Pulliam Airport}

(1982-1990)

WIND SPEED

$(\mathrm{m} / \mathrm{s})$

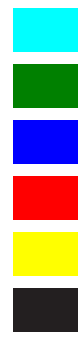

$>=11.1$

$8.8-11.1$

$5.7-8.8$

$3.6-5.7$

$2.1-3.6$

$0.5-2.1$

Calms: $3.76 \%$

Source: http://www.webmet.com/

WRPLOT View - Lakes Environmental Softare
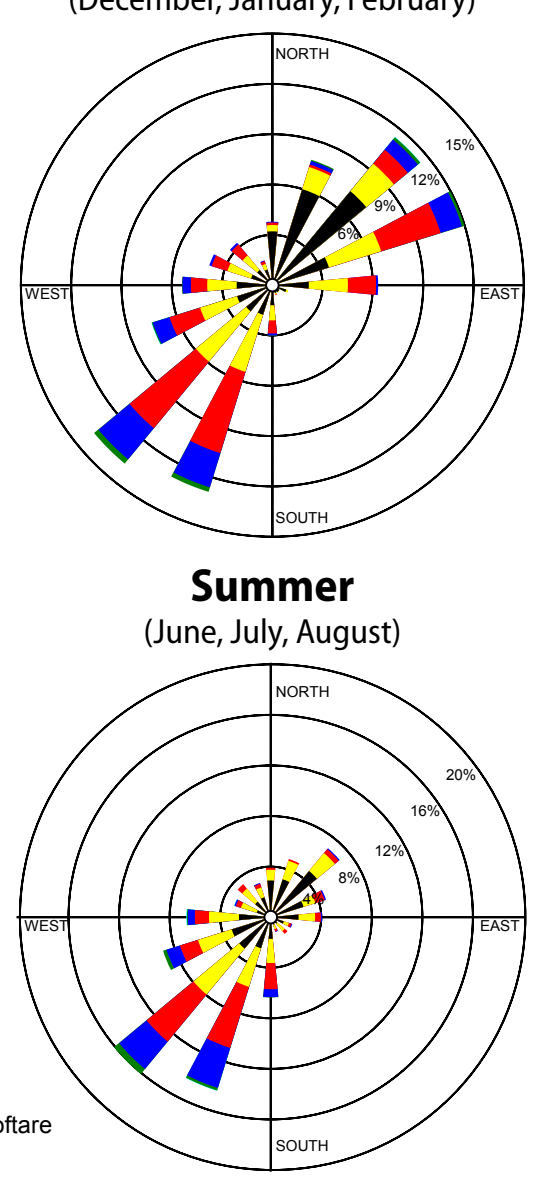

Summer

(June, July, August)
Spring

(March, April, May)

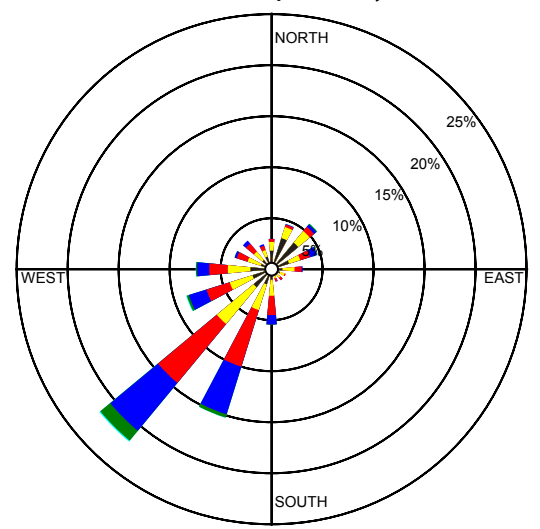

Fall

(September, October, November)

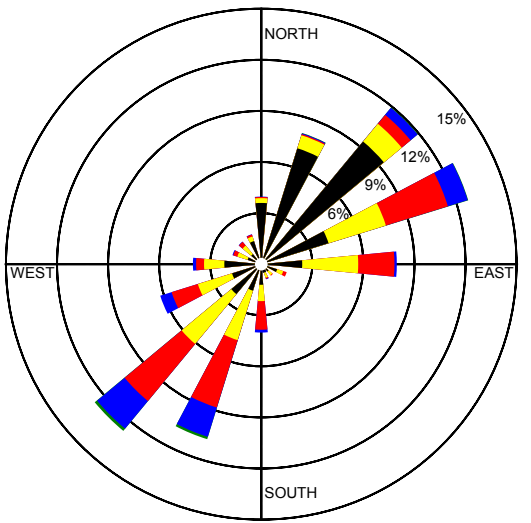

Figure 5-5. Annual and seasonal wind roses for Flagstaff, Arizona 
Finally, the second study authors also pointed out that CALPUFF simulations had predicted marked improvement in visibility at GCNP if MGS had been retrofitted with $\mathrm{SO}_{2}$ control, and because their study showed no visibility improvement, even with a total shutdown of MGS, their conclusions called into question the usefulness of CALPUFF for Regional Haze regulatory purposes. One should understand that this critique refers to earlier versions of CALPUFF, including Version 5.8 which is being used by EPA as its basis for BART analysis, and not necessarily the most recent Version 6.4, which attempts to improve CALPUFF's handling of chemical conversion processes.

In addition to the two studies based on measurements/ monitoring, a recent modeling study by Carlton et al. used the Community Multiscale Air Quality (CMAQv4.7) model to assess the extent to which anthropogenic air pollutant emissions may contribute to formation of secondary organic aerosol (SOA). ${ }^{24}$ Anthropogenic emissions may help to create oxidants that convert both natural and human emissions of volatile organic compounds (VOCs) to particulate matter in the form of SOA. CMAQ is a much more sophisticated model than CALPUFF; CMAQ accounts for transport over long distances and numerous chemical reactions that can produce particulate matter such as sulfates, nitrates, and SOA.

For the cited CMAQ modeling study, the modeling domain included the entire lower 48 states, southern Canada, and most of Mexico. This modeling study predicted that elimination of all controllable anthropogenic emissions in the domain could eliminate $50 \%$ or more of the SOA over much of the eastern United States. (Nearly all anthropogenic emissions were placed in the category of "controllable" for the study.) However, in northern Arizona and southern Utah, the model predicted that elimination of all controllable emissions would accomplish only a $10 \%-20 \%$ reduction in SOA. Thus, in addition to reducing nitrate particle formation, CMAQ indicates that controlling $\mathrm{NO}_{\mathrm{x}}$ and other pollutants may help to substantially reduce SOA in the eastern United States. However, in the Colorado Plateau region, the potential for $\mathrm{NO}_{\mathrm{x}}$ emission reductions to accomplish SOA reduction in addition to possible nitrate particle reduction seems to be very limited, according to this modeling study.

24Carlton et al. 2010. To What Extent Can Biogenic SOA be Controlled? Environmental Science \& Technology, Vol. 44, p. 3376-3380.

\subsection{Visibility Monitoring Metrics and Regional Trends}

Navajo GS already has the best available $\mathrm{SO}_{2}$ emissions control. At question in the current BART proceeding is the extent to which further $\mathrm{NO}_{\mathrm{x}}$ control would lead to further visibility improvement. The answer may lie, at least in part, in the correlation between two pieces of information: the emissions decrease due to the closure of MGS, and the substantial region-wide $\mathrm{NO}_{\mathrm{x}}$ emissions decreases as summarized in Table 5-1. Between 2002 and 2008, the region-wide $\mathrm{NO}_{\mathrm{x}}$ emissions, as summarized in Table 5-1, decreased by nearly 600,000 tons/year, or approximately $23 \%$ from the 2002 value. Nearly all of this decrease took place from 2006 through 2008.

Tighter EPA emission standards for new on-road and nonroad engines took effect during this period. In addition, some power plant retrofits (e.g., low $\mathrm{NO}_{\mathrm{x}}$ burners) were in place by 2008 . Recessionary pressures and slower economic activity may also have reduced $\mathrm{NO}_{\mathrm{x}}$ emissions for 2008. After 2008, the on-road and non-road emission sector emissions, which make up a large fraction of the inventory, are expected to continue to drop substantially due to continued fleet replacement with newer on-road and non-road vehicles in 2009 and 2010.

Whatever the causes, $\mathrm{NO}_{\mathrm{x}}$ emissions in the region from the 2006-2010 period are on the order of 23\% lower than $\mathrm{NO}_{\mathrm{x}}$ emissions in 2002. Based on the slight change from 2002 to 2005 , the 2002 data are probably representative of the 2001 to 2005 period. Given this significant drop in $\mathrm{NO}_{\mathrm{x}}$ emissions between the first half and last half of the past decade, the nitrate measurements from several of the Class I areas in the region around Navajo GS were analyzed to see if there were similar decreases in nitrate concentrations.

The data in Table 5-6 show the calculated ammonium nitrate concentrations available from IMPROVE sites in the region for the first half and the last half of the past decade. One caveat is that the 2010 data were only available through October 2010. Because winter nitrate values tend to be much higher in the summer, this may have biased the 2006-2010 averages slightly on the low side. Also, the Meadview site only had data starting in February 2003, so the 2001-2005 average for that site represents most of 2003, plus 2004 and 2005. 
This analysis presumes that a 5 -year period is long enough to establish a reasonable nitrate average, and that this parameter is not significantly affected by climate or precipitation cycles, such as El Nino/La Nina that have a typical cycle length on the order of 5 years. Based on this presumption, the nitrate concentrations values do exhibit a slight downward trend. Because measured nitrate concentrations in the region appear to have dropped by around $12 \%$, this is presumably in response to a drop in $\mathrm{NO}_{\mathrm{x}}$ emissions in the region, which are likely around 23\% lower for 2006-2010 compared to 2001-2005 based on the data in Table 5-1. However, because formation of nitrate aerosol is dependent on a complex, non-linear, set of atmospheric conditions and pollutant concentrations, it should not be anticipated that a linear rollback of emissions would have a linear effect on concentrations.

While there appears to be a decrease in nitrate concentrations along with the decrease in regional $\mathrm{NO}_{\mathrm{x}}$ emissions, the nitrate decrease at these sites averages about half the magnitude on a percentage basis. This could imply that much of the nitrate is transported in from outside the region, or is from natural sources. It could also be that because the relationship between $\mathrm{NO}_{\mathrm{x}}$ emissions and nitrate is nonlinear due to complex atmospheric chemical reactions or deposition of nitrogen compounds. One nonlinear effect is the competition in the atmosphere for the chemicals (such as ammonia) that help to form ammonium nitrate.
The preference for sulfate formation over nitrate is evident all year, and is especially exaggerated in the summer as shown in Figure 5-6, which shows the annual profile of monthly average sulfate and nitrate concentrations, as well as the ratio of sulfate to nitrate, for Indian Gardens, based on more than 20 years of data. This dominance of sulfate is even more remarkable given the much larger $\mathrm{NO}_{\mathrm{x}}$ emissions compared to $\mathrm{SO}_{2}$ emissions in the region as shown in Table 5-1. In coal-fired power plant plumes, even with the best possible scrubbing, there is still a fair amount of $\mathrm{SO}_{2}$ and sulfate present relative to the amount of ammonia in the atmosphere. Whatever the mechanisms, reductions in atmospheric loadings of $\mathrm{NO}_{\mathrm{x}}$ in the southwest United States do not seem to correspond to equal reductions in nitrate loadings at most of the Class I IMPROVE sites in the Navajo GS region.

To gain an additional, longer-term perspective on nitrate concentration trends at the regional IMPROVE monitoring locations, the annual averages for the period of record are plotted in Figures 5-7 through 5-12 for all the sites listed in Table 5-6, except Meadview, which has limited long-term data. Also shown on these figures are the annual averages of fine particulate matter concentration (PM2.5) and sulfate concentration, calculated as ammonium sulfate.

While there are some perceptible downward trends in sulfate and $\mathrm{PM}_{2.5}$ at several sites, the nitrate concentrations have been relatively constant over the period of record. One important concept to emphasize in looking at these

Table 5-6. Ammonium Nitrate Concentration Trends

\begin{tabular}{|c|c|c|c|}
\hline Class 1 Area/Location & $\begin{array}{c}2001-2005 \text { Avg. } \\
(\mu g / m 3)\end{array}$ & $\begin{array}{c}2006-2010^{d} \text { Avg } \\
(\mu g / m 3)\end{array}$ & $\begin{array}{c}\text { Percent } \\
\text { Reduction }\end{array}$ \\
\hline Bryce Canyon & 0.270 & 0.237 & 12.2 \\
\hline Canyonlands & 0.274 & 0.247 & 9.9 \\
\hline Grand Canyon/Hance Camp ${ }^{a}$ & 0.212 & 0.219 & -2.9 \\
\hline Grand Canyon/Indian Gardens ${ }^{\text {b }}$ & 0.238 & 0.209 & 12.2 \\
\hline Grand Canyon/Meadview c & 0.281 & 0.248 & 12.1 \\
\hline Mesa Verde & 0.236 & 0.192 & 18.4 \\
\hline Petrified Forest & 0.288 & 0.226 & 21.6 \\
\hline Summation \& Avg. Percent & 1.799 & 1.577 & 11.9 \\
\hline
\end{tabular}

(a) Hance Camp is on the canyon rim, near the east end of the wide portion of GCNP.

(b) Indian Gardens is about half way down the south canyon wall, near the east end of the wide portion of GCNP.

(c) Meadview is in the far western portion of GCNP. Meadview data for 2001-2005 begin in February 2003.

(d) The 2010 data include only measurements through October. 


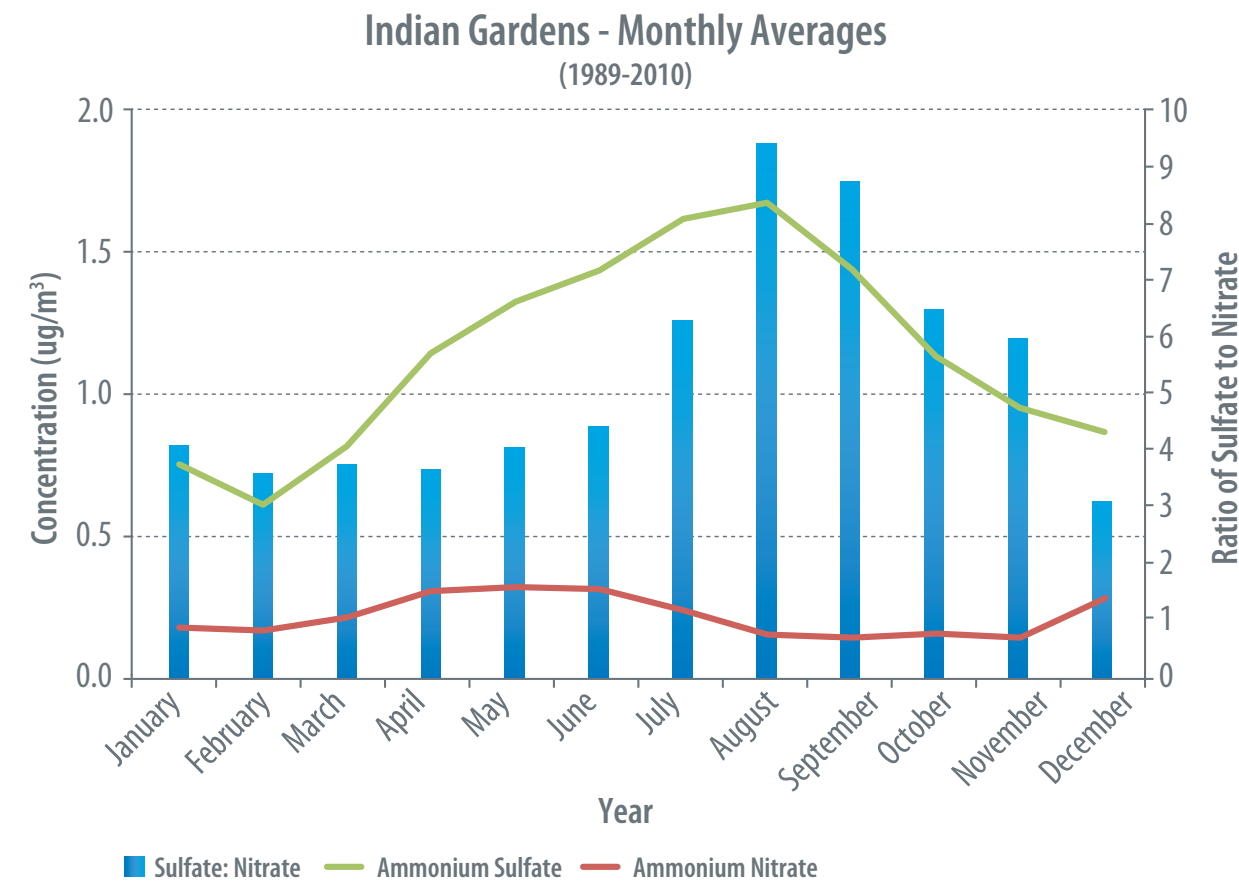

Figure 5-6. Annual profile of sulfate, nitrate and sulfate:nitrate ratio for Indian Gardens

\section{Bryce Canyon}

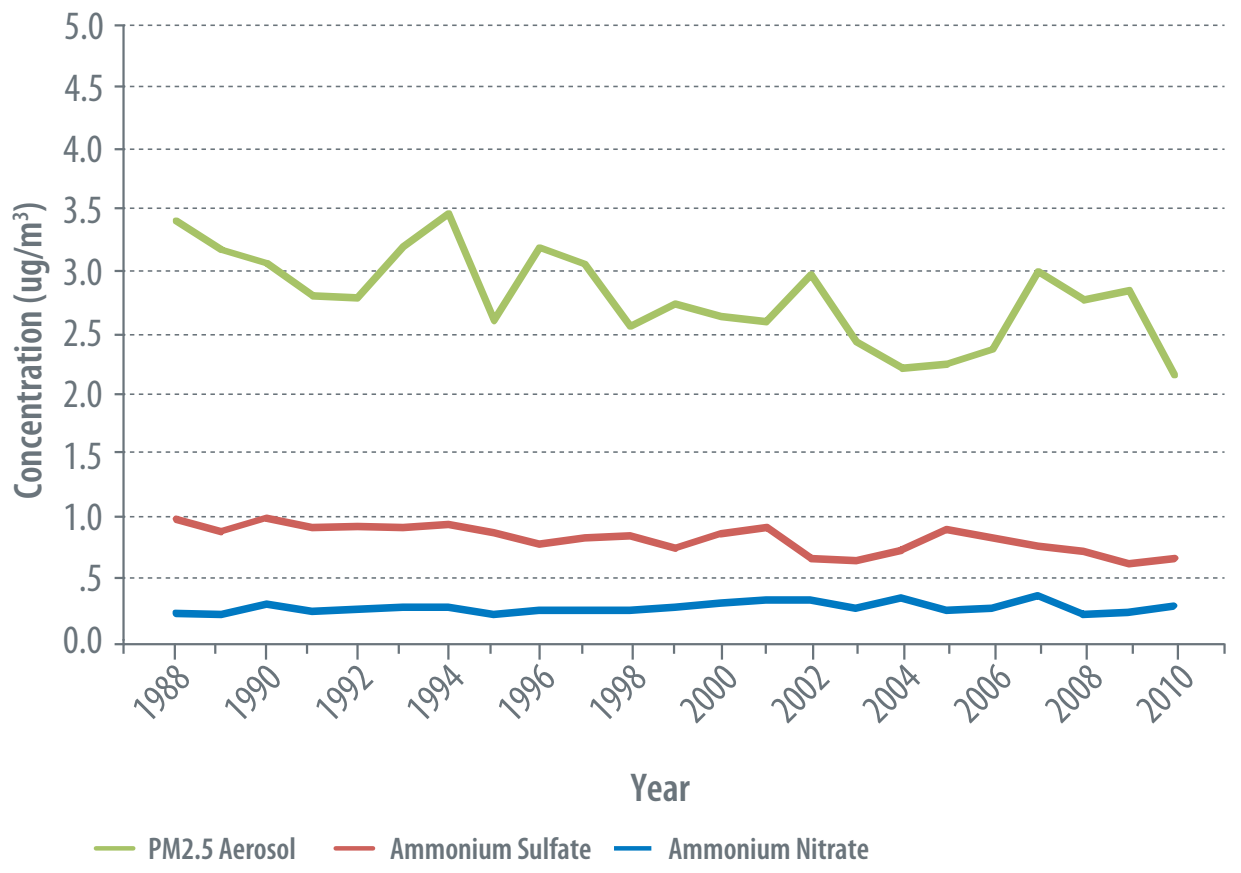

Figure 5-7. $\mathrm{PM}_{2.5}$, sulfate and nitrate annual average trends for Bryce Canyon charts is that ammonium sulfate and ammonium nitrate are assumed, for visibility impact purposes, to have the same effect per mass concentration amount. Thus, despite the fact that anthropogenic $\mathrm{SO}_{2}$ emissions in the region have dropped far below those of $\mathrm{NO}_{\mathrm{x}}$ (see Table 5-1), the fine sulfate particles still represent, on average, around three or more times the amount of visibility degradation as nitrate particles, on an annual average basis.

\subsection{Control Technology Options and Cost/Benefit Analysis}

Navajo GS is already using the best available control for reduction of $\mathrm{SO}_{2}$, the pollutant with the largest potential impact on visibility. The other major regulated pollutants that can significantly impact visibility are particulate matter and $\mathrm{NO}_{\mathrm{x}}$.

\subsection{1}

\section{Future Air Quality Regulatory Impact on Navajo GS}

In addition to the pending Regional Haze/BART determination for Navajo GS, there are other programs and rules that could eventually force emissions reductions at Navajo GS that may help to further mitigate any potential contributions to regional haze. One recently-issued rule is the mercury and air toxics standards (MATS) rule. Depending on current performance of Navajo GS in comparison to the final limits for existing coal boilers in the MATS rule, the plant may need additional emissions control to attain compliance within three years of the date of final rule publication in 




Figure 5-8. $\mathrm{PM}_{2.5}$, sulfate and nitrate annual average trends for Canyonlands

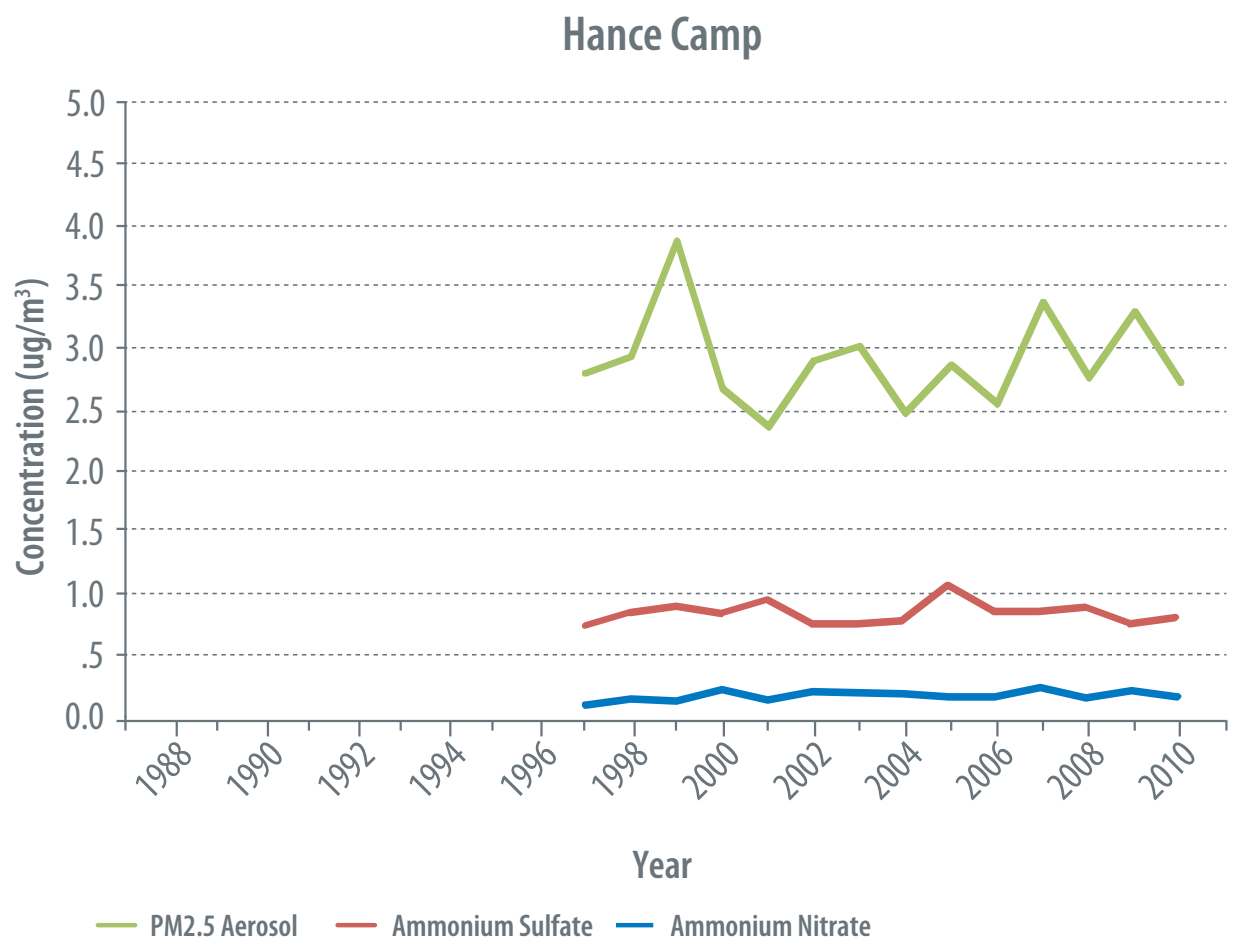

Figure 5-9. $\mathrm{PM}_{2.5}$, sulfate and nitrate annual averagetrends for GCNP/Hance Camp 


\section{Indian Gardens}

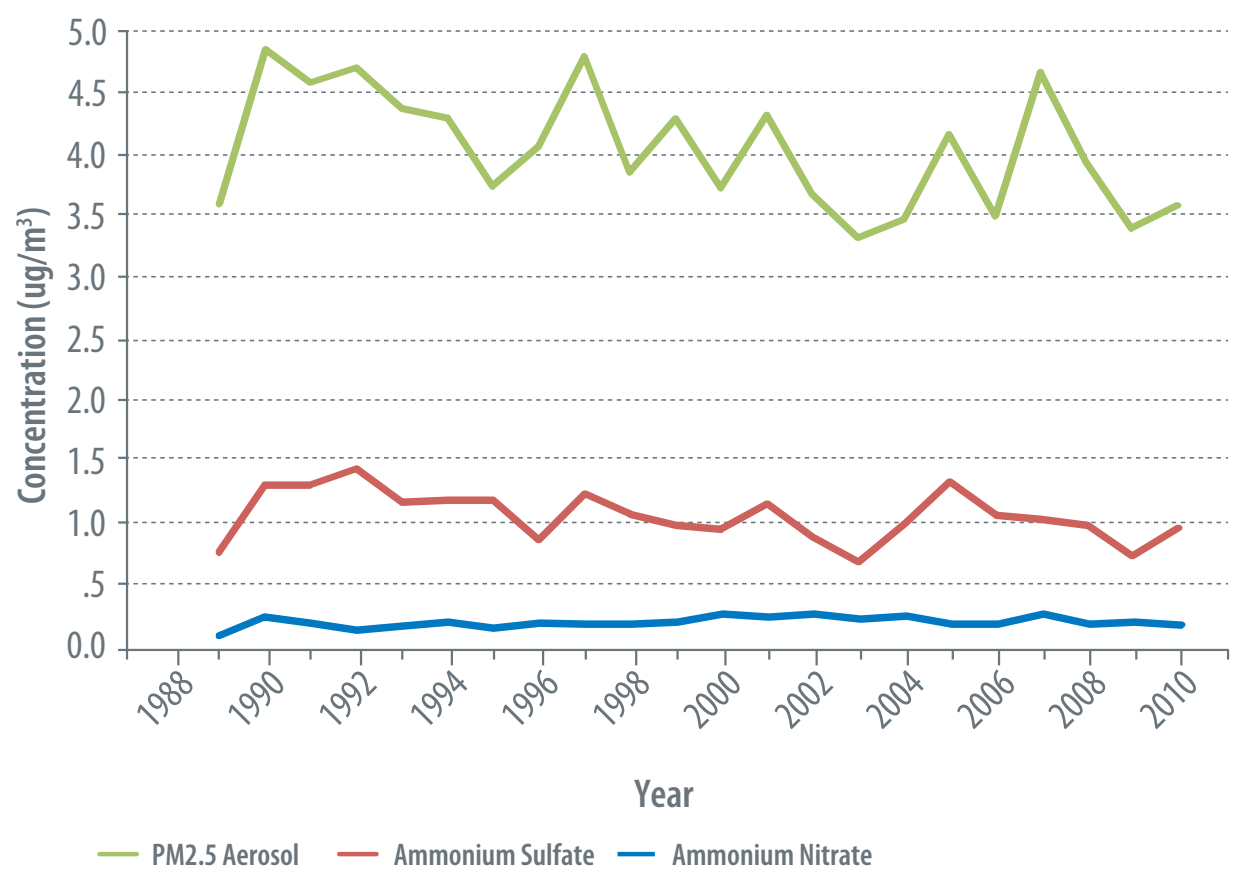

Figure 5-10. $\mathrm{PM}_{2.5^{\prime}}$ sulfate and nitrate annual average trends for GCNP/Indian Gardens

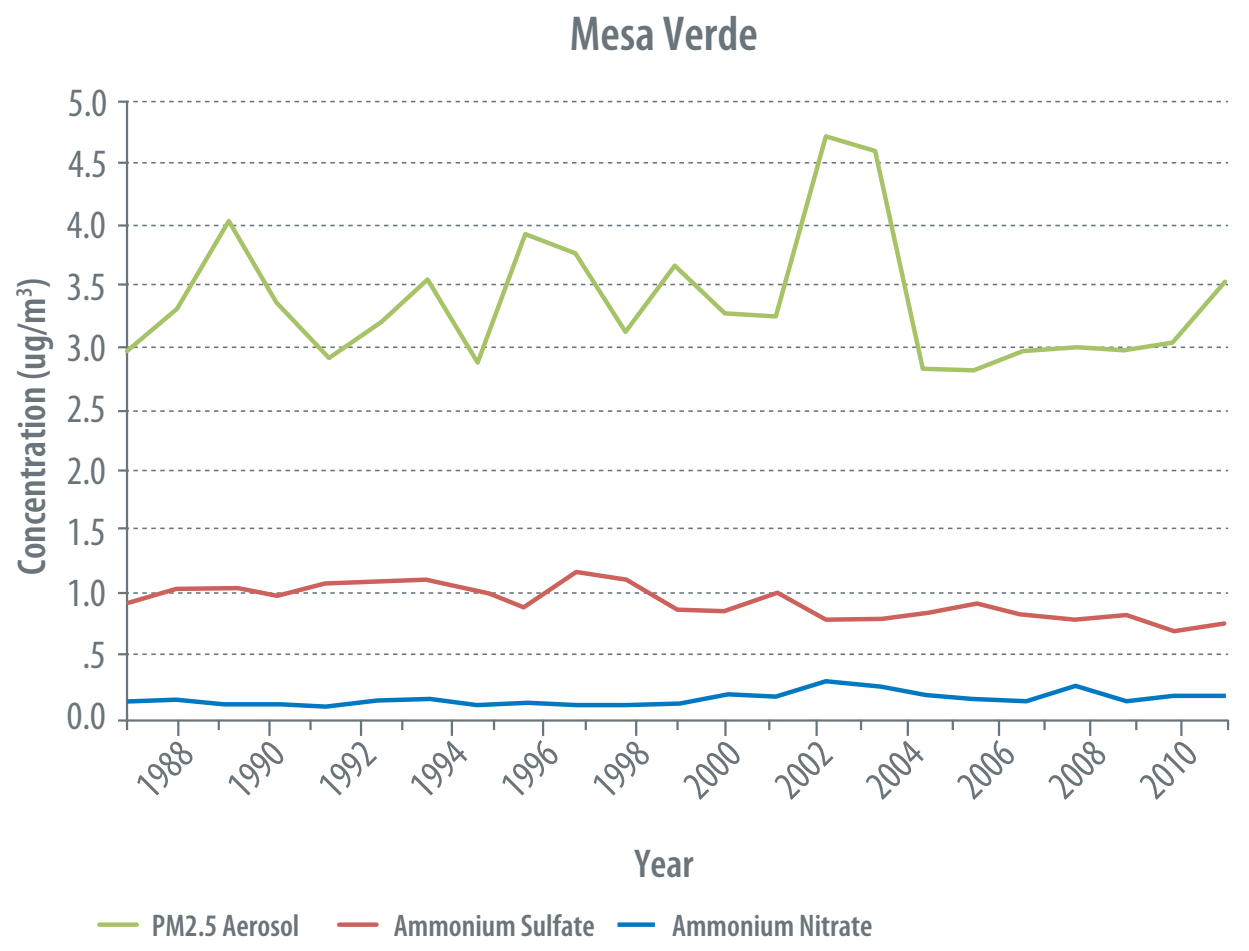

Figure 5-11. $\mathrm{PM}_{2.5^{\prime}}$ sulfate and nitrateannual average trends for Mesa Verde 




Figure 5-12. $\mathrm{PM}_{2.5}$, sulfate and nitrate annual average trends for Petrified Forest and ozone, namely $\mathrm{SO}_{2}$ and $\mathrm{NO}_{x}$ emissions. However, a federal court stayed CSAPR on December 30, 2011 in response to legal challenges, so its implementation will be delayed.

The MATS rule could require the Navajo GS owners to install additional particulate matter control, perhaps baghouses, as well as mercury control in the form of sorbent injection (possibly activated carbon). However, it is expected that any change in PM emissions by these controls would have a negligible impact on visibility in Class I areas.

If a "CSAPR2" rule was implemented in response to a new ozone standard, it is possible that Navajo GS would need to install more aggressive $\mathrm{NO}_{x}$ emission controls. However, given the expected rule timing and implementation timeframes, the Federal Register. ${ }^{25}$ The rule was signed in December 2011 and will likely be published in January 2012. On this timeline, any retrofits to attain compliance would need to be in place by January 2016 .

Another proposed rule that could affect Navajo GS, but has recently been put off until 2013 or later, is a new National Ambient Air Quality Standard (NAAQS) for ozone. If a tighter ozone NAAQS is eventually enacted, it would likely affect most major sources of $\mathrm{NO}_{\mathrm{x}}$ in the nation, possibly requiring many of them to install the best possible $\mathrm{NO}_{\mathrm{x}}$ emissions control. This requirement could take the form of a second version of the Cross State Air Pollution Rule (CSAPR) that was recently issued ${ }^{26}$ and that applies to larger $(>25 \mathrm{MW})$ utility units in generally the eastern half of the lower 48 states. CSAPR regulates only the principal precursor emissions of fine particulate matter

\footnotetext{
25 EPA, May 3, 2011. National Emission Standards for Hazardous Air Pollutants From Coal- and Oil-Fired Electric Utility Steam Generating Units and Standards of Performance for Fossil-Fuel-Fired Electric Utility, Industrial-Commercial-Institutional, and Small Industrial-CommercialInstitutional Steam Generating Units; Proposed Rule. 76 FR 24976.

26EPA, Aug. 8, 2011. Federal Implementation Plans: Interstate Transport of Fine Particulate Matter and Ozone and Correction of SIP Approvals; Final Rule. 76 FR 48208.
} implementation of an Navajo GS retrofit, if required for such a rule, is likely 8-10 years away. Obviously, if such controls were implemented, they would also decrease the potential for Navajo GS impacts on visibility.

\subsubsection{Cost/Benefit Analysis}

For the purposes of evaluating whether costs for a facility, a commonly used metric is the annualized cost of the control divided by the visibility improvement to be gained, in units of dollars per deciview $(\$ / \mathrm{dv})$. The annualized cost of control is calculated as the sum of the annualized initial capital cost for design, equipment, and installation, plus the annual operation and maintenance (O\&M) cost.

Most of the focus of studies for $\mathrm{NO}_{\mathrm{x}}$ control on Navajo GS to date has been on SCR technology. Chapter 4 discussed selective non-catalytic reduction (SNCR) as another potential $\mathrm{NO}_{\mathrm{x}}$ reduction technology, with much lower total prospective control technology are justified for a given 
annualized costs compared to SCR, but also significantly lower $\mathrm{NO}_{\mathrm{x}}$ removal rates. In this chapter, the analysis of cost and benefits focuses on SCR.

EPA provides a range of estimated site-specific annualized costs for installation and operation of an SCR system on Navajo GS. This range is from two estimates, one by SRP, and the other by the NPS. According to the EPA's ANPR for Navajo GS, the annualized cost estimates were approximately $\$ 71.7$ million as estimated by Sargent \& Lundy for SRP, and approximately $\$ 67.6$ million as estimated by the NPS. (Note that the annualized SCR costs used throughout the remainder of this report are different from those calculated by Sargent \& Lundy and NPS and used in their cost/benefit ratios.)

Using this range of estimated annualized costs, a range of cost/benefit ratios can be calculated as shown in Table 5-7. These data are based on the modeled visibility (dv) improvements listed in Table 5-5 of this section, the annualized costs estimated by SRP as cited in the EPA's ANPR, and the NPS-estimated annualized costs as cited in the EPA's ANPR. Note that SRP updated its cost estimate for an SCR retrofit in 2010 and submitted it to EPA, but the earlier SRP cost is used here to provide a more consistent measure of how the updated CALPUFF Version 6.4 model (SRP 2011) affected the cost/benefit metric, expressed in million dollars per year per deciview $(\mathrm{M} \$ / \mathrm{yr} / \mathrm{dv})$.

Given that the SRP and EPA/NPS estimates of capital costs and operating costs are relatively close, the differences between the SRP-based \$/yr/dv values and the EPA-based $\$ / y r / d v$ values are largely a function of the different modeling results. SRP's 2011 cost/benefit ratios are large, even when compared to those calculated for other facilities. However, these ratios were calculated using a significantly different modeling procedure (CALPUFF 6.4 and different ammonia inputs) than that used by many other states and EPA. This difference in methodology is crucial factor when comparing the cost/ benefit values derived with CALPUFF 6.4 and CALPUFF 5.8. EPA is reviewing CALPUFF 6.4 but has not endorsed its use as a regulatory standard. CALPUFF 5.8 is currently EPA's accepted model, despite inconsistencies between its predicted visibility improvements and actual measurements (discussed previously in this chapter).

Arizona's Regional Haze State Implementation Plan (SIP), submitted to EPA in 2011, examines the cost/benefit of various $\mathrm{NO}_{\mathrm{x}}$ emission control options for the coal-fired Units 2 and 3 of the Apache Generating Station (Apache GS), each rated at $195 \mathrm{MW} .{ }^{27}$ The control options include various LNB, SNCR, and SCR technologies. The SIP concludes that the BART should be LNB with overfire air (OFA) for each unit. The calculated $\$ / y r / d v$ values were $\$ 2$ million to $\$ 2.5$ million for these units, as compared to \$9-\$10 million for each unit with SCR included.

In Nevada, the coal-fired 557-MW Reid Gardner Station north of Las Vegas includes three BART-subject units (\#1, \#2, and \#3) rated at $100 \mathrm{MW}$ each. Nevada's SIP analysis ${ }^{28}$ included $\$ / \mathrm{dv}$ values for several $\mathrm{NO}_{\mathrm{x}}$ control options, including LNB/OFA, rotating opposed-fire air (ROFA) with Rotamix, and LNB/OFA plus SCR (shown in Table 5-8). The $\mathrm{NO}_{\mathrm{x}}$ emission limits originally proposed by $\mathrm{EPA}^{29}$ to be approved for BART on these units are slightly higher than the current performance of the recently installed LNB/SOFA units on Navajo GS. However, after consideration of public comments on its rule proposal regarding Nevada's SIP, EPA recently finalized approval of the SIP as proposed with the exception of the Reid Gardner BART limits for $\mathrm{NO}_{\mathrm{x}}$. EPA has decided to take more time to review the supporting information for $\mathrm{NO}_{\mathrm{x}}$ and will take action in the future on this portion of Nevada's SIP. ${ }^{30}$

Table 5-8 compares the BART controls proposed for Apache and Reid Gardner with current $\mathrm{NO}_{\mathrm{x}}$ controls at Navajo GS ; all calculated $\$ / \mathrm{dv}$ values are based on CALPUFF 5.8 or earlier model versions. For the Reid Gardner Station, the EPA's original proposed BART determination (now withdrawn) was in agreement with Nevada's SIP proposal, consisting of a low- $\mathrm{NO}_{x}$ combustion/SNCR technique (ROFA w/Rotamix) that results in a three-unit average emission limit of $0.23 \mathrm{lb} /$ MMBtu. Recent (2011) data from Units 2 and 3 at Navajo GS with recently installed LNB/OFA in operation are showing average $\mathrm{NO}_{\mathrm{x}}$ emissions between 0.21 and $0.22 \mathrm{lb} /$ MMBtu.

27 Arizona State Implementation Plan - Regional Haze Under Section 308 of the Federal Regional Haze Rule, January 2011

28 Nevada Division of Environmental Protection, Nevada Regional Haze SIP (October 2009), Appendix B Support Documents (BART Analysis for Reid Gardner Station Unit 1, BART Analysis for Reid Gardner Station Unit 2, BART Analysis for Reid Gardner Station Unit 3).

29EPA, June 22, 2011. Approval and Promulgation of Air Quality Implementation Plans; State of Nevada; Regional Haze State Implementation Plan. 76 FR 36450.

30 See EPA rulemaking (not yet published in Federal Register) at http://www. epa.gov/region9/air/actions/nv.html\#haze 
Table 5-7. Navajo GS Cost/Benefit Analysis Ranges for SCR Based on SRP and EPA/NPS Analyses

\begin{tabular}{|l|c|c|c|}
\hline \multirow{2}{*}{ Annualized Cost (millions)=> } & \multicolumn{3}{|c|}{$\begin{array}{c}\text { Navajo GS Plant: SCR Cost/Benefit over } \\
\text { LNB/SOFA (MS/yr/dv) }\end{array}$} \\
\cline { 2 - 4 } & $\mathbf{7 1 . 7}$ & $\mathbf{6 7 . 6}$ & $\mathbf{7 1 . 7}$ \\
\hline Class 1 Area & SRP 2007 & EPA 2009 & SRP 2011 \\
\hline Arches & 138 & 57 & 312 \\
\hline Bryce Canyon & 205 & 50 & 478 \\
\hline Canyonlands & 118 & 39 & 239 \\
\hline Capitol Reef & 171 & 33 & 126 \\
\hline Grand Canyon & NA & 36 & 7170 \\
\hline Mazatzal & 797 & 188 & NA \\
\hline Mesa Verde & 156 & 83 & 896 \\
\hline Petrified Forest & 189 & 77 & 1024 \\
\hline Pine Mountain & 598 & 211 & NA \\
\hline Sycamore Canyon & 247 & 98 & 1793 \\
\hline Zion & 194 & 42 & NA \\
\hline
\end{tabular}

(a) Uses same cost basis as the SRP 2007 column, but recalculates the cost/benefit metric based on SRP's 2011 visibility impact modeling results using the CALPUFF Version 6.4 model.

Installation of SCR technology on Navajo GS would result in a calculated cost/benefit ratio larger than those calculated for BART controls proposed for other units in the region. It remains to be seen whether EPA will approve the more modest levels of $\mathrm{NO}_{\mathrm{x}}$ control proposed by the states on Reid Gardner and Apache GS. However, even if EPA determines that these other facilities should install SCR, the cost/benefit values for Navajo GS based on EPA modeling/analysis for Navajo would be higher than for SCR installation on the other facilities.

\subsection{Summary of Key Points}

Following are some of the key points regarding visibility science with respect to Navajo GS impacts and the prospective visibility emission control costs to benefit comparison.

- $\mathrm{SO}_{2}$ emissions in the Southwestern United States as a whole have dropped by more than a factor of two in the past decade, due in part to $\mathrm{SO}_{2}$ scrubber retrofits and shutdowns at coal-fired power plants, but primarily due to fuel sulfur reductions for transportation fuels. This appears to be correlated with observed drops in sulfate concentrations and improved visibility at Class I areas in the region. However, the measured sulfate reductions in the Class I areas are much smaller than the percentage $\mathrm{SO}_{2}$ emissions decreases from the region as a whole.

- While $\mathrm{NO}_{\mathrm{x}}$ emissions in the Southwest as of 2008 were nearly an order of magnitude higher than $\mathrm{SO}_{2}$ emissions, sulfate particles were still three to five or more times (depending on monitoring site and time of year) as large a factor as nitrate particles in calculated visibility impacts, based on annual averages of IMPROVE measurements. It appears that under most conditions, sulfate is the preferred mate for any free ammonia, whether in the background atmosphere or in emission source plumes. Even under cold weather conditions in this region, sulfate is usually dominant over nitrate, although the sulfate-to-nitrate ratio is smaller in the cold months. 
Table 5-8. Visibility Cost/Benefit Comparisons

\begin{tabular}{|c|c|c|c|c|c|}
\hline Facility \& Unit(s) & $\begin{array}{l}\mathrm{NO}_{\mathrm{x}} \\
\text { Control }\end{array}$ & $\begin{array}{c}\text { Modeled } \\
\text { NO } \\
\text { Emission } \\
\text { Rate (Ib/ } \\
\text { MMBtu) }\end{array}$ & $\begin{array}{c}\text { Cost/ } \\
\text { Benefit } \\
\text { (M\$/yr/ } \\
\text { dv) a }\end{array}$ & $\begin{array}{l}\text { Proposed } \\
\text { as BART }\end{array}$ & $\begin{array}{l}\text { Prospective } \\
\text { NO Limit } \\
\text { (lb/MMBtu) }\end{array}$ \\
\hline Reid Gardner \#1 & $\begin{array}{l}\text { ROFA w/ } \\
\text { Rotamix }\end{array}$ & 0.16 & 2.45 & by EPA & 0.20 \\
\hline Reid Gardner \#2 & $\begin{array}{l}\text { ROFA w/ } \\
\text { Rotamix }\end{array}$ & 0.16 & 2.38 & by EPA & 0.20 \\
\hline Reid Gardner \#3 & $\begin{array}{l}\text { ROFA w/ } \\
\text { Rotamix }\end{array}$ & 0.20 & 2.68 & by EPA & 0.28 \\
\hline Reid Gardner \#1-3 Avg. & $\begin{array}{l}\text { ROFA w/ } \\
\text { Rotamix }\end{array}$ & & & & 0.23 \\
\hline Reid Gardner \#1 & $\begin{array}{l}\text { LNB/OFA + } \\
\text { SCR }\end{array}$ & 0.07 & 7.73 & No & NA \\
\hline Reid Gardner \#2 & $\begin{array}{l}\text { LNB/OFA + } \\
\text { SCR }\end{array}$ & 0.07 & 7.44 & No & NA \\
\hline Reid Gardner \#3 & $\begin{array}{l}\mathrm{LNB} / \mathrm{OFA}+ \\
\text { SCR }\end{array}$ & 0.07 & 8.29 & No & NA \\
\hline Apache Gen. Station \#2 & LNB/OFA & 0.31 & 2.00 & by ADEQ & 0.31 \\
\hline Apache Gen. Station \#3 & LNB/OFA & 0.31 & 2.59 & by ADEQ & 0.31 \\
\hline Apache Gen. Station \#2 & $\begin{array}{l}\text { LNB/OFA + } \\
\text { SCR }\end{array}$ & 0.07 & 9.03 & No & NA \\
\hline Apache Gen. Station \#3 & $\begin{array}{l}\mathrm{LNB} / \mathrm{OFA}+ \\
\text { SCR }\end{array}$ & 0.07 & 9.58 & No & NA \\
\hline $\begin{array}{l}\text { Navajo Gen. Station (all } \\
\text { units) }\end{array}$ & LNB/OFA & 0.24 & 1.16 & $?$ & $?$ \\
\hline $\begin{array}{l}\text { Navajo Gen. Station (all } \\
\text { units) }\end{array}$ & $\begin{array}{l}\text { LNB/OFA + } \\
\text { SCR }\end{array}$ & 0.08 & 33.00 & $?$ & $?$ \\
\hline
\end{tabular}

(a) Based on the maximum 98th percentile deciview impact in a Class I area. 
- Measurements specific to this region indicate that actual visibility impacts may not be as great as those estimated by CALPUFF 5.8 as applied by EPA. The data and other studies summarized here are inconsistent and inconclusive as to whether current levels of $\mathrm{NO}_{x}$ emissions from Navajo GS (especially with recent LNB/SOFA in operation) by themselves impact visibility. Therefore, the overall effect of removing approximately two-thirds of the current $\mathrm{NO}_{\mathrm{x}}$ emissions by installing SCR in addition to LNB/SOFA remains uncertain, based on the current state of modeling atmospheric chemical processes. Installing SCR controls might not create any perceptible improvement in visibility; not installing them might postpone addressing a contributing element to regional haze

- The largest source of differences in visibility impact modeling performed by SRP and EPA is the background ammonia concentration, especially in the critical winter period when nitrates tend to be a more significant factor in visibility impairment. SRP used winter background ammonia concentrations that were several times lower than used in EPA's modeling. The SRP winter values correspond with data from rural monitoring sites at Mesa Verde (considered a Four Corners area regional background site) in southwest Colorado, Halls Crossing in southern Utah, and Navajo Lake in northwest New Mexico. EPA's ammonia background values correspond more closely with data collected in more urban or agriculturally developed areas near Farmington that are impacted by local ammonia sources. If the model input ammonia values are too high compared to actual background ammonia concentrations that are mixed into the power plant plumes as they travel downwind of a source, the modeling process can significantly overestimate nitrate particle formation, thus overestimating visibility impact of the plumes.

- Navajo GS emissions have recently dropped by more than $40 \%$, and region-wide $\mathrm{NO}_{\mathrm{x}}$ emissions are on a significant downward trend that should continue for several years (due especially to mobile source engine emissions standards).
It would therefore be prudent, whether or not Navajo GS is fitted with SCR during the current round of $\mathrm{NO}_{\mathrm{x}}$ reductions, to take a similar look at regional IMPROVE monitor results in a few years. $\mathrm{NO}_{\mathrm{x}}$ and $\mathrm{SO}_{2}$ compete for ammonia, so observing actual improvements as both continue to decline significantly in the region should help to understand whether further controlling $\mathrm{NO}_{\mathrm{x}}$ emissions from Navajo GS or other sources are likely to provide any significant visibility improvement. 


\section{Impacts on American Indian Tribes in Arizona}

This chapter examines how the Navajo GS, the Peabody Western Kayenta coal mine, and the Central Arizona Project (CAP) impact Arizona's Indian tribes, their people, and homelands. The power plant is on Navajo land, while the coal mine is on land within the boundaries of both the Navajo and Hopi Indian Reservations. The CAP, which depends on electricity from the Navajo plant to operate its water distribution infrastructure, delivers water to nine tribes in Arizona.

The EPA's final BART determination will have diverse impacts on Arizona's tribes. ${ }^{1}$ This chapter separately examines two categories of effects: those related to power generation, and those affecting the cost of delivering the water that tribes depend on for domestic and agricultural use. For the Hopi Tribe and Navajo Nation in northeast Arizona, a power plant shutdown would impact areas such as local employment, tribal revenues, and public health. For the tribes that receive CAP water, any change to the status quo is likely to increase costs for CAP water rates. While changes to water rates are addressed fully in Chapter 4, this chapter will describe more fully the tribes' use of the CAP water.

\subsection{Tribes and Power Generation}

Early plant retirement is the only BART scenario that would seriously harm the economies of the Navajo Nation and the Hopi Tribe, the two tribes engaged in various aspects of coal mining and power production. As discussed in the previous chapters, Navajo GS would continue to run at nearly the same level of production if SCRs or any other control technology were installed. The plant's capital costs would be higher, but its production costs would increase by a modest $3 \%$ to $4 \%$. The plant would still have lower operating costs than most other generators in the Desert Southwest, and would require the same amount of coal and at least the same number of employees to run.

Also recall from Chapters 2 and 3 that the likely power

1 EPA's policies for framing the considerations of decisions that could affect Indian tribes were set forth in 1984 and re-affirmed in 2009. "EPA Policy for the Administration of Environmental Programs on Indian Reservations," available at http://www.epa.gov/tribalportal/pdf/indianpolicy-84.pdf (last visited on December 27, 2011). replacement costs resulting from shutdown are likely to be higher than the capital cost and additional production cost of adding emission controls. ${ }^{2}$ Those analyses suggest that the basic economics (apart from uncertainties discussed elsewhere in this report) would not favor retirement. Even with baghouses added to the plausible cost range of SCRs, the additional cost would still in all likelihood be less than the cost of replacing Navajo GS with spare capacity on existing generators elsewhere in the region.

The tribes have already experienced plant and mine closures. The Mohave Generating Station in southeastern Nevada closed at the end of 2005, due largely to the cost of retrofitting the power plant with $\mathrm{SO} 2$ scrubbers. At that time, all the coal for Mohave came from the Black Mesa Mine, one of two mines at the Black Mesa Mining Complex. The company used water from the Navajo Aquifer (N Aquifer) to slurry the coal to the power plant in Laughlin, Nevada, some 273 miles away. When Mohave closed, nearly a third of the Hopi's operating budget - then \$21.5 million-was eliminated.

The 2005-2006 Navajo Nation strategic plan anticipated that the loss of mining jobs caused by the closure of the Mohave Power Plant would have a severe impact on the regional economy, including less revenue for the tribal government and the services it provided. The plan noted that levying a tribal income tax and developing gaming revenues were both being considered to replace the lost revenues. Since that time, the Navajo Nation has opened two tribal casinos in New Mexico and has broken ground on a third one that will be outside Flagstaff, Arizona.

\subsubsection{Employment and Economic Conditions}

Nearly 1,000 people are employed at Navajo GS and the Kayenta coal mine with the majority being American Indians (450 at the power plant and 400 at the mine). Wages and benefits for all Native employees are $\$ 52$ million at the plant and $\$ 46.8$ million at the Kayenta Mine. ${ }^{3}$

2 Recall that these analyses hold all other factors constant, and do not factor in uncertainties due to investment recovery timelines, changes in future plant ownership, renegotiating the site lease with Navajo Nation, and changes in transmission path ratings.

3 Information supplied by Salt River Project and Peabody Energy. The companies do not collect information about the particular tribal affiliations of any individual employee. 


\section{Navajo Generating Station Tribe Map}

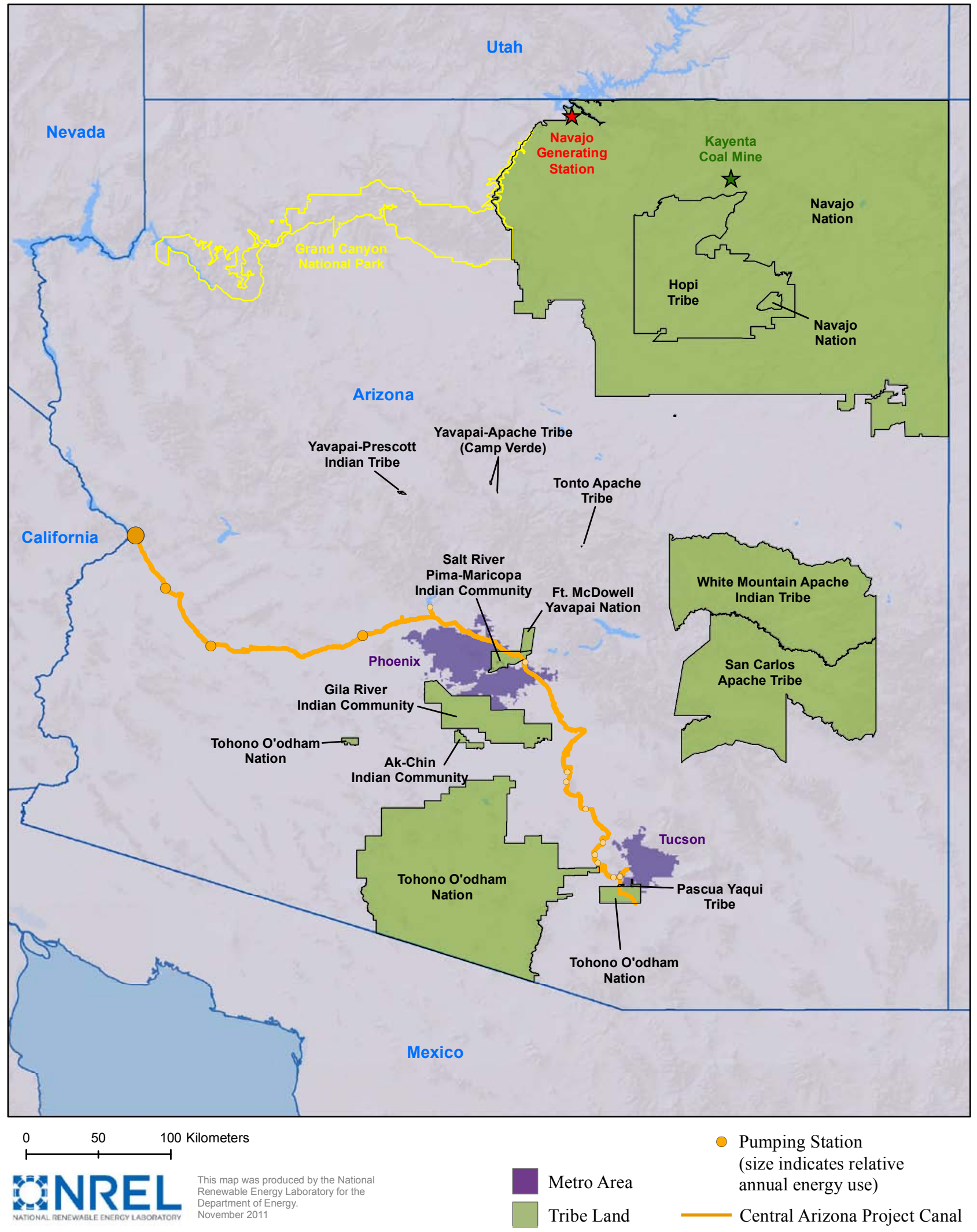

Figure 6-1. Navajo generating station tribe map 


\begin{tabular}{|l|c|c|c|}
\hline & $\begin{array}{c}\text { Poverty Rate, } \\
\text { All People }\end{array}$ & $\begin{array}{c}\text { Poverty Rate, Under } \\
\mathbf{1 8}\end{array}$ & $\begin{array}{c}\text { Average Annual } \\
\text { Income }\end{array}$ \\
\hline Navajo Reservation & $37.4 \%$ & $44.1 \%$ & $\$ 35,926$ \\
\hline Hopi Reservation & $34.9 \%$ & $44.0 \%$ & $\$ 38,062$ \\
\hline Arizona & $14.7 \%$ & $20.8 \%$ & $\$ 67,331$
\end{tabular}

(a) U.S. Census, 2005-2009 American Community Survey. http://www.census.gov/acs/www/data_documentation/2009_5yr_data/

The power plant's 450 full-time Native American preference employees represent $83 \%$ of its workforce, and include both hourly and salaried positions. Eighty-three of the Navajo-preference positions are in management or professional roles. The average hourly wage at the plant, around $\$ 35.00$ per hour ${ }^{4}$, is twice Coconino County's average wage. $^{5}$

The Kayenta Mine, which is operated by Peabody Western Coal Company (PWCC), employs 400 Native Americans among its total workforce of 425. Native Americans make up $79 \%$ of the managers, supervisors, and officials. Annual wages and benefits are around $\$ 46.8$ million, or about $\$ 117,000$ per employee on average.

Although the wages and benefits from the mine are high, 2000 Census data show that only $0.7 \%$ of the Hopi tribal members are employed in the mining industry. The numbers are slightly higher for the Navajo Nation- $-2.7 \%$. However, these figures are much higher in some areas directly surrounding the mine area, such as in the Navajo Nation's Chilchinbito, Dennehotso, Shonto, and Inscription House areas, ranging from $11.7 \%$ to $18.4 \%{ }^{6}$

Both the Navajo Nation and the Hopi Tribe have communities living in extreme poverty. The U.S. Census Bureau's American Community Data show that $37 \%$ of the Navajo Nation's population lives in poverty. The statistics are similar for the Hopi Tribe. In the years 2005$2009,35 \%$ of Hopi people were in poverty. Within both tribes, $54 \%$ of related children under 18 lived below the poverty level. The proportion of the population living

\footnotetext{
4 Hourly wage interpolated from Table D-12, Office of Surface Mining, "Kayenta Mine Permit Renewal Environmental Assessment." August 2011.

5 Bureau of Labor Statistics, "Quarterly Census of Employment and Wages." 2010 data. http://www.bls.gov/cew. Last visited November 18, 2011.

6 U.S. Census Bureau 2000 (SF3, QT-P24 and SF3, QT -P30). The 2010 Census data is not yet available at this level of analysis.
}

below the poverty level in both tribes is more than twice that of Arizona as a whole, while the average annual income on the reservations was nearly half that of the state population.

Census data indicate that both tribal populations have high dependency ratios, in that the proportion of the non-working population to the working population is higher than for the rest of the State of Arizona. ${ }^{7}$ This trend generally indicates more people relying on wages as well as on government and community support services. In interviews, Peabody officials said that each mining job typically supports large and extended families.

\subsubsection{Leases, royalties, and other payments}

The royalties and bonus payments from the Kayenta Mine consistently provide one of the largest sources of revenue for both the Hopi Tribe and Navajo Nation. Table 6-2 summarizes some of the benefits paid to the tribes. According to a recent strategic development plan for the Navajo Nation, mining-related revenues - including the Kayenta Mine and other mining activity on the reservation - have provided more than $55 \%$ of the tribe's operating expenses in recent years. ${ }^{8}$ The Hopi have said that more than $80 \%$ of their 2009 budget was funded by mining revenue. ${ }^{9}$

7 The dependency ratio is calculated by dividing the non-working population ( $0-14$ years and over 65 years) by the working population and multiplying by 100 .

8 Navajo Nation Division of Economic Development.“2009-2010 Economic Development Strategy." Available at http://www.navajobusiness.com/pdf/ CEDS/CED_NN_Final_09_10.pdf. Last visited November 18, 2011.

9 Leroy Shingoitewa, Testimony to U.S. House of Representatives, Water and Power Subcommittee and Indian and Alaska Native Affairs Subcommittee, Joint Oversight Hearing on "Protecting Long Term Tribal Energy Jobs and Keeping Arizona Water and Power Costs Affordable: The Current and Future Role of the Navajo Generating Station, May 24, 2011. Available at http://naturalresources.house.gov/UploadedFiles/ ShingoitewaTestimony05.24.11.pdf. Last visited November 18, 2011. 
Table 6-2. Tribal Benefits Paid by PWCC (\$ Millions) ${ }^{a}$

\begin{tabular}{|l|c|c|}
\hline & $\begin{array}{c}\text { Annual Average } \\
\text { Payments }\end{array}$ & Total Payments (1987-2010) \\
\hline Coal Royalties & $\$ 34.7$ & $\$ 988.10$ \\
\hline Coal Bonuses $^{b}$ & $\$ 6.4$ & $\$ 64.2$ \\
\hline Water Fees $^{-1}$ & $\$ 3.2$ & $\$ 73.0$ \\
\hline NTUA Revenue $^{c}$ & $\$ 6.3$ & $\$ 151.5$ \\
\hline Total & $\$ 50.6$ & $\$ 1,276.80$ \\
\hline
\end{tabular}

(a) Office of Surface Mining. "Kayenta Mine Permit (AZ-0001D) Renewal Environmental Assessment.” August 2011.

Available at http://www.wrcc.osmre.gov/Current_Initiatives/Kayenta_Mine/Renewal.shtm. Last visited November 16, 2011. Appendix F; Charts F-7, F-8, and F-10.

(b) Peabody began paying coal bonuses in 1998. Total includes a $\$ 24$ million bonus in 2006 after lease extension

(c) The Navajo Tribal Utility Authority is a business enterprise of the Navajo Nation. Total payments include 2010 estimated payment of $\$ 9.9$ million

Table 6-3. Hopi Tribal Revenue from Kayenta Mine Operations (\$ Millions) ${ }^{a}$

\begin{tabular}{|l|c|c|}
\hline & Annual Average & Total Payments (1987-2010) \\
\hline Coal Royalties & $\$ 10.2$ & $\$ 235.3$ \\
\hline Coal Bonus Payments & $\$ 2.2$ & $\$ 19.6$ \\
\hline Water Fees & $\$ 1.6$ & $\$ 36.5$ \\
\hline Total & $\$ 14.0$ & $\$ 291.40$ \\
\hline
\end{tabular}

(a) This table represents the Hopi Tribe's share of the totals from Table 6-2.

Table 6-4. Navajo Nation Revenue from Kayenta Mine Operations (\$ Millions) ${ }^{a}$

\begin{tabular}{|l|c|c|}
\hline & Annual Average & Total Payments (1987-2010) \\
\hline Coal Royalties & $\$ 24.4$ & $\$ 562.1$ \\
\hline Coal Bonus Payments & $\$ 4.5$ & $\$ 19.6$ \\
\hline Water Fees & $\$ 1.6$ & $\$ 36.5$ \\
\hline NTUA Revenue & $\$ 6.7$ & $\$ 153.8$ \\
\hline Total & $\$ 37.2$ & $\$ 772.0$ \\
\hline
\end{tabular}

(a) This table represents the Navajo Nation's share of the totals from Table 6-2.

Overall, PWCC pays about $\$ 50$ million/year to the two tribes, and since 1987 has paid a total of nearly $\$ 1.3$ billion to the tribes. In 2010, the total tribal payments for coal royalties were $\$ 34.4$ million and the coal bonuses for the two tribes totaled $\$ 5$ million. Bonuses are fixed and currently triggered and paid when the first ton is mined for the given year. Royalties are based on the volume of production. Table 6-3 and Table 6-4 show how the sums have been allocated to each tribe based on their interest in the mining operations.

Peabody has a lease from the tribes to use water from the N Aquifer, paying $\$ 943.48$ an acre-foot for its use. The total payment for the mine's 2010 water usageapproximately $\$ 1.1$ million - was split equally between the two tribes. The amount of revenue from water sales 
has decreased significantly, nearly $75 \%$, since the closing of the Black Mesa Mining operation in 2005 and the subsequent termination of coal slurry operations.

The Kayenta Mine also pays the Navajo Tribal Utility Authority (NTUA) for electricity use at the mine and related operations. These payments average about $\$ 6.3$ million a year, although payments have shown a steady increase. In 2010, Peabody estimates it paid NTUA \$9.9 million. On average, Peabody's payments make up approximately $15 \%$ of the NTUA's revenue from electricity sales and around $10 \%$ of its overall revenue. ${ }^{10}$

The mine also pays state property taxes, providing a major source of revenue for Navajo County and the Kayenta Unified School District. Property tax revenues in 2010 were about $\$ 1.6$ million, $\$ 1.2$ million of which went to the school district.

From 1988 through 2010, the Hopi Tribe received a total of $\$ 3,876,000$ in scholarship funds through the coal lease agreements. The annual amount in 2010 was $\$ 173,000$ with the amount set to escalate each year. For that same time period, the Navajo have received a total of $\$ 4,422,000$ in scholarship funds through the coal lease agreements. Both Peabody and the power plant fund these scholarships. Peabody officials say the company provides other local area benefits such as resident land use payments; assistance with grazing management programs and education; road maintenance and improvements; water supply assistance; free public coal to area residents; an annual health fair, a 24-hour emergency health care facility and ambulance service; and emergency assistance with roads, coal, and water.

\subsubsection{Public health concerns}

Several stakeholders and individuals expressed concerns over how the mine and the power plant affect public health. The lack of epidemiological studies specific to the population living on the Hopi and Navajo Reservations means that conclusions about public health impacts near the Navajo Plant and Kayenta Mine must instead be drawn from personal experiences and more general studies.

\footnotetext{
10 Office of Surface Mining. "Kayenta Mine Permit (AZ-0001D) Renewal Environmental Assessment.” August 2011. Available at http://www.wrcc. osmre.gov/Current_Initiatives/Kayenta_Mine/Renewal.shtm. Last visited November 16, 2011. Appendix F-10.
}

The following is a compilation and description of the information available.

Although the scope of the current EPA proceeding is visibility, Navajo GS owners are analyzing the economic impacts of visibility, toxics, and other potential regulations as an aggregation of risk (see Chapter 1). The business decisions resulting from all these regulatory outcomes will have some impact on the health of tribal populations living near Navajo GS or the mine.

Power plant emissions have long been a key priority for EPA monitoring, regulation, and enforcement, because of their potentially serious public health effects. ${ }^{11}$ Uncontrolled releases of mercury from power plants damage children's developing brains, affecting memory, attention, language, and fine motor and visual spatial skills. Mercury and other toxics also pollute lakes, streams, and fish. Other metals such as arsenic, chromium, and nickel can cause cancer.

On March 16, 2011, EPA proposed mercury and air toxics standards, applicable to new and existing power plants using coal and fuel oil. The standards aim to reduce emissions of metals, including mercury, arsenic, chromium, and nickel; acid gases, including hydrogen chloride and hydrogen fluoride; and particulate matter. EPA published its final rule in December 2011. For coal-fired units, such as the Navajo plant, the proposed standards would establish numerical limits for mercury, acid gases, and particulate matter.

A related concern raised by non-governmental organizations (NGOs) with regard to the Navajo plant is the disposal of coal combustion residuals (CCRs) such as coal ash. The Sierra Club, for example, cited studies that concluded waste from coal plants carries into the environment 100 times more radiation than a nuclear power plant producing the same amount of energy. ${ }^{12}$

In June 2010, the EPA proposed a draft rule on disposing of CCRs. The EPA noted that the environmental concerns over coal ash pertain to "pollution from impoundment

\footnotetext{
11 Environmental Protection Agency. "Mercury and Air Toxics Standards (MATS).” http://www.epa.gov/airquality/powerplanttoxics/. Last visited November 18, 2011.

12 Hvistendahl, Mara. "Coal Ash is More Radioactive than Nuclear Waste.” Scientific American, Dec. 17, 2007. Available at: http://www. scientificamerican.com/article.cfm?id=coal-ash-is-more-radioactive-thannuclear-waste. Last visited November 16, 2011.
} 
and landfills leaching into ground water and structural failures of impoundments." 13 The proposed rule does not address the recycling of coal ash into building materials, such as concrete used in commercial and infrastructure applications. In the proposed rule, the EPA stated "there is wide acceptance of the use of CCRs in encapsulated uses, such as wallboard, concrete, and bricks because the CCRs are bound into products. The Agency believes that such beneficial uses of CCRs offer significant environmental benefits." 14

On the Navajo Reservation, coal ash is recycled into concrete to pave streets and is used in construction of facilities in the form of FlexCrete. ${ }^{15}$ The Navajo Housing Authority has used the FlexCrete bricks to build homes on the Navajo reservation. ${ }^{16}$ The Navajo FlexCrete plant is 3 miles from the power plant, and the company estimates that approximately 21 tons of coal ash is recycled into every house built with their product. ${ }^{17}$

\subsubsection{Groundwater Issues}

Several NGOs who met with NREL expressed concern about the mine and the power plant contaminating groundwater, depleting natural springs, and the impacts of coal ash and the mercury and particulates it contains impacting the health of residents on both the Navajo and Hopi reservations. Navajo Nation officials, on the other hand, cite a USGS study commissioned by the Office of Surface Mining (OSM) that refuted concerns that the mining operations are pumping water from the $\mathrm{N}$ Aquifer to the detriment of the land or natural springs.

OSM recently released a draft Environmental Assessment (EA) and Finding of No Significant Impact for the 5-year

\footnotetext{
13 Environmental Protection Agency. "Coal Combustion Residuals - Proposed Rule.” http://www.epa.gov/wastes/nonhaz/industrial/special/fossil/ccr-rule/ index.htm. Last visited November 16, 2011.

14 Environmental Policy Agency. "Hazardous and Solid Waste Management System; Identification and Listing of Special Wastes; Disposal of Coal Combustion Residuals From Electric Utilities; Proposed Rule.” 75 Fed. Reg. 35128, 35154 (June 21, 2010).

15 See http://www.navajoflexcrete.biz/

16 Thompson, Jonathan. "Ashes to Houses." High Country News. November 20, 2007. Available at: http://www.hcn.org/articles/17384. Last visited November 16, 2011.

17 Navajo FlexCrete Building Systems, Inc. Promotional presentation. Available at http://www.navajoflexcrete.biz/presentations. Last visited November 16, 2011.
}

renewal of the Kayenta Mine. ${ }^{18}$ A significant portion of this document addressed ground and surface water impacts. However, multiple NGOs provided public comments on the EA that question these assessments and the OSM's finding for the mine permit renewal. ${ }^{19}$

Black Mesa Water Coalition, Diné C.A.R.E., To Nizhoni Ani, Center for Biological Diversity, and Sierra Club argue the EA does not properly analyze depletion to the $\mathrm{N}$ Aquifer or the diminution in water quality to water impoundments at the mine. An updated comment to the EA provides a third-party analysis critical of the hydrological studies that support the EA's FONSI. ${ }^{20}$ OSM collected public comments on the EA through November 3, 2011. They have not issued a Record of Decision regarding the permit renewal.

\subsubsection{Hopi Tribe}

The Hopi Tribe is located 250 miles northeast of Phoenix. Most of the tribe's area is completely surrounded by the Navajo Nation reservation. Hopi Indian trust lands include the Moenkopi District reservation near Tuba City, and its Ranch Lands area between Flagstaff, Winslow and Holbrook. There are approximately 7,000 Hopi people living on the 1.5-million-acre reservation, far fewer than the Navajo population. The terrain is high desert, dotted with pinion, juniper, and sagebrush.

The Hopi Tribe is party to joint mining leases along with the Navajo Nation for some of the coal in the Black Mesa Mine Complex. The Hopi receive about $\$ 13$ million annually from the Kayenta Mine operations in coal royalties and bonus payments. However, the Hopi Tribe does not receive any revenues from the operations of the Navajo plant. The revenues contribute to supporting its government functions, directly impacting nearly every aspect of Hopi life, including the education of Hopi young people; health and social service programs; governmental

\footnotetext{
18 Office of Surface Mining. "Kayenta Mine Permit (AZ-0001D) Renewal Environmental Assessment." August 2011. Available at http://www.wrcc. osmre.gov/Current_Initiatives/Kayenta_Mine/Renewal.shtm. Last visited November 16, 2011.

19 Letter from Brad A. Bartlett, Energy Minerals Law Center to Richard Holbrook, Office of Surface Mining, June 4, 2010. Available at: www.nrel. gov/ngs.

20 Daniel Higgins, “Comments on Peabody Western Coal Company’s Permit Renewable for the Kayenta Coal Mine: Review of 2008 Cumulative Hydrologic Impact Assessment, 2010 Probable Hydrologic Consequences, 2011 Environmental Assessment, and Peabody Groundwater Model." October 2011. Not peer reviewed. Available at: www.nrel.gov/ngs.
} 


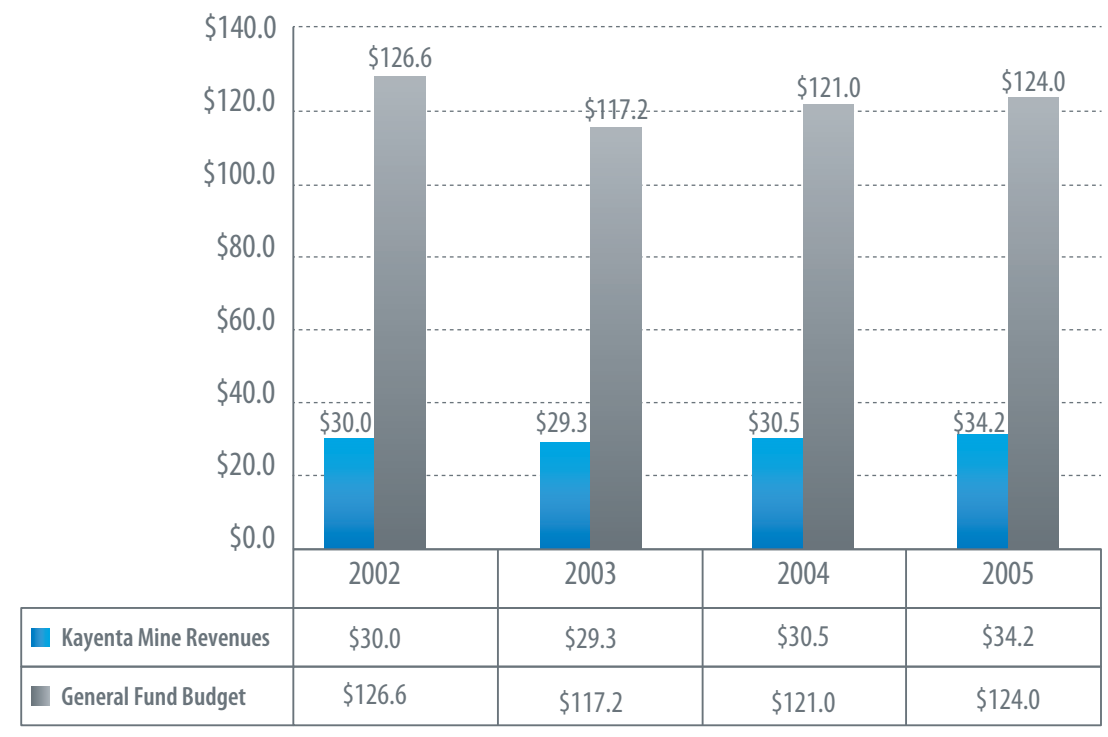

Figure 6-2. Navajo Nation, Kayenta Mine revenues and general fund budget 20022005 (\$ millions)

infrastructure; and many other essential tribal programs. ${ }^{21}$

Hopi leaders initially were concerned that closing the Navajo plant would have severe and immediate economic impacts on the tribe, including increasing unemployment, severe curtailment of social programs, slowing of capital advancements, weakened tribal government infrastructure programs, and other indirect economic losses. ${ }^{22}$ More recently, however, the leadership changed to a position of neutrality based on information that the future of the Lower Colorado River adjudication settlement - a water rights lawsuit that the Hopi have participated in for more than 10 years - is directly related to the continued operability of the Navajo plant. In a July 25, 2011, letter to U.S. Secretary of Interior Ken Salazar, Hopi Chairman Leroy Shingoitewa said the tribe intends to remain neutral on the power plant issue until they are able to understand the relationship between the plant and the river adjudication. ${ }^{23}$

21 Chairman Shingoitewa, personal communication.

22 Hopi Chairman Leroy Shingoitewa testified to Congress on May 24, 2011, that "...implementation of the BART decision would undermine the Hopi Tribe's ability to maintain its homeland." Testimony to U.S. House of Representatives' Water and Power Subcommittee and Indian and Alaska Native Affairs Subcommittee, Joint Oversight Hearing on "Protecting Long Term Tribal Energy Jobs and keeping Arizona Water and Power Costs Affordable: The Current and Future Role of the Navajo Generating Station, May 24, 2011.

23 Letter from Chairman Leroy Shingoitewa to Secretary Ken Salazar. July 25, 2011. Available at www.nrel.gov/ngs.
The remoteness of the reservation creates many challenges and limits opportunities for economic development. A total of $26 \%$ of the employed workforce is in the public administration sector, heightening the potential impact of a significant decrease in the revenues from the mine. In terms of other energy development, the Hopi Tribe is one of the few tribes with an established and dedicated Renewable Energy Office, and NREL resource assessments show large amounts of high-quality solar resource areas across the Hopi Reservation. ${ }^{24}$ NGOs, such as the Black Mesa Water Coalition, have issued reports on the potential for renewable energy development on Hopi lands, including the Black Mesa Mining complex. ${ }^{25}$

\subsubsection{Navajo Nation}

The Navajo Nation is located 260 miles northeast of Phoenix. It is the largest tribal nation in the United States, both in population and landmass. The population is approximately 300,000 . The reservation covers more than 27,000 square miles in 13 counties of Arizona, New Mexico, and Utah.

Historically, mining has been an important stream of income for the Navajo Nation. Navajo Nation President Ben Shelly said that the power plant is, therefore, "an essential component of the Navajo Nation's economy and our energy portfolio, and must remain viable, for the sake of the Nation and our People, for years to come." ${ }^{26}$ As Figure 6-2 demonstrates, historically, a significant portion of the Navajo Nation's annual budget comes from revenues related to the Kayenta Mine. ${ }^{27}$ Including other mining operations, such as the now-closed Black Mesa

\footnotetext{
24 National Renewable Energy Laboratory. "Solar Prospector.” http://maps. nrel.gov/prospector

25 Black Mesa Water Coalition. "Solar Potential on Black Mesa.” February 2011. Available at: www.nrel.gov/ngs.

26 Navajo Nation Division of Economic Development."2009-2010 Economic Development Strategy." Available at http://www.navajobusiness.com/pdf/ CEDS/CED_NN_Final_09_10.pdf. Last visited November 18, 2011.

27 Navajo Nation 2005-2006 Comprehensive Economic Development Strategy of the Navajo Nation, page 13 (total Budget amounts); Kayenta Mine Renewal EA, Appendix F (Kayenta Mine Revenues).
} 
and Pittsburgh \& Midway mines, the Navajo Nation has recently depended on mining revenues for upwards of $50 \%$ of its annual budget.

The Navajo Nation receives an average of \$37.2 million per year from PWCC from the Kayenta mine, and total payments since 1987 have been $\$ 772$ million. Because the power plant is on reservation lands, the Navajo Nation receives additional leasing income. In 2009, the Navajo Nation received site lease payments from the power plant site in the amount of $\$ 600,000$, and air permit fees in the amount of $\$ 400,000 .{ }^{28}$ Negotiations for a new site lease are currently taking place; the current lease is set to expire in 2019. Currently, the rights-of-way used by the railway to deliver coal to the plant are not assessed any fees, and such fees will be part of the new lease when it is finalized, according to Navajo officials.

NTUA, an enterprise of the Navajo Nation, provides electricity, natural gas, water, wastewater treatment, and solar energy to residents and businesses of the Navajo Nation, and provides service to limited areas of the Hopi Reservation. The NTUA purchases electrical power from sources off the reservation and distributes it to homes across northeastern Arizona, northwestern New Mexico, and southeastern Utah. The Kayenta Mine is a major user of power provided by NTUA, with the value of power purchases amounting to just under \$10 million in 2010. Two 69-kilovolt $(\mathrm{kV})$ feeder lines serve the mines. Under an agreement with NTUA, Peabody operates the substation that serves the mine. Arizona Public Service provides electrical service to other parts of the Hopi Reservation.

Neither the tribe's strategic development plan nor any other document reviewed for this study contained an economic transition plan for when the Navajo power plant closes. Several efforts aim to promote economic diversification, but none are explicitly linked to a transition plan. In July of 2009, for example, the Navajo Nation Council passed legislation establishing a Navajo Green Economy Commission, a five-person commission that will seek funding to help foster a green economy for the Navajo Nation. However, funding for the commission was not included in this year's Navajo Nation appropriations.

\footnotetext{
28 Comments of the Central Arizona Water Conservation District on the Environmental Protection Agency's Advanced Notice of Proposed Rulemaking Regarding Best Available Retrofit Technology for Nitrogen Oxide Emissions at the Navajo Generating Station, Docket Number EPA-R09-OAR-2009-0598, Oct. 28, 2011. Table I - Benefits to the Navajo Nation, page 5 .
}

The commission is charged with overseeing the approval of small-scale green projects, such as wool mills, farmers markets, and home weatherization. The Council also voted to create a Navajo Green Economy Fund that creates an account for receiving federal, state, local, and private funds to make these green projects possible.

The Navajo Nation is pursuing several renewable energy projects through the NTUA:

- Boquillas Wind Project: SRP announced in July 2011 that it had selected the NTUA and Edison Mission Energy to build and operate the 85-MW Boquillas wind project in Coconino County, Ariz. SRP anticipates purchasing $100 \%$ of the output from the wind project under a 25 -year power purchase agreement. ${ }^{29}$

\section{- Gray Mountain Wind Farm (Cameron,} Arizona): Potential to produce up to $500 \mathrm{MW}$; likely the best wind site on the Navajo Nation. An independent power producer (IPP) is working with the local community and potential developers to realize this project. NTUA and the IPP have secured the interconnection queue position to transmit power from this proposed wind farm. This project is in early pre-development stages.

- Black Mesa Wind Farm (Kayenta, Arizona): Potential to generate up to $60 \mathrm{MW}$; preliminary wind data warrants a formal wind study at two sites on Black Mesa. NTUA is exploring the feasibility of development and the project is in the early pre-development stage.

- NTUA Chevron Mine Solar Project (Window Rock, Arizona): This project will build out an existing 60-MW solar farm. NTUA is working on this development with Sun Carrier.

- Paragon Ranch Solar Project (Paragon, New Mexico): This project has potential to build out to more than $200 \mathrm{MW}$. The Navajo-Hopi Land Commission is working with TetraTech on the feasibility studies.

\section{- Gray Mountain Solar Project (Cameron/Gray} Mountain, Arizona): This project has potential to build out to $40 \mathrm{MW}$. 
- To'hajiilee Solar Farm (Tohajiilee, NM):

Project developers entered into an agreement with SunPower and began negotiations on the power purchase agreement (PPA) and financing.

- Iyanbito Solar Farm (Iyanbito, NM): Project developers are working with the community to establish a 20-MW solar farm. Project is early predevelopment stages.

\section{- NTUA Chevron Biomass Facility (Window}

Rock, AZ): Project developers are looking to build a 20-MW biomass facility. NTUA has already purchased the lands and is working on a PPA.

The Navajo Nation is also involved in potential new fossil fuel plants that could be sited on its land. Two-a combined cycle natural gas plant augmented with concentrating solar power, and a generator powered by waste heat from a proposed coal gasification and liquefaction plant - are in early pre-development. The Desert Rock Energy Project, a 1,500-MW coal-fired power plant that would be owned and operated by the Navajo Nation, initially gained the required EPA permits it needed during the Bush Administration. Those permits have since been rescinded and the project remains on the drawing board. ${ }^{30}$

\subsection{Tribes with CAP water allocations}

Nine tribes (including three districts of the Tohono O'odham Nation) have CAP water contracts. Early federal acts include the Ak-Chin Settlement of 1984 and the Southern Arizona Water Rights Settlement Act of 1982 (SAWRSA). More recently, the Arizona Water Settlement Act of 2004 (AWSA) settled claims for the Gila River Indian Community (GRIC) and amended the SAWRSA to provide additional CAP water needed to implement the 1984 agreement.

The Navajo Nation and the Hopi Tribe - the two tribes most affected by operations at the power plant and the coal mine - are also in the midst of water rights settlement negotiations for the CAP and other water allocations to meet the needs of the tribes' citizens.

A significant increase in the cost of power from the power plant can affect key provisions of these agreements to the detriment of the tribes. The consequences are magnified by the fact that several of the settlements include language that waives the tribes' claim to future water aside from those specified in the settlement. Many of these settlements anticipate a role for the Lower Colorado River Basin Development Fund in meeting the terms of the agreement.

The tribal water issues that stand to be affected by the BART rule can be traced back to U.S.-Indian treaty law. The United States government established reservations for tribes throughout the country as permanent homelands where tribal populations could live undisturbed, in exchange for the lands they gave up. Over time, the courts established the doctrine of federally reserved water rights, known as the Winters Doctrine. ${ }^{31}$ The courts held that, along with the reservations of land, the tribes also required reservations of water to sustain the people and their lands; the Winters Doctrine holds that the treaties between the tribes and the United States implied corollary rights to such natural resources. ${ }^{32}$ This legal principle is also carried through for reservations created through executive order or by Congressional acts. These federally reserved water rights have been the subject of litigation, negotiations, and, in some cases, water rights settlements.

Access to water was critical to the development of many non-Indian communities in Arizona, which was the justification for developing CAP. As Chapter 4 explains in further detail, the Colorado River Basin Project Act (CRBPA) of 1968 established the Development Fund as part of the overall CAP plan to hold (among other monies) revenues from selling excess power from the federal government's share of the Navajo plant, and payments made each year by CAWCD toward CAP debt obligations. The Hoover Power Plant Act of 1984 authorized applying revenues from excess power sales toward CAWCD's CAP repayment obligations. The AWSA further amended the CRBPA in 2004. Under these most recent changes, revenues in excess of what is needed to fund CAP repayment is earmarked for offsetting the cost of delivering CAP water to tribes, for the construction and rehabilitation of distribution systems to deliver CAP water to tribes, and for payment for an Indian water rights settlement yet to be reached. The 2004 amendment established statutory priorities for

31 Winters v. U. S., 207 U.S. 564, 28 S. Ct. 207 (1908).

32207 U.S. at 577, 28 S. Ct. at 212.

30 http://navajotimes.com/news/2010/0410/040810desertrock.php 
the use of monies from the Development Fundbeyond those credited toward CAP repayment. These cascading priorities start with payments toward the tribes' operations, maintenance and replacement (OM\&R) charges for water delivery. Rehabilitating irrigation systems and building new water distribution systems are among the priorities. Once CAP repayment is completed in 2043, all Development Fund payments will go toward these and other designated statutory obligations.

Less revenue flowing into the Development Fund would mean less money available for improving tribal water infrastructure. Chapter 4 explains the flow of money in and out of the Development Fund and how higher power costs from the Navajo GS might affect the amount of funds available. Tribal CAP projects previously funded from appropriations are now funded from the Development Fund, pursuant to the AWSA. Several of the tribes have started or have proposed infrastructure projects through the Development Fund.

A more direct potential impact is on tribal agriculture because of higher irrigation costs. Arizona's arid climate allows little if any dry farming; nearly all of the state's harvested cropland is irrigated..$^{33}$ Farm profit margins are tight statewide; only $22 \%$ of all farms in Arizona reported any net gain in $2007 .{ }^{34}$ Tribes with entitlements to CAP water receive assistance through the Development Fund for a portion of their irrigation delivery charges - the fund pays the tribes' OM\&R charges, leaving the tribes responsible only for the variable pumping charges.

The pumping charge, however, is where any increase in electricity cost would be recovered. In other words, if BART-related upgrades at the Navajo plant translated into higher electricity costs for running the CAP water pumps, CAWCD could recover the additional cost through the variable pumping charge assessed to all users, including the tribes.

GRIC is the largest CAP water customer. A study commissioned by the tribe concluded that future increases in CAP water costs - increases that would

\footnotetext{
33 U.S. Department of Agriculture, "Census of Agriculture,” 2007. Data tables for Arizona show 832,406 acres of harvested cropland, of which 823,468 acres were irrigated.

34 U.S. Department of Agriculture, "Census of Agriculture," 2007.
}

occur without any BART-related changes at the Navajo plant - would continue to erode farm operating margins for the tribe. Assuming that the federal government's share of capital costs would be recovered entirely through higher pumping charges, GRIC estimates that adding SCR technology at the Navajo plant would reduce the tribe's net farm income by around $2 \%$ in 2015 , and by $3.3 \%$ in 2020 . The tribe's study estimates that the additional cost of baghouses along with SCR would increase the impact on net farm income by a factor of two. ${ }^{35}$

\subsubsection{Impacts on specific tribes}

The foregoing discusses the potential impacts that would be common to all tribes using CAP water. Each tribe has particular needs and circumstances, however, so there would also be individual impacts that would affect water deliveries and infrastructure development, depending upon the terms of each tribal settlement.

\section{Ak-Chin Indian Community}

The Ak-Chin Tribe has a CAP allocation of up to 85,000 acre-feet (a.f.) per year if available. ${ }^{36}$ This includes a lease of up to 10,000 a.f. annually to Del Webb Corporation for a development north of Phoenix called Anthem. ${ }^{37}$ Whatever portion of water the Ak-Chin Indian Community doesn't use is available for delivery to the San Carlos Apache Tribe to fulfill obligations made to them.

\section{Ft. McDowell Yavapai Nation}

The tribe has an allocation of 18,233 a.f. and is currently leasing 4,300 a.f. of their allocation to the City of Phoenix. The tribe is currently entering into annual leases for all but 250 a.f. of the balance. ${ }^{38}$ Full cost of delivery for the leased water is paid by Phoenix.

\section{Gila River Indian Community}

In testimony to Congress, GRIC officials described the importance of upholding the terms of the Community's water settlement based on the trust obligations of the

\footnotetext{
35 Harvey Economics, transmittal letter and exhibits of draft findings, November 16, 2011.

36 An acre-foot is the amount of water needed to fill an acre with water 1 foot deep and is generally abbreviated as a.f. An acre-foot is typically the water needed to fulfill the needs of a five-member family for 1 year.

37 http://www.onlineatanthem.com/

38 U.S. Bureau of Reclamation, personal communication to NREL.
} 
United States. The tribe has a vision of returning to a traditional lifestyle of farming that enhances the status of its culture, economy, and health, and is developing a 2,400-mile irrigation canal system to deliver agricultural, municipal, industrial, riparian repair, and recreational water to the reservation. The Community says it believes that increased CAP water costs will put those community goals in jeopardy. ${ }^{39}$

The GRIC has a CAP allocation of 311,800 a.f., which represents about $23 \%$ of the total annual CAP supply. The Community is the largest CAP customer in Arizona. ${ }^{40}$ The GRIC is leasing a portion of its allocation, taking direct delivery of some of its water on the reservation and recharging groundwater at a water savings facility. The Arizona Water Settlement Act of 2004 provides for GRIC to lease or exchange any of its CAP water for offreservation use within 10 Arizona counties. Several lease agreements have been reached with cities in the Phoenix area totaling 41,000 a.f. Phelps Dodge has leased another 12,000 a.f. with an option to lease another 10,000 a.f. in the future. The City of Chandler has an agreement to provide 11,200 a.f. of reclaimed water to GRIC in exchange for 8,970 a.f. of CAP water. Mesa will provide 29,400 a.f. of reclaimed water to GRIC in exchange for 23,530 CAP water.

In addition, the AWSA provides monies from the Development Fund to construct a GRIC water distribution system, as well as for rehabilitation of the San Carlos Irrigation Project. Full cost of the leased water is paid by lessees.

GRIC currently pays for the variable energy costs of their CAP water, although the AWSA established a trust fund that the tribe can elect to use for this purpose. The tribe's fixed OM\&R costs are paid by the Development Fund.

The tribes that constitute GRIC are historically farming tribes, currently irrigating 35,600 acres to grow a variety of crops, including alfalfa, vegetables, melons, small grains, and cotton. GRIC has plans to farm 77,000 acres by 2030 and is planning a total investment of $\$ 645$

\footnotetext{
39 Manual testimony to Congress, May 24, 2011

40 Manuel, Joseph, Gila River Indian Community Lieutenant Governor testimony to U.S. House of Representatives Subcommittee on Water and Power and Subcommittee on Indian and Alaskan Native Affairs, Joint Subcommittee Oversight Hearing on "Protecting Long-Term Tribal Energy Jobs and keeping Arizona Water and Power Costs Affordable: The Current and Future Role of the Navajo Generating Station, May 24, 2011
}

million dollars. Gross operating margins are currently about $\$ 113$ an acre; an analysis conducted for GRIC forecasts that the additional cost of SCRs will reduce margins by $3 \%$ in 2020 , and by $8.5 \%$ in $2030 .{ }^{41}$

Cumulative employment losses could be 1,218 people, and it is estimated that total personal income loss would be \$1billion if the power plant were to close. ${ }^{42}$

\section{Hopi Tribe}

The Hopi Tribe does not have a CAP water allocation. In 2010 and 2011, the tribe purchased 2,000 a.f. of excess CAP water from CAWCD through the Access to Excess program. Excess water available in 2012 will be distributed based on CAWCD's Access to Excess policies.

\section{Pascua Yaqui Tribe}

The tribe has a contract with the Department of the Interior, dated Dec. 11, 1980, for the delivery of 500 a.f. of CAP water. The Pascua Yaqui take delivery of their full allocation via an exchange with the City of Tucson. The tribe's full water right is the subject of a current adjudication; the Pascua Yaqui are currently claiming a water right of 3,520 a.f. per year. This amount is subject to change during the adjudication, and the updated amount is confidential at this time. ${ }^{43}$ In 2012 , CAP water rates are set at $\$ 122$ per a.f. with $\$ 73$ per a.f. in fixed OM\&R paid from the LCRBDF and the variable pumping energy component, $\$ 49$ per a.f., will be paid by the tribe. The Pascua Yaqui also pay a fee of $\$ 15.17$ per a.f. to the City of Tucson for storing the tribe's water.

\section{Salt River Pima-Maricopa Indian Community (SRPMIC)}

The SRPMIC settlement entitles the Community to 122,400 a.f. annually from different sources. The CAP allocation is 13,300 a.f. and the full allocation is leased to Phoenix-area cities. The full cost of delivery is paid by the lessees.

\section{San Carlos Apache Tribe}

The tribe's CAP allocation is variable, ranging from 45,565 a.f. to 60,665 a.f. annually. The City of Scottsdale leases 12,500 a.f. from the tribe, while Phelps Dodge leases another 14,000 a.f. for its Morenci Mine. Some

\footnotetext{
41 Harvey Economics, transmittal letter and exhibits of draft findings, November 16, 2011

42 Ibid.

43 Yucupicio, Peter, Pascua Yaqui Chairman letter to Cynthia Hoeft, Bureau of Reclamation, September 23, 2011
} 
of the tribe's allocation comes from the unused portion of the Ak-Chin allocation. The San Carlos Apache Tribe is working with the Bureau of Reclamation to get water delivered to the reservation. The AWSA provides funding to build a water system sufficient to deliver 12,700 a.f. of CAP water.

\section{Tohono O'odham Nation}

The Nation has two separate entitlements of CAP water to meet the needs of distinct areas of the reservation. The largest entitlement is for 66,000 a.f., which the Nation may use for any purpose, anywhere in the CAP service area (Maricopa, Pinal, and Pima Counties). A smaller 8,000 a.f. allocation is solely for agricultural purposes in the Sif Odak District. There is no existing authority for the Nation to exchange or lease this allocation of water. The Tohono O'odham have not been able to use this water because no delivery or distribution system has been constructed. Planning studies are underway for construction of such a system that would allow the Nation to develop agricultural endeavors in this district.

As part of the AWSA agreement, the Nation also agreed to limit groundwater withdrawals from two districts on its reservation, the San Xavier Reservation and the eastern Schuk Toak District. Groundwater is the sole source of domestic water on the reservation. There are no plans to use CAP water for domestic uses because a water treatment plant would have to be built and operated to allow the Tohono O'odham to use the water.

In its water settlements to date, the Nation has released its superior claims to other waters, including surface and groundwater, in exchange for CAP water. The settlements also created two separate sources for paying the higher delivery costs associated with CAP water. The fixed OM\&R components of delivering water for both allocations are paid from the LCRBDF. The energy pumping charges for the 66,000 a.f. allocation are to be paid from a Cooperative Fund first established by the 1982 SAWRSA and reauthorized in the 2004 AWSA. The Cooperative Fund is also slated to be used as a backup financing mechanism for fixed OM\&R charges. However, only the interest accrued in the Cooperative Fund may be used to pay the charges. In addition, the settlements clarify that if the two sources, the LCRBDF and the Cooperative Fund, are no longer available, the Nation is responsible for paying all the delivery charges of CAP water to fulfill the settlement allocations. $^{44}$

44 Norris, Ned, Tohono-O'odham Chairman letter to David Peterson, NREL, October 5, 2011

\section{Tonto Apache Tribe}

The tribe has an allocation and a CAP contract for 128 a.f. but has not reached a water rights settlement. However, the Tonto Apache are currently not using their water and there is no existing authority for them to exchange or lease the water. The tribe is remote and has not been able to receive its CAP water directly because of the lack of infrastructure. Most likely, the tribe's ability to use its CAP allocation will depend on finding exchange partners.

\section{Yavapai-Apache Tribe (Camp Verde)}

The tribe has a contract with the Department of the Interior, dated Dec. 11, 1980, for the delivery of 1,200 a.f. of water to the reservation and currently relies on the Verde River and groundwater to sustain its homelands. The tribe's full water rights have not been quantified and are part of an ongoing adjudication. ${ }^{45}$ The Yavapai-Apache claim a right to 6,848 a.f. from various sources in the Verde River watershed as well as in stream flow rights, but this amount is subject to change as the adjudication proceeds. Like the Tonto Apache Tribe, the Yavapai-Apachi Tribe is remote, has not been able to receive its CAP water directly because of the lack of infrastructure, and will likely need exchange partners in order to use its CAP allocation.

\section{Yavapai-Prescott Indian Tribe}

The Yavapai-Prescott Indian Tribe Water Rights Settlement Act of 1994 provides 500 a.f. for the Yavapai-Prescott Indian Tribe. The tribe has now assigned this water to the City of Scottsdale. The water is subject to the original Indian CAP priority.

\section{White Mountain Apache Indian Tribe}

The White Mountain Apache Tribe entered into an agreement in January 2009, that became law in December 2010. Under the agreement, the tribe is entitled to 23,782 a.f. of CAP water per year, all of which has been leased under the terms of the settlement. A portion of the leased water has a non-Indian agriculture delivery priority. The tribe is also entitled to 1,218 acre-feet acquired from an irrigation project, which is being firmed to M\&I priority by the United States and the State of Arizona. The tribe is not responsible for any water service charges for the tribal CAP water, even if it is leased. Fixed OM\&R costs are paid from the LCRBDF as long as funds are available.

\footnotetext{
45 David Kwail, Yavapai-Apache Chairman letter to Cynthia Hoeft, Bureau of Reclamation, Sept. 21, 2011
} 


\section{Economic and Employment Impacts}

This chapter discusses the Navajo GS plant's employment impacts and broader economic influence in Apache, Coconino, and Navajo counties. It describes at a regional level the economic and employment relationships between the plant, the Peabody Western Kayenta Mine, and the communities nearest to them. The first part of the analysis applies a jobs and economic development impact tool developed by NREL. The chapter then analyzes economic trends to estimate the role that the Navajo plant and the Kayenta Mine play in the local economy

The previous chapter examined job and other impacts specific to Arizona tribal populations. By contrast, this chapter provides an economic overview of the threecounty area using data available from the U.S. Bureau of Labor Statistics and other traditional sources.

\subsection{Estimation of primary and secondary effects related to Navajo GS}

Modeling of employment and economic impacts was conducted with the suite of NREL input-output models known as the Jobs and Economic Development Impacts (JEDI) models. This analysis uses the JEDI module for coal power plants. ${ }^{1}$

JEDI model results for new plants are displayed in two different time periods: construction and operations. This particular analysis is different, in that it aims to estimate the economic footprint of an existing plant. Operationsperiod results are long term, for the life of the project, and are reported as annual jobs and economic activity, which continue to accrue throughout the operating life of the facility.

Total economic impacts include on-site labor and professional services as well as jobs and economic activity that result from spending in supporting industries (e.g., construction material and component suppliers, analysts and attorneys who assess project feasibility and negotiate

\footnotetext{
1 NREL's JEDI models are publicly available spreadsheet tools that apply state-specific IMPLAN multiplier data. This analysis relied on year 2009 data for the three-county region under consideration (i.e., Apache, Coconino, and Navajo Counties). The JEDI analysis tools were developed by NREL in conjunction with MRG \& Associates. For more information on the JEDI tools, see http://www.nrel.gov/analysis/jedi/.
}

contract agreements, banks financing the projects, and equipment manufacturers) and by local government, from project related property and sales tax revenues. Total impacts also include induced effects that are driven by reinvestment and spending of earnings by direct and indirect beneficiaries. Induced impacts are often associated with increased business at local restaurants, hotels, and retail establishments but also include child care providers and any other entity affected by increased economic activity and spending occurring at the first two tiers.

Payments to tribal governments are a special category of economic benefit particular to Navajo GS. As JEDI is designed as a more general model of economic impact, it does not specifically account for these payments.

Therefore, the total economic impact would include those modeled by JEDI, plus the payments described in Chapter 6 , plus the induced impacts associated with the tribal payments.

\subsubsection{Methodology and inputs}

This analysis includes the results of modeled data on the operational impacts associated with a facility comparable to NGS. In the case of coal about $70 \%$ of total operations costs (including fuel) were estimated to be sourced from the three-county area of interest. Operations costs are estimated at $\$ 35 / \mathrm{kW}$ fixed, $\$ 3.65 / \mathrm{MWh}$ variable, and fuel costs at $\$ 1.70 / \mathrm{mmbtu}$. These modeling inputs allowed the results to approximate the on-site employment reported by NGS as well as Peabody Energy (for the Kayenta Mine) to within $10 \%$.

JEDI results are not intended to be a precise forecast; they are an estimate of potential activity resulting from a specific set of projects and modeling inputs. In addition, JEDI results presuppose that projects are financially viable and can be justified independent of their economic development value. Results generated by the JEDI models are gross (not net) results. They do not consider potential increases or decreases in electricity rates resulting from investments in new infrastructure, nor do they consider whether the respective projects displace economic activity elsewhere. JEDI model categories and default information are based on real-world projects. NREL analysts perform interviews with project owners, developers, engineering 
and design firms, construction firms, and others to align model inputs and the corresponding results with reality, as closely as possible. Of course, individual projects will have varying results depending on a wide variety of factors including project location and topography, available local labor, available local goods and services, and commodity prices at the time of construction. Results presented here are in 2010 dollars.

\subsubsection{Results}

The modeled results for on-site employment (450 persons) calibrates lower than actual employment as reported by plant operator SRP (around 540). JEDI estimated the additional employment effects at 2,025 jobs. This includes employment in the supply chain serving Navajo GS (including the Kayenta mine's 400 employees) as well as indirect employment. Table 7-1 shows the jobs and earnings associated with on-going operation of Navajo GS, as modeled in JEDI.

Table 7-1. Estimated On-site and Regional Employment Effect of Navajo GS

\begin{tabular}{|l|c|c|}
\hline & $\begin{array}{c}\text { Full-time } \\
\text { employment }\end{array}$ & $\begin{array}{c}\text { Annual } \\
\text { earnings }\end{array}$ \\
\hline $\begin{array}{l}\text { On-site } \\
\text { Rest of region } \\
\text { (direct, indirect, and } \\
\text { induced employment }\end{array}$ & 450 & $\$ 29,250,000$ \\
\hline
\end{tabular}

Beyond the employment effects, the total economic output associated with Navajo GS operations is \$511 million annually. This includes the sum value of all goods and services associated with operating the facility through its various stages of production.

A handful of factors could alter the impacts noted Table 7-1, most notably the degree to which the Navajo GS operations rely on local labor, goods, and services. In addition, the model does not work at a level of detail sufficient to estimate the jobs that would accrue to native Hopi or Navajo populations or to even potentially to others residing within this three-county area. While it is possible that the type of local business activity supported by these projects could be provided by the native populations it is also possible that local labor and services anticipated in this effort could be provided by other parties in the counties or potentially even by labor and service providers from outside the region entirely. This is of particular importance as the analysis of the existing economic impact of NGS and the Kayenta Mine suggests that the potential closing is likely to disproportionately affect the native Hopi and Navajo populations.

\subsection{Economic and employment profile of the three-county region}

This analysis uses published data from a variety of sources. The 2000 and 2010 United States Census are used for population and ethnicity data. ${ }^{2}$ The U.S. Bureau of Labor Statistics (BLS) provides unemployment data by county, and discloses wage and employment data by county and industry when there are enough employers to meet disclosure guidelines. ${ }^{3}$ In addition to data served by U.S. government agencies, this analysis uses reservationlevel unemployment data received from the Navajo Nation, ${ }^{4}$ and wage and payment data received directly from SRP, the Navajo plant operator, and Peabody Energy, operator of the Kayenta Mine. ${ }^{5}$

Unfortunately, data are often aggregated at a level that prevents a clear analysis of local effects of a potential shutdown of the Navajo plant. For example, the U.S. government provides county-level data on employment and wages, but this data is limited in its ability to reflect tribal concerns. The Hopi Reservation is located within two counties, and the Navajo Reservation is located in three Arizona counties as well as in the States of New Mexico and Utah. Additionally, the BLS and the Tribes have a different methodology for calculating unemployment. The BLS only considers someone unemployed if they do not have a job, are available to work, and have actively looked for a job in the last four weeks. The BIA definition, on the other hand, counts people as unemployed who would like a job but have stopped looking for one. According to the BIA, "[t]he difference in calculation generally leads to the Tribes

\footnotetext{
2 U.S. Census Bureau, Census 2000 Gateway, http://www.census.gov/main/ www/cen2000.html; U.S. Census Bureau, 2010 Census, http://2010.census. gov/2010census.

3 Bureau of Labor Statistics, Databases, Tables \& Calculators by Subject, http://bls.gov/data/.

4 Navajo Nation Department of Justice, email correspondence, October 4, 2011. www.nrel.gov/navajo

5 Navajo Nation, email correspondence, September 24, 2011 and October 11, 2011.
} 
Table 7-2. Population and Ethnicity by County and Tribe

\begin{tabular}{|c|c|c|c|c|c|}
\hline & \multicolumn{3}{|c|}{ County } & \multicolumn{2}{c|}{ Tribal Lands } \\
\hline Population & Coconino & Navajo & Apache & Hopi Tribe & Navajo Nation \\
\hline $\mathbf{5 0 0 0}$ & & & & \\
\hline AIAN & 33,161 & 46,532 & 53,375 & 6,470 & 174,847 \\
\hline Total & 116,318 & 97,468 & 69,423 & 6,836 & 181,269 \\
\hline $\mathbf{2 0 1 0}$ & & & & \\
\hline AIAN & 36,714 & 46,611 & 52,514 & 6,857 & 167,031 \\
\hline Total & 134,421 & 107,449 & 71,518 & 7,185 & 173,667 \\
\hline
\end{tabular}

reporting significantly higher unemployment rates than those reported by BLS for counties and states in proximity to the reservations." ${ }^{\text {"This }}$ analysis acknowledges and explains the limitations in the available data.

\subsubsection{Current Economic Conditions}

The Navajo Generating Station is located in Coconino County, and the Kayenta Mine is located in Navajo County, Arizona. While shutting down the Navajo plant may affect other parts of Arizona or surrounding states, local communities would likely feel the most direct impact, especially the Navajo and Hopi Reservations. The Navajo Nation is located in Apache, Coconino, and Navajo Counties and crosses state borders into New Mexico and Utah, and the Hopi Reservation is located in Coconino and Navajo Counties.

Data from the 2000 and 2010 United States Census provides a picture of how the local population has changed over the last decade (see Table 7-2). The data show total population growing in all three counties with Coconino County experiencing the highest growth rate (with $15 \%$ growth over the decade). When the data are subdivided by ethnic groups, the trend in population growth becomes more nuanced. Navajo County gained less than 100 people classified as American Indian and Alaskan Native (AIAN), and Apache County lost over 800 people classified as AIAN. In fact, while the Hopi Reservation saw an increase in population of $5 \%$, the Navajo Nation experienced a $4 \%$ loss in population. As a whole, the

\footnotetext{
6 Bureau of Indian Affairs, Department of the Interior, 2005 American Indian Population and Labor Force Report, 2005, p. viii.
}

census data suggests that while the population of the three counties is growing, the share of AIAN people has grown at a slower rate.

Data from the BLS and the Navajo Nation suggest differences in the average unemployment rate for Apache, Coconino, and Navajo Counties, and for the Navajo Reservation. ${ }^{7}$ Due to the methodological differences between the data sets explained previously, however, a direct comparison between the numbers is problematic. While the unemployment rate for the three counties is slightly higher than the U.S. national unemployment rate, it has closely followed movements in the national unemployment rate. Biennial unemployment data provided by the Navajo Nation show that unemployment on the reservation has averaged around $50 \%$ for the last twenty years. Other than a short-term dip in 1998, trends in the unemployment rate for Navajo paralleled the gradual improvement seen in the county and national data up to 2007. Navajo data for 2008 and later were not yet available as of this writing.

The BLS provides industry-level employment and wage information using the 2002 North American Industry Classification System (NAICS) and an internal system of 11 aggregate sectors referred to as "super sectors." County-level employment and wage data are not consistently available in all industries in all three counties

\footnotetext{
7 Detailed employment data for the Hopi Reservation were not available for this analysis.

8 Bureau of Labor and Statistics, Overview of BLS Wage Data by Area and Occupation, http://bls.gov/bls/blswage.htm.
} 




Figure 7-1. Unemployment rates of U.S., Navajo Nation, and Coconino, Apache, and Navajo Counties, AZ, 1990-2010.



Figure 7-2. Total wages, by Sector, Apache, Coconino, and Navajo Counties, AZ, 2001-2010. of interest, ${ }^{9}$ so this analysis utilizes "Natural resources and mining" (BLS sector 1101) as an estimator of the relative importance of the local mining industry.

Total employment in the three counties increased for most of the last decade, though it has declined since 2007, likely due to the lingering U.S. recession (Table 7-3). In contrast, the number of natural resources and mining employees steadily declined over the entire time period; a $15 \%$ drop from 2005 to 2006 coincided with the closure of the Mohave coal plant in southern Nevada, which relied on the Kayenta Mine for fuel. Average annual pay for those employees increased by $12 \%$ over the decade, however, seemingly immune to the stagnating average wages for all industries. Furthermore, Navajo provided an average wage estimate of $\$ 50.54$ per hour (including benefits) for Navajo employees. Given the data provided by the Navajo Nation and BLS data on mining industry wages, these jobs provide above average wages and benefits to their employees.

Total product data are not available for the Navajo plant and the Kayenta Mine, so to assess the diversity of the local economy, this analysis uses total income data provided by the BLS. $^{10}$ At an aggregate level, the BLS categorizes data from "goodsproducing" and "service-providing" industries with both the Navajo plant and the Kayenta Mine categorized as goods-producing companies. While

\footnotetext{
9 This is due to disclosure rules that ensure aggregate statistics cannot be used to ascertain wage and employment data for individual companies.

10 The U.S. Department of Commerce does not publish production data at the county level.
} 
Table 7-3. Apache, Coconino, and Navajo County Employment and Wages by Industry

\begin{tabular}{|c|c|c|c|c|c|c|}
\hline & \multicolumn{2}{|c|}{ Employees } & \multicolumn{2}{c|}{$\begin{array}{c}\text { Total Wages } \\
\text { (\$K 2010) }\end{array}$} & \multicolumn{2}{c|}{$\begin{array}{c}\text { Average Annual Pay } \\
\text { (\$ 2010) }\end{array}$} \\
\hline & $\begin{array}{c}\text { All } \\
\text { Industries }\end{array}$ & $\begin{array}{c}\text { Natural } \\
\text { Resources } \\
\text { and } \\
\text { Mining }\end{array}$ & $\begin{array}{c}\text { All } \\
\text { Industries }\end{array}$ & $\begin{array}{c}\text { Natural } \\
\text { Resources } \\
\text { and Mining }\end{array}$ & $\begin{array}{c}\text { All } \\
\text { Industries }\end{array}$ & $\begin{array}{c}\text { Natural } \\
\text { Resources } \\
\text { and } \\
\text { Mining }\end{array}$ \\
\hline $\mathbf{2 0 0 1}$ & 94,501 & 1,402 & $3,001,621$ & 74,281 & 31,763 & 52,982 \\
\hline $\mathbf{2 0 0 2}$ & 96,063 & 1,436 & $3,122,043$ & 74,830 & 32,500 & 52,110 \\
\hline $\mathbf{2 0 0 3}$ & 97,092 & 1,334 & $3,220,679$ & 68,894 & 33,171 & 51,645 \\
\hline $\mathbf{2 0 0 4}$ & 99,385 & 1,277 & $3,308,374$ & 71,494 & 33,288 & 55,986 \\
\hline $\mathbf{2 0 0 5}$ & 103,513 & 1,299 & $3,535,847$ & 70,906 & 34,158 & 54,585 \\
\hline $\mathbf{2 0 0 6}$ & 106,463 & 1,130 & $3,645,247$ & 61,190 & 34,240 & 54,150 \\
\hline $\mathbf{2 0 0 7}$ & 108,249 & 1,093 & $3,833,831$ & 58,158 & 35,417 & 53,209 \\
\hline $\mathbf{2 0 0 8}$ & 106,684 & 1,140 & $3,741,142$ & 57,359 & 35,068 & 50,315 \\
\hline $\mathbf{2 0 0 9}$ & 102,512 & 1,018 & $3,696,133$ & 56,855 & 36,056 & 55,849 \\
\hline $\mathbf{2 0 1 0}$ & 101,088 & 986 & $3,619,227$ & 58,378 & 35,803 & 59,207 \\
\hline
\end{tabular}

total wages for goods-producing companies had a slight peak in 2007, over the past decade the service-providing sector increased to nearly $80 \%$ of the economy of the three counties (Figure 7-2). More specifically, the natural resources and mining industry provided $2.5 \%$ of total income in 2001, but by the end of the decade, that percentage had dropped to $1.6 \%$ (Figure 7-2). These statistics suggest that the economy of the three counties is largely based around services, and that the natural resources and mining industries only modestly contribute to aggregate income.

While a direct accounting of the taxes paid by Navajo was not made available for this analysis, Peabody Energy provided state and local taxes paid by the Kayenta Mine. In 2010, the mine paid $\$ 17$ million in state sales taxes and $\$ 1.6$ million in Navajo County property tax. According to Peabody Energy estimates, around \$1.2 million of their property tax payment went to the Kayenta Unified School District located in Navajo County. State and local tax revenue would certainly be reduced in the event of an Navajo shutdown. Additionally, according to the Navajo Nation's 2009-2010 Comprehensive Economic Develop- ment Strategy, the Nation notes that payments from three mines on Navajo land (the Peabody Mine, Pittsburgh and Midway Mine, and the Navajo Mine) account for more than $\$ 60$ million in revenue, roughly $60 \%$ of the Nation's 2008 General Fund budget. ${ }^{11}$

\footnotetext{
11 Navajo Nation, 2009-2010 Comprehensive Economic Development Strategy, 2008, p.16.
} 


\section{Conclusions}

The foregoing chapters of this study support several conclusions relating to factors that EPA will consider in its BART determination. Nevertheless, this study makes no recommendation about what the BART determination should be for Navajo GS, and none of the conclusions that follow should be construed as implying a recommendation.

\section{Cost of compliance}

- The basic costs of installing SCRs at Navajo $G S$ would likely be less than the basic costs of shutting it down and replacing it with power from unused capacity elsewhere in the West.

The plausible range of additional annual cost resulting from SCR installation is between $\$ 57$ million and $\$ 70$ million per year. This includes capital costs (amortizing each owner's share over 20 years using each partners' cost of capital as its discount rate) and production costs (calculated based on Navajo GS' historical production levels). It does not include other unknown costs that may be related to additional control technologies, such as changes in plant ownership, changes in ownership shares, costs relating to the negotiation of the Navajo GS site lease, the cost of coal from the Kayenta mine, or other factors.

By comparison, if Navajo GS were retired and the same amount of power came from the least-cost redispatch of existing units, total production costs throughout the Western Interconnection would likely increase \$197 million to $\$ 502$ million. As explained in Chapter 2, these estimates represent an economically optimal outcome that accounts for known, quantifiable constraints, with natural gas prices defining the plausible range of total replacement costs. Unknown factors could introduce inefficiencies that would generally increase actual costs. For example, existing power contracts may bind a utility to an agreement that is less than optimal, while unplanned changes in transmission line ratings could limit the flow of power across paths that would otherwise be preferred economically. Therefore, the replacement costs represent best-case scenarios.
The economic balance does not change when adding the cost of baghouses and sorbent injection, which might not address visibility issues but might be required as a result of future EPA emission rules. The annual retrofit costs (with capital costs recovered over 20 years) would be double that of SCR alone, but even so, the annual cost is still about $\$ 67$ million per year below replacement costs under the most optimistic natural gas price scenario.

- The cost burden of additional retrofits would probably fall more heavily on CAP water users than it would on customers of any of the five utilities that own shares of Navajo GS. Replacing the plant would likely result in an even greater impact disparity.

The capital costs and additional production costs of SCR controls at Navajo GS would likely increase the retail rates of each utility partner by $0.2 \%$ to $0.6 \%$. With baghouses and sorbent injection, and capital recovery accelerated to 10 years, the impact on retail rates would be about triple.

Each Navajo GS utility partner would add its share of retrofit capital costs to its net utility plant (the total value of all capital assets minus depreciation). This base aggregates all of the utility's capital assets, and the total revenue required each year to service the equity and debt that finance these assets make up the base rates paid by all of the utility's retail customers. For example, the additional capital cost of SCR control technology at Navajo GS would increase by $1.4 \%$ to $1.7 \%$ SRP's net utility plant (the total value of all capital assets minus depreciation). Applied across all its electricity sales, the impact on SRP's retail rates would be around 0.04 cents per kilowatt-hour.

The Bureau of Reclamation is not an electric utility and therefore lacks a comparable rate structure for recovering capital costs. In fact, this study found considerable uncertainty regarding how the federal government's share of new capital costs might be recovered. Lacking clearer guidance for the purpose of analysis, this study's default assumption was that public-sector revenue bonds or a similar instrument would finance Reclamation's share of capital costs, with the revenue requirement added to 
water rates charged by CAWCD. Assuming an interest rate of $5 \%$ and a 20 -year term, the debt service would add 0.32 cents to 0.38 cents per kilowatt-hour to the cost of pumping water - ten times the per-kilowatt-hour impact that the utility partners' electric customers would see.

- SCR retrofits will affect the water rates that CAWCD charges CAP water users by $5 \%$ to $16 \%$.

The installation of BART emission controls at Navajo GS could require CAWCD to recover additional revenues to apply towards the federal government's share of the new capital costs. Federal appropriations toward this obligation would mitigate the impact on CAP water users, but as of this writing no appropriation has been proposed. The revenue tools available to CAWCD include water rates, revenue bonds, and an ad valorem tax.

An increase in production costs could result in lost Navajo GS surplus power sales revenues, which would increase the amount CAWCD would need to pay into the Lower Colorado River Basin Development Fund toward its CAP repayment obligation. This could also require additional revenues from water rates.

- Even in the absence of the installation of BART emissions controls at Navajo GS, the second cascade of priorities under the Arizona Water Settlements Act would only receive Development Fund revenues when market power prices are substantially higher than they are today.

Revenues from excess power sales on the open market are neither stable nor predictable regardless of how BART capital costs may be recovered. Beginning in October 2011, Reclamation and CAWCD implemented a strategy to rely more on the regional power market to dispose of excess power. The increase in Navajo GS production costs due to BART retrofits would in all likelihood be lost in the larger and more erratic fluctuations of wholesale power prices. Currently, wholesale prices are relatively depressed due to low natural gas prices and to lower electricity demand resulting from the recession. Therefore, with or without BART costs in the equation, Reclamation and CAWCD will still need to deal with the likelihood of lower revenues into the development fund and the potential impact on CAP water rates.

\section{Energy impacts of compliance}

- Installing SCRs would, in all likelihood, cause little change in the amount of energy provided by Navajo GS.

The additional operating and maintenance costs associated with SCR retrofits would likely increase production costs at Navajo GS by between $\$ 0.73$ and $\$ 1.02$ per megawatthour, or between $3 \%$ and $4 \%$. It is unlikely that a change of this magnitude would significantly change how much power Navajo GS would produce, as it would still be one of the lowest-cost resources in the Desert Southwest with respect to production costs.

- Shutdown would tend to reduce power exports from the Desert Southwest to Southern California, and would tend to increase electricity production from combined cycle gas units in Southern California.

A large amount of power currently flows from generators in Arizona, New Mexico and Nevada to Southern California. When Navajo GS is removed from the West's regional generation fleet in simulations based production costs, changes in the cost of local power (as reflected in LMPs) create an economic incentive to reduce the commercial flow of power westward across the Colorado River. The tendency is for more generated power to stay in Arizona, and more generation to come from combined cycle gas turbines located in California. Contract delivery obligations might restrict this tendency, but the consequences would be to increase replacement costs even more.

\section{Remaining useful life of Navajo GS}

- While BART retrofits would be unlikely to force retirement of Navajo GS for economic reasons, the plant nevertheless might be halfway through its operating life.

Navajo GS will have been in service 45 years when its site lease with Navajo Nation expires in 2019. While 45 years was a typical useful lifespan for smaller coal plants in the U.S. built prior to Navajo GS, larger coal plants built around the time of Navajo GS and later appear to 
be lasting longer. Survival analyses conducted by NREL and others indicate that relatively fewer units of Navajo GS' generation are retiring early, and the ones that remain continue to sustain high capacity factors. Statistical analysis point to a normal operating life of 65 to 70 years. The utility partners' capital investments in Navajo GS (including retrofits to date, but excluding future retrofits) are on track to be fully depreciated no later than 2026, when the plant will have had more than 50 years in service.

\section{Degree of improvement in visibility}

- The body of research to date is inconclusive as to whether removing approximately two-thirds of the current NOx emissions from Navajo GS would lead to any perceptible improvement in visibility at the Grand Canyon and other areas of concern.

Evidence suggests that NOx emissions from Navajo GS are a likely incremental contributor to haze at the Grand Canyon. Whether the incremental contribution is significant or even perceptible is a matter of debate among experts in the field of visibility science. Resolving these questions requires expertise in atmospheric chemistry and air transport modeling, not power sector expertise.

Monitoring and other evidence suggests NOx is a weaker contributor than $\mathrm{SO} 2$, which has already declined $95 \%$ at Navajo GS since the installation of scrubbers in 2000.

\section{Impacts on Indian tribes}

- For agricultural users and Indian tribes, water rates from CAP would likely increase between $13 \%$ and $16 \%$. Baghouses and sorbent injection would roughly double the impact on water rates.

A significant increase in the cost of power from Navajo GS could affect settlements with some Indian tribes who surrendered future water right claims in exchange for low-cost access to CAP water and other benefits. While this study estimates the magnitude of potential water rate increases, a more detailed examination of what they mean for tribal water settlements (for example, determining the threshold at which a rate increase would be materially significant) would require a legal analysis that was beyond the scope of this study.
A significant area of concern for CAP water-using tribes relates to the potential for sales of surplus Navajo GS power to exceed the $\$ 55$ million annual CAP repayment obligation. In cases where annual revenue into the fund exceed $\$ 55$ million, the "second cascade" of funding disbursements would kick-in, with initial funds in the second cascade going to reduce the fixed operations, maintenance and replacement charges associated with the delivery of CAP water to Indian tribes. Under a new agreement related to the sales of surplus Navajo generation, approximately $1 \mathrm{TWh}$ of primarily off-peak power would be up for sale on the general wholesale power market, making this portion of excess power revenue more directly subject to market prices. Current power prices are not high enough to support flows into second-cascade disbursements, nor have they been since 2008. Two factors could mitigate against higher power prices in the future: success of energy efficiency programs in Arizona and other Southwest states, and additional natural gas supplies resulting from the development of shale gas.

- Early plant retirement is the only BART scenario likely to result in serious harm to the economies of the Navajo Nation and the Hopi Tribe.

Navajo GS would likely run at nearly the same level of production as it is currently if SCR controls were installed. Most of the capital costs would be recovered through the owner utilities' rate base, but production costs would only increase by between $3 \%$ and $4 \%$.

Similarly, many of the environmental impacts of compliance other than air quality (which primarily affect the Hopi and Navajo living close to the plant and to the Kayenta mine) would not change significantly if the plant had to install additional NOx controls but ran at close to its normal production level. 


\section{INREL \\ NATIONAL RENEWABLE ENERGY LABORATORY}

Analysis at NREL aims to increase

the understanding of the

current and future interactions

and roles of energy policies,

markets, resources, technologies,

environmental impacts, and

infrastructure. These analyses

are used to inform decisions as

energy-efficient and renewable

energy technologies advance

from concept to commercial

application.

\section{National Renewable \\ Energy Laboratory}

15013 Denver West Parkway

Golden, CO 80401

303-275-3000 • www.nrel.gov

NREL is a national laboratory of the U.S. Department of Energy, Office of Energy Efficiency and Renewable Energy, operated by the Alliance for Sustainable Energy, LLC.

NREL/TP-6A20-53024 • Revised March 2012 